UNIVERSIDADE DE SÃO PAULO

FACULDADE DE ECONOMIA, ADMINISTRAÇÃO E CONTABILIDADE DEPARTAMENTO DE ECONOMIA

\title{
INÉRCIA INFLACIONÁRIA E O CUSTO DAS ESTABILIZAÇÕES NOS EUA
}

André Lunardelli

Orientador: Prof. Dr. Gilberto Tadeu Lima 


\section{INÉRCIA INFLACIONÁRIA E O CUSTO DAS ESTABILIZAÇÕES NOS EUA}

Candidato: ANDRÉ LUNARDELLI

Orientador: PROF. DR. GILBERTO TADEU LIMA

Tese apresentada ao Departamento de Economia da Faculdade de Economia e Administração da Universidade de São Paulo para a obtenção do título de Doutor em Teoria Econômica - área de concentração: MACROECONOMIA 
Lunardelli, André

Inércia Inflacionária e o Custo das Estabilizações nos EUA / André Lunardelli -São Paulo, 2002

$182 p$.

Tese (Doutorado) -- Instituto de Pesquisas Econômicas - Universidade de São Paulo, 2002

Orientador: Prof. Dr. Gilberto Tadeu Lima

1. Inflação. 2. Macroeconomia. 3. Economia Comportamental.

4. Psicologia e Economia. 


\section{AGRADECIMENTOS}

- Ao meu orientador, Gilberto Tadeu Lima, e aos outros membros da banca examinadora, Joaquin Andrade, Francisco Carneiro, Fabiana Rocha e Jorge Soromenho.

- Aos professores do Instituto de Pesquisas Econômicas, que foram extremamente acessíveis para consultas, sugestões e críticas. Especialmente Denisard Alves, Ricardo Suganuma, Sigfried Bender, Reynaldo Fernandes, Márcio Nakane, Naércio M. Aquino, Paulo Picchetti, Fábio Kanjusky e Vera Fava. Agradeço também aos professores Eduardo Gianetti da Fonseca e Ana Maria Bianchi que, pela divulgação de temas de economia comportamental no departamento de economia da FEA-USP, mostraram uma abordagem que me era desconhecida. Ressalto, no entanto, que todos os erros e falhas inerentes a este trabalho são de minha total responsabilidade.

- À Décio Kadota e José Paulo Chaad, pelo apoio como coordenadores do curso de pós-graduação do IPE-USP.

- Ao CNPq , pelo apoio financeiro.

- À minha família, meus companheiros (alunos) do IPE-USP, e a todos os meus a amigos e amigas, pelo apoio, compreensão e convívio.

- A todos os que de alguma forma colaboraram com este trabalho os meus mais sinceros agradecimentos. 


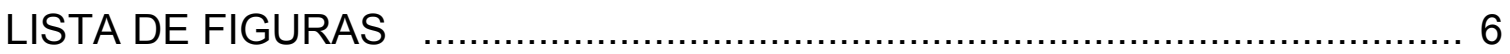

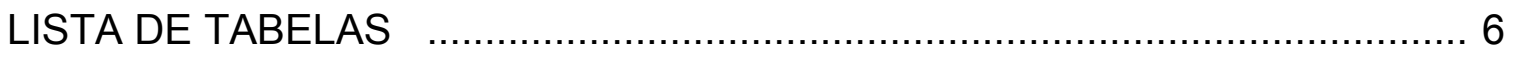

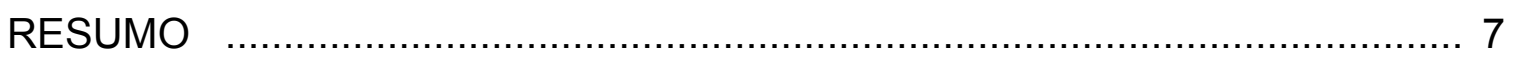

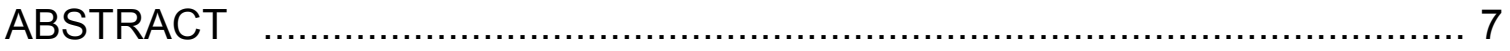

INTRODUÇÃO

1 - O MODELO DE JOHN TAYLOR E A INÉRCIA INFLACIONÁRIA

1.1 - O modelo de John Taylor................................................................... 14

1.2 - Inércia e o custo de estabilizações no modelo de Taylor ........................... 23

1.3 - A literatura empírica a respeito de inércia inflacionária e o modelo de

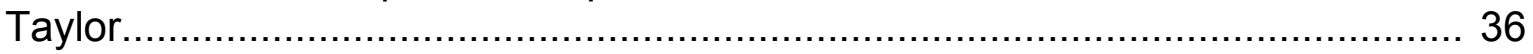

1.4 - Expectativas e o modelo de Taylor com aprendizado................................ 47

2 - AS EXPECTATIVAS DOS AGENTES E O MODELO DE TAYLOR

2.1 - Os dados e a metodologia das estimações........................................... 57

2.2 - Propriedades das expectativas inflacionárias da "survey" do UMSDC......... 65

2.3 - Estimando as expectativas dos agentes a respeito dos ciclos econômicos 71

2.4 - Expectativas e o modelo de Taylor - resultados empíricos......................... 80

3 - MODELOS QUE GERAM INÉRCIA INFLACIONÁRIA E O CUSTO DAS ESTABILIZAÇÕES NOS EUA

3.1 - Agentes heterogêneos e inércia inflacionária...........................................111

3.2 - Incerteza knightiana e o custo das estabilizações........................................116

3.3 - Uma abordagem comportamental com mercado de trabalho...................... 132

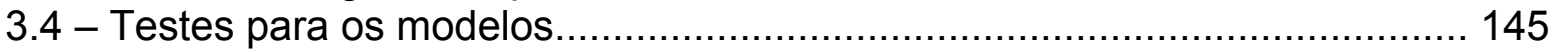

3.5 - A metodologia e os resultados das estimações......................................... 161

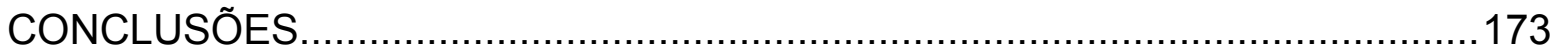

\section{APÊNDICES}

A - Simulações de estabilizações em uma economia sem rigidez real.....

B - Resumo da literatura a respeito de "fairness" e reciprocidade em economia 179

C - A dificuldade da obtenção de evidências de "survey" a respeito de F1.......... 185

D - Um modelo com salário eficiente e monitoramento imperfeito....................... 186

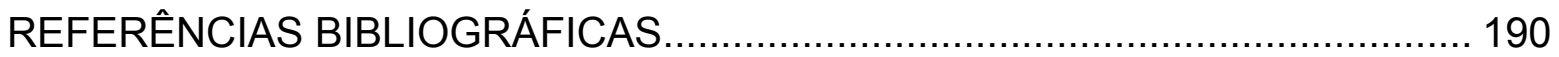




\section{LISTA DE FIGURAS}

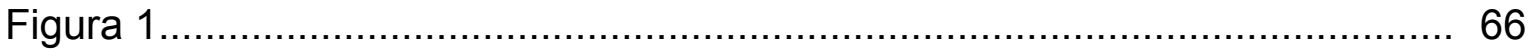

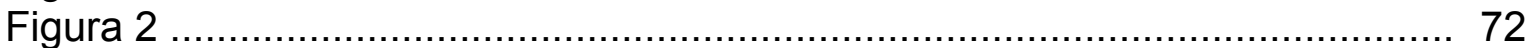

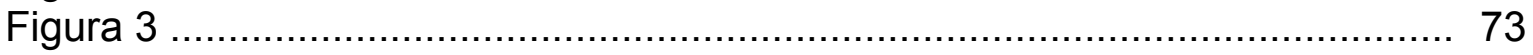

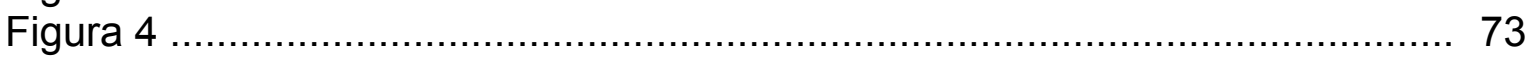

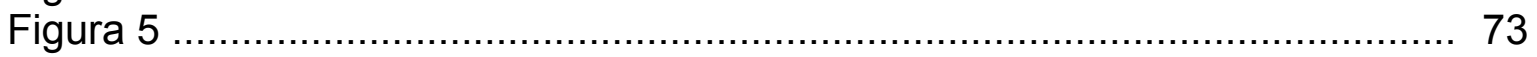

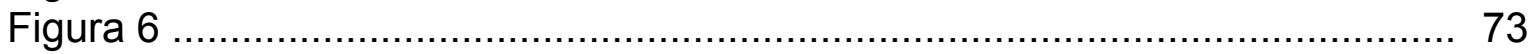

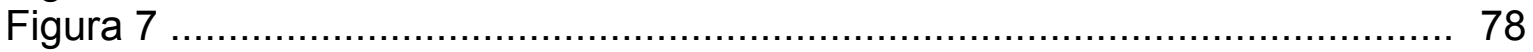

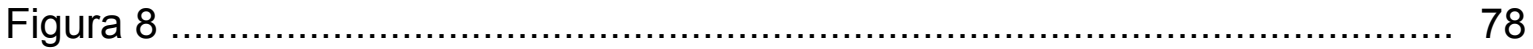

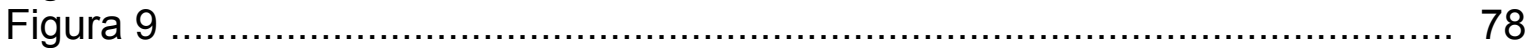

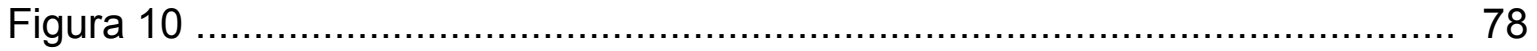

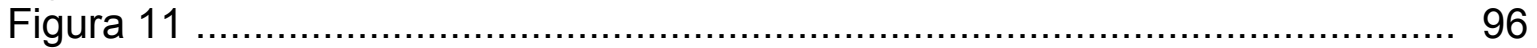

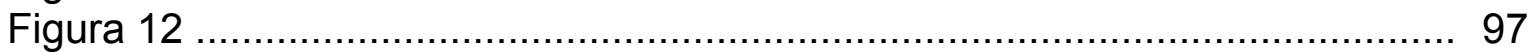

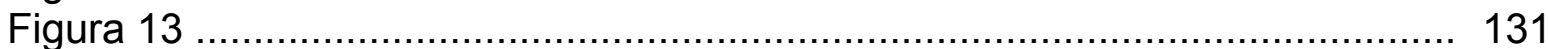

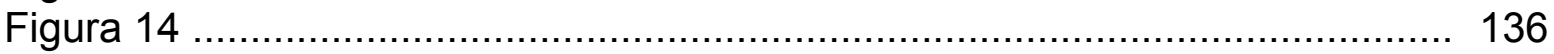

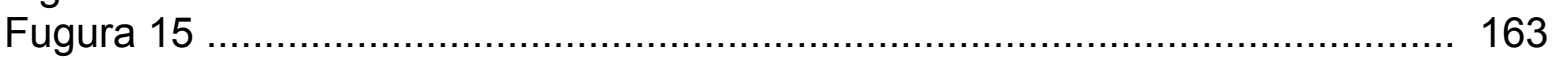

\section{LISTA DE TABELAS}

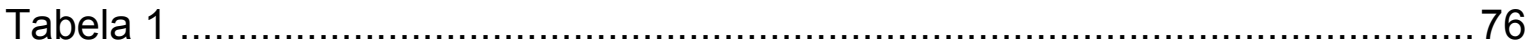

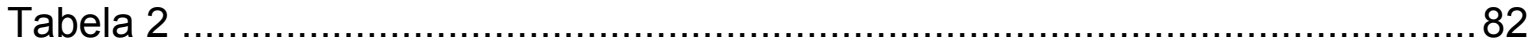

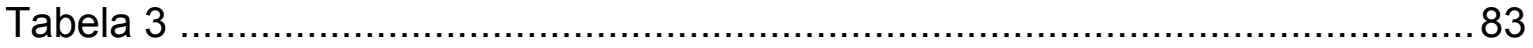

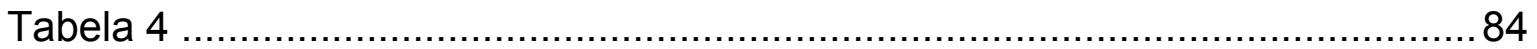

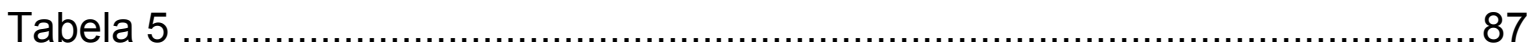

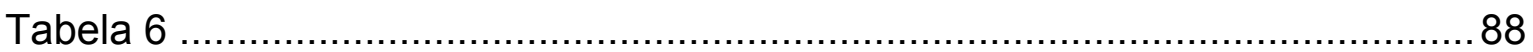

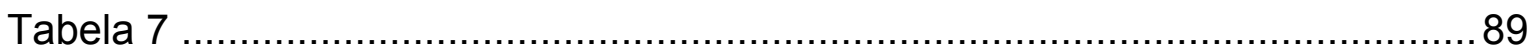

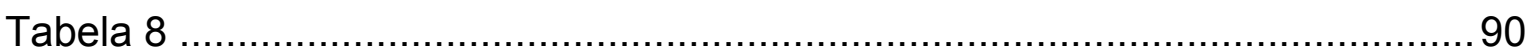

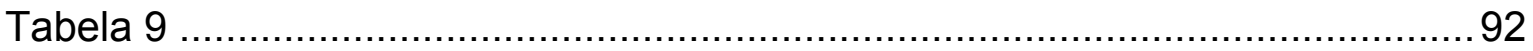

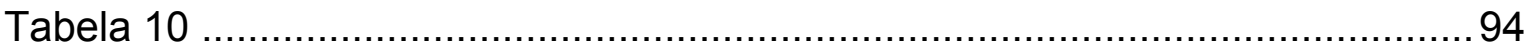

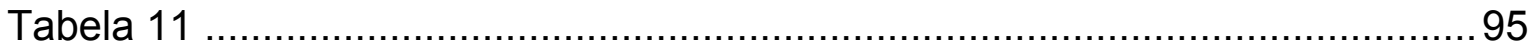

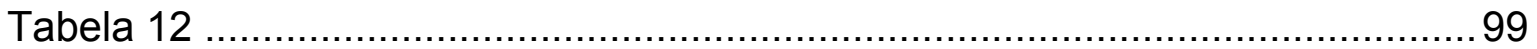

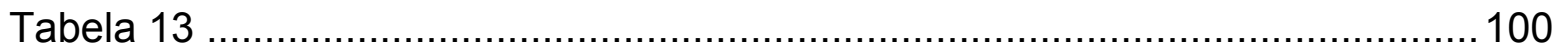

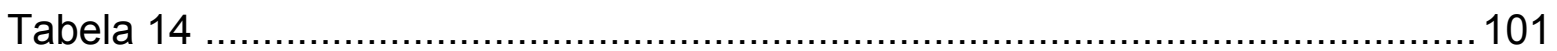

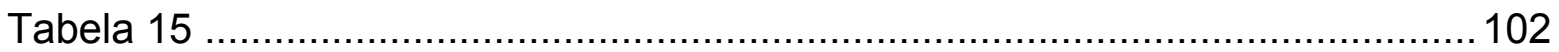

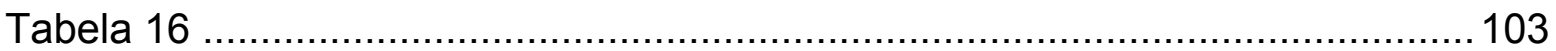

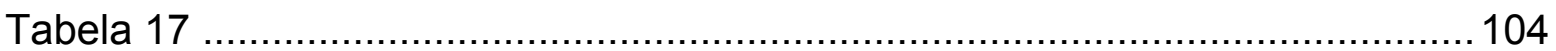

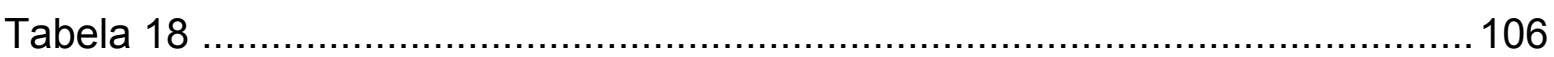

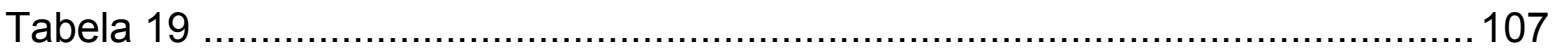

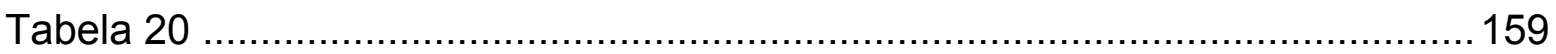

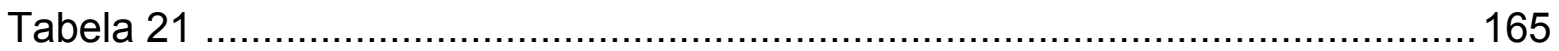

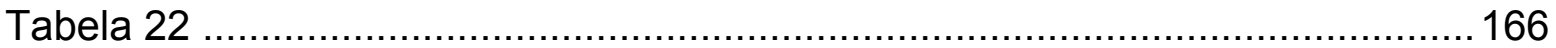

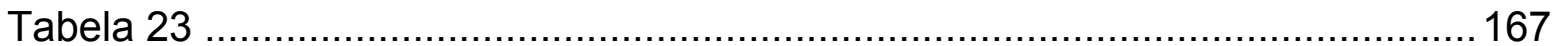

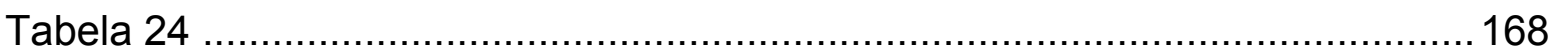

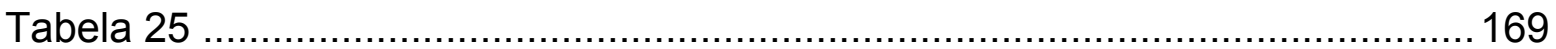

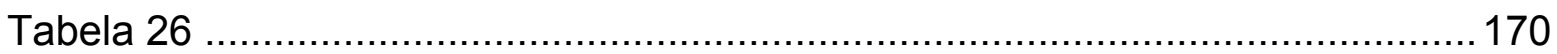




\section{RESUMO}

Desde o trabalho empírico de Roberts (1997) com dados de "surveys", os modelos com reajustes justapostos e informação defasada tem merecido um destaque crescente (ver, por exemplo, Mankiw e Reis (2002)). Utilizando a "survey" junto ao consumidor da universidade de Michigan, obtivemos dados a respeito das expectativas dos agentes não só sobre inflação, mas também sobre nível de atividade (os estudos de Roberts utilizaram apenas os dados de "survey" sobre expectativas inflacionárias). Verificamos, então, que grande parcela do custo das estabilizações dos EUA foi antecipado pela maior parte dos agentes, o que nos levou a rejeitar o modelo de Taylor $(1979,1980)$, mesmo em suas versões com as hipóteses de falta de credibilidade e informação homogeneamente defasada. Para explicar estes custos, examinamos, então, três possíveis fatores (mutuamente compatíveis): a hipótese de que parte da população tenha expectativas inconsistentes, incerteza knightiana e um modelo inspirado na economia comportamental. Nossos resultados empíricos penderam a favor de uma combinação de pelo menos uma das duas últimas alternativas com a primeira.

\section{ABSTRACT}

Since Roberts $(1997,1998)$ works with surveys' data, models with staggered readjusts with sticky information have been increasingly in focus (see mankiw and Reis (2002), for example). Using the Michigan University's consumer survey, we obtained data about agents' expectations of both inflation and output (the latter had not been used in Roberts' studies). With this, we were able to verify that a great part of the sacrifice ratios of the US stabilizations were anticipated by common agents, rejecting the Taylor $(1979,1980)$ model and, with it, hypothesis that the only reasons underlying them are staggered contracts, homogeneous sticky information and lack in credibility. With the aim of explaining these costs, we examinated three additional (mutually consistent) factors: the hipothesis that part of the population have inconsistent expectatitons, Knightian uncertainty and a model inspired in behavioral economics. The results favored the combination of at least one of the two latter alternatives with te former. 


\section{INTRODUÇÃO}

Este trabalho retoma a discussão a respeito da dificuldade de a teoria econômica explicar a inércia inflacionária e o custo das estabilizações.

A principal referência teórica para modelar a evolução do nível agregado de preços tem sido, desde o final dos anos 70, o modelo de Taylor (1979 e 1980). Por ser considerada uma razoável aproximação de um modelo microfundamentado (ver Taylor (1999)) o modelo de Taylor também é chamado de "curva de Phillips novo keynesiana"1. Mas uma grande confusão tem persistido, ao longo do tempo, em torno deste modelo: apesar de ele levar o produto a um nível abaixo do pleno emprego quando há uma deflação, uma política gradualista crível pode evitar que isto ocorra diante de uma desinflação. Ou seja, grosso modo, o modelo de Taylor gera inércia no nível de preços mas não na taxa de inflação. Este ponto já havia sido levantado por Phelps (1978) e foi utilizado em um artigo pelo próprio Taylor (1983). Além disso, Ball (1994a) mostrou que, na ausência de surpresas desde o mais antigo reajuste salarial vigente, as desinflações geram, no modelo, "booms" e não recessões.

Há vários trabalhos empíricos que mostram a inadequação do modelo de Taylor para explicar a inércia inflacionária. Os trabalhos de referência da literatura, dos quais destacamos Fuhrer e Moore (1995) e Fuhrer (1997), foram feitos com dados da economia dos EUA.

\footnotetext{
${ }^{1}$ Ver, por exemplo, Mankiw (2001) e McCallum (1997).
} 
Como o resultado obtido em Ball (1994a) corresponde ao oposto do que se tem verificado na realidade, postulou-se a hipótese de que as recessões que acompanham as estabilizações se deveriam à falta de credibilidade e à racionalidade imperfeita. Roberts $(1997,1998)$ realizou trabalhos empíricos que foram particularmente favoráveis a esta última hipótese. Estes trabalhos utilizaram dados de "surveys", nas quais se pergunta diretamente às pessoas a respeito das expectativas inflacionárias, e isto levou a uma não rejeição de um modelo com estas expectativas, preços rígidos e reajustes justapostos. Roberts fez também uma estimação que confirmou o resultado de alguns trabalhos anteriores (como Bagestani (1992)) que mostravam que as expectativas inflacionárias das "surveys" não utilizam as informações disponíveis de modo eficiente.

Com isto, os artigos de Roberts geraram uma onda de prestígio, ainda em vigor, para os modelos com informação defasada. A adição desta hipótese teria, inclusive, resgatado o modelo novo keynesiano, tornando-o compatível com os dados. Encontramos esta linha de argumentação em diversos trabalhos, como Mankiw e Reis (2002).

O presente trabalho realiza duas tarefas. A primeira delas, compreendendo os capítulos 1 e 2, procura verificar se a hipótese adicional de informação defasada é capaz de fazer com que o modelo de Taylor se concilie com os dados. Em primeiro lugar, ele mostra que os artigos de Roberts têm alguns problemas em termos de especificação de modelo e não entram no mérito da importante questão de se as expectativas dos agentes são ou não 
consistentes $^{2}$ (ainda que utilizando informação defasada). Para fazermos estimações com a especificação correta dedicamos às expectativas relativamente ao nível de atividade um tratamento similar ao dado às expectativas inflacionárias: as inferimos a partir de uma "survey" junto aos consumidores (isto não havia sido feito por Roberts(1997, 1998)). Nossa análise empírica leva, então, à rejeição do modelo de Taylor, mesmo em sua versão com informação defasada.

$\mathrm{Na}$ segunda parte deste trabalho, constituída pelo capítulo 3, procuramos avaliar que modelos seriam capazes de nos fornecer uma explicação para a dinâmica da oferta agregada nominal mostrada pelos dados, especialmente no que diz respeito à inércia inflacionária e ao custo das estabilizações. Explicitamos e testamos, então, três hipóteses. Consideramos, em primeiro lugar, um modelo no qual parte dos agentes econômicos tem expectativas inconsistentes ${ }^{3}$. Em segundo lugar, exploramos a abordagem de Simonsen (1986) e Dow, Simonsen e Werlang (1993), na qual o custo das estabilizações é associado à elevação da incerteza. Nosso terceiro modelo é pautado em conceitos da economia comportamental - níveis de referência, aversão à perda, viés de julgamento em favor de si próprio e preferências que incluem "fairness", conceitos advindos da psicologia social cognitiva - e utiliza a hipótese de que a indexação pela inflação passada é uma referência importante.

Estes dois últimos modelos são compatíveis com uma assimetria: a de, diante de estabilizações, a maior parte dos agentes esperar recessões, mas

\footnotetext{
${ }^{2}$ Ver seção 1.4.

${ }^{3}$ Ver seção 1.4.
} 
diante de elevações inflacionárias antecipadas esta maioria não esperar, de modo significante, nem recessões nem expansões no produto ${ }^{4}$. Na parte empírica do último capítulo, verificamos que o modo como os dados são melhor explicados é com uma combinação entre um ou ambos os modelos que implicam assimetria com a hipótese de que parte dos agentes econômicos tem expectativas ingênuas e inconsistentes.

Avaliamos que, diante das nossas evidências, não há outras alternativas mais adequadas para explicar o custo das estabilizações nos EUA. Informação defasada e contratos salarias de três anos podem contribuir para estes custos, mas não geram assimetria. Um outro modelo novo, de Céspedes, Kumhof e Parrado (2002) tem como hipótese chave a suposição de que regras de reajustes sub-ótimos ocorrem de forma generalizada. Esta hipótese, além de não ser verificada nos casos de inflação moderada, também não gera assimetria. No que diz respeito, finalmente, às expectativas adaptativas, além de elas também não gerarem assimetria, elas representam uma formulação incompleta, pois não explicitam como são formadas as expectativas a respeito do nível de atividade (neste sentido, a hipótese de informação defasada constitui seu sucedâneo completo - na medida em que ela nos apresenta expectativas tanto a respeito da inflação quanto do nível de atividade).

A metodologia que utilizamos para testar os modelos é a mesma de alguns dos trabalhos mais importantes desta literatura, incluindo Roberts (1997), Fuhrer (1997) e Galí e Gertler (1999): testamos os coeficientes obtidos em uma equação reduzida. Avaliamos que a crítica de Woodford (2001) a esta metodologia não é correta. Ele argumenta que, uma vez que Galí e Gertler

\footnotetext{
${ }^{4} \mathrm{Na}$ seção 3.4 discutimos assimetrias relacionadas com esta e encontradas na literatura.
} 
(1999) chegaram ao resultado oposto do de Fuhrer, ela não gerou resultados robustos. Conforme veremos na seção 1.3 , no entanto, o procedimento adotado por Galí e Gertler não foi adequado. Uma vez que Roberts (1997) também incorreu em problemas (conforme análise das seções 1.3 e 1.4), restam o resultado de Fuhrer (1997) e o nosso. O primeiro rejeita o modelo de Calvo (tido como uma variação mais tratável do modelo de Taylor) sem a hipótese de informação defasada, enquanto o nosso rejeita um modelo de Taylor com esta hipótese e discute e testa algums modelos alternativos. 
CAPÍTULO 1

O MODELO DE JOHN TAYLOR

E A INÉRCIA INFLACIONÁRIA 
O modelo de Taylor $(1979,1980)$ tem sido, desde o final da década de 70, a mais importante referência para modelar a lentidão da reação do nível geral de preços às mudanças na demanda agregada. Este capítulo pretende apresentar os elementos teóricos e discutir a literatura empírica a respeito deste assunto, inclusive no que diz respeito à possibilidade de hipóteses adicionais, como falta de credibilidade e informação defasada (como em Mankiw e Reis (2002)), serem capazes de conciliar o modelo com os dados.

$\mathrm{Na}$ primeira seção revisaremos o modelo e faremos uma rápida discussão sobre sua microfundamentação. A seguir, verificaremos em que medida o modelo, inclusive com as acima mencionadas hipóteses adicionais, implica inércia inflacionária e estabilizações com custo. $\mathrm{Na}$ terceira seção analisaremos a literatura empírica existente sobre o assunto da seção anterior. Na quarta e última seção discutiremos a importância de se verificar o modo como os agentes econômicos formam suas expectativas e como checar a possibilidade de o custo das estabilizações ser atribuído à hipótese de estas expectativas incorporarem com lentidão as inovações da política monetária e seus efeitos. 


\section{1 - O MODELO DE JOHN TAYLOR}

Esta seção deriva e discute o modelo de Taylor. No item (A) expomos o modelo original e no seguinte discutimos seus microfundamentos.

\section{A) O MODELO ORIGINAL}

Os modelos com reajustes justapostos surgiram como uma alternativa tida como mais plausível do que o modelo de Lucas (1972) para explicar a curva de Phillips de curto prazo dentro do contexto das expectativas racionais. O primeiro destes modelos foi proposto por Fischer (1977). Nesse modelo, os salários eram pré-estabelecidos para vários períodos, mas poderiam ser fixados diferentes níveis salariais para cada um desses períodos. Taylor (1979 e 1980) aproveitou esta idéia de reajustes intercalados e utilizou-a em um modelo no qual salários pré-acordados permaneciam fixos durante vários períodos. Seu modelo se pauta nas seguintes hipóteses:

T1) salários ficam fixos durante um espaço de tempo considerável e prédeterminado (geralmente se assume um ano), com reajustes de outros salários ocorrendo de modo intercalado ao logo deste período.

T2) Markups constantes.

T3) Ao invés de se preocupar diretamente com o salário real, o assalariado olha para o salário nominal relativo. 
T4) Expectativas racionais.

Em seu artigo de 1999, Taylor substituiu a hipótese (T4) por:

T4') Salários são fixados no nível de equilíbrio esperado ${ }^{5}$.

A mudança de (T4) para (T4') pode ser considerada, no entanto, apenas semântica. A hipótese (T4') deixa explícita a possibilidade de os agentes não utilizarem as informações macroeconômicas disponíveis ao público de modo eficiente, mas ainda assume que eles tomam suas decisões de acordo com o conceito de equilíbrio de Nash. Discutiremos melhor esta hipótese na seção (1.4).

Para o caso com apenas dois períodos justapostos, partimos destas duas equações:

$$
\begin{gathered}
w_{t}=\alpha_{1} \cdot w_{t-1}+\alpha_{2} \cdot E_{t-1}\left[w_{t+1}\right]+\beta \cdot E_{t-1}\left[\alpha_{1} \cdot y_{t}+\alpha_{2} \cdot y_{t+1}\right]+v_{t} \\
\operatorname{com} \alpha_{1}+\alpha_{2}=1, \quad \beta>0 \\
p_{t}=\left(w_{t}+w_{t-1}\right) / 2 \Rightarrow w_{t}=2 p_{t}-w_{t-1}
\end{gathered}
$$

Observando-se que todas as variáveis estão em $\log , \mathbf{w}_{\mathbf{t}}$ representa os salários fixados na passagem do período $t-1$ para o período $t$, para prevalecerem durante $\mathrm{t}$ e $\mathrm{t}+1, \mathbf{p}$ é o nível geral de preços (markups são

\footnotetext{
${ }^{5}$ Nas palavras de Taylor, seu modelo é um "expected market clearing model”, em contraposição a modelos como o de Lucas (1972), que são "market clearing models".
} 
assumidos constantes e normalizados em zero) e y corresponde ao nível de produto real menos seu nível de pleno emprego (igual ao hiato do produto vezes menos um). $O$ operador $E_{t-1}[$ ] representa expectativa com base nas informações obtidas até o final do período $\mathrm{t}-1$, enquanto $v$ representa um componente de erro aleatório que é i.i.d..

Normalmente se assume $\alpha_{1}=\alpha_{2}=1 / 2$, o que nos leva a:

$\mathrm{w}_{\mathrm{t}}=\left(\mathrm{w}_{\mathrm{t}-1}+\mathrm{E}_{\mathrm{t}-1}\left[\mathrm{w}_{\mathrm{t}+1}\right]\right) / 2+\beta \cdot \mathrm{E}_{\mathrm{t}-1}\left[\left(\mathrm{y}_{\mathrm{t}}+\mathrm{y}_{\mathrm{t}+1}\right) / 2\right]+v_{\mathrm{t}}, \quad \beta>0$

O uso de (1.1') ao invés de (1.1) facilita sobremaneira a manipulação algébrica do modelo. Rearranjando (1.1'), obtemos :

$w_{t}-w_{t-1}=E_{t-1}\left[w_{t+1}\right]-w_{t}+2 \cdot \beta \cdot E_{t-1}\left[\left(y_{t}+y_{t+1}\right) / 2\right]+2 \cdot v_{t}$

o que, utilizando o conceito de $w_{t}$ em (1.2) nos leva a:

$2 p_{t}-w_{t-1}-2 p_{t-1}+w_{t-2}=E_{t-1}\left[2 p_{t+1}-w_{t}\right]-2 p_{t}+w_{t-1}+2 \cdot \beta \cdot E_{t-1}\left[\left(y_{t}+y_{t+1}\right) / 2\right]+2 \cdot v_{t}$

Com exceção de $v_{t}$, no final de $\mathrm{t}-1$ já existem todos os elementos para os agentes saberem qual será $w_{t}$. Em função disso, assume-se que $E_{t}$ ${ }_{1}\left[w_{t}\right]=w_{t}$ e $E_{t-1}\left[\pi_{t}\right]=\pi_{t}$. Ao fazermos isto, além de estarmos desprezando o efeito de $v_{\mathrm{t}}$, estamos também assumindo que as expectativas dos agentes se pautam no modelo (ou seja, que os agentes estabelecem suas expectativas com base no modelo, o que significa que temos expectativas consistentes, 
mais conhecidas como racionais). Conforme o que será dito na seção (1.4), este procedimento está de acordo com a hipótese (T4'), que demanda, implicitamente, que os agentes sejam estrategistas de Nash.

Utilizando o recurso acima e a definição:

$\pi_{t}=p_{t}-p_{t-1}$

obtemos:

$2 \pi_{t}-w_{t-1}=2 E_{t-1}\left[\pi_{t+1}\right]-\left(w_{t-2}+w_{t}\right)+w_{t-1}+2 \cdot \beta \cdot E_{t-1}\left[\left(y_{t}+y_{t+1}\right) / 2\right]+2 \cdot v_{t}$

o que, levando-se em conta que (rearranjando (1.1') em t-1)

$\mathrm{w}_{\mathrm{t}-2}+\mathrm{E}_{\mathrm{t}-2}\left[\mathrm{w}_{\mathrm{t}}\right]=2 \cdot \mathrm{w}_{\mathrm{t}-1}-2 \cdot \beta \cdot \mathrm{E}_{\mathrm{t}-2}\left[\left(\mathrm{y}_{\mathrm{t}}+\mathrm{y}_{\mathrm{t}+1}\right) / 2\right]-2 \cdot v_{\mathrm{t}-1}$

nos dá:

$2 \pi_{\mathrm{t}}=2 \mathrm{E}_{\mathrm{t}-1}\left[\pi_{\mathrm{t}+1}\right]+2 \cdot \beta \cdot\left(\mathrm{E}_{\mathrm{t}-1}\left[\left(\mathrm{y}_{\mathrm{t}}+\mathrm{y}_{\mathrm{t}+1}\right) / 2\right]+\mathrm{E}_{\mathrm{t}-2}\left[\left(\mathrm{y}_{\mathrm{t}-1}+\mathrm{y}_{\mathrm{t}}\right) / 2\right)-\left(\mathrm{w}_{\mathrm{t}}-\mathrm{E}_{\mathrm{t}-2}\left[\mathrm{w}_{\mathrm{t}}\right]\right)\right.$
$+2\left(v_{\mathrm{t}}+v_{\mathrm{t}-1}\right)$

O único termo da equação acima a respeito do qual não temos dados é $\left(w_{t}-E_{t-2}\left[w_{t}\right]\right)$. Para resolver este problema, primeiro utilizamos (1.2):

$\left(w_{t}-E_{t-2}\left[w_{t}\right]\right)=2 p_{t}-w_{t-1}-E_{t-2}\left[2 p_{t}+w_{t-1}\right]$ 
Depois disso, subtraímos e somamos $2 \mathrm{p}_{\mathrm{t}-1}$ do lado direito da equação e usamos o fato de, no modelo, $E_{t-2}\left[w_{t-1}\right]=w_{t-1}$ :

$$
\left(w_{t}-E_{t-2}\left[w_{t}\right]\right)=\left(2 p_{t}-2 p_{t-1}\right)-\left(E_{t-2}\left[2 p_{t}\right]-2 p_{t-1}\right)=2\left(\pi_{t}-E_{t-2}\left[\pi_{t}\right]\right)
$$

O que, substituindo em (1.4) e dividindo tudo por 2, nos dá:

$$
\begin{array}{r}
\pi_{t}=E_{t-1}\left[\pi_{t+1}\right]+\beta \cdot\left(E_{t-1}\left[\left(y_{t}+y_{t+1}\right) / 2\right]+E_{t-2}\left[\left(y_{t-1}+y_{t}\right) / 2\right]\right) \\
+\left(\pi_{t}-E_{t-2}\left[\pi_{t}\right]\right) \\
+\left(v_{t}+v_{t-1}\right)
\end{array}
$$

Ou seja, a taxa de inflação do período $t$ depende da taxa de inflação esperada para $t+1$ com base nas informações obtidas até 0 final de $t-1$, de $\left(E_{t-1}\left[\left(y_{t}+y_{t+1}\right) / 2\right]+E_{t-2}\left[\left(y_{t-1}+y_{t}\right) / 2\right]\right)$ e de um componente de erro expectacional passado.

Rearranjando (1.5), podemos dar outras interpretações para o modo como o modelo de Taylor determina a taxa de inflação. Uma possibilidade é:

$$
\begin{array}{r}
\pi_{t}=\left(E_{t-1}\left[\pi_{t+1}\right]+E_{t-2}\left[\pi_{t}\right]\right) / 2+(\beta / 2) \cdot\left(E_{t-1}\left[\left(y_{t}+y_{t+1}\right) / 2\right]+E_{t-2}\left[\left(y_{t-1}+y_{t}\right) / 2\right]\right) \\
+(1 / 2) \cdot\left(v_{t}+v_{t-1}\right)
\end{array}
$$


Ou seja, a taxa de inflação em t é igual a média entre a taxa esperada no final de $t-2$ para $t$ e a taxa esperada no final de $t-1$ para $t+1$, mais um componente associado às expectativas a respeito do hiato de produto.

\section{B) MICROFUNDAMENTOS E O MODELO DE TAYLOR}

O modelo de Taylor foi proposto em uma época na qual a microfundamentação não aparecia explicitamente nos modelos macroeconômicos. Taylor não fez uma derivação a partir da maximização (intertemporal) de uma função utilidade do agente representativo e da maximização (intertemporal) de lucros das firmas. Em um trabalho mais recente, no entanto, Taylor (1999) procura mostrar que o modelo corresponde a uma razoável aproximação do modelo microfundamentado e calibrado. Essa visão parece ser compartilhada por grande parte dos macroeconomistas ${ }^{6}$, que chamam o modelo e suas variações (como a de Calvo (1983)) de "curva de Phillips novo keynesiana".

Do ponto de vista dos microfundamentos, uma das principais críticas ao modelo tem sido a de ele assumir que a duração dos "contratos" (implícitos) salariais é dada exogenamente, independendo da taxa de inflação, das incertezas (idiossincráticas e agregadas) e dos choques (idiossincráticos e agregados). Ou seja, o "timing" dos reajustes depende apenas do tempo, e não do estado $^{7}$ (da diferença entre o preço ótimo e o preço praticado). Foge ao

\footnotetext{
${ }^{6}$ Ver McCallum (1997), Galí e Gertler (1999) e Mankiw (2001).

${ }^{7}$ Ver Caplin e Spulber (1987).
} 
escopo do presente trabalho uma análise formal a respeito da inércia inflacionária no contexto de um modelo com regras dependentes do estado, mas serão feitos alguns comentários a esse respeito na seção 3.4 e na conclusão. Evidências favoráveis ao uso do modelo de Taylor como uma aproximação são encontrados, no entanto, em vários trabalhos citados em Taylor (1999), nos quais verificamos que a moda da duração dos contratos salariais nos EUA permaneceu em um ano mesmo diante de elevações e quedas na taxa de inflação. Isto parece indicar que os custos de menú, principal hipótese por traz dos modelos com regras dependentes do estado, não são a principal razão por traz da rigidez de preços. Esta conjectura é corroborada por Blinder (1994). A justificação de regras dependentes do tempo se pauta no argumento de que elas reduzem custos associados à coleta de informações e à tomada de decisões e outros custos relacionados com negociações (como greves, por exemplo).

Feita esta ressalva, para as outras hipóteses necessárias ao modelo markup constante, firmas fixadoras (ao invés de tomadoras) de preços, salários e preços permanecendo rígidos por um período de tempo considerável e não sincronização de reajustes - foram derivados microfundamentos. Um primeiro passo nessa direção foi dado por modelos como o de Blanchard e Kiyotaki (1987), no qual as firmas são monopolistas competidoras. Este modelo justificou as idéias de firma fixadora (ao invés de tomadora) de preços e de markup acíclico sobre salários ${ }^{8}$.

\footnotetext{
${ }^{8}$ Para uma discussão a respeito de markups e ciclos econômicos, ver Romer $(1996,2001)$ e Rotemberg e Woodford (1999).
} 
Mas o modelo de Blanchard e Kiyotaki é estático. O uso da mesma estrutura em um contexto dinâmico e com justaposição de reajustes logo apareceu no livro texto de Blanchard e Fischer (1989). Mais adiante, Kimball (1995), derivou um modelo dinâmico a partir da maximização do agente representativo.

Adicionalmente à consolidação deste modelo, trabalhos como Akerlof e Yellen (1985) ajudaram a trazer fundamentação para a idéia de rigidez de preços e salários. Finalmente, Fethke e Policano (1984) e Ball e Cecchetti (1988), justificaram a racionalidade do comportamento não sincronizado dos reajustes.

Finalizaremos a análise da fundamentação das hipóteses subjacentes ao modelo com a hipótese (T3) (ao invés de se preocupar diretamente com o salário real, o assalariado olha para o salário nominal relativo). Nossa observação é a de que esta hipótese não influi nos resultados do modelo. Isto ocorre porque a hipótese de markup constante faz com que seu efeito seja equivalente ao da hipótese de que eles olhassem para o salário real. A demonstração deste ponto é extremamente simples. Sem (T3), ao invés de (1.1), teremos:

$w_{t}=(1 / 2) \cdot E_{t-1}\left[p_{t}+p_{t+1}\right]+\chi \cdot E_{t-1}\left[\left(y_{t}+y_{t+1}\right) / 2\right]+\xi_{t}$

Ou seja, o salário (nominal) é fixado em função das expectativas relativas ao nível de preços e ao produto durante o tempo em que ele vigorará. Mas, se voltarmos às equações originais de Taylor, chegaremos à (1.6). Para tanto, basta utilizar os conceitos de $\mathrm{w}_{\mathrm{t}-1}$ e $\mathrm{w}_{\mathrm{t}+1}$ de (1.2) em (1.1'), obtendo: 
$w_{t}=(1 / 2) E_{t-1}\left[2 p_{t}-w_{t}+2 p_{t+1}-w_{t}\right]+\beta \cdot E_{t-1}\left[\left(y_{t}+y_{t+1}\right) / 2\right]+\xi_{t}$

que, rearranjada e assumindo-se novamente $E_{t-1}\left[w_{t}\right]=w_{t}$, se converterá em:

$$
\begin{aligned}
& 2 w_{t}=(1 / 2)\left(2 p_{t}+E_{t-1}\left[2 p_{t+1}\right]\right)+\beta \cdot E_{t-1} E_{t-1}\left[\left(y_{t}+y_{t+1}\right) / 2\right]+\xi_{t} \\
& \Rightarrow w_{t}=(1 / 2)\left(p_{t}+E_{t-1}\left[p_{t+1}\right]\right)+(\beta / 2) . E_{t-1}\left[\left(y_{t}+y_{t+1}\right) / 2\right]+\xi_{t}
\end{aligned}
$$

que $(\operatorname{com} \chi=\beta / 2)$ será igual à (1.6) se $p_{t}=E_{t-1}\left[p_{t}\right]$.

1.2 - INÉRCIA E O CUSTO DE ESTABILIZAÇÕES NO MODELO DE TAYLOR COM E SEM INFORMAÇÃO DEFASADA 
Conforme já foi dito na introdução, o modelo de Taylor quase não gera inércia na taxa de inflação, podendo gerar taxas de sacrifício (em termos de hiato de produto acumulado) negativas em estabilizações pré-anunciadas ou gradualistas, desde que haja credibilidade. Uma estabilização crível iniciada em t e anunciada em t-2 terá custo negativo. Isto pode ser melhor visualizado se rearranjarmos (1.5):

$$
\begin{gathered}
\mathrm{E}_{\mathrm{t}-1}\left[\pi_{\mathrm{t}+1}\right]-\pi_{\mathrm{t}}=- \\
\beta\left(\mathrm{E}_{\mathrm{t}-1}\left[\mathrm{y}_{\mathrm{t}}+\mathrm{y}_{\mathrm{t}+1}\right]+\mathrm{E}_{\mathrm{t}-2}\left[\mathrm{y}_{\mathrm{t}-1}+\mathrm{y}_{\mathrm{t}}\right]\right)+\gamma \cdot\left(\pi_{\mathrm{t}}-\mathrm{E}_{\mathrm{t}-2}\left[\pi_{\mathrm{t}}\right]\right)-\left(v_{\mathrm{t}}+v_{\mathrm{t}-1}\right) \\
\text { com as restrições: }-\beta<0 \text { e } \gamma=1
\end{gathered}
$$

Em (1.5") está explicitado que quando se espera que $\left(E_{t-1}\left[\pi_{t+1}\right]-\pi_{t}\right)<0$ (isto é, quando se espera que a inflação vá cair) e não houve erro expectacional com relação à $\left(\pi_{t}-E_{t-2}\left[\pi_{t}\right]\right)$, espera-se que o produto fique acima de seu nível "natural". É importante notar que esta equação continua valendo quando se adota a hipótese de informação defasada, como em Mankiw e Reis (2002), pois trabalha diretamente com as expectativas dos agentes (façam eles uso eficiente das informações ou não).

Caso uma estabilização visando inflação zero surpreenda os agentes ou não tenha credibilidade, ela poderá gerar perda de produto por vários períodos. Mas, se houver simultaneamente credibilidade e uma política de transição (gradualismo), pode-se obter uma estabilização sem custos (ou mesmo com custos, na média, negativos), mesmo iniciando-a subitamente. 
Para ilustrar o que ocorre, simularemos quatro tipos de estabilização: pré-anunciada, iniciada de surpresa e gradualista com e sem informação defasada. O efeito da surpresa e da falta de credibilidade são exatamente iguais ao da informação defasada - nos três casos, um aperto monetário anunciado tem conseqüências sobre a demanda nominal agregada que surpreendem os agentes.

Nas derivações feitas até agora, obtivemos os salários a partir dos níveis de produto real e preços esperados, mas o que ocorre em uma estabilização é uma mudança na política a respeito da demanda agregada nominal. Por isso, devemos, agora, derivar o modo como os salários são fixados a partir dos salários do período anterior e da demanda agregada nominal esperada para os próximos períodos. Para tanto, utilizaremos o chamado "método dos coeficientes indeterminados"9.

Em primeiro lugar introduzimos a variável log do produto nominal, que chamaremos de $\mathbf{m}$, e explicitamos a identidade:

$m_{t} \equiv p_{t}+y_{t} \Rightarrow y_{t} \equiv m_{t}-p_{t}$

Em estado estacionário, o nível de preços acompanha as variações nominais do produto e o (log do) desvio do produto com relação ao seu nivel de estado estacionário é igual a zero.

Substituindo (1.8) em (1.1'), obtemos:

\footnotetext{
${ }^{9}$ Ver Blanchard e Fischer (1989), anexo do capítulo 5 ou Romer (2001).
} 


$$
w_{t}=(1 / 2)\left(w_{t-1}+E_{t-1}\left[w_{t+1}\right]\right)+(\beta / 2) \cdot E_{t-1}\left[\left(m_{t}-p_{t}\right)+\left(m_{t+1}-p_{t+1}\right)\right]
$$

$\mathrm{O}$ que, utilizando os conceitos de $\mathrm{p}_{\mathrm{t}}$ e $\mathrm{p}_{\mathrm{t}+1}$ de (1.2), levando-se em conta que $\mathrm{w}_{\mathrm{t}}$ e $\mathrm{w}_{\mathrm{t}-1}$ já são conhecidos em $\mathrm{t}-1$, ignorando $v_{\mathrm{t}}$ e rearranjando, nos dá:

$$
(1+(\beta / 2)) \cdot w_{t}=(1 / 2)(1-(\beta / 2))\left(w_{t-1}+E_{t-1}\left[w_{t+1}\right]\right)+(\beta / 2) \cdot E_{t-1}\left[\left(m_{t}+m_{t+1}\right)\right.
$$

que rearranjando novamente, nos dá:

$$
\begin{aligned}
\mathrm{w}_{\mathrm{t}}=(1 / 2)\{(1-(\beta / 2)) /(1+(\beta / 2))\}\left(\mathrm{w}_{\mathrm{t}-1}+\mathrm{E}_{\mathrm{t}-1}\left[\mathrm{w}_{\mathrm{t}+1}\right]\right) \\
+\left\{( ( \beta / 2 ) / ( 1 + ( \beta / 2 ) ) \} \cdot \mathrm { E } _ { \mathrm { t } - 1 } \left[\left(\mathrm{m}_{\mathrm{t}}+\mathrm{m}_{\mathrm{t}+1}\right)\right.\right.
\end{aligned}
$$

A equação (1.9) nos informa que $w_{t}$ é função do valor desta variável no passado e no futuro e da quantidade de moeda esperada para os períodos t e $t+1$. Se substituirmos recursivamente os valores futuros de $w$ no lado direito da equação (1.9), verificaremos que $w_{t}$ pode ser escrita como função de toda a evolução monetária futura esperada e de $\mathrm{w}_{\mathrm{t}-1}$. Sendo assim, é razoável propor (como uma "educated guess") que a solução de (1.9) tenha a forma:

$$
w_{t}=\lambda w_{t-1}+\sum c_{i \cdot} \cdot E_{t-1}\left[m_{t+i}+m_{t+i+1}\right]
$$

onde $\sum$ é o somatório de $\mathrm{i}=0$ até $\mathrm{i}=\infty$. 
Se derivarmos $E_{t-1}\left[w_{t+1}\right]$ a partir de (1.10), teremos:

$E_{t-1}\left[w_{t+1}\right]=\lambda w_{t}+\sum c_{i} \cdot E_{t-1}\left[m_{t+i+1}+m_{t+i+2}\right]$

Substituindo a expressão que obtivemos para $E_{t-1}\left[W_{t+1}\right]$ em (1.11) em (1.9), obtemos:

$$
\begin{gathered}
w_{t}=(1 / 2)\{(1-(\beta / 2)) /(1+(\beta / 2))\}\left\{w_{t-1}+\lambda w_{t}+\sum c_{i} \cdot E_{t-1}\left[m_{t+i+1}+m_{t+i+2}\right\}\right. \\
+\{(\beta / 2) /(1+(\beta / 2))\} \cdot E_{t-1}\left[m_{t}+m_{t+1}\right] \\
\Rightarrow\{1-(1 / 2) a \lambda\} \cdot w_{t}=(a / 2) w_{t-1}+(a / 2) \sum c_{i j} \cdot E_{t-1}\left[m_{t+i+1}+m_{t+i+2}\right\} \\
+\{(\beta / 2) /(1+(\beta / 2))\} \cdot E_{t-1}\left[m_{t}+m_{t+1}\right] \\
\operatorname{com~a~}=(1-(\beta / 2)) /(1+(\beta / 2)) \\
\Rightarrow w_{t}=\{a /(2-a \lambda)\} \cdot w_{t-1}+\sum\{a /(2-a \lambda)\} \cdot c_{i j} \cdot E_{t-1}\left[m_{t+i+1}+m_{t+i+2}\right\} \\
(\beta / 2) /\{(1+(\beta / 2))(1-a \lambda / 2)\} \cdot E_{t-1}\left[m_{t}+m_{t+1}\right]
\end{gathered}
$$

Para que (1.10) e (1.12) sejam ambas válidas, $\lambda \neq 0$ e $\forall c_{i} \neq 0$, a solução é obtida igualando os coeficientes de $w_{t-1}$ e os associados às quantidades de moeda esperadas das duas equações. Fazendo primeiro para $\mathrm{w}_{\mathrm{t}-1}$, temos:

$$
\lambda=a /(2-a \lambda) \Rightarrow a \lambda^{2}-2 \lambda+a=0
$$


Essa equação do segundo grau tem como raízes:

$$
\lambda=\left\{1 \pm\left(1-a^{2}\right)^{(1 / 2)}\right\} / a
$$

Sendo a raiz não explosiva (com módulo entre zero e um):

$$
\lambda_{1}=\left\{1-\left(1-a^{2}\right)^{(1 / 2)}\right\} / a
$$

Podemos obter $\lambda_{1}$ em função apenas de $\beta$. Substituindo o termo a por sua definição, obtemos, após algumas operações:

$$
\lambda_{1}=\left\{(1+\beta)-2 \cdot \beta^{1 / 2}\right\} /(1-\beta)
$$

que, multiplicando o numerador e o denominador por $\left(1+\beta^{1 / 2}\right) /(1-\beta)$, nos dá:

$$
\lambda_{1}=\left\{\left(1-\beta^{1 / 2}\right\} /\left(1+\beta^{1 / 2}\right)\right.
$$

Para obtermos $c_{i}$, verificamos o que ocorre para $t=0$ e para os períodos seguintes:

$$
c_{0}: \quad c_{0}=\beta /\{(1+\beta)(1-a \lambda / 2)\}
$$


$\mathrm{c}_{1}: \quad \mathrm{c}_{1}=\mathrm{c}_{0} \cdot\{\mathrm{a} /(2-\mathrm{a} \lambda)\}$

$c_{2}: \quad c_{2}=c_{1} \cdot\{a /(2-a \lambda)\}$

E assim por diante, de modo que podemos generalizar:

$c_{i}: \quad c_{i}=\{a /(2-a \lambda)\}^{i} \cdot \beta /\{(1+\beta)(1-a \lambda / 2)\}$

Após várias transformações, podemos reescrever $c_{i}$ em termos de $\lambda_{1}$ :

$\mathrm{C}_{\mathrm{i}}=\left\{\left(1-\lambda_{1}\right)^{2} / 2\right\} \cdot \lambda_{1}{ }^{\mathrm{i}}$

De modo que chegamos finalmente à expressão que determina $w_{t}$ em função de $\mathrm{w}_{\mathrm{t}-1}$ e da expectativa da evolução monetária futura:

$$
\mathrm{w}_{\mathrm{t}}=\lambda_{1} \mathrm{w}_{\mathrm{t}-1}+\sum\left\{\left(1-\lambda_{1}\right)^{2} / 2\right\} \cdot \lambda_{1}{ }^{i} \cdot \mathrm{E}_{\mathrm{t}-1}\left[\mathrm{~m}_{\mathrm{t}+\mathrm{i}}+\mathrm{m}_{\mathrm{t}+\mathrm{i}+1}\right]
$$

Utilizando as equações (1.13), (1.2) e (1.8) podemos, então, examinar o que ocorre diante de situações que simulam estabilizações. Para fazermos isto, basta definir a política sobre $\mathrm{m}_{\mathrm{t}}$ e definir um valor para $\beta$.

O parâmetro $\beta$ corresponde ao inverso da elasticidade da curva de oferta de trabalho relativamente ao salário. Quando $\beta$ tem um valor próximo de zero, pequenas variações no salário real são associadas a grandes variações no nível de emprego, de modo que teremos o salário real variando pouco ao longo 
dos ciclos. Por isso, diz-se que quando $\beta$ tem um valor próximo a zero, a rigidez real da curva de oferta (agregada) é elevada. Um resultado comumente associado ao modelo de Taylor é o de que quanto maior a rigidez real, maior a inércia no nível de $\operatorname{preços}^{10}$. Conforme mostrou Ball (1990), isto não se traduz em estabilizações inflacionárias com perda líquida de produto, desde que haja credibilidade, racionalidade e as políticas sejam pré-anunciadas ou gradualistas. Para ilustrar este ponto, faremos nossas simulações com $\beta=$ 0,10 , valor geralmente assumido em modelos calibrados para os EUA ${ }^{11}$ e consistente com as estimações de Blanchflower e Oswald (1994). Mostramos no apêndice $A$ o caso sem rigidez real (ou seja, com $\beta=1,00$ ).

Nas simulações abaixo, partimos de uma taxa de inflação anual em log estável em $100 \%$ por período. Isso equivale a uma inflação de $171,8 \%$ ao período. Com períodos semestrais, serão $638,9 \%$ ao ano. A meta das políticas de estabilização abaixo é mudar o patamar inflacionário para zero no estado estacionário.

a) estabilização pré-anunciada e com credibilidade e racionalidade plenas:

\footnotetext{
${ }^{10}$ Ver Blanchard e Fischer (1989), cap. 8, por exemplo.

${ }^{11}$ Ver, por exemplo, Ball e Romer (1990), Chary, Kehoe e McGrattan(2000) e Jeanne (1997). Nossas estimativas apontam, no entanto, para um $\beta$ um pouco mais alto (ou seja para um grau de rigidez real um pouco menor). Observamos que a oferta de trabalho agregada da economia e da oferta de trabalho dos têm elasticidades diferentes, sendo esta última bem mais inelástica. Ver, por exemplo, Romer (1996, 2001). Outros fatores que contribuem para um $\beta$ baixo são sumarizados e discutidos em Woodford (2001).
} 
Desde um longo tempo até o período $t=2$, a política seguida é manter $m_{t}=t . E m t=1$ é anunciado que, a partir do período seguinte, $m$ ficará constante (para sempre), igual a 2. Uma simulação desta situação é reportada na tabela abaixo:

\begin{tabular}{|l|llllllll|}
\hline Período: & $\mathrm{t}=0$ & $\mathrm{t}=1$ & $\mathrm{t}=2$ & $\mathrm{t}=3$ & $\mathrm{t}=4$ & $\mathrm{t}=5$ & $\mathrm{t}=6$ & $\mathrm{t}=7$ \\
\hline $\mathrm{m}$ & 0,00 & 1,00 & 2,00 & 2,00 & 2,00 & 2,00 & 2,00 & 2,00 \\
$\mathrm{w}$ & 0,50 & 0,98 & 1,35 & 1,59 & 1,74 & 1,83 & 1,90 & 1,93 \\
$\mathrm{p}$ & 0,00 & 0,74 & 1,17 & 1,47 & 1,67 & 1,79 & 1,87 & 1,92 \\
$\pi$ & 1,00 & 0,74 & 0,43 & 0,31 & 0,20 & 0,12 & 0,08 & 0,05 \\
$\mathrm{y}$ & 0,00 & 0,26 & 0,84 & 0,53 & 0,34 & 0,22 & 0,14 & 0,09 \\
\hline
\end{tabular}

Ou seja, em concordância com a equação (5"), a estabilização préanunciada fez com que tivéssemos inflação cadente com produto acima do nível de longo prazo. Ambos corretamente previstos com até dois períodos de antecedência.

b) estabilização pré-anunciada, mas com esta informação assimilada pelos agentes somente no final do período anterior à mudança:

Dinâmica de $\mathrm{m}$ idêntica à do caso anterior, mas com a mudança acreditada ou compreendida somente no final de $t=2$ ao invés de em $t=1$, 


\begin{tabular}{|lllllllll|}
\hline Período & $\mathrm{t}=0$ & $\mathrm{t}=1$ & $\mathrm{t}=2$ & $\mathrm{t}=3$ & $\mathrm{t}=4$ & $\mathrm{t}=5$ & $\mathrm{t}=6$ & $\mathrm{t}=7$ \\
\hline $\mathrm{m}$ & 0,00 & 1,00 & 2,00 & 2,00 & 2,00 & 2,00 & 2,00 & 2,00 \\
$\mathrm{w}$ & 0,50 & 1,50 & 2,50 & 2,32 & 2,20 & 2,13 & 2,08 & 2,05 \\
$\mathrm{p}$ & 0,00 & 1,00 & 2,00 & 2,41 & 2,26 & 2,17 & 2,11 & 2,07 \\
$\pi$ & 1,00 & 1,00 & 1,00 & 0,41 & $-0,15$ & $-0,09$ & $-0,06$ & $-0,04$ \\
$\mathrm{y}$ & 0,00 & 0,00 & 0,00 & $-0,41$ & $-0,26$ & $-0,17$ & $-0,11$ & $-0,06$ \\
\hline
\end{tabular}

A mudança de política em $t=3$ surpreendeu os agentes que fixaram salários no final de $t=1$, os quais prevaleceram durante os períodos $t=2$ e $t=3$. Isto fez com que $\pi_{3}-E_{1}\left[\pi_{3}\right]=0,59$, o que fez com que já no final de $t=2$ se tenha previsto um y fortemente negativo em $\mathrm{t}=3$, apesar da queda (também já prevista no final de $t=2$ ) de $\pi_{3}$ frente $a_{2}$. A partir de $t=4$, os salários prevalecentes foram todos pautados em previsões inflacionárias corretas. Em função disso temos (a partir de $\mathrm{t}=4$ ) inflação subindo e hiato de produto negativo. Tudo perfeitamente de acordo com a equação (1.5").

Em termos práticos, falta de credibilidade ou lentidão na disseminação ou na compreensão de uma política econômica tem o mesmo efeito: a surpresa a respeito da política monetária.

Observamos que longa duração ("memória") da forte recessão ocorre porque este cenário implica um longo período de significativa deflação. Conforme já dissemos, o modelo de Taylor implica duradoura inércia no nível de preços, apesar de baixa inércia na taxa de inflação.

c) estabilização gradualista anunciada no final do período anterior à mudança: 
Como em (a), este cenário assume plena credibilidade e racionalidade. Mas no presente caso, a mudança de política só é anunciada em $t=2$. Por outro lado, há uma regra de transição para a política monetária:

Até $\mathrm{t}=2, \mathrm{~m}=\mathrm{t}$

$\mathrm{Em} \mathrm{t}=3, \mathrm{~m}$ aumenta 0,5 , atingindo 2,5 .

Depois disto, $\mathrm{m}$ permanece constante em 2,5

\begin{tabular}{|lllllllll|}
\hline Período & $\mathrm{t}=0$ & $\mathrm{~T}=1$ & $\mathrm{t}=2$ & $\mathrm{t}=3$ & $\mathrm{t}=4$ & $\mathrm{~T}=5$ & $\mathrm{t}=6$ & $\mathrm{t}=7$ \\
$\mathrm{~m}$ & 0,00 & 1,00 & 2,00 & 2,50 & 2,50 & 2,50 & 2,50 & 2,50 \\
$\mathrm{w}$ & 0,50 & 1,50 & 2,50 & 2,50 & 2,50 & 2,50 & 2,50 & 2,50 \\
$\mathrm{p}$ & 0,00 & 1,00 & 2,00 & 2,50 & 2,50 & 2,50 & 2,50 & 2,50 \\
$\pi$ & 1,00 & 1,00 & 1,00 & 0,50 & 0,00 & 0,00 & 0,00 & 0,00 \\
$\mathrm{y}$ & 0,00 & 0,00 & 0,00 & 0,00 & 0,00 & 0,00 & 0,00 & 0,00 \\
\hline
\end{tabular}

Neste caso, houve tanto o efeito surpresa, quanto a "curva de Phillips ao contrário", do modelo de Taylor. Nesta simulação (com esta regra de transição e em um modelo com apenas dois períodos justapostos) os dois efeitos se anularam perfeitamente, mas nem sempre isso ocorre nessa medida exata ${ }^{12}$.

d) estabilização gradualista com mas com a mudança de política só sendo assimilada pelas expectativas dos agentes após um período de recessão:

\footnotetext{
${ }^{12}$ Ver Ball (1994).
} 
Neste caso, assumimos que os gestores anunciam uma regra de transição que durará 3 períodos, mas que os agentes só entendem os efeitos da mudança após um período de recessão. Como nos casos anteriores, $\mathrm{m}$ só sai de sua trajetória inicial em $t=3$. Assim, somente a partir do final deste período a mudança de política é compreendida.

\begin{tabular}{|l|llllllll|}
\hline Período & $\mathrm{t}=0$ & $\mathrm{t}=1$ & $\mathrm{t}=2$ & $\mathrm{t}=3$ & $\mathrm{~T}=4$ & $\mathrm{t}=5$ & $\mathrm{t}=6$ & $\mathrm{t}=7$ \\
$\mathrm{~m}$ & 0,00 & 1,00 & 2,00 & 2,50 & 3,00 & 3,50 & 3,50 & 3,50 \\
$\mathrm{w}$ & 0,50 & 1,50 & 2,50 & 3,50 & 3,47 & 3,48 & 3,49 & 3,49 \\
$\mathrm{p}$ & 0,00 & 1,00 & 2,00 & 3,00 & 3,48 & 3,47 & 3,48 & 3,49 \\
$\pi$ & 1,00 & 1,00 & 1,00 & 1,00 & 0,48 & $-0,01$ & 0,01 & 0,01 \\
$\mathrm{y}$ & 0,00 & 0,00 & 0,00 & $-0,50$ & $-0,48$ & 0,03 & 0,02 & 0,01 \\
\hline
\end{tabular}

Como $w_{3}=3,5$ e o $w$ de estado estacionário após a transição também tem este valor e como o grau de rigidez real é bem alto, $\mathrm{w}_{4}$ também tem um valor próximo deste nível, apesar de $\mathrm{m}_{4}$ ser apenas 3,0. Deste modo, temos forte recessão não só em $t=3$, mas também em $t=4$. Observe também que os valores de $\left(E_{t-1}\left[\pi_{t+1}\right]-\pi_{t}\right)$ estão plenamente de acordo com a equação (1.5").

Observamos que teríamos um resultado análogo se houvesse falta de credibilidade, com esta só sendo conquistada após um período de recessão.

Concluindo, estas quatro simulações exemplificam as implicações da equação (1.5"):

- Na ausência do fator surpresa, o modelo de Taylor implica taxas 
de sacrifício, de estabilizações, negativas.

- Surpresas só têm efeito real caso não sejam antecipadas em um período de tempo equivalente ao em que os preços (ou salários) ficam rígidos. Por exemplo: se os preços (salários) ficam rígidos durante dois períodos, uma política anunciada com dois períodos de antecedência será equivalente a uma política sem surpresa.

- Através de uma política gradualista, pode-se obter uma estabilização com custo zero ou negativo, mesmo que o anúncio desta ocorra somente na véspera de sua implantação. Neste caso há uma combinação dos dois efeitos anteriores:

- Falta de credibilidade ou lentidão no entendimento dos efeitos da política monetária podem gerar custos em estabilizações ainda que estas sejam graduais.

Portanto, para que uma estabilização tenha custo (em termos de perda de produto), o efeito negativo da não antecipação da política monetária ou de seus efeitos deve predominar sobre o efeito positivo que a queda prevista da inflação tem sobre o modelo de Taylor.

Observamos, finalmente, que trabalhamos com tempo discreto e apenas dois períodos. Mas modelos com tempo contínuo e um continuum uniforme de reajustes ao longo do tempo, como os desenvolvidos por Ball $(1990,1994 a$ e 1995), chegaram a resultados análogos ${ }^{13}$.

\footnotetext{
13 Ball (1994a) ressalva, porém, que um modelo do tipo Fischer (1977), no qual são fixados com antecedência diferentes níveis de salários para períodos subseqüentes, gera um nível de inércia sobre a taxa de inflação maior do que a gerada pelo modelo de Taylor. Em um resultado que converge com este de Ball, Bonomo e Garcia (1994) mostraram que contratos salariais com indexação (que também
} 


\section{3- A LITERATURA EMPÍRICA RELACIONANDO INÉRCIA INFLACIONÁRIA COM O MODELO DE TAYLOR}

Conforme apontamos na introdução, o debate empírico no qual este trabalho está inserido tem sido travado com base nos dados da economia dos Estados Unidos durante o período que vai de meados dos anos 60 até meados da década de 90 . É este o caso de todos os artigos citados nesta seção.

implicam diferentes níveis salariais após uma única negociação) também tendem a tornar mais complicada a obtenção de estabilizações sem custo. Voltaremos a este ponto na conclusão. 
A literatura pode ser classificada de acordo com a duração dos contratos assumida na estimação empírica. Até meados dos anos 90 houve alguns trabalhos com modelos com contratos salariais de até 3 anos. Os trabalhos mais importantes desta literatura são Taylor (1983) e Taylor (1993).

No trabalho de 1983, Taylor verificou que se a distribuição da duração dos contratos salariais na economia como um todo fosse um espelho do que ocorre no setor sindicalizado, seria necessária uma política gradualista com duração de 4 anos, agentes racionais e credibilidade perfeita para se obter uma estabilização sem custos.

No capítulo 2 do livro de 1993, Taylor estima um modelo no qual se tenta espelhar a verdadeira situação em termos da duração dos contratos salariais. Há salários que permanecem rígidos por apenas um trimestre, grande parte dos salários fica fixa por um ano e há casos nos quais se pactuam os salários para os próximos 3 anos. Em uma de suas simulações, de uma estabilização gradualista na qual os agentes se surpreendem (pode-se pensar em falta de credibilidade ou aprendizado) no primeiro momento da estabilização (como na nossa simulação (d) das páginas 20 e 21), fez com que uma queda de $1 \%$ na taxa de inflação custasse algo em torno de $2 \%$ de perda de produto.

No próprio livro de Taylor de 1993 e também em outros trabalhos ${ }^{14}$, verificou-se que a duração média e também a mais comum (a moda) dos contratos (implícitos e explícitos) salariais nos EUA tem sido de 1 ano. Talvez em função disso, a maior parte dos trabalhos tidos como mais importantes na

\footnotetext{
${ }^{14}$ Ver uma relação deles em Taylor (1999).
} 
literatura empírica com reajustes justapostos vem, desde então, utilizando modelos nos quais todas negociações estabelecem salários rígidos para os 12 meses seguintes. Esta simplificação foi adotada por Fuhrer e Moore (1995), Fuhrer (1997), Roberts (1997, 1998), Galí e Gertler (1999), Chary et al (2000), Jeanne (1997), Kiley (1997). Os três últimos são trabalhos da literatura recente sobre persistência dos ciclos de produto em modelos com rigidez nominal ${ }^{15}$. Já os outros são o cerne da literatura mais recente sobre inércia inflacionária, de modo que constituem o nosso próximo assunto.

Utilizando a metodologia VAR para testar o modelo de Taylor frente aos dados da economia norte-americana, Fuhrer e Moore (1995) e Fuhrer (1997) chegaram à rejeição deste - o modelo gera um grau de inércia inflacionária muito menor do que o observado. Os períodos analisados foram 1965/1-1993/3 (trabalho de 1995) e 1966/1-1994/1 (trabalho de 1997). Cabe observar, no entanto, que eles fizeram uma aproximação, não explicitada em nenhum trabalho aqui citado, que representa uma pequena alteração frente ao modelo original. Para chegarmos ao modelo que eles rodaram, partiremos da equação (1.4) da seção (1.1-A) :

$$
\begin{array}{r}
2 \pi_{t}=2 E_{t-1}\left[\pi_{t+1}\right]+2 \cdot \beta \cdot\left(E_{t-1}\left[y_{t}+y_{t+1}\right]+E_{t-2}\left[y_{t-1}+y_{t}\right]\right)-\left(w_{t}-E_{t-2}\left[w_{t}\right]\right) \\
+2 .\left(v_{t}+v_{t-1}\right)
\end{array}
$$

\footnotetext{
${ }^{15}$ Ver Taylor (1999).
} 
Diferentemente da derivação que mostramos acima, eles ignoraram o termo $\left.E_{t-2}\left[y_{t-1}+y_{t}\right]\right)$, utilizaram o conceito:

$E_{t-2}\left[w_{t}\right]=w_{t}+\psi_{t} \Rightarrow-\psi_{t}=\left(w_{t}-E_{t-2}\left[w_{t}\right]\right)$

e estimaram:

$2 \pi_{\mathrm{t}}=2 \mathrm{E}_{\mathrm{t}-1}\left[\pi_{\mathrm{t}+1}\right]+2 \cdot \beta \cdot \mathrm{E}_{\mathrm{t}-1}\left[\mathrm{y}_{\mathrm{t}}+\mathrm{y}_{\mathrm{t}+1}\right]+\psi_{\mathrm{t}}+2 \cdot\left(v_{\mathrm{t}}+v_{\mathrm{t}-1}\right)$

colocando $\psi_{\mathrm{t}}$ como parte do termo de erro, e não como variável explicativa. De acordo com esta especificação, a taxa de inflação de um determinado período não depende nem de nenhuma taxa de inflação passada, nem de nenhuma expectativa defasada a respeito da taxa de inflação.

No mesmo trabalho de 1995, Fuhrer e Moore (de agora em diante, FM) propuseram, como alternativa ao modelo de Taylor, a substituição da equação (1.1') por:

$w_{t}-p_{t}=(1 / 2) \cdot\left(w_{t-1}-p_{t-1}+E_{t-1}\left[w_{t+1}-p_{t+1}\right]\right)+\beta \cdot E_{t-1}\left[y_{t}+y_{t+1}\right]+v_{t}$

Assim, a taxa de inflação no período t passaria (omitindo-se novamente o termo $\left.E_{t-2}\left[y_{t-1}+y_{t}\right]\right)$ a ser dada por:

$\pi_{t}=(1 / 2) \cdot\left(\pi_{t-1}+E_{t-1}\left[\pi_{t+1}\right]\right)+\beta \cdot E_{t-1}\left[y_{t}+y_{t+1}\right]+v_{t}+v_{t-1}$ 
De modo que ela passaria a depender da inflação passada, o que aumentaria substancialmente a inércia. Este modelo de FM não foi rejeitado pela análise empírica que eles fizeram.

Um outro problema na análise de FM diz respeito à interpretação original dada ao modelo que idealizaram. Segundo o trabalho de 1995, a equação (1.15) representaria uma especificação na qual os agentes se preocupariam com salários reais relativos, em contraposição à idéia do artigo original de Taylor, onde o que importava eram salários nominais relativos. Porém, conforme apontado pelo próprio Taylor (1999), FM deflacionaram erroneamente $w_{t}, w_{t-1}$ e $w_{t+1}$. Como $w_{t}$ fica fixo durante os períodos $t$ e $t+1$, deveria ter sido deflacionado por uma média dos preços dos dois períodos e não apenas por $p_{t}$. O raciocínio sobre $w_{t-1}-p_{t-1} e$ $\mathrm{w}_{\mathrm{t}+1}-\mathrm{p}_{\mathrm{t}+1}$ é análogo. Conforme mostramos na seção 1.1 , a preocupação com salários reais ao invés de nominais não altera o modelo.

Estes dois problemas foram corrigidos no trabalho de Fuhrer (1997), que, no entanto, não os mencionou. Quanto à questão da especificação do modelo empírico, Fuhrer trocou o modelo de Taylor original pelo modelo de Calvo (1983), que é uma aproximação deste, e que nos leva à especificação utilizada em Fuhrer e Moore (1995). Neste modelo, as empresas têm uma probabilidade (1 - $\theta)$ de reajustarem seu preço durante um período específico, independentemente da data de seu último reajuste. Por exemplo, se quisermos fazer um modelo com períodos semestrais e no qual o intervalo de tempo médio em que um preço fica rígido é um ano, $\theta$ será igual a 0,50. Este modelo nos leva a: 


$$
\pi_{t}=E_{t-1}\left[\pi_{t+1}+\right]+\beta \cdot E_{t-1}\left[y_{t}\right]+v_{t}
$$

Já com relação à interpretação equivocada do modelo FM, Fuhrer passou a simplesmente olhá-lo como uma representação na qual o comportamento dos agentes é parcialmente "voltado para trás" ("mixed backward/forward looking model"), ao invés de se voltar apenas para as expectativas quanto ao futuro.

Especificamente, Fuhrer estimou

$$
\begin{gathered}
\pi_{\mathrm{t}}=(\alpha / 3)\left[\pi_{\mathrm{t}-1}+\pi_{\mathrm{t}-2}+\pi_{\mathrm{t}-3}\right]+((1-\alpha) / 3) \mathrm{E}_{\mathrm{t}-1}\left[\pi_{\mathrm{t}+1}+\pi_{\mathrm{t}+2}+\pi_{\mathrm{t}+3}\right]+\beta . \mathrm{E}_{\mathrm{t}-1}\left[\mathrm{y}_{\mathrm{t}}\right]+v_{\mathrm{t}} \\
\operatorname{com} \quad 0<\alpha<1
\end{gathered}
$$

com base em séries trimestrais. Estas estimações mostraram que a inflação passada tem uma enorme importância na fixação dos preços, enquanto a expectativa quanto à inflação futura é não significante e tem pequeno impacto sobre a fixação dos preços (e salários). O próprio título do artigo - "The (Un)Importance of Forward Looking Behavior in Price Specification" - já diz tudo. Como no modelo de Calvo (um modelo de Taylor "simplificado") a inflação corrente depende da inflação futura esperada mas não dependem da inflação passada, ele foi rejeitado.

Posteriormente Galí e Gertler (1999) substituíram (1.17) pela seguinte equação: 
$\pi_{\mathrm{t}}=\mathrm{E}_{\mathrm{t}-1}\left[\pi_{\mathrm{t}+1}\right]+\chi \cdot \mathrm{E}_{\mathrm{t}-1}\left[\mathrm{mc}_{\mathrm{t}+1}\right]+v_{\mathrm{t}}$

e, voltando um período para traz e supondo $E_{t-2}\left[\pi_{t}\right]=\pi_{t}$ e $E_{t-2}\left[m_{t}\right]=m c_{t}$, estimaram:

$\pi_{\mathrm{t}}=\pi_{\mathrm{t}-1}-\chi \cdot \mathrm{mc}_{\mathrm{t}}+v_{\mathrm{t}}$

onde mc é o custo marginal real (desvio deste relativamente ao seu nível de estado estacionário), com Galí e Gertler utilizando a participação do trabalho na renda ("labor share") para representar esta variável em suas estimações.

A substituição de y por mc é admissível, pois uma interpretação possível do modelo de Taylor é a de markups constantes sobre o custo, com y acima (abaixo) do pleno emprego aumentando (diminuindo) estes custos. Mas ocorre um problema quando Galí e Gertler identificam mc com a participação do trabalho na renda (labor share). O problema decorre de que Imperfeições de mercado, como custos de demissão, contratação e treinamento ou contratos salariais implícitos ${ }^{16}$ podem fazer com que a participação do trabalho na renda seja anticíclica mesmo com a variável mc sendo pró-cíclica. Esta hipótese encontra suporte em trabalhos empíricos como o de Bernanke e Parkinson (1991). Eles nos mostraram que boa parte dos trabalhadores empregados durante a grande depressão ficavam ociosos, o que implica que o custo marginal do trabalho estava próximo de zero (pois, como os trabalhadores empregados estavam ociosos, poder-se-ia produzir mais sem aumento do

\footnotetext{
${ }^{16}$ Seja devido a "risk sharing" (como em Azariadis (1975)) ou a reciprocidade (Akerlof (1982)).
} 
custo da mão de obra). Por outro lado, como grande parte das empresas estava tendo prejuízo enquanto trabalhadores empregados recebiam seus salários, é difícil supor que a participação do trabalho na renda estivesse em um nível extremamente baixo. Reforçando nossa linha de argumentação, há um trabalho de Krueger (1999), que avaliou que a participação do trabalho na renda é claramente anti-cíclica.

A hipótese de que o capital físico fica ocioso durante as recessões é, por sua vez, quase uma redundância, de modo que podemos assumir que também o custo marginal deste insumo produtivo (mas não seu custo médio por unidade vendida) é pró-cíclico.

No sentido contrário podemos ter o efeito dos choques de produtividade e de preços de insumos básicos levando a uma correlação negativa entre mc e y. Mas não é tão simples defender a idéia de que a participação do trabalho na renda sobe quando o custo dos insumos básicos também sobe, de modo que podemos ter, também aqui, participação do trabalho e mc se movendo em direções opostas.

Os resultados de Galí e Gertler foram favoráveis ao modelo de Taylor, mas avaliamos que as objeções levantadas acima são graves.

Mas o artigo empírico apontado pelo próprio Taylor (1998) como o mais importante com relação ao assunto inércia inflacionária versus seu modelo é Roberts $(1997)^{17}$. Supera os mencionados acima em pelo menos dois importantes aspectos. O primeiro deles é o de ter incluído o preço real do

\footnotetext{
${ }^{17}$ Roberts usou dados da economia norte-americana, período 1961/1 - 1995/2, séries
} semestrais. 
petróleo entre suas variáveis explicativas, englobando adequadamente (ao contrário de Galí e Gertler (1999)) nas estimações os mais importantes choques de oferta do período. Mas sua inovação mais original foi a de ter utilizado como medida das expectativas inflacionárias os resultados de "surveys", onde se pergunta diretamente às pessoas a respeito de suas expectativas.

Roberts tomou como ponto de partida o trabalho de FM de 1995 e postulou a hipótese de que há mais inércia no mundo real do que no modelo de Taylor porque as expectativas dos indivíduos não são racionais e eles não utilizam as informações de modo eficiente ${ }^{18}$. Para testar esta hipótese, ele utilizou dados da pesquisa junto ao consumidor da Universidade de Michigan e da chamada "Livingston survey", uma pesquisa junto a várias modalidades de pessoas (incluindo economistas, jornalistas e administradores) a respeito de previsões macroeconômicas.

A seguir, Roberts deu uma nova interpretação para o modelo FM. Rearranjando a equação (1.15), ele chegou a:

$\left(w_{t}-w_{t-1}\right)=\left(\pi_{t}+E_{t-1}\left[\pi_{t+1}\right]\right) / 2+\beta\left(E_{t-1}\left[y_{t}+y_{t+1}\right]+v_{t}\right.$

que nos diz que os agentes fixam a variação dos salários com base na variação esperada do nível de preços e no nível de atividade, enquanto tínhamos, em (1.6), os agentes fixando o nível dos salários com base nos níveis de preços esperados e no nível de atividade. Por isto, Roberts chamou o

\footnotetext{
${ }^{18} \mathrm{O}$ conceito de expectativas racionais utilizado por Roberts inclui o uso eficiente das informações disponíveis.
} 
modelo FM de modelo com inflação rígida, em contraposição ao modelo que ele defendeu, que chamou de modelo com preços rígidos e expectativas imperfeitamente racionais. Este modelo ("modelo de Roberts") é bastante próximo do de Taylor, só se diferenciando deste por não assumir expectativas racionais.

Roberts fez, então, dois testes "nested" de seu modelo de preços rígidos e expectativas imperfeitamente racionais contra o modelo FM, com equações reduzidas estimadas com variáveis instrumentais. O resultado favoreceu 0 modelo com preços rígidos e expectativas imperfeitamente racionais (ainda que não tenha rejeitado totalmente o modelo de FM), que seria compatível, portanto, com a inércia inflacionária encontrada nos dados.

Acontece que a análise de Roberts tem, assim como as de FM e Galí e Gertler, seus problemas. Em primeiro lugar, assim como FM, Roberts também não foi totalmente fiel ao modelo microfundamentado. Ao invés de (1.1') ou (1.7'), Roberts assumiu:

$w_{t}=(1 / 2) \cdot\left(p_{t}+E_{t}\left[p_{t+1}\right]\right)+c-\beta \cdot u_{t}+\varepsilon_{t}$

A dissonância mais visível, com relação à (1.21) é a substituição de ${ }_{1}\left[\mathrm{y}_{t}+\mathrm{y}_{t+1}\right]$ (tomando-se por base (1.7')) por $\mathrm{u}_{\mathrm{t}}$. Ocorrem aí dois problemas: $\mathrm{o}$ valor efetivo de $u_{t}$ não é conhecido no momento em que $w_{t}$ é fixado e o que se espera que ocorra na demanda durante a segunda metade do período em

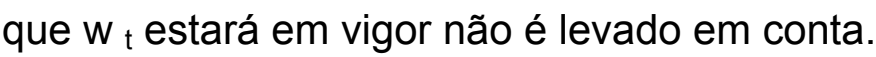

Uma questão menor se refere à utilização de u (desemprego) ao invés de y (produto) como medida do ciclo econômico. Observamos que os modelos 
teóricos microfundamentados utilizam $\mathrm{E}_{\mathrm{t}-1}\left[\mathrm{y}_{\mathrm{t}}+\mathrm{y}_{\mathrm{t}+1}\right]$, mas há problemas de ordem prática na estimação do hiato de produto. Assim, estimações empíricas usam tanto y quanto u e também a estatística da utilização da capacidade instalada na indústria. Foi o que Roberts fez e o que nós faremos adiante.

Mas o termo (1/2). $\left(p_{t}+E_{t}\left[p_{t+1}\right]\right)$ também não está de acordo com (1.7'). Quando se está fixando $w_{t}$, as expectativas devem utilizar somente os dados disponíveis até o final de $t-1$, de modo que Taylor utilizou a notação $E_{t-1}\left[p_{t+1}\right]$ ao invés de $E_{t}\left[p_{t+1}\right]$ de Roberts. Não sabemos se este é um problema meramente de notação ou se a especificação de Roberts está equivocada (Roberts não explicitou se $\mathrm{E}_{\mathrm{t}}[\mathrm{]}$ engloba apenas as informações de até o início do semestre $t$ ou se inclui as informações de até o final deste semestre - no segundo caso há erro de especificação, mas no primeiro não).

Na notação de Roberts, o "modelo de preços rígidos" a ser testado é dado por:

$\pi_{t}-(1 / 2) \cdot\left(E_{t}\left[\pi_{t+1}\right]+E_{t-1}\left[\pi_{t}\right]\right)=c-\beta \cdot\left(u_{t}+u_{t-1}\right)+\varepsilon_{t}+\varepsilon_{t-1}$

enquanto ele deveria ter proposto:

$$
\begin{gathered}
\pi_{t}-\left(E_{t-1}\left[\pi_{t+1}\right]+E_{t-2}\left[\pi_{t}\right]\right) / 2=(\beta / 2) \cdot\left(E_{t-1}\left[\left(y_{t}+y_{t+1}\right) / 2\right]+E_{t-2}\left[\left(y_{t-1}+y_{t}\right) / 2\right]\right) \\
+(1 / 2) \cdot\left(v_{t}+v_{t-1}\right)
\end{gathered}
$$

que nada mais é do que (5') rearranjado. 
O que faremos a partir de agora é retomar esta discussão a partir deste ponto. Partiremos, em primeiro lugar, para uma análise empírica do modelo de Taylor com a especificação correta. Na próxima seção discutiremos uma variação do modelo de Taylor no qual os agentes têm alguma lentidão para entender a política econômica e/ou para dar crédito a ela. Ainda na próxima seção, traçaremos as diretrizes para testar este modelo com aprendizado. No capítulo 3 examinaremos outros modelos, nos quais os custos das estabilizações são causados por fatores completamente distintos dos postulados por Taylor.

\section{4- EXPECTATIVAS E O MODELO DE TAYLOR COM INFORMAÇÃO DEFASADA}

Antes de deixarmos de lado o modelo de Taylor, examinaremos a possibilidade de que a realidade possa ser adequadamente representada por um modelo de agente representativo com informação assimilada com defasagem temporal, tal como em Mankiw e reis (2002). Esta abordagem equivale ao cenário descrito no cenário (d) da seção 2. No item (A) faremos 
uma discussão teórica sobre o(s) conceito(s) de expectativas racionais e sobre porque esta abordagem não implica em não abandonar o modelo de Taylor. No item (B) discutiremos como avaliar empiricamente esta hipótese.

Observamos que a equação (1.5') nos explicita que, no modelo de Taylor, o nível de preços acompanha a evolução das expectativas inflacionárias. Dado o pequeno efeito do hiato de produto esperado sobre 0 modelo com alta rigidez real, podemos dizer que, grosso modo, o nível de preços acompanha as expectativas. Se estas expectativas não têm relação com o modelo, isto implica que os custos das estabilizações que forem antecipados pelos agentes se devem a fatores diversos dos postulados pelo modelo original. Ou seja, uma representação adequada dos mecanismos pelos quais se gera a inércia inflacionária demanda uma explicitação da forma como estas expectativas são geradas.

\section{A) UM MODELO COM EXPECTATIVAS CONSISTENTES MAS SEM O USO EFICIENTE DAS INFORMAÇÕES}

O modelo de Taylor foi desenvolvido dentro do paradigma das expectativas racionais e teve como objetivos explicar o efeito duradouro da política monetária e o custo das estabilizações dentro deste paradigma. Portanto, falar em um modelo com expectativas imperfeitamente racionais parece excluir o modelo de Taylor dentre as possibilidades.

A hipótese (T4'), do trabalho de Taylor de 1999 deixa, no entanto, a porta claramente aberta para um modelo no qual os agentes estão aprendendo 
("learning") a respeito da política macroeconômica, mesmo que sem a eficiência de um econometrista:

T4') Salários são fixados no nível de equilíbrio esperado ${ }^{19}$.

Ou seja, como já dissemos, (T4’) deixa claramente aberta a possibilidade de que se abra mão da hipótese de que os agentes utilizam de modo eficiente as informações disponíveis sem deixar, no entanto, de assumir que eles tomam suas decisões de acordo com o conceito de equilíbrio de Nash. A hipótese (T4') é compatível com algo como o anúncio de uma mudança na política monetária só ter seus efeitos totalmente entendidos após uma defasagem temporal ou mesmo após estes se manifestarem.

Para clarificar esta discussão, acreditamos ser importante definir o que se pode entender por expectativas racionais. O ponto é que se recorrermos à literatura, encontraremos pelo menos dois conceitos distintos.

Um deles é encontrado, por exemplo, em Townsend (1978) e Werlang (1998). Segundo esta definição, há uma equivalência entre o conceito de expectativas racionais e o de equilíbrio de Nash. A derivação de quais são as hipóteses necessárias para garantir que os agentes ajam como estrategistas de Nash é encontrada em Tan e Werlang (1988). Eles mostram que é necessário assumir, além de que os agentes sejam racionais e que esta racionalidade seja de conhecimento comum, que "a teoria seja de conhecimento comum". Este último requisito significa que cada agente sabe (que todos sabem, que todos sabem...) que cada um dos agentes vai desempenhar seu papel dentro de uma teoria que é escolhida por todos (por

\footnotetext{
${ }^{19}$ Nas palavras de Taylor, seu modelo é um “expected market clearing model”, em contraposição à modelos como o de Lucas (1972), que são "market clearing models".
} 
ser a melhor dentre as conhecidas por todos os agentes). Deste modo, para supormos que os agentes reais agem como estrategistas de Nash no modelo de Taylor, temos que assumir que este modelo é de conhecimento comum, é tido por eles como o melhor modelo, e que cada agente acredita que os outros agentes agirão de acordo com o modelo ${ }^{20}$. Ou seja, as expectativas dos agentes devem ser consistentes com o próprio modelo de Taylor. Devido a isto, Simon (1978) disse que seria mais adequado (e mais neutro) chamarmos os modelos com expectativas racionais de modelos com expectativas consistentes.

Uma definição alternativa, porém, foi popularizada entre os macroeconomistas: a de que além das expectativas serem consistentes, os agentes façam uso das informações macroeconômicas disponíveis de modo tão eficiente quanto economistas ou econometristas. Esta definição é compartilhada, entre outros, pelo próprio Roberts $(1997)^{21}$.

O que nos interessa, porém, é que a hipótese de uso eficiente das informações não é essencial ao modelo de Taylor (vide hipótese (T4’)).

Deste modo, podemos concluir que, se quisermos trabalhar com um "modelo de Taylor com expectativas imperfeitamente racionais", devemos verificar se as expectativas são consistentes mas “obtidas sem o uso 'eficiente'

\footnotetext{
${ }^{20}$ A rigor, cada agente deveria ter certeza absoluta a respeito do comportamento dos outros agentes. $\mathrm{Na}$ prática, porém, , podemos seguir a metodologia do "as if", de Friedman (1953), e aceitar um modelo que não seja rejeitado pelos dados agregados.

${ }^{21}$ A confusão entre os dois conceitos parece ser generalizada. Em Sargent (1993), pág. 6, temos a seguinte definição de expectativas racionais: "A idéia de expectativas racionais tem dois componentes: primeiro, que o comportamento de cada pessoa pode ser descrito como o produto da maximização de uma função objetivo sujeita a restrições percebidas; e segundo, que as restrições percebidas por todos no sistema sejam mutuamente consistentes" (grifos nossos). Esta passagem parece nos indicar que Sargent considera o primeiro dos nossos conceitos suficiente. Por outro lado, este seu livro predica que mesmo modelos com racionalidade limitada devem supor "agentes econometristas".
} 
das informações" (se as expectativas são parcialmente defasadas) ou se precisamos recorrer a algum outro modelo. Faremos isto no capítulo 2, seguindo os procedimentos descritos no item B a seguir. Caso as expectativas dos agentes sejam inconsistentes com o modelo de Taylor, é necessário que se faça uma discussão devidamente fundamentada sobre qual o modelo encontrado na realidade, o que será o objeto do nosso capítulo 3.

\section{B) A CONSITÊNCIA ENTRE AS EXPECTATIVAS DE "SURVEYS" E O MODELO DE TAYLOR 22}

De acordo com a discussão acima, para definirmos se uma economia funciona como um modelo de Taylor com informação defasada, devemos verificar se as expectativas dos agentes do mundo real podem ou não ser aproximadas pelo modelo.

Isto pode ser feito levando-se em conta que, se o modelo que está na cabeça dos agentes é o de Taylor, podemos obter uma boa estimativa das expectativas inflacionárias dos agentes para o próximo período a partir dos dados do nível de preços escolhido pelos agentes, das expectativas

\footnotetext{
${ }^{22}$ Agradecemos uma sugestão de Denisard Alves utilizada nesta seção.
} 
inflacionárias dos agentes no período anterior, das expectativas destes mesmos agentes a respeito da demanda agregada e dos coeficientes estimados para o modelo de Taylor. Assim, dada a estimativa dos coeficientes do modelo de Taylor, temos que verificar que a relação dada pela equação (1.5") prevalece no mundo real. Ou seja, descontado um componente associado a um erro expectacional, quando os agentes esperarem uma queda na taxa de inflação, eles devem esperar um boom, e não uma recessão. Deste modo, deveremos ter:

$$
\begin{gathered}
E_{t-1}\left[\pi_{t+1}\right]-\pi_{t}=\gamma \cdot\left(\pi_{t}-E_{t-2}\left[\pi_{t}\right]\right)-\beta\left(E_{t-1}\left[y_{t}+y_{t+1}\right]+E_{t-2}\left[y_{t-1}+y_{t}\right]\right)-\left(v_{t}+v_{t-1}\right) \\
\text { com as restrições: } \gamma=1 e-\beta<0
\end{gathered}
$$

Onde testar as restrições equivale a checar se temos expectativas consistentes. Caso elas sejam não rejeitadas, estaremos não rejeitando a hipótese de que o modelo de Taylor corresponde a uma boa aproximação do modo como as expectativas dos agentes são tecidas.

Uma segunda idéia, que implica em dar uma outra chance para o modelo, consiste em seguir o procedimento abaixo:

1) Estimar a equação (1.26)

$$
\begin{gathered}
\pi_{t}-\left(E_{t-1}\left[\pi_{t+1}\right]+E_{t-2}\left[\pi_{t}\right]\right) / 2=(\beta / 2) \cdot\left(E_{t-1}\left[\left(y_{t}+y_{t+1}\right) / 2\right]+E_{t-2}\left[\left(y_{t-1}+y_{t}\right) / 2\right]\right) \\
+(1 / 2) \cdot\left(v_{t}+v_{t-1}\right)
\end{gathered}
$$


De modo a obter uma série de "valores estimados para

$\left(\pi_{t}-\left(E_{t-1}\left[\pi_{t+1}\right]+E_{t-2}\left[\pi_{t}\right]\right) / 2\right)$ ", que chamaremos de "fittedTaylor". Ou seja:

$$
\begin{aligned}
\text { fittedTaylor } & =(\mathrm{b} / 2) \cdot\left(\mathrm{E}_{\mathrm{t}-1}\left[\left(\mathrm{y}_{\mathrm{t}}+\mathrm{y}_{\mathrm{t}+1}\right) / 2\right]+\mathrm{E}_{\mathrm{t}-2}\left[\left(\mathrm{y}_{\mathrm{t}-1}+\mathrm{y}_{\mathrm{t}}\right) / 2\right]\right) \\
& =\pi_{\mathrm{t}}-\left(\mathrm{E}_{\mathrm{t}-1}\left[\pi_{\mathrm{t}+1}\right]+\mathrm{E}_{\mathrm{t}-2}\left[\pi_{\mathrm{t}}\right]\right) / 2-(1 / 2) \cdot\left(\mathrm{u}_{\mathrm{t}}+\mathrm{u}_{\mathrm{t}-1}\right)
\end{aligned}
$$

Onde (b/2) corresponde ao coeficiente estimado na regressão estimando (1.26) e (1/2). $\left(u_{t}+u_{t-1}\right)$ corresponde aos resíduos desta regressão.

2) Obter uma estimativa para a variável $E_{t-1}\left[\pi_{t+1}\right]$ a partir de "fittedTaylor", ou seja, a partir de uma estimação na qual as restrições necessárias ao modelo de Taylor foram impostas. Isto pode ser feito levando-se em conta que:

$$
\begin{aligned}
& \pi_{t}-\left(E_{t-1}\left[\pi_{t+1}\right]+E_{t-2}\left[\pi_{t}\right]\right) / 2=\text { fittedTaylor }+(1 / 2) \cdot\left(u_{t}+u_{t-1}\right) \\
& \Rightarrow E_{t-1}\left[\pi_{t+1}\right]=2 \cdot\left\{\pi_{t}-\text { fittedTaylor }\right\}-E_{t-2}\left[\pi_{t}\right]-\left(u_{t}+u_{t-1}\right)
\end{aligned}
$$

Definindo, então:

$\left[\mathrm{E}_{\mathrm{t}-1}\left[\pi_{\mathrm{t}+1}\right]\right]_{\text {Taylor }}=\mathrm{E}_{\mathrm{t}-1}\left[\pi_{\mathrm{t}+1}\right]+\left(\mathrm{u}_{\mathrm{t}}+\mathrm{u}_{\mathrm{t}-1}\right)$

teremos:

$$
\left[\mathrm{E}_{\mathrm{t}-1}\left[\pi_{\mathrm{t}+1}\right]\right]_{\text {Taylor }}=2 .\left(\pi_{\mathrm{t}}-\text { fittedTaylor }\right)-\mathrm{E}_{\mathrm{t}-2}\left[\pi_{\mathrm{t}}\right]
$$


$\left[E_{t-1}\left[\pi_{t+1}\right]\right]_{\text {Taylor }}=\pi_{t}-2$ fittedTaylor $-\left(\pi_{t}-E_{t-2}\left[\pi_{t}\right]\right)$

Sendo $\left[E_{t-1}\left[\pi_{t+1}\right]\right]$ Taylor nossa estimativa de $E_{t-1}\left[\pi_{t+1}\right]$ obtida através de uma estimação do modelo de Taylor com as restrições subjacentes a ele impostas nesta estimação.

2) Verificar qual graficamente a semelhança entre $E_{t-1}\left[\pi_{t+1}\right]$ e $\left[E_{t-1}\left[\pi_{t+1}\right]\right]$ Taylor

3) Conforme veremos na seção 2.2 , as variáveis $E_{t-1}\left[\pi_{t+1}\right]$ e $\pi_{t}$ são $I(1)$ e cointegram. Se olharmos para o modo como $\left[E_{t-1}\left[\pi_{t+1}\right]\right]$ Taylor é explicado na equação (1.29), veremos que o primeiro termo do lado direito da equação é $\pi_{t}$. Os outros termos são I(0). Deste modo, é inretressante verificarmos o quão bom é $\left[\mathrm{E}_{\mathrm{t}-1}\left[\pi_{\mathrm{t}+1}\right]\right]$ Taylor como preditor de $\left[E_{t-1}\left[\pi_{t+1}\right]\right]$ quando não se espera inflação estável. 
CAPÍTULO 2

AS EXPECTATIVAS DOS AGENTES

E O MODELO DE TAYLOR 
No capítulo anterior fizemos um levantamento da literatura teórica a respeito da relação entre inércia inflacionária e o modelo de J. Taylor e uma análise crítica da literatura empírica do assunto. Verificamos que o modelo tem uma fundamentação teórica suficiente para que seu uso seja defensável, mas que o modo como ele funciona em uma desinflação entra em choque com o que tem ocorrido no mundo real. O modelo é compatível, no entanto, com a hipótese de informação defasada, como em Mankiw e Reis (2002). Antes de deixarmos de lado o modelo deveríamos, então, testar a incorporação desta hipótese.

Neste capítulo, desenvolveremos os elementos necessários à análise empírica que julgamos adeqüada. Para isto nos pautaremos em expectativas derivadas de uma "survey" representativa de agentes do mundo real, que serão utilizadas seguindo as diretrizes traçadas no item (B) da seção (1.4). 
Na primeira seção justificaremos nossa metodologia, faremos um rápido apanhado dos dados, discutiremos o procedimento adotado para lidar com a presença simultânea de endogeneidade e autocorrelação e falaremos sobre a estabilidade dos parâmetros. Na seção seguinte discutiremos alguns pontos que julgamos importantes a respeito das "surveys" sobre expectativas inflacionárias. Na seção 2.3 explicaremos como utilizaremos uma pergunta de "survey" para inferir o efeito da variável "expectativa dos agentes a respeito do desvio do produto com relação ao seu nível de pleno emprego". Esta seção constitui uma das contribuições mais importantes do trabalho, e seus resultados serão utilizados de modo decisivo no capítulo 3 . Terminaremos, enfim, por realizar as estimações e os testes idealizados na seção 1.4 item (B).

\section{1 - OS DADOS E A METODOLOGIA DAS ESTIMAÇÕES}

\section{A) JUSTIFICAÇÃO DA METODOLOGIA ADOTADA}

Nossa avaliação empírica do modelo de Taylor com informação defasada será feita de acordo com o descrito na seção 1.3. No ítem 1.4.A, argumentamos que devido ao fato de, no nível agregado, os salários serem pouco elásticos relativamente ao nível de atividade (ou seja, devido ao fato de

o coeficiente $\beta$ se situar apenas em torno de $+0,10$ ), o principal componente que determina a taxa de inflação é dado pelas próprias expectativas 
inflacionárias. Por isto, um modelo só explicará adequadamente a dinâmica inflacionária se explicar como estas expectativas são formadas.

O modo como podemos testar se o modelo de Taylor com informação defasada nos dá uma explicação razoável para estas expectativas foi descrtito em 1.4.B. Ele nos forneceu uma equação reduzida na qual testamos dois coeficientes e uma outra que tem uma restrição adicional e que nos fornece uma expectativa inflacionária obtida a partir dos dados com este modelo restrito.

O teste dos coeficientes é um procedimento padrão em ecomonetria e foi usado em alguns dos trabalhos mais importantes do assunto em pauta, como Fuhrer (1997), Roberts (1997) e Galí e Gertler (1999). Houve uma crítica de Woodford (2001) de que este procedimento não gerou resultados robustos, dado o conflito dos resultados de Fuhrer (1997) com os de Galí e Gertler (1999), mas nossa análise da seção 1.3 explica o porque esta crítica é improcedente: O procedimento de Galí e Gertler (1999) está sujeito a uma ressalva bastante séria que, no nosso entender, compromete o trabalho deles de modo decisivo.

Observamos, ainda, que as evidências a favor da curva de Phillips novo keynesiana apontadas por Woodford utilizaram a especificação do modelo de Calvo (1983), que é tida como menos realista do que a do modelo de Taylor (que é a que nós utilizamos).

\section{B) OS DADOS}


Os modelos teóricos que derivamos tinham dois períodos justapostos. $\mathrm{O}$ trabalho que temos como referência, Roberts (1997), assumiu, como tem sido a prática mais usual ${ }^{23}$, que os salários ficam fixos durante um ano. Deste modo, cada período $\mathrm{t}$ equivale a um semestre. Como a maior parte das séries macroeconômicas é trimestral ou mensal, trabalhamos estas séries trimestrais e mensais para obtermos as séries semestrais que desejávamos.

Como já dissemos, a confrontação dos dados com o modelo será feita com os dados da economia norte-americana. Dois motivos contribuíram para esta escolha. Em primeiro lugar, foi a economia para a qual conseguimos obter os dados necessários, incluindo dados de "survey" sobre a expectativa dos agentes sobre inflação e demanda futuros. Em segundo lugar, os artigos de referência do nosso debate (Roberts (1997), Fuhrer e Moore (1995) e Fuhrer (1997)) utilizam dados dos EUA.

O período compreendido pelos dados que analisamos vai do início de 1961 até o final de 1999. O ano de 1961 foi quando a pesquisa junto ao consumidor do "University of Michigan Survey Data Center" (UMSDC), a "survey" que fornece nossas expectativas, passou a ser feita em bases mais regulares (trimestralmente).

Todos os dados, com exceção dos relativos à pesquisa do UMSDC, foram obtidos na página do Federal Reserve Board de St. Louis, na internet.

Para medir os ciclos econômicos que ocorreram de fato, utilizamos as mesmas alternativas consideradas por Roberts (1997): taxa de desemprego ("seasonally adjusted civilian unemployment rate"), utilização de capacidade

\footnotetext{
${ }^{23}$ Ver seção 1.3 , página 38 .
} 
instalada da indústria e desvio do produto real ${ }^{24}$ com relação à tendência de longo prazo. Esta tendência foi obtida de dois modos: com o uso de um filtro de Hodrick-Prescot, com parâmetro de suavização igual a 16.000 (mesmo parâmetro utilizado por Roberts) e com uma tendência linear.

Mostramos, nas tabelas 1 e 2, os testes ADF e Phillips Perron de raiz unitária e KPSS de estacionariedade. A única série que se mostrou estacionária em todos os testes foi a do desvio do produto frente a tendência do filtro HP. Como todos estes testes tem poder baixo, especialmente o KPSS, a rejeição da raiz unitária a $1 \%$ no teste $\mathrm{ADF}$ e a $5 \%$ no PP indicam que a série utilização de capacidade é também I(0) (além disto, é difícil imaginar uma explicação teórica que justifique que esta série seja I(1)). Quanto à série taxa de desemprego, a análise do período mais longo feita no próprio artigo original de KPSS indicou que ela é I(0), o que foi confirmado pelo teste ADF, mas não pelo PP. Deste modo, avaliamos ser também razoável admitir que esta série seja I(0). A série com piores resultados foi a de desvio do produto com relação à tendência linear. Como, conforme veremos adiante, as outras variáveis das equações estimadas são $\mathrm{I}(0)$, uma série $\mathrm{I}(1)$ tornaria a estimação desbalanceada. Como, no entanto, a utilização desta medida para verificar a robustez dos estimações com as outras é praxe na literatura (além de Roberts (1997), ver também Fuhrer (1997)), reportaremos também as estimações com ela. Em função deste problema, porém, estas estimações podem ser vistas com certa cautela, pois: 1) supõe-se que o nível de atividade seja I(1);2) uma única variável I(1) nos daria uma regressão desbalanceada, o que implicaria resultados espúrios.

\footnotetext{
${ }^{24}$ Produto nacional bruto até 1966 e produto interno bruto a partir de 1967.
} 


\begin{tabular}{|c|c|c|c|c|c|c|c|c|}
\hline \multicolumn{9}{|c|}{$\begin{array}{l}\text { TABELA } 1 \text { - TESTES DE ESTACIONARIEDADE VERS } \\
\text { SÉRIES DE MEDIDAS DE NÍVEL DE ATIVIDADE } \\
\text { TESTES A. DICKEY-FULLER E PHILLIPS- PERRON } \\
\text { Ho: há uma raiz unitária, H1: estacionariedade }\end{array}$} \\
\hline SÉRIE & \multicolumn{2}{|c|}{ prod. real - filtro HP } & \multicolumn{2}{|c|}{$\begin{array}{l}\text { pro. real - tend. } \\
\text { lin. }\end{array}$} & \multicolumn{2}{|c|}{ util. de capacidade } & \multicolumn{2}{|c|}{ desemprego } \\
\hline intercepto & \multicolumn{2}{|c|}{ não } & \multicolumn{2}{|c|}{ não } & \multicolumn{2}{|c|}{$\operatorname{sim}$} & \multicolumn{2}{|c|}{$\operatorname{sim}$} \\
\hline LAG & ADF & PP & ADF & PP & ADF & PP & ADF & PP \\
\hline 0 & $-1,95^{* *}$ & $-1,95^{* *}$ & $-0,77$ & $-0,77$ & $-2,52$ & $-2,52$ & $-1,46$ & $-1,46$ \\
\hline 1 & $-3,92^{* * *}$ & $-2,50 * * *$ & $-1,74^{*}$ & $-1,14$ & $-3,43^{* *}$ & $-2,81^{*}$ & $-2,93^{* *}$ & $-1,88$ \\
\hline 2 & $-3.30^{* * *}$ & $-2,70^{\star * *}$ & $-1,43$ & $-1,28$ & $-3,57^{* \star *}$ & $-2,94^{* *}$ & $-2,05$ & $-2,03$ \\
\hline 3 & $-3,00 * * *$ & $-2,72^{* * *}$ & $-1,30$ & $-1,32$ & $-3,39^{* *}$ & $-2,96^{* *}$ & $-2,28$ & $-2,08$ \\
\hline 4 & $-3,25^{\star * *}$ & $-2,67^{* * *}$ & $-1,37$ & $-1,32$ & $-2,47$ & $-2,83^{*}$ & $-1,89$ & $-2,08$ \\
\hline 5 & $-3,19^{\star * *}$ & $-2,60^{\star * \star}$ & $-1,32$ & $-1,31$ & $-2,89^{*}$ & $-2,72^{*}$ & $-1,94$ & $-2,04$ \\
\hline
\end{tabular}

TABELA 2 - TESTES DE ESTACIONARIEDADE VERSUS RAIZ UNITÁRIA SÉRIES DE MEDIDAS DE NÍVEL DE ATIVIDADE TESTE KPSS

Ho: estacionariedade, $\mathrm{H} 1$ : há uma raiz unitária

\begin{tabular}{|c|c|c|c|c|}
\hline SÉRIE & prod.real - filtr.HP. & prod.real - tend.lin. & util. de capacid. & desemprego \\
\hline LAG & & & & \\
0 & $0,363^{*}$ & $2,119^{\star * *}$ & $1,041^{* * *}$ & $1,277^{* * *}$ \\
1 & 0,198 & $1,103^{\star * *}$ & $0,576^{* *}$ & $0,665^{* *}$ \\
2 & 0,147 & $0,765^{\star * *}$ & $0,425^{*}$ & $0,466^{* *}$ \\
3 & 0,124 & $0,597^{* *}$ & $0,356^{*}$ & $0,369^{*}$ \\
4 & 0,113 & $0,497^{* *}$ & 0,319 & 0,313 \\
5 & 0,107 & $0,430^{*}$ & 0,298 & 0,276 \\
\hline
\end{tabular}

Quanto à taxa de inflação, o índice que utilizamos foi o de preços ao consumidor. A razão desta escolha é que as expectativas captadas pelas "surveys" junto aos consumidores tendem a ter este índice como principal 
referência, pois o IPC é o índice inflacionário mais difundido. Conforme mostra a tabela 3, os testes PP e KPSS que a série é I(1), enquanto o teste ADF indicou que ela é I(0). Fizemos os mesmos testes também dividindo a série pelos períodos propostos no item $D$ da seção anterior, obtivemos resultados similares.

\begin{tabular}{|c|c|c|c|}
\hline \multirow{2}{*}{\multicolumn{4}{|c|}{ 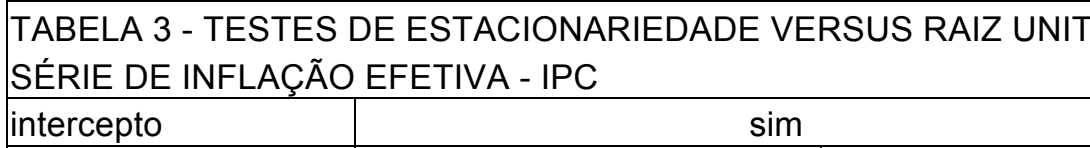 }} \\
\hline & & & \\
\hline LAG & ADF & $\mathrm{PP}$ & KPSS \\
\hline 0 & $-2,26$ & $-2,26$ & $1,142^{* \star *}$ \\
\hline 1 & $-2,49^{*}$ & $-2,37$ & $0,609^{* *}$ \\
\hline 2 & $-2,60^{*}$ & $-2,44$ & $0,431^{*}$ \\
\hline 3 & $-3,03^{\star *}$ & $-2,52$ & 0,343 \\
\hline 4 & $-2,09$ & $-2,47$ & 0,293 \\
\hline 5 & $-2,09$ & $-2,41$ & 0,260 \\
\hline
\end{tabular}

Quanto às variáveis relacionadas com a taxa de inflação que utilizamos nas nossas regressões:

$$
\left[\pi_{t}-\left(E_{t-2}\left[\pi_{t}\right]+E_{t-1}\left[\pi_{t+1}\right]\right) / 2\right]
$$

$\left(E_{t-1}\left[\pi_{t+1}\right]-\pi_{t}\right)$

e

$$
\left(\pi_{t}-E_{t-2}\left[\pi_{t}\right]\right)
$$


A tabelas 4 nos mostra que os testes ADF e PP indicam que elas são $\mathrm{I}(0)$, mas a tabela 5 nos mostra que o teste KPSS indica que elas são I(1). Como a não estacionariedade foi rejeitada em altos níveis de significância nos dois testes em que ela representa Ho e como o teste KPSS tem poder baixo, admitiremos que estas variáveis sejam I(0).

\begin{tabular}{|c|c|c|c|c|c|c|}
\hline $\begin{array}{l}\text { TABELA } 4 \\
\text { SÉRIES DE } \\
\text { TESTES A } \\
\text { Ho: há uma }\end{array}$ & $\begin{array}{l}\text { ES DE } \\
\text { ÁVEIS R } \\
\text { EY-FULL } \\
\text { nitária, }\end{array}$ & $\begin{array}{l}\text { ACION } \\
\text { ACIONA } \\
\text { E PHIL } \\
\text { stacion }\end{array}$ & $\begin{array}{l}\text { DADE I } \\
\text { COM I } \\
\text { - PERR } \\
\text { ade }\end{array}$ & $\begin{array}{l}\text { US RA } \\
\text { AÇÃOO }\end{array}$ & VITÁRIA & \\
\hline SÉRIE & $\mathrm{E} \mathrm{t-1}[\mathrm{p}$ & $-1]-p t$ & $\mathrm{pt}-\mathrm{E}$ & $2[p t]$ & $p t-(E t-2[p$ & $t-1[p t+1])$ \\
\hline intercepto & & & & & & \\
\hline LAG & ADF & PP & ADF & PP & ADF & PP \\
\hline 0 & $-3,63^{* * *}$ & $-3,63^{* * *}$ & $-5,49^{* * *}$ & $-5,49^{* * *}$ & $-4,23^{* * *}$ & $-4,23^{* * *}$ \\
\hline 1 & $-3,28^{* * *}$ & $-3,63^{* * *}$ & $-3,93^{* * *}$ & $-5,42^{* * *}$ & $3,55^{\star * *}$ & $-4,19^{* * *}$ \\
\hline 2 & $-3,04^{* * *}$ & $-3,62^{* * *}$ & $-3,19 * * *$ & $-5,45^{\star * *}$ & $-2,95^{\star * *}$ & $-4,15^{\star \star *}$ \\
\hline 3 & $-3,42^{* * *}$ & $-3,70^{* * *}$ & $-3,65^{\star * *}$ & $-5,89^{* * *}$ & $-3,57^{* * *}$ & $4,28^{* * *}$ \\
\hline 4 & $-2,97^{* * *}$ & $-3,67^{* * *}$ & $-2,98^{* * *}$ & $-5,59^{* * *}$ & $-2,79^{* * *}$ & $-4,25^{\star * *}$ \\
\hline 5 & $-2,55^{\star *}$ & $-3,60^{* * *}$ & $-2,75^{\star * *}$ & $-5,62^{\star * *}$ & $-2,75^{\star \star *}$ & $-4,24^{* * *}$ \\
\hline
\end{tabular}

Obs: Um asterisco indica significância a $10 \%$, dois asteriscos indicam a $5 \%$ e três asteriscos, a $1 \%$.

\begin{tabular}{|c|c|c|c|}
\hline $\begin{array}{l}\text { TABELf } \\
\text { SÉRIES } \\
\text { TESTE } \\
\text { Ho: esta }\end{array}$ & $\begin{array}{l}\text { - TESTES DE ES } \\
\text { E INFLAÇÃO EFE } \\
\text { SSS } \\
\text { onariedade, H1: há }\end{array}$ & $\begin{array}{l}\text { ACIONARIEDA } \\
\text { IVA E ESPERA } \\
\text { Ima raiz unitária }\end{array}$ & $\begin{array}{l}\text { DE VERSUS RAIZ UNITÁRIA } \\
\text { DA }\end{array}$ \\
\hline SÉRIE & $E t-1[p t+1]-p t$ & $p t-E t-2[p t]$ & $p t-(E t-2[p t]+E t-1[p t+1]) / 2$ \\
\hline LAG & & & \\
\hline 0 & $0,787^{* * *}$ & $0,807^{* * *}$ & \\
\hline 1 & $0,473^{* *}$ & $0,511^{* *}$ & \\
\hline 2 & $0,361^{*}$ & $0,400^{*}$ & \\
\hline 3 & 0,304 & 0,340 & \\
\hline 4 & 0,275 & 0,310 & \\
\hline 5 & 0,259 & 0,291 & \\
\hline
\end{tabular}

Adicionalmente a estas variáveis, incluímos no modelo uma variável relacionada com choques de oferta. Para tanto, seguimos procedimento similar ao de Roberts, que utilizou uma medida dos choques de preços do petróleo do 
período $t$ entre as variáveis explicativas das suas estimações. A variável utilizada foi a variação do log do preço real do petróleo (deflacionado pelo índice de preços ao consumidor). Nas nossas estimações incluímos também os choques do petróleo de t-1 entre as variáveis explicativas, pois as variáveis $\left(\pi_{t}-E_{t-2}\left[\pi_{t}\right]\right)$ e $\left[\pi_{t}-\left(E_{t-2}\left[\pi_{t}\right]+E_{t-1}\left[\pi_{t+1}\right]\right) / 2\right]$ medem o erro de previsão de $E_{t-2}[\pi t$, que é feita anteriormente a $t-1$.

\section{C) ENDOGENEIDADE}

Tanto no modelo de Taylor quanto nos modelos que discutiremos no capítulo 3, os agentes econômicos estabelecem suas expectativas a respeito de preços e do produto e fixam seus preços (e salários) para o futuro com base em variáveis do passado e na política econômica percebida. Sendo assim, a variável explicativa $E_{t-1}\left[y_{t}+y_{t-1}\right]$ não pode ser considerada exógena. Também a variável $\mathrm{y}_{\mathrm{t}-1}$, que entra (conforme veremos adiante) em metade das estimações, é contemporânea de $\mathrm{p}_{\mathrm{t}-1}$ (que faz parte de todas as variáveis dependentes, pois $\left.\pi_{t}=p_{t}-p_{t-1}\right)$. Além disso, a própria política econômica corrente também não pode ser considerada exógena, pois também ela reage a choques e expectativas.

Ao mesmo tempo que temos endogeneidade, o próprio modelo teórico nos indica haver autocorrelação nos termos de erro seguindo o padrão $M A(1)$, devido à justaposição de reajustes. Esta autocorrelação apareceu nos resíduos de boa parte das regressões estimadas. 
A autocorrelação dos resíduos faz com que estes sejam correlacionados com variáveis defasadas. Estas só poderão ser utilizadas como instrumentos se a autocorrelação for eliminada.

Para lidar com o problema de termos, simultaneamente, endogeneidade e autocorrelação, utilizamos a metodologia de Fair $\left(1970\right.$ e 1984) ${ }^{25}$. Fair mostrou que podemos fazer estimações iterativas como a da equação abaixo utilizando variáveis defasadas como instrumentos:

$Y_{t}=\alpha+\beta X_{t}+\varepsilon_{t}+\theta \varepsilon t-1$

contanto que $\theta$ entre nas iterações desde a primeira vez em que é estimado o segundo estágio (neste caso, teremos um estimador consistente).

Nas estimações deste capítulo utilizamos como instrumentos três lags (a partir do trimestre anterior a $\mathrm{t}-1$ ) de $\mathrm{BT}$, três lags (a partir de $\mathrm{t}-2$ ) do nível de atividade e duas variáveis relacionadas com inovações na política monetária:

$$
\begin{aligned}
& \mathrm{i}_{\mathrm{t}-2}-\left(\mathrm{i}_{\mathrm{t}-5}+\mathrm{i}_{\mathrm{t}-6}\right) / 2 \\
& \mathrm{e} \\
& \left(\mathrm{i}_{\mathrm{t}-2}-\mathrm{E}_{\mathrm{t}-3}\left[\pi_{\mathrm{t}-2}\right]\right)-\left(\mathrm{i}_{\mathrm{t}-4}-\mathrm{E}_{\mathrm{t}-5}\left[\pi_{\mathrm{t}-4}\right]\right)
\end{aligned}
$$

onde $\mathrm{i}_{\mathrm{t}}$ é a taxa de juros dos FED-funds do trimestre anterior ao período $\mathrm{t}$.

\footnotetext{
${ }^{25}$ Ver também Davidson e MacKinnon (1993), cap. 10, págs. 369-371.
} 
Para as estimações da equação (1.5") adicionamos $\left(\pi b_{t-1}-E_{t-2}\left[\pi_{t}\right]\right)$ ao conjunto de instrumentos, uma vez que $\pi_{\mathrm{t}}$ (que faz parte da variável explicativa $\left.\left(\pi_{t}-E_{t-2}\left[\pi_{t}\right]\right)\right)$ é endógena.

Em algumas (poucas) regressões tivemos que retirar um ou dois destes instrumentos para que não houvesse superidentificação ${ }^{26}$. Observamos que estimações com menos instrumentos geraram resultados similares. A motivação para termos mantido este número razoavelmente grande de instrumentos para as equações deste capítulo, que têm de uma a três variáveis explicativas endógenas, foi a de tentarmos alterar os instrumentos o mínimo possível ao longo desta tese (de modo que diferentes resultados não possam ser atribuídos a mudanças nos instrumentos). Nas estimações do capítulo 3 utilizaremos estes mesmos instrumentos mais três choques do petróleo defasados, mas as variáveis explicativas endógenas estão em maior número e são mais complicadas.

\section{D) A ESTABILIDADE DOS PARÂMETROS}

Como a taxa de inflação foi moderadamente alta durante parte do período analizado e baixa durante dois outros sub-períodos, avaliamos ser conveniente verificar a existência de quebras estruturais. Caso contrário, estaríamos sujeitos à crítica de Lucas $(1976)^{27}$

\footnotetext{
${ }^{26} \mathrm{O}$ critério foi sempre retirar o instrumento que diminuísse menos o $\mathrm{R}^{2}$ da regressão e eliminasse a superidentificação (ao nível crítico de 10\%).

${ }^{27}$ A crítica: mudanças de regime podem levar a mudanças estruturais que dizem respeito aos parâmetros estimados.
} 
Verificamos, também, que não houve estabilidade dos parâmetros para estimações com a amostra inteira. Realizamos dois testes de estabilidade dos parâmetros: o teste de Chow com quebra de amostra ("Chow breakpoint test") e um teste de Wald para mudanças estruturais. Com relação ao primeiro, tivemos o cuidado de utilizar os erros gerados pela diferença entre a variável dependente e a projeção gerada pelos coeficientes obtidos através de mínimos quadrados de dois estágios multiplicando os dados originais (e não os projetados) das variáveis explicativas ${ }^{28}$. Quanto ao teste de Wald, ele tem a vantagem de, ao contrário do teste de Chow, não ser afetado quando há heterocedasticidade. Este teste tem distribuição $\chi^{2}$ e é dado por:

Waldestr $=(B 1-B 2)^{\prime} *(\text { CovB1+CovB2 })^{-1} *(B 1-B 2)$

onde B1 e B2 são os vetores com os coeficientes estimados respectivamente para a primeira e a segunda amostra, e CovB1 e CovB2 são as respectivas matrizes de covariância destes coeficientes ${ }^{29}$.

Para avaliar a possibilidade de quebra estrutural, avaliamos que houve quatro grandes "fases" na economia. Durante a primeira, que vai até 1967/1, não houve grandes turbulências e a taxa de inflação, ainda que com tendência ascendente, permaneceu abaixo de 3,5\% anuais $^{30}$. De 1967/2 a 1984/2 tivemos o período mais turbulento, com a inflação se mantendo acima de $3,5 \%$ anuais e bastante volátil, fortes recessões e dois choques do petróleo. De

\footnotetext{
${ }^{28} \mathrm{O}$ teste oferecido pelo menu do programa E-Views não toma este cuidado.

${ }^{29}$ Ver tópicos de ajuda do programa E-Views 3.0.

${ }^{30}$ Neste parágrafo me refiro sempre à soma da inflação de ponta a ponta dos semestres t e t- 1 .
} 
1985/1 a 1991/1, a taxa de inflação oscilou acima e abaixo de 3,5\% a.a e a instabilidade dos indicadores macro foi menor do que no período anterior, mas ainda não tão pequena quanto durante o período inicial e o último período, que vai de 1991/2 a 1999/2, e durante a qual a taxa de inflação anual se manteve abaixo de $3,5 \%$ a.a..

Destes quatro períodos, apenas o segundo conta com um número de observações razoável. Optamos, então, por testar a possibilidade de quebra estrutural do segundo período (1967/2-1984/2) contra o terceiro e o quarto período juntos (ou seja, de 1985/1 a 1999/2). Os dois testes que realizamos rejeitaram a hipótese de estabilidade dos parâmetros. Em particular, o período 1985/1-1999/2 apresentou uma autocorrelação dos resíduos muito mais forte e não nos gerou coeficientes $\beta$ (o coeficiente do nível de atividade) significantes em nenhuma estimação.

Fizemos, então, diversas estimações, tanto com o período 1967/21984/2 quanto com uma amostra (1967/2-1991/1) que juntou a fase turbulenta com a fase de transição. As estimações dos dois casos foram bastante semelhantes e optamos por mostrar, nas nossas tabelas, as que englobam a fase turbulenta juntamente com a de transição (1967/2 - 1991/1). O outro período analisado será 1/1985-2/1999/que engloba a época de transição e a do regime recente de inflação baixa. Observamos, finalmente, que fizemos os testes ADF, PP e KPSS para os dois subperíodos das nossas estimações e que os resultados conflitantes entre os testes para a questão da estacionariedade da taxa de inflação permaneceram em ambos. 


\section{2 - PROPRIEDADES DAS EXPECTATIVAS INFLACIONÁRIAS DA “SURVEY” DO UMSDC}

Os dados a respeito da expectativa dos agentes quanto à taxa de inflação foram obtidos pela pesquisa junto ao consumidor feita pelo UMSDC. Eles foram obtidos através de três perguntas, sendo as duas primeiras: “Durante os próximos 12 meses, você acredita que os preços subirão, cairão ou se manterão no mesmo patamar?" e "Aproximadamente em quanto você 
acha que os preços subirão (ou cairão), em média, nos próximos 12 meses?"31. Desde março de 1982, tem sido feita uma terceira pergunta àqueles que responderam à primeira pergunta que os preços ficariam estáveis: "Você quer dizer que os preços continuarão a subir à mesma taxa que agora ou que os preços em geral não subirão durante os próximos 12 meses?". Verificou-se, então, que boa parte dos entrevistados entendia errado a primeira pergunta (achavam que estavam sendo perguntados sobre se a taxa de inflação - ao invés dos preços - iria ou não subir). Os dados referentes ao período anterior à existência desta pergunta foram devidamente corrigidos para incorporar seu efeito.

É importante notar que a expectativa relativa à taxa de inflação dos próximos 12 meses não é exatamente o dado que necessitávamos para o modelo de Taylor. O modelo pede, na verdade, a expectativa da taxa de inflação do período que vai do sétimo ao décimo-segundo mês futuros. Nosso procedimento foi idêntico ao de Roberts: assumimos que os agentes esperam a mesma taxa de inflação para cada um dos próximos dois semestres.

Até 1977 as pesquisas eram trimestrais, e incluíam respostas coletadas no mês anterior e nos dois primeiros meses do trimestre em questão (por exemplo, as repostas referentes ao primeiro trimestre foram coletadas em dezembro do ano anterior e em janeiro e fevereiro do ano corrente). A partir de 1978 a pesquisa passou a ser mensal. Utilizamos, para nossa série inteira, os dados do primeiro e do terceiro trimestres de cada ano.

\footnotetext{
${ }^{31}$ Em inglês: "During the next 12 months, do you think that prices will go up, or go down, or stay where they are now?" e "By about what extent do you expect prices will go (up/down) on the average, during the next 12 months?"
} 
Mostramos, abaixo, um gráfico com as séries de inflação esperada (de acordo com a pesquisa) e efetiva para os próximos 12 meses.

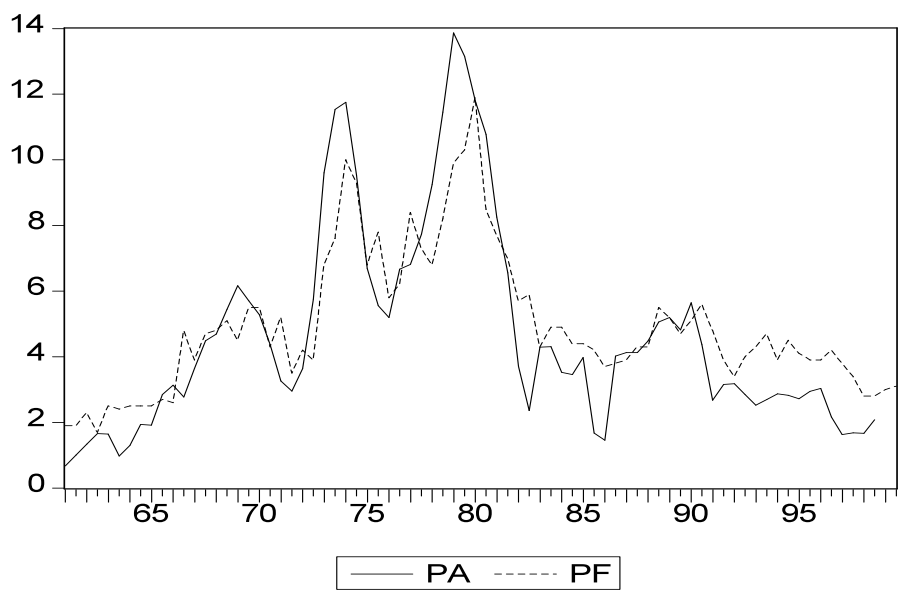

Fig. 1 - Taxas de inflação efetiva (PA) e esperada (PF) para os próximos 12 meses.

Diversas análises, entre elas a do apêndice de Roberts (1997), mostraram que as expectativas inflacionárias da pesquisa do UMSDC não fazem uso eficiente das informações disponíveis (não podendo, portanto, ser consideradas racionais). Outros estudos (como Baghestani (1992), por exemplo), mas não todos na literatura, rejeitaram a hipótese de que as expectativas inflacionárias desta pesquisa sejam não viesadas.

Se as expectativas não fossem viesadas, a estimação de:

$$
\left[\pi b_{t+1}+\pi b_{t+2}\right]=\alpha+\beta\left[E_{t-1}\left[\pi b_{t+1}+\pi b_{t+2}\right]\right] \text { "survey" }
$$


(onde cada período é um semestre, $\pi b_{t}$ representa a inflação do início do período $t-1$ até o início do período $t$ e $\left[\mathrm{E}_{\mathrm{t}-1}\left[\pi \mathrm{b}_{\mathrm{t}+1}+\pi \mathrm{b}_{\mathrm{t}+2}\right]\right]$ "survey" representa as expectativas dos agentes captadas através das "surveys")

deveria resultar $\alpha=0, \beta=1$.

Mostramos, na tabela 6 abaixo os testes de raiz unitária para a variável $E_{t-1}\left[\pi b_{t+1}+\pi b_{t+2}\right]_{\text {"survey" }}$, que mostram que ela é induvitavelmete $\mathrm{I}(1)$.

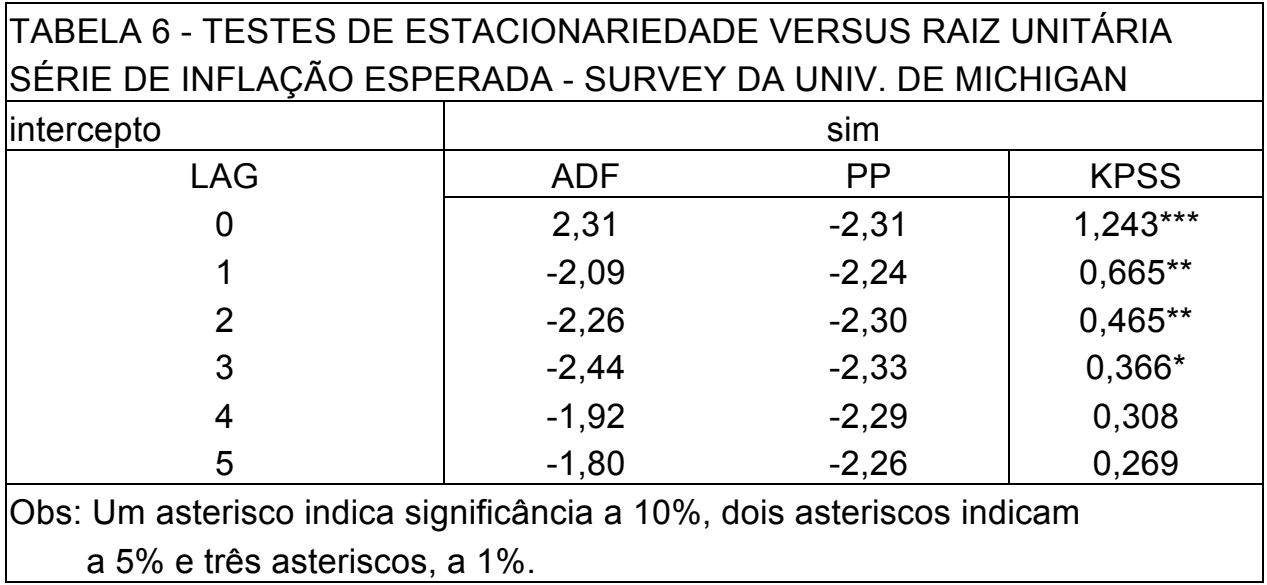

Lembramos que a tabela 3, da seção anterior, nos mostrou que os testes PP e KPSS indicaram que a taxa de inflação efetiva é I(1), mas que o teste ADF indicou que ela é I(0). Para que (2.1) não seja desbalanceada (o que nos daria uma regressão espúria), a inflação efetiva deve ter o mesmo grau de estacionariedade da inflação esperada. Como os testes tem poder baixo e o conflito de resultados não nos permite uma rejeição conclusiva da hipótese de 
que a primeira é I(1), a regressão (2.1) pode ser estimada assumindo-se que os dois lados da equação tem este grau de integração.

Em função de as variáveis serem I(1), a estimação através de OLS está sujeita ao viés de amostra pequena. Além disto, a utilização de dados justapostos gera resíduos autocorrelacionados, não nos permitindo o uso do procedimento de Johansen (1988) na série completa. Para lidar com estes problemas, utilizamos o estimador de Phillips-Hansen (1990) (o qual, além de ter sido criado justamente para lidar com estes problemas, também não é afetado quando há endogeneidade). Isto já foi feito antes em Bakhshi e Yates (1998) que estudaram as expectativas da "survey" do instituto Gallup para a taxa de inflação no Reino Unido. Assim como Bakhshi e Yates, nós usamos janela uniforme com 3 "lags" e assumimos que pelo menos um dos regressores tem "drift". O resultado da estimação de (2.1) foi:

$$
\left[\pi b_{t+1}+\pi b_{t+2}\right]=-2.100+1.364\left[E_{t-1}\left[\pi b_{t+1}+\pi b_{t+2}\right]\right] " \text { survey" }
$$

$$
(0.321) \quad(0.061)
$$

As séries foram semestrais e o período foi de 1/1961 a 2/1999. Os números entre parênteses são desvios padrão.

A seguir testamos as restrições de que $\alpha=0, \beta=1$ através de um "teste de Wald modificado" (A distribuição dos estimadores dos coeficientes obtidos através do método Phillips Hansen é $\chi^{2}$ ) . O resultado foi a rejeição da hipótese nula de não viés, tanto para os coeficientes individualmente quanto no 
teste conjunto, a níveis de significância extremamente elevados (todos os "Pvalues" foram menores do que 0,001 ).

Mas os resultados que nós obtivemos não indicam um viés do tipo subestimação ou superestimação sistemática. Nossa estimativa indica que quando a taxa de inflação esteve acima de $5,77 \%$ a.a., as expectativas captadas pela "survey" a subestimaram, enquanto houve superestimação quando a inflação ficou abaixo deste nível. O viés foi, portanto, na direção de uma taxa de inflação "média".

Caso este viés seja inerente ao modo como a média dos agentes obtêm suas expectativas, ele não chega a comprometer nossa análise empírica dos modelos. Afinal, estamos usando expectativas das "surveys" justamente para captar expectativas não racionais dos agentes. Mas é possível que parte do viés se deva a erros de medida. Uma ponderação nesta direção é a de que uma coisa é responder uma pergunta razoavelmente complexa de relance, junto com mais 23 perguntas (além das 3 acima) pelo telefone e sem maiores incentivos envolvidos, e outra é fazer a avaliação diante de uma negociação salarial. Poderemos ter, então, erros de medida correlacionados com a taxa de inflação. Neste caso, as variáveis $\left[\pi_{t}-\left(E_{t-1}\left[\pi_{t}\right]+E_{t}\left[\pi_{t+1}\right]\right) / 2\right],\left(E_{t}\left[\pi_{t+1}\right]-\pi_{t}\right)$ e $\left(\pi_{t}-E_{t-1}\left[\pi_{t}\right]\right)$ podem significar algo sem relação com nossos modelos. A variável $\left[\pi_{t}-\left(E_{t-1}\left[\pi_{t}\right]+E_{t}\left[\pi_{t+1}\right]\right) / 2\right]$, por exemplo, terá um viés negativo quando a taxa de inflação for baixa e positivo quando a taxa de inflação for alta. Então, ao estimarmos uma regressão relacionando uma destas variáveis com os ciclos econômicos, haverá uma contaminação da relação esperada pelo modelo com a correlação entre estes ciclos e a taxa de inflação (Friedman 
(1977), por exemplo, mostrou evidências de que taxas elevadas de inflação estão positivamente correlacionadas com baixo nível de atividade). Assim, para testar a robustez das nossas estimativas, rodamos regressões adicionais dos modelos testados, utilizando os valores projetados ("fitted values") por (2.2):

$E_{t-1}\left[\pi b_{t+1}+\pi b_{t+2}\right]_{\text {unbiased }}=\left[\pi b_{t+1}+\pi b_{t+2}\right]_{\text {fitted }}$

$=-2.100+1.364\left[\mathrm{E}_{\mathrm{t}-1}\left[\pi \mathrm{b}_{\mathrm{t}+1}+\pi \mathrm{b}_{\mathrm{t}+2}\right]\right]^{\text {"survey" }}$

no lugar das expectativas inflacionárias obtidas na pesquisa UMSDC, onde $E_{t-1}\left[\pi b_{t+1}+\pi b_{t+2}\right]_{\text {unbiased }}$ corresponde à série das expectativas inflacionárias expurgadas do viés.

Observamos, no entanto, que $\mathrm{E}_{\mathrm{t}-1}\left[\pi \mathrm{b}_{\mathrm{t}+1}+\pi \mathrm{b}_{\mathrm{t}+2}\right]_{\text {unbiased }}$ não representa nossa estimativa das expectativas inflacionárias com correção para erros de medida. Este tipo de correção é de difícil determinação e nem sabemos, na verdade, se há erros de medida que comprometam uma análise utilizando as expectativas originais. Camerer (1995) relata que vários estudos mostraram que expectativas de preços e inflação obtidas em experimentos são geralmente viesadas. Em Williams (1987), por exemplo, as expectativas subestimavam os preços quando estes estavam subindo e os superestimavam quando eles caiam (ou seja, havia um viés na direção de uma taxa de inflação média igual a zero). Deste modo, as regressões estimadas com $E_{t-1}\left[\pi b_{t+1}+\pi b_{t+2}\right]_{\text {unbiased }}$, no lugar das expectativas originais, devem ser encaradas como o caso limite, caso este no qual se assume que a totalidade do viés se deve a erros de medida. 
Verificaremos, então, em que medida este caso limite pode ou não comprometer os resultados obtidos com as expectativas originais da "survey".

2.3 - AS EXPECTATIVAS DOS AGENTES

A RESPEITO DO NÍVEL DE ATIVIDADE 
A pesquisa da UMSDC não faz uma pergunta pedindo uma medida da taxa de desemprego ou do hiato de produto esperados. Também, não há nenhuma outra pesquisa fazendo isso a uma população não dominada por pessoas com grau de racionalidade econômica bem acima da média. Mas a pesquisa da UMSDC faz uma outra pergunta bastante próxima desta: "Olhando para as condições dos negócios do país como um todo, - você acha que nos próximos 12 meses nós teremos uma época boa, em termos financeiros, uma época ruim ou o quê?"32. Utilizamos, então, as respostas a esta pergunta para inferir as expectativas dos agentes com relação aos ciclos econômicos.

A pergunta tem a virtude de ser razoavelmente simples, e demandar uma resposta extremamente simples. Isto faz com que os ruídos citados na seção anterior (para expectativas inflacionária), tendam a não ser graves neste caso. Por outro lado, para construir artificialmente a variável que nos interessa, teremos que utilizar os dados qualitativos agregados para inferir a média de uma variável quantitativa determinada individualmente. Por outro lado, temos dificuldade de visualizar em função de que fatores poderia ocorrer um viés, o que equivale a não dispormos de motivos potenciais para supor que ele ocorra.

Nossa idéia foi, então, tomar o percentual dos que responderam que a época seria ruim para os negócios ("bad times for business") como um indicador da medida da avaliação média dos respondentes. Esta variável foi chamada de BT. A lógica de tal transposição reside na postulação de que quanto mais pessoas acham que as perspectivas futuras são ruins, maior deve ser o grau médio de pessimismo das pessoas tomadas individualmente.

\footnotetext{
${ }^{32}$ A pergunta em inglês é:" Now, turning to business conditions in the country as a whole -- do you think that during the next 12 months we'll have good times financially or bad times or what?"
} 
Algumas pessoas são mais pessimistas e outras mais otimistas. Se a ("função de") distribuição do grau de pessimismo não tiver uma forma muito estranha, nosso postulado será razoável.

Uma outra alternativa teria sido utilizar o percentual dos que achavam que a época seria boa para os negócios ou um indicador da relação entre otimistas e pessimistas utilizado pelo UMSDC, dado pelo percentual de "good times" menos o percentual de "bad times" mais 100. De qualquer modo, a figura abaixo mostra que os percentuais referentes aos otimistas e aos pessimistas tem uma correlação bastante forte, sendo uma série quase o espelho da outra. No Capítulo 3, quando colocaremos uma simetria em questão, utilizaremos a relação entre otimistas e pessimistas ao invés de BT.

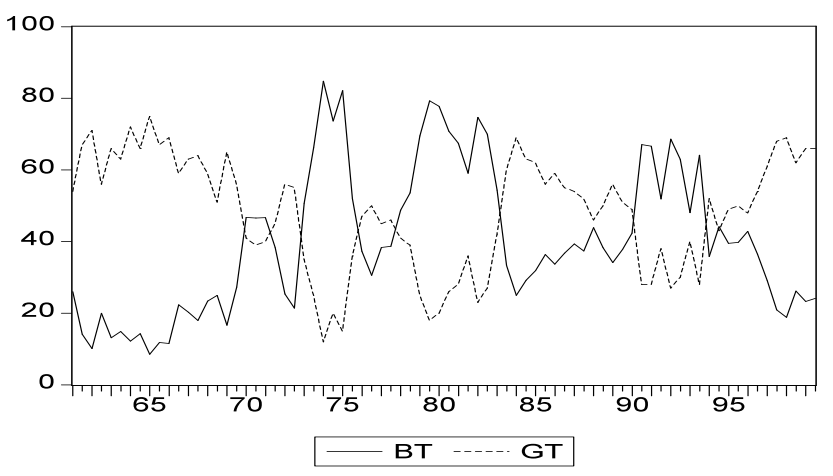

Fig. 2 - O percentual de "good times" (GT) e o de "bad times" (BT).

Observando as figuras abaixo, verificamos que BT é correlacionada tanto com o ciclo econômico quanto com sua "primeira diferença". Esta última correlação é ainda mais acentuada. Observamos que esta primeira diferença mostrada abaixo é para intervalos de 12 meses intercalados (justapostos) a cada 6 meses. Para a variável taxa de desemprego, ela reflete a taxa daqui a 6 meses menos a taxa há 6 meses atrás. Para desvio do produto com relação a 
tendência, ela mostra a diferença entre o nível médio dos 12 meses seguintes com relação ao nível médio dos 12 meses anteriores.

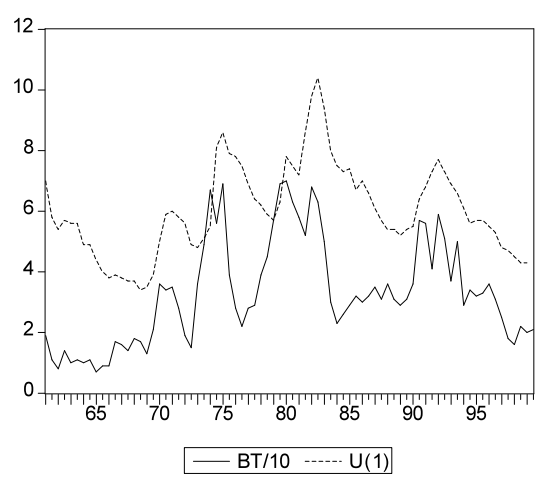

Fig. 3 - BT/10 e desemprego

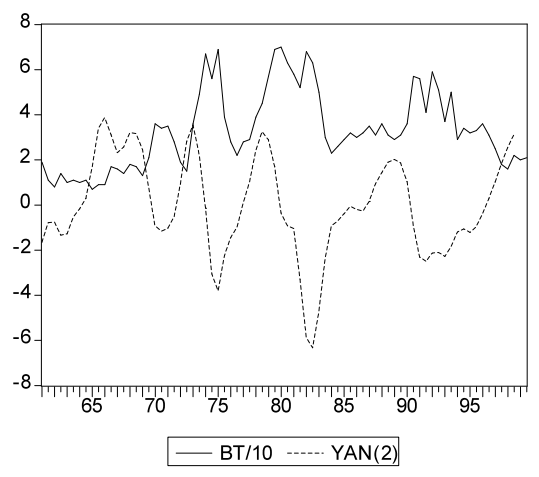

Fig. 5 - BT/10 e o desvio do produto Com relação à tendência do filtro HP

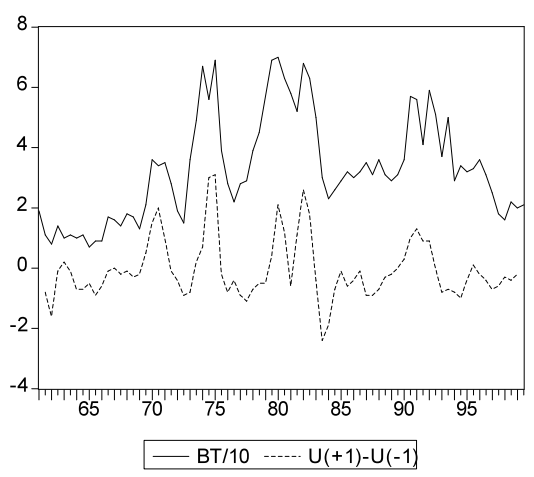

Fig. 4 - BT/10 e a primeira diferença da taxa de desemprego

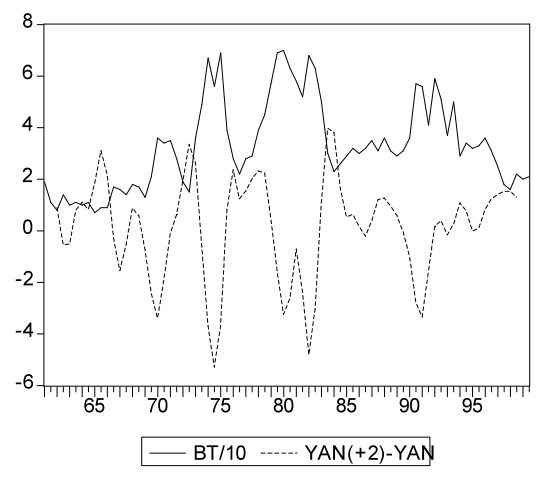

Fig. 6 - BT/10 e a primeira diferença do desvio do produto com relação a tendência do filtro HP

Com base nestes gráficos, parece razoável supor que BT reflete as perspectivas tanto do ciclo econômico quanto de sua primeira diferença. Alternativamente, testamos também se ela espelha apenas esta última isoladamente. Ou seja, os gráficos das figuras 2 a 5 sugerem que BT reflete uma das seguintes alternativas:

$B T_{t}=C_{1}+B_{1}\left\{\left(E_{t-1}\left[\left(y_{t}+y_{t+1}\right) / 2\right]\right)-y_{t-1}\right\}+B_{2} \cdot E_{t-1}\left[\left(y_{t}+y_{t+1}\right) / 2\right]+\gamma_{t}$ 
onde $\mathrm{C}_{1}$ e $\mathrm{C}_{2}$ são interceptos. Rearranjando estas equações obtemos:

$$
\begin{aligned}
\left(E_{t-1}\left[\left(y_{t}+y_{t+1}\right) / 2\right]\right)= & -\left(C_{1} /\left(B_{1}+B_{2}\right)\right)+\left(1 /\left(B_{1}+B_{2}\right)\right) B T_{t} \\
& +\left(B_{1} /\left(B_{1}+B_{2}\right)\right) y_{t-1}-\left(1 /\left(B_{1}+B_{2}\right)\right) \gamma_{1}
\end{aligned}
$$

e

$\left.\left(E_{t-1}\left(y_{t}+y_{t+1}\right) / 2\right]\right)=-\left(C_{2} / B_{3}\right)+\left(1 / B_{3}\right) B T_{t}+B_{4} \cdot y_{t-1}+\left(1 / B_{3}\right) \gamma_{2} t, \quad B_{4}=1$

Definiremos, então:

$$
\begin{aligned}
& \xi_{1 \mathrm{t}}=\mathrm{y}_{\mathrm{t}+1}-\mathrm{E}_{\mathrm{t}-1}\left[\mathrm{y}_{\mathrm{t}+1}\right] \Rightarrow E_{\mathrm{t}-1}\left[\mathrm{y}_{\mathrm{t}+1}\right]=\mathrm{y}_{\mathrm{t}+1}-\xi_{1 \mathrm{t}} \\
& \xi_{2 \mathrm{t}}=\mathrm{y}_{\mathrm{t}}-\mathrm{E}_{\mathrm{t}-1}\left[\mathrm{y}_{\mathrm{t}}\right] \Rightarrow \mathrm{E}_{\mathrm{t}-1}\left[\mathrm{y}_{\mathrm{t}}\right]=\mathrm{y}_{\mathrm{t}}-\xi_{2 \mathrm{t}}
\end{aligned}
$$

Substituindo os conceitos de $\mathrm{E}_{\mathrm{t}-1}\left[\mathrm{y}_{\mathrm{t}+1}\right]$ e $\mathrm{E}_{\mathrm{t}-1}\left[\mathrm{y}_{\mathrm{t}+1}\right]$ de (2.5) e (2.6) em $\left(2.3^{\prime}\right)$ e $\left(2,4^{\prime}\right)$, obtemos:

$\left(y_{t}+y_{t+1}\right) / 2=-\left(C_{1} /\left(B_{1}+B_{2}\right)\right)+\left(1 /\left(B_{1}+B_{2}\right)\right) B T_{t}+\left(B_{1} /\left(B_{1}+B_{2}\right)\right) y_{t-1}$ 


$$
\begin{gathered}
-\left(1 /\left(B_{1}+B_{2}\right)\right) \gamma_{1 t}+\left(\xi_{1 t}+\xi_{2 t}\right) \\
\left(y_{t}+y_{t+1}\right) / 2=-\left(C_{2} / B_{3}\right)+\left(1 / B_{3}\right) B T_{t}+B_{4 \cdot} y_{t-1}+\left(1 / B_{3}\right) \gamma_{2 t} \\
+\left(\xi_{1 t}+\xi_{2 t}\right) \quad, \quad B_{4}=1
\end{gathered}
$$

que podem ser estimadas por mínimos quadrados ordinários, pois a variável BT é colhida em uma "survey" anterior à realização de y t . Observamos que o único modo de diferenciar (2.7) de (2.8) em uma estimação é através da restrição $B_{4}=1$. Deste modo, se estimarmos (2.7), os valores obtidos na regressão podem ser vistos como uma estimativa da expectativa dos agentes a respeito do nível de atividade nos próximos 12 meses inferido a partir da "survey" da UMSDC.

Estimamos (2.7) com as já mencionadas quatro medidas de nível de atividade. Uma pequena modificação foi feita, na medida em que a relação entre o quadrado de BT e a variável dependente mostrou melhor capacidade explicativa do que a relação linear. Os resultados são mostrados abaixo na tabela 7.

\section{TABELA 7 - ESTIMAÇÕES DA EQUAÇÃO (2.7)}

ESTIMAÇÃO DA EXPECTATIVA DOS AGENTES COM RELA ÇÃO AO NÍVEL DE ATIVIDADE FUTURO

MÉTODO DE ESTIMAÇÃO - mínimos quadrados ordinários

VARIÁVEL

DEPENDENTE:

PERÍODO -

$(Y(t)+Y(t+1))$

1/1999 - 2/1961 


\begin{tabular}{|l|ccccc|}
\cline { 2 - 4 } & $\begin{array}{r}\text { medida de ciclo } \\
\text { econômico }\end{array}$ & $\begin{array}{c}\text { Y Hodrick- } \\
\text { Pr. }\end{array}$ & $\begin{array}{c}\text { Y - tend. } \\
\text { Linear }\end{array}$ & ut. de capac. & desemprego \\
\hline Intercepto & & & & \\
& 0,0109 & 0,0134 & 0,2955 & 0,8036 \\
BT2 & $(0,0019)$ & $(0,0022)$ & $(0,0468)$ & $(0,2242)$ \\
& $-0,0742$ & $-0,0957$ & $-0,1350$ & $-0,0436$ \\
Y(t-1) & $(0,0099)$ & $(0,0121)$ & $(0,0187)$ & $(0,0042)$ \\
& 0,6962 & 0,7750 & 0,6621 & 0,7591 \\
& $(0,0588)$ & $(0,0344)$ & $(0,0570)$ & $(0,0373)$ \\
\hline R2 ajustado & & & & \\
DW & 0,73 & 0,93 & 0,72 & 0,90 \\
& 0,89 & 0,90 & 0,81 & 0,90 \\
\hline
\end{tabular}

Obs.:

(1) Números entre parênteses são desvios padrão robustos.

(2) Todos os coeficientes estimados foram significantes a pelo menos $0,1 \%$ de nível crítico.

Testes de Wald destas regressões rejeitaram que o coeficiente de $y_{t-1}$ seja igual a 1, o que nos leva a rejeitar as especificações de (2.4) e (2.8) em favor de (2.3) e (2.7)

Quando fizemos as estimações, não foi possível a eliminação da autocorrelação quando utilizamos séries semestrais. Esta autocorrelação é, na verdade, inerente ao modelo, pois $\xi_{2 \mathrm{t}}$ é correlacionada com $\xi_{1 \mathrm{t}-1}$. O primeiro destes termos de erro reflete inovações no nível de atividade ocorridas no período $t$ enquanto o segundo reflete estas inovações em t e em t-1. Ou seja, assim como no caso das estimações do modelo de Taylor, esta regressão implica um termo de erro com uma estrutura MA(1). Porém, ao contrário do caso do modelo de Taylor, aqui não podemos utilizar um termo MA(1) na estimação. $O$ problema, no presente caso, é que o uso de $\xi_{1 \text { t-1 }}$ na regressão equivale à utilização da informação sobre um erro expectacional que os 
agentes ainda não souberam que cometeram para inferirmos suas expectativas (pois $\xi_{1 \mathrm{t}-1}=\mathrm{y}_{\mathrm{t}}-\mathrm{E}_{\mathrm{t}-2}\left[\mathrm{y}_{\mathrm{t}}\right]$, sendo que $\mathrm{y}_{\mathrm{t}}$ ainda não é conhecido no final de $\mathrm{t}-1$ ).

Um modo de verificar se a autocorrelação se deve apenas à correlação entre $\xi_{2 \mathrm{t}}$ e $\xi_{1 \mathrm{t}-1}$ é a realização de estimações de (2.7) com séries não justapostas. Isto foi feito por nós com o desdobramento das nossas séries com justaposição em dois grupos de séries anuais, um deles com base no primeiro semestre de cada ano e o outro com base nos dados do segundo semestre (eliminamos, assim, a justaposição - ou intercalação - das séries). Nas estimações de (2.7) com estas séries desdobradas não houve autocorrelação, o que indica que não há erro de especificação nas estimações da tabela 1.

As figuras 6 a 9, abaixo, mostram os gráficos das 4 estimativas das expectativas dos agentes a respeito do nível futuro de atividade mostradas na tabela 1 contra o que de fato aconteceu.

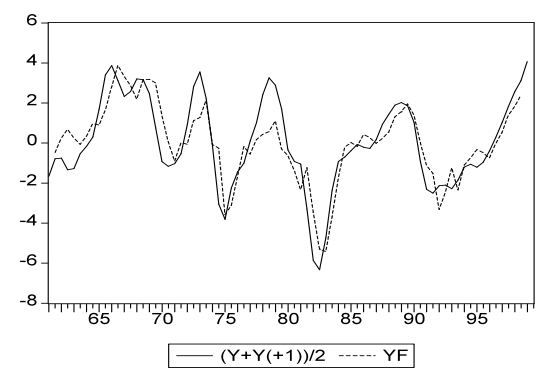

Fig. $7-\left(y_{t}+y_{t+1}\right) / 2$ obtido com o filtro HP (linha contínua) e sua expectativa com base na estimação da equação (2.7) (linha tracejada)

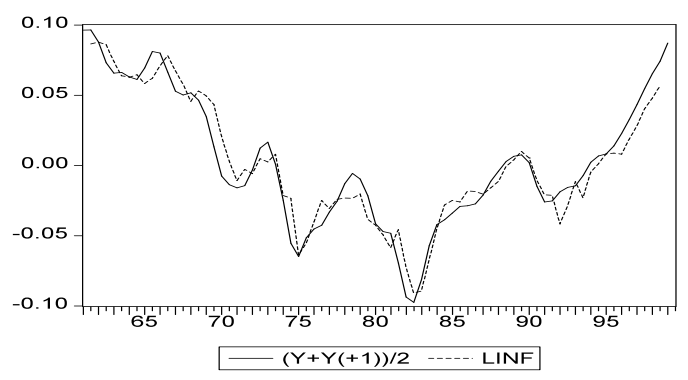

Fig. $8-\left(y_{t}+y_{t+1}\right) / 2$ obtido com tendência linear (linha contínua) e sua expectativa com base na estimação da equação (2.7) (linha tracejada) 


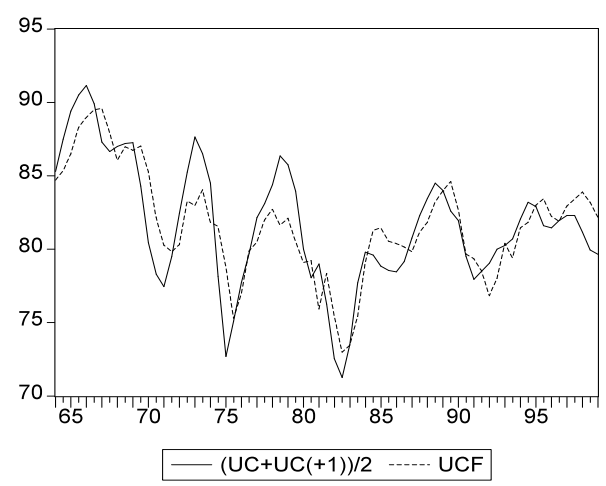

Fig. 9 - utilização de capacidade (linha contínua) e sua expectativa com base na estimação da da equação (2.7) (linha tracejada)

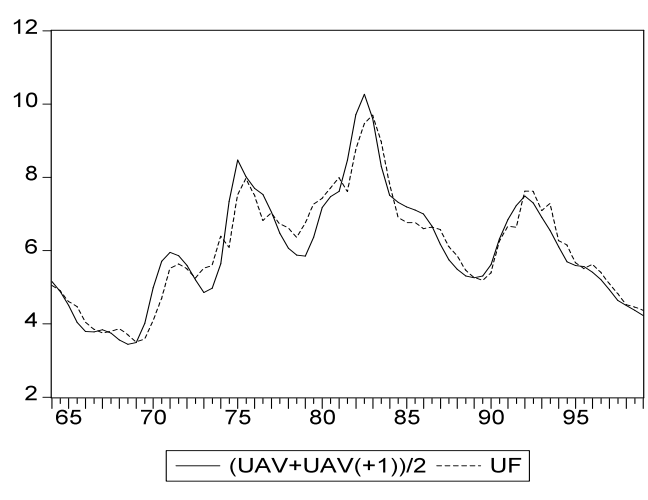

Fig. 10 - taxa de desemprego (linha contínua) e sua expectativa com base na estimação da equação (2.7) (linha tracejada)

O elevado grau de acuidade das expectativas aparente nesta análise superficial está sujeito, no entanto, à crítica de que a regressão utilizando tanto BT quanto $\mathrm{y}_{\mathrm{t}-1}$ corre o risco de combinar estas duas informações de modo significativamente melhor do que um espelho que refletisse fielmente as expectativas dos agentes reais. Por outro lado, lembramos que as figuras 2 a 5 , nas quais havia apenas BT, já nos davam um bom indício de que estas recessões não constituíram grandes surpresas para os agentes.

Mas a análise que realmente interessa para o nosso trabalho não se pauta nestes gráficos, e sim nas estimações dos modelos. Nelas, rodamos não só regressões com as quatro estimativas de $E_{t-1}\left[\left(y_{t}+y_{t+1}\right) / 2\right]$ das regressões da tabela 1, mas também regressões com BT diretamente como variável explicativa. Neste caso, quando $B_{t}$ e $y_{t-1}$ entram juntas, elas se combinam de maneira ótima para explicar a variável dependente, e não para explicar $\left(y_{t}+y_{t+1}\right) / 2$. Além disso, mostraremos também resultados de regressões que utilizam apenas $B T$, sem $y_{t-1}$ entre as variáveis explicativas. 
Vale observar também que, nas regressões dos modelos, as estimativas de $E_{t-1}\left[\left(y_{t}+y_{t+1}\right) / 2\right]$ são projetadas por instrumentos que são variáveis defasadas, o que faz piorar (ou tornar mais realista) a capacidade de previsão destas medidas das expectativas (ou seja, acumulamos os erros de duas projeções, a da regressão de (2.7) a de uma regressão com variáveis defasadas). 


\section{4 - EXPECTATIVAS E O MODELO DE TAYLOR - RESULTADOS EMPÍRICOS}

Nesta seção iremos mostrar os resultados que obtivemos nas estimações da equação (1.5"), apontada na seção 1.4 item (B) como indicadoras da consistência ou não entre as expectativas dos agentes e o modelo de Taylor. Mostraremos também os resultados de estimações da equação (1.26). Esta equação pode ser interpretada como um indicador de se, dadas as expectativas, o modelo de Taylor é consistente com o modo como os agentes fixam os salários e preços.

Mostraremos estimativas com e sem histerese no nível de atividade. No caso com histerese, colocamos $\left(\mathrm{BT}_{\mathrm{t}}+\mathrm{BT}_{\mathrm{t}-1}\right)$ ao lado de $\left(\mathrm{y}_{\mathrm{t}-1}+\mathrm{y}_{\mathrm{t}-2}\right) / 2$ como variáveis explicativas. Nas estimações sem histerese, utilizamos nossas estimativas de $E_{t-1}\left[\left(y_{t}+y_{t+1}\right) / 2\right]$ para as expectativas dos agentes, obtidas a partir da equação (2.7), mostradas na tabela 1 (conforme gráficos e comentários da seção anterior, a variável BT parece refletir um forte componente relacionado com histerese). Não mostramos estimações tendo $E_{t-1}\left[\left(y_{t}+y_{t+1}\right) / 2\right]$ junto com $\left(y_{t-1}+y_{t-2}\right) / 2$ porque, novamente de acordo com a seção anterior, o uso de $\left(\mathrm{BT}_{\mathrm{t}}+\mathrm{B} \mathrm{T}_{\mathrm{t}-1}\right)$ ao lado de $\left(\mathrm{y}_{\mathrm{t}-1}+\mathrm{y}_{\mathrm{t}-2}\right) / 2$ é mais adequado para estimar o modelo de Taylor com histerese.

As tabelas abaixo nos mostram os resultados das estimações para dois períodos, de 2/1967 a 1/1991 e de 1/1985 a 2/1999. Para cada caso foram feitas quatro estimações, cada uma com expectativas a respeito da demanda agregada esperada pautadas em uma medida de ciclo econômico diferente (as 
quatro alternativas consideradas foram: desvio do produto com base em tendência obtida com filtro de Hodrick-Prescott, com base em tendência linear, utilização de capacidade instalada na indústria e taxa de desemprego). Em algumas tabelas não aparecem estimativas com todas estas medidas de nível de atividade. Isto se deve a termos optado por não mostrar estimativas nas quais houve autocorrelação dos resíduos - que implicariam estimações viesadas, devido à estimação em dois estágios com variáveis defasadas como instrumentos.

Observamos, ainda, que o teste de superidentificação reportado é o teste de Sargan (1964).

\section{A) RESULTADOS DA EQUAÇÃO (1.5')}

Esta equação é dada por:

$E_{t-1}\left[\pi_{t+1}\right]-\pi_{t}=\gamma \cdot\left(\pi_{t}-E_{t-2}\left[\pi_{t}\right]\right)-\beta\left(E_{t-1}\left[y_{t}+y_{t+1}\right]+E_{t-2}\left[y_{t-1}+y_{t}\right]\right)-\left(v_{t}+v_{t-1}\right)$

com as restrições: $\gamma=1$ e $-\beta<0$

e o propósito de estimá-la é o de testar as restrições. A primeira delas

$(\gamma=1)$ é avaliada através de um teste de Wald. Este procedimento não pode ser utilizado, no entanto, com relação à segunda $(-\beta<0)$, por não ser esta uma igualdade. Neste caso, coeficientes com sinal incorreto a um nível significante indicam uma rejeição à restrição. Mas sinal incorreto a um nível não significante e não significância com o sinal correto também depõem contra o modelo. 


\begin{tabular}{|c|c|c|c|c|}
\hline $\begin{array}{l}\text { TABELA } 8 \text { - ESTIMAÇÕES DA } \\
\text { COM BT E NÍVEL DE ATIVIDAD } \\
\text { MÉTODO DE ESTIMAÇÃO - mír }\end{array}$ & $\begin{array}{l}\text { EQUAÇÃO (1.5' } \\
\text { OE PASSADO C } \\
\text { imos quadrados }\end{array}$ & $\begin{array}{l}\text { ") com expectati } \\
\text { OMO VARIÁVEI } \\
\text { s de dois estágios }\end{array}$ & $\begin{array}{l}\text { iva inflacioná } \\
\text { IS EXPLICATI } \\
\text { S }\end{array}$ & $\begin{array}{l}\text { Iria original } \\
\text { VAS }\end{array}$ \\
\hline VARIÁVEL DEPENDENTE: & $\mathrm{E}_{\mathrm{t}-1}\left[\pi_{\mathrm{t}+1}\right]-\pi_{\mathrm{t}}$ & & & \\
\hline PERÍODO - 2/1967 - 1/1991 & & & & \\
\hline medida de $(y(t-1)+y(t-2)) / 2$ & Y - Hodrick-Pr. & Y - tend. Linear & ut. de capac. & desemprego \\
\hline constante & $\begin{array}{l}0,0083^{* *} \\
(0,0025)\end{array}$ & $\begin{array}{l}0,0067^{* * *} \\
(0,0025)\end{array}$ & $\begin{array}{l}0,0460^{* *} \\
(0,0194)\end{array}$ & $\begin{array}{c}0,0038 \\
(0,0026)\end{array}$ \\
\hline$\left(\pi_{t}-\mathbf{E}_{t-2}\left[\pi_{t}\right]\right)$ & $\frac{-0,3798}{(0,3500)}$ & $\frac{-0,4747 \#}{(0,2103)}$ & $\begin{array}{c}0,0120 \\
(0,1764)\end{array}$ & $\frac{-0,4430 \#}{(0,1764)}$ \\
\hline teste de Wald - P-Value & 0,000 & 0,000 & 0,000 & 0,000 \\
\hline$(\mathrm{BT}+\mathrm{BT}(\mathrm{t}-1)) / 2$ & $\frac{-0,0181 \#}{(0,0054)}$ & $\frac{-0,0156 \#}{(0,0060)}$ & $\frac{-0,0244 \#}{(0,0091)}$ & $\frac{-0,0164 \#}{(0,0046)}$ \\
\hline$(\mathrm{y}(\mathrm{t}-1)+\mathrm{y}(\mathrm{t}-2)) / 2$ & $\begin{array}{l}-0,0485 \\
(0,0499)\end{array}$ & $\begin{array}{l}-0,0252 \\
(0,0206)\end{array}$ & $\begin{array}{l}-0,0429^{*} \\
(0,0228)\end{array}$ & $\begin{array}{c}0,0576 \\
(0,0437)\end{array}$ \\
\hline preço real do petróleo (t) & $\begin{array}{c}0,0030 \\
(0,0070)\end{array}$ & $\begin{array}{c}0,0012 \\
(0,0056)\end{array}$ & $\begin{array}{l}-0,0072 \\
(0,0058)\end{array}$ & $\begin{array}{c}0,0006 \\
(0,0047)\end{array}$ \\
\hline preço real do petróleo (t-1) & $\begin{array}{l}-0,0015 \\
(0,0038)\end{array}$ & $\begin{array}{l}-0,0020 \\
(0,0032)\end{array}$ & $\begin{array}{l}-0,0028 \\
(0,0052)\end{array}$ & $\begin{array}{l}-0,0019 \\
(0,0036)\end{array}$ \\
\hline $\mathrm{MA}(1)$ & & & $\begin{array}{c}0,2736 \\
(0,1669)\end{array}$ & \\
\hline R2 ajustado & 0,65 & 0,66 & 0,47 & 0,66 \\
\hline DW & 1,77 & 1,99 & 1,82 & 1,93 \\
\hline teste de superident. - P. Value & 0,15 & 0,17 & 0,32 & 0,19 \\
\hline Jarque-Bera - P. Value & 0,99 & 0,91 & 0,86 & 0,67 \\
\hline $\begin{array}{l}\text { autocorr. - estat. Q (P-values): } \\
\text { lag } 1\end{array}$ & 0,57 & 0,86 & - & 0,96 \\
\hline $\operatorname{lag} 2$ & 0,84 & 0,98 & 0,35 & 1,00 \\
\hline $\operatorname{lag} 3$ & 0,43 & 0,61 & 0,26 & 0,61 \\
\hline $\operatorname{lag} 4$ & 0,29 & 0,33 & 0,24 & 0,36 \\
\hline $\operatorname{lag} 5$ & 0,42 & 0,46 & 0,37 & 0,00 \\
\hline $\operatorname{lag} 6$ & 0,29 & 0,46 & 0,19 & $\begin{array}{l}0,50 \\
0,43\end{array}$ \\
\hline $\begin{array}{l}\text { Obs.: } \\
\text { (1) Números entre parênteses sã } \\
\text { (2) Os coeficiêntes de interesse } \\
\text { (3) Números sublinhados em ver } \\
\text { (4) \# indica coeficiente com sinal } \\
\text { (5) Um asterisco indica coeficien } \\
\text { de } 10 \% \text {; dois asteriscos, signif }\end{array}$ & $\begin{array}{l}\text { o desvios padrã } \\
\text { foram sombread } \\
\text { melho indicam c } \\
\text { errado e signific } \\
\text { te (quando não t } \\
\text { icante à } 5 \% \text {; três }\end{array}$ & $\begin{array}{l}\text { o robustos. } \\
\text { os com fundo cin } \\
\text { oeficientes com s } \\
\text { cante ao nível crít } \\
\text { tem sinal errado) } \\
\text { s asteriscos, sign }\end{array}$ & $\begin{array}{l}\text { zza. } \\
\text { sinal errado. } \\
\text { tico de } 5 \% \text { ou } \\
\text { significante ac } \\
\text { ificância à } 1 \%\end{array}$ & $\begin{array}{l}\text { menos. } \\
\text { o nível crítico }\end{array}$ \\
\hline
\end{tabular}




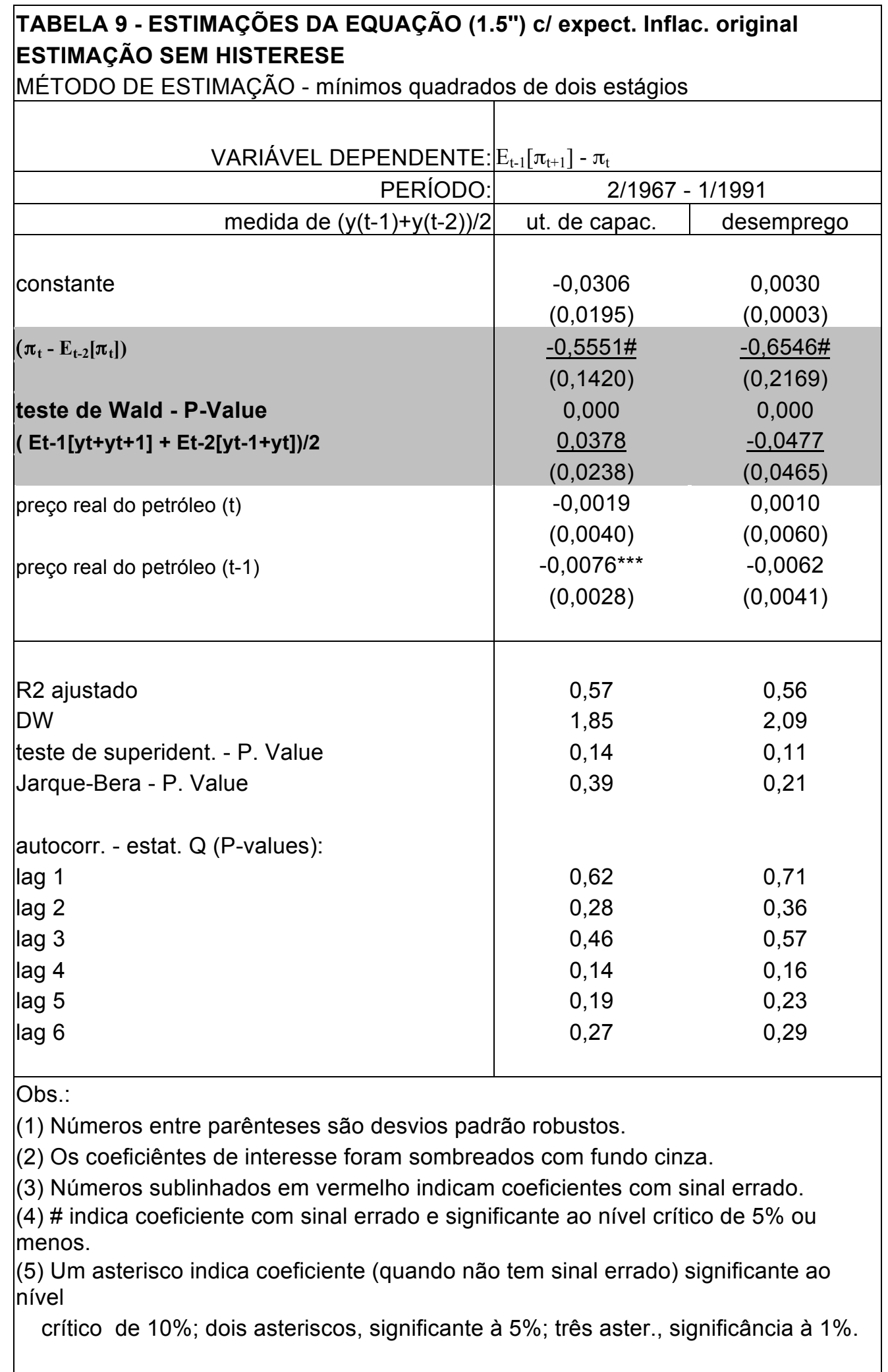




\begin{tabular}{|c|c|c|c|}
\hline $\begin{array}{l}\text { TABELA } 10 \text { - ESTIMAÇÕES DA EQU } \\
\text { MÉTODO DE ESTIMAÇÃO - mínimos }\end{array}$ & $\begin{array}{l}\text { AÇÃO (1.5") - cl } \\
\text { quadrados de do }\end{array}$ & $\begin{array}{l}\text { xpect. inflac } \\
\text { estágios }\end{array}$ & lária original \\
\hline VARIÁVEL DEPENDENTE: $\mathrm{E}$ & $\mathrm{E}_{\mathrm{t}-1}\left[\pi_{\mathrm{t}+1}\right]-\pi_{\mathrm{t}}$ & & \\
\hline PERÍODO - 1/1985 - 2/1999 & & & \\
\hline medida de $(\mathrm{y}(\mathrm{t}-1)+\mathrm{y}(\mathrm{t}-2)) / 2$ & Y - Hodrick-Pr. & ut. de capac. & ut. de capac. \\
\hline constante & $\begin{array}{c}0,0007 \\
(0,0007)\end{array}$ & $\begin{array}{c}0,0151 \\
(0,0134)\end{array}$ & $\begin{array}{c}0,0193 \\
(0,0185)\end{array}$ \\
\hline$\left(\pi_{t}-E_{t-2}\left[\pi_{t}\right]\right)$ & $\frac{-0,7632 \#}{(0,1588)}$ & $\frac{-0,6429 \#}{(0,2344)}$ & $\frac{-0,6504 \#}{(0,1964)}$ \\
\hline teste de Wald - P-Value & 0,000 & 0,000 & 0,000 \\
\hline$(\mathrm{BT}+\mathrm{BT}(\mathrm{t}-1)) / 2$ & & $\begin{array}{c}0,0014 \\
(0,0040)\end{array}$ & \\
\hline$(E t-1[y t+y t+1]+E t-2[y t-1+y t]) / 2$ & $\frac{-0,0420}{(0,0330)}$ & & $\begin{array}{l}-0,0222 \\
(0,0227)\end{array}$ \\
\hline$(\mathrm{y}(\mathrm{t}-1)+\mathrm{y}(\mathrm{t}-2)) / 2$ & & $\begin{array}{l}-0,0177 \\
(0,0167)\end{array}$ & \\
\hline preço real do petróleo (t) & $\begin{array}{c}0,0000 \\
(0,0034)\end{array}$ & $\begin{array}{l}-0,0013 \\
(0,0041)\end{array}$ & $\begin{array}{l}-0,0015 \\
(0,0040)\end{array}$ \\
\hline preço real do petróleo (t-1) & $\begin{array}{l}-0,0024 \\
(0,0023)\end{array}$ & $\begin{array}{l}-0,0027 \\
(0,0030)\end{array}$ & $\begin{array}{l}-0,0029 \\
(0,0027)\end{array}$ \\
\hline R2 ajustado & 0,73 & 0,75 & 0,75 \\
\hline DW & 2,10 & 1,92 & 1,87 \\
\hline teste de superident. - P. Value & 0,66 & 0,54 & 0,69 \\
\hline Jarque-Bera - P. Value & 0,79 & 0,97 & 0,98 \\
\hline Estabilidade - Wald - P.Value & 0,30 & 0,01 & 0,13 \\
\hline $\begin{array}{l}\text { autocorr. - estat. Q (P-values): } \\
\text { lag } 1\end{array}$ & 0,76 & 0,82 & 0,24 \\
\hline $\operatorname{lag} 2$ & 0,92 & 0,45 & 0,38 \\
\hline $\operatorname{lag} 3$ & 0,34 & 0,29 & 0,46 \\
\hline $\operatorname{lag} 4$ & 0,30 & 0,22 & 0,59 \\
\hline $\operatorname{lag} 5$ & 0,41 & 0,31 & 0,64 \\
\hline $\operatorname{lag} 6$ & 0,43 & 0,39 & 0,20 \\
\hline $\begin{array}{l}\text { Obs.: } \\
\text { (1) Números entre parênteses são des } \\
\text { (2) Os coeficiêntes de interesse foram } \\
\text { (3) Números sublinhados em vermelho } \\
\text { errado. } \\
\text { (4) \# indica coeficiente com sinal errad } \\
\text { (5) Um asterisco indica coeficiente (qu } \\
\text { crítico de } 10 \% \text {; dois asteriscos, sign }\end{array}$ & $\begin{array}{l}\text { vios padrão robus } \\
\text { sombreados com } \\
\text { indicam coeficie } \\
\text { o e significante a } \\
\text { ando não tem sin } \\
\text { ificante à } 5 \% \text {; três }\end{array}$ & $\begin{array}{l}\text { os. } \\
\text { undo cinza. } \\
\text { es com sinal } \\
\text { nível crítico de } \\
\text { errado) signifi } \\
\text { asteriscos, sigr }\end{array}$ & $\begin{array}{l}5 \% \text { ou menos. } \\
\text { ante ao nível } \\
\text { ficância à } 1 \% \text {. }\end{array}$ \\
\hline
\end{tabular}


Os números das três tabelas são bastante ruins. Nas tabelas 8 e 9 temos as estimações do período $2 / 1967-1 / 1991$. Nelas, a restrição de que $\gamma=$ 1 foi rejeitada a $0,1 \%$ de significância em todas as estimações e em todos os casos tivemos $(-\beta)$ com sinal errado (e, em todas as estimações com histerese, com significância de $5 \%$ ou mais). Observamos que, como a taxa de desemprego é negativamente correlacionada com a demanda agregada, seu coeficiente deveria ser positivo e significante.

Para o período 1/1985 - 2/1999, apenas três estimações não apresentaram autocorrelação. Elas são mostradas na tabela 10. Os resultados de (- $\beta$ ) foram ligeiramente melhores, com sinal correto em níveis não significantes em duas das três estimações. Por outro lado, a restrição $(\gamma=1)$, além de ter sido rejeitada a $0,1 \%$ em todos os casos, teve sinal errado e significante nas três estimações.

Tendo obtido resultados bastante ruins na estimação com menos restrições, representada por (1.5"), passaremos para os resultados nas estimações onde assumimos $(\gamma=1)$, ou seja, as estimações da equação (1.26).

B) A EXPLICAÇÃO DE $E_{t-1}\left[\pi_{t+1}\right]$ A PARTIR DA EQUAÇÃO (1.26)

A equação (1.26) é dada por:

$\pi_{t}-\left(E_{t-1}\left[\pi_{t+1}\right]+E_{t-2}\left[\pi_{t}\right]\right) / 2=(\beta / 2) \cdot\left(E_{t-1}\left[\left(y_{t}+y_{t+1}\right) / 2\right]+E_{t-2}\left[\left(y_{t-1}+y_{t}\right) / 2\right]\right)$ 


$$
+(1 / 2) \cdot\left(v_{t}+v_{t-1}\right)
$$

Como dissemos, esta equação corresponde à especificação correta do modelo de Taylor mais próxima da que foi utilizada por Roberts em suas estimações. Mostramos, nas tabelas 11 a 14, oito estimações para cada um dos dois sub-períodos considerados na nossa análise.

Do ponto de vista do nosso trabalho, ao estimarmos (1.26), impomos as restrições do modelo, que não foram aceitas ao estimarmos (1.5"). Damos, assim, uma segunda chance ao modelo que havia sido rejeitado nas estimações irrestritas. Estas estimações nos permitem calcular $\left[E_{t-1}\left[\pi_{t+1}\right]\right]$ Taylor , uma estimativa das expectativas inflacionárias obtidas através do modelo de Taylor com a restrição apontada acima, sendo:

$\left[E_{t-1}\left[\pi_{t+1}\right]\right]$ Taylor $=2 .\left(\pi_{t}-\right.$ fittedTaylor $)-E_{t-2}\left[\pi_{t}\right]$

ou

$\left[E_{t-1}\left[\pi_{t+1}\right]\right]_{\text {Taylor }}=\pi_{t}-2$. fittedTaylor $-\left(\pi_{t}-E_{t-2}\left[\pi_{t}\right]\right)$

Depois de calculado $\left[\mathrm{E}_{\mathrm{t}-1}\left[\pi_{\mathrm{t}+1}\right]\right]_{\text {Taylor }}$, comparamos graficamente sua série com a $\left[\mathrm{E}_{\mathrm{t}-1}\left[\pi_{\mathrm{t}+1}\right]\right]$ da survey. 


\begin{tabular}{|c|c|c|c|c|}
\hline \multicolumn{5}{|c|}{$\begin{array}{l}\text { TABELA } 11 \text { - ESTIMAÇÕES DA EQUAÇÃO (1.26) com expectati } \\
\text { COM BT E NÍVEL DE ATIVIDADE PASSADO COMO VARIÁVEIS } \\
\text { MÉTODO DE ESTIMAÇÃO - mínimos quadrados de dois estágios }\end{array}$} \\
\hline \multicolumn{5}{|c|}{ 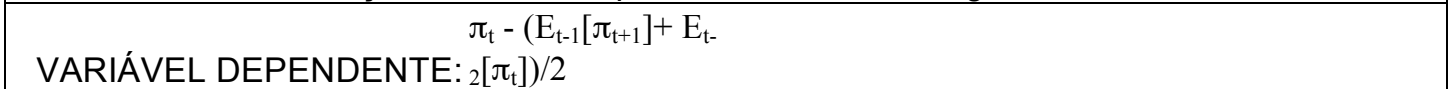 } \\
\hline \multicolumn{5}{|l|}{ PERÍODO - 2/1967 - 1/1991 } \\
\hline medida de $(\mathrm{y}(\mathrm{t}-1)+\mathrm{y}(\mathrm{t}-2)) / 2$ & Y - Hodrick-Pr. & $\begin{array}{l}\text { Y - tend. } \\
\text { Linear }\end{array}$ & $\begin{array}{l}\text { ut. de } \\
\text { capac. }\end{array}$ & desemprego \\
\hline constante & $\begin{array}{l}-0,0065^{* *} \\
(0,0027)\end{array}$ & $\begin{array}{l}-0,0065^{* *} \\
(0,0031)\end{array}$ & $\begin{array}{r}-0,0513^{* *} \\
(0,0193)\end{array}$ & $\begin{array}{c}0,0015 \\
(0,0034)\end{array}$ \\
\hline$(\mathrm{BT}+\mathrm{BT}(\mathrm{t}-1)) / 2$ & $\underline{0,0142 \#}$ & $\underline{0,0163 \#}$ & $\frac{0,0142}{(0,0071)}$ & $\frac{0,0118}{(0,0064)}$ \\
\hline$(\mathrm{y}(\mathrm{t}-1)+\mathrm{y}(\mathrm{t}-2)) / 2$ & $\begin{array}{l}0,1076^{* *} \\
(0,0414)\end{array}$ & $\begin{array}{c}0,0527 \\
(0,0319)\end{array}$ & $\begin{array}{l}0,0552^{* *} \\
(0,0228)\end{array}$ & $\begin{array}{l}-0,1085^{* *} \\
(0,0510)\end{array}$ \\
\hline preço real do petróleo $(\mathrm{t})$ & $\begin{array}{c}0,0122^{* * *} \\
(0,0045)\end{array}$ & $\begin{array}{l}0,0131^{* * *} \\
(0,0045)\end{array}$ & $\begin{array}{r}0,0124^{* * *} \\
(0,0044)\end{array}$ & $\begin{array}{c}0,0150^{* * *} \\
(0,0040)\end{array}$ \\
\hline preço real do petróleo (t-1) & $\begin{array}{c}0,0040 \\
(0,0048)\end{array}$ & $\begin{array}{c}0,0058 \\
(0,0048)\end{array}$ & $\begin{array}{c}0,0043 \\
(0,0047)\end{array}$ & $\begin{array}{c}0,0063 \\
(0,0042)\end{array}$ \\
\hline $\mathrm{MA}(1)$ & & $\begin{array}{c}0,2504 \\
(0,1988)\end{array}$ & $\begin{array}{c}0,1530 \\
(0,2146)\end{array}$ & \\
\hline R2 ajustado & 0,54 & 0,48 & 0,51 & 0,48 \\
\hline $\begin{array}{l}\text { DW } \\
\text { teste de superident. - P. }\end{array}$ & 1,79 & 2,01 & 2,00 & 1,59 \\
\hline Value & 0,62 & 0,70 & 0,26 & 0,38 \\
\hline $\begin{array}{l}\text { Jarque-Bera - P. Value } \\
\text { autocorr. - estat. Q (P- } \\
\text { values): }\end{array}$ & 0,96 & 0,73 & 0,92 & 0,66 \\
\hline $\operatorname{lag} 1$ & 0,62 & - & - & 0,19 \\
\hline $\operatorname{lag} 2$ & 0,40 & 0,40 & 0,22 & 0,37 \\
\hline $\operatorname{lag} 3$ & 0,57 & 0,69 & 0,46 & 0,57 \\
\hline $\operatorname{lag} 4$ & 0,37 & 0,28 & 0,21 & 0,47 \\
\hline $\operatorname{lag} 5$ & 0,30 & 0,29 & 0,16 & 0,52 \\
\hline $\operatorname{lag} 6$ & 0,27 & 0,41 & 0,20 & 0,61 \\
\hline \multicolumn{5}{|c|}{$\begin{array}{l}\text { Obs.: } \\
\text { (1) Números entre parênteses são desvios padrão robustos. } \\
\text { (2) Os coeficiêntes de interesse foram sombreados com fundo cinza. } \\
\text { (3) Números sublinhados em vermelho indicam coeficientes com sinal errado. } \\
\text { (4) \# indica coeficiente com sinal errado e significante ao nível crítico de } 5 \% \text { ou menos. } \\
\text { (5) Um asterisco indica coeficiente (quando não tem sinal errado) significante ao nível crítico } \\
\text { de } 10 \% \text {; dois asteriscos, significante à } 5 \% \text {; três asteriscos, significância à } 1 \% \text {. }\end{array}$} \\
\hline
\end{tabular}




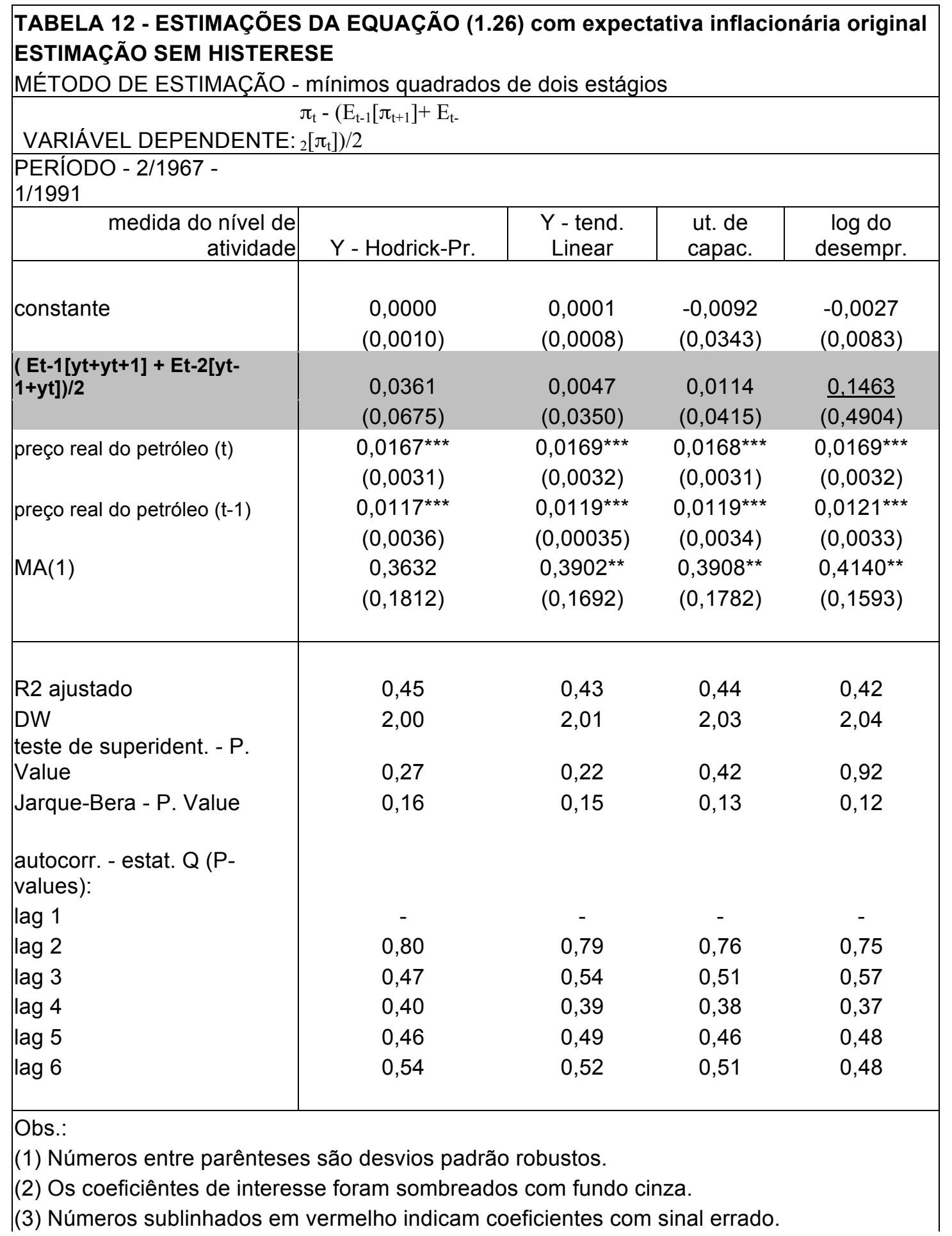


(4) \# indica coeficiente com sinal errado e significante ao nível crítico de $5 \%$ ou menos.

(5) Um asterisco indica coeficiente (quando não tem sinal errado) significante ao nível crítico de $10 \%$; dois asteriscos, significante à $5 \%$; três asteriscos, significância à $1 \%$.

\begin{tabular}{|c|c|c|c|c|}
\hline $\begin{array}{l}\text { TABELA } 13 \text { - ESTIMAÇÕES } \\
\text { COM BT E NÍVEL DE ATIVID } \\
\text { MÉTODO DE ESTIMAÇÃO - I }\end{array}$ & $\begin{array}{l}\text { EQUAÇÃO }(1.2 \\
\text { E PASSADO C } \\
\text { imos quadrados }\end{array}$ & $\begin{array}{l}\text { om expect } \\
\text { VARIÁVE } \\
\text { lois estágic }\end{array}$ & $\begin{array}{l}\text { inflacio } \\
\text { XPLICA }\end{array}$ & $\begin{array}{l}\text { ária original } \\
\text { VAS }\end{array}$ \\
\hline VARIÁVEL DEPENDENTE: & $\begin{array}{l}\left(E_{t-1}\left[\pi_{t+1}\right]+E_{t-}\right. \\
t]) / 2\end{array}$ & & & \\
\hline PERÍODO - 1/1985 - 2/1999 & & & & \\
\hline medida de $(\mathrm{y}(\mathrm{t}-1)+\mathrm{y}(\mathrm{t}-2)) / 2$ & Y - Hodrick-Pr. & $\begin{array}{l}\text { Y - tend. } \\
\text { Linear }\end{array}$ & $\begin{array}{l}\text { ut. de } \\
\text { capac. }\end{array}$ & desemprego \\
\hline constante & $\begin{array}{c}-0,0088^{* * *} \\
(0,0025)\end{array}$ & $\begin{array}{l}-0,0029 \\
(0,0036)\end{array}$ & $\begin{array}{c}0,0059 \\
(0,0266)\end{array}$ & $\begin{array}{l}-0,0034 \\
(0,0059)\end{array}$ \\
\hline$(\mathrm{BT}+\mathrm{BT}(\mathrm{t}-1)) / 2$ & $\frac{0,0117}{(0,0060)}$ & $\begin{array}{l}-0,0034 \\
(0,0077)\end{array}$ & $\begin{array}{l}-0,0103 \\
(0,0637)\end{array}$ & $\begin{array}{l}-0,0030 \\
(0,0081)\end{array}$ \\
\hline$(\mathrm{y}(\mathrm{t}-1)+\mathrm{y}(\mathrm{t}-2)) / 2$ & $\begin{array}{c}0,1061 \\
(0,0494)\end{array}$ & $\begin{array}{l}-0,0207 \\
(0,0334)\end{array}$ & $\begin{array}{l}-0,0073 \\
(0,0321)\end{array}$ & $\begin{array}{c}0,0058 \\
(0,1094)\end{array}$ \\
\hline preço real do petróleo (t) & $\begin{array}{l}0,0116^{* * *} \\
(0,0028)\end{array}$ & $\begin{array}{l}0,0092^{* * *} \\
(0,0030)\end{array}$ & $\begin{array}{l}0,0090^{* * *} \\
(0,0032)\end{array}$ & $\begin{array}{l}0,0090^{* * *} \\
(0,0029)\end{array}$ \\
\hline preço real do petróleo (t-1) & $\begin{array}{c}0,0040 \\
(0,0035)\end{array}$ & $\begin{array}{l}0,0087^{* * *} \\
(0,0029)\end{array}$ & $\begin{array}{l}0,0083^{* *} \\
(0,0034)\end{array}$ & $\begin{array}{l}0,0084^{* * *} \\
(0,0029)\end{array}$ \\
\hline $\mathrm{MA}(1)$ & & $\begin{array}{r}0,9646^{* * *} \\
(0,0274)\end{array}$ & $\begin{array}{l}0,9449^{* * *} \\
(0,0337)\end{array}$ & $\begin{array}{c}0,9573^{* * *} \\
(0,0269)\end{array}$ \\
\hline R2 ajustado & 0,49 & 0,55 & 0,49 & 0,54 \\
\hline $\begin{array}{l}\text { DW } \\
\text { teste de superident. - P. }\end{array}$ & 1,48 & 2,21 & 1,99 & 2,17 \\
\hline Value & 0,64 & 0,53 & 0,56 & 0,44 \\
\hline Jarque-Bera - P. Value & 0,40 & 0,15 & 0,26 & 0,15 \\
\hline $\begin{array}{l}\text { Estabilidade - Wald - P.Value } \\
\text { autocorr. - estat. Q (P- } \\
\text { values): }\end{array}$ & 0,00 & 0,00 & 0,00 & 0,00 \\
\hline $\operatorname{lag} 1$ & 0,25 & - & - & - \\
\hline $\operatorname{lag} 2$ & 0,40 & 0,42 & 0,45 & 0,48 \\
\hline $\operatorname{lag} 3$ & 0,50 & 0,20 & 0,16 & 0,16 \\
\hline $\operatorname{lag} 4$ & 0,33 & 0,35 & 0,20 & 0,26 \\
\hline $\operatorname{lag} 5$ & 0,23 & 0,51 & 0,30 & 0,40 \\
\hline $\operatorname{lag} 6$ & 0,23 & 0,64 & 0,39 & 0,49 \\
\hline
\end{tabular}


Obs.:

(1) Números entre parênteses são desvios padrão robustos.

(2) Os coeficiêntes de interesse foram sombreados com fundo cinza.

(3) Números sublinhados em vermelho indicam coeficientes com sinal errado.

(4) \# indica coeficiente com sinal errado e significante ao nível crítico de $5 \%$ ou menos.

(5) Um asterisco indica coeficiente (quando não tem sinal errado) significante ao nível crítico de $10 \%$; dois asteriscos, significante à $5 \%$; três asteriscos, significância à $1 \%$.

TABELA 14 - ESTIMAÇÕES DA EQUAÇÃO (1.26) com expectativa inflacionária original ESTIMAÇÃO SEM HISTERESE

MÉTODO DE ESTIMAÇÃO - mínimos quadrados de dois estágios

VARIÁVEL DEPENDENTE: $\left.{ }_{2}\left[\pi_{\mathrm{t}}\right]\right) / 2$

PERÍODO - 1/1985 - 2/1999

\begin{tabular}{|c|c|c|c|c|}
\hline medida do nível de atividade & $\mathrm{Y}$ - Hodrick-Pr. & $\begin{array}{c}\text { Y - tend. } \\
\text { Linear }\end{array}$ & $\begin{array}{c}\text { ut. de } \\
\text { capac. }\end{array}$ & desemprego \\
\hline
\end{tabular}

\begin{tabular}{l|llll} 
constante & $-0,0040^{* * *}$ & $-0,0040^{* * *}$ & $-0,0233$ & $-0,0001$
\end{tabular}

\begin{tabular}{|lcccc} 
& $(0,0011)$ & $(0,0011)$ & $(0,0264)$ & $(0,0069)$ \\
( Et-1[yt+yt+1] + Et-2[yt- & 0,0891 & 0,1846 & 0,0236 & $-0,0671$ \\
& $(0,0798)$ & $(4,2486)$ & $(0,0327)$ & $(0,1085)$ \\
preço real do petróleo (t) & $0,0103^{* * *}$ & $0,0101^{* * *}$ & $0,0101^{* * *}$ & $0,0099^{* * *}$ \\
& $(0,0035)$ & $(0,0035)$ & $(0,0033)$ & $(0,0032)$ \\
preço real do petróleo (t-1) & $0,0096^{* * *}$ & $0,0093^{* * *}$ & $0,0093^{* * *}$ & $0,0088^{* * *}$ \\
& $(0,0029)$ & $(0,0030)$ & $(0,0032)$ & $(0,0028)$ \\
MA(1) & $0,9724^{* * *}$ & $0,9899^{* * *}$ & $0,9897^{* * *}$ & $0,9899^{* * *}$ \\
& $(0,0234)$ & $(0,0000)$ & $(0,0002)$ & $(0,0002)$
\end{tabular}

R2 ajustado

DW

teste de superident. - P.

Value

$(0,0000) \quad(0,0002) \quad(0,0002)$

Jarque-Bera - P. Value

Estabilidade - Wald - P.Value

0,58

0,58

0,57

0,58

2,35

2,26

2,23

2,26

0,35

0,53

0,58

0,61

0,68

0,27

0,38

0,33

0,00

0,00

0,00

0,00

autocorr. - estat. Q (P-

values):

lag 1

$\operatorname{lag} 2$

lag 3

0,26

0,13

0,40

0,10

0,42

0,10

0,38

0,10 


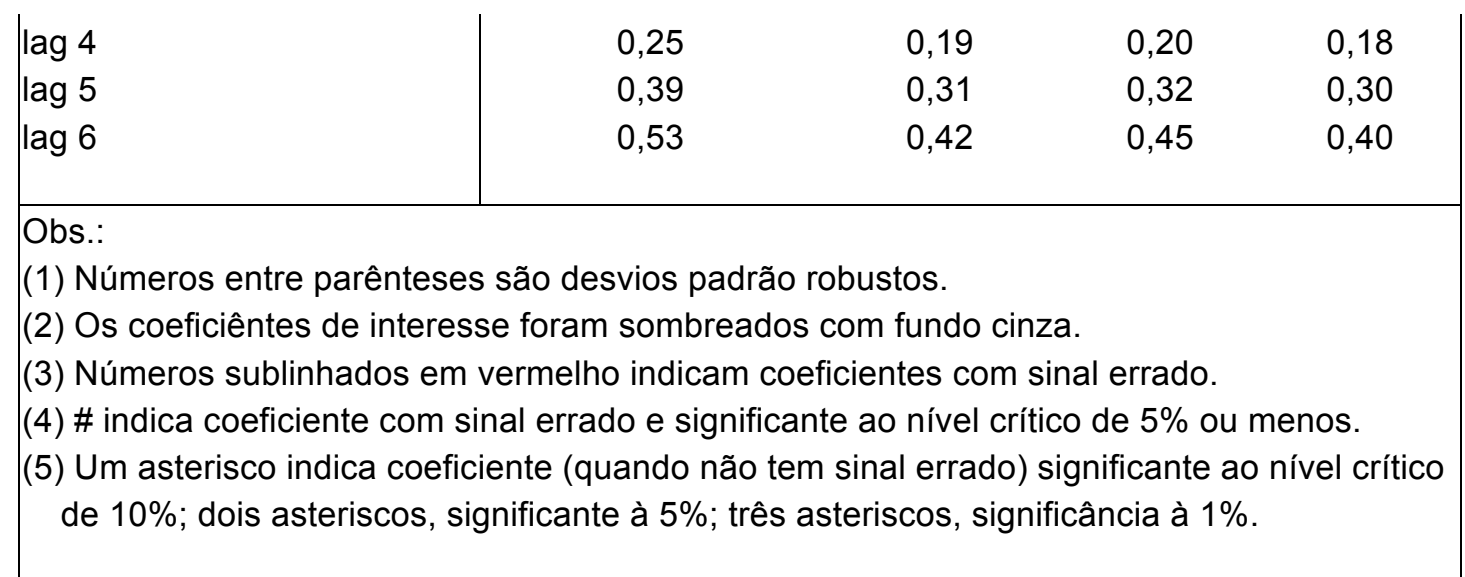

Para o primeiro sub-período, de 2/1967 a 1/1991, os coeficientes de BT (nas estimações com histerese) apresentaram sempre o sinal errado. Em duas das quatro vezes, a níveis significantes. Nas estimações sem histerese, o coeficiente de $\left(\mathrm{E}_{\mathrm{t}-1}\left[\mathrm{y}_{\mathrm{t}}+\mathrm{y}_{\mathrm{t}+1}\right]+\mathrm{E}_{\mathrm{t}-2}\left[\mathrm{y}_{\mathrm{t}-1}+\mathrm{y}_{\mathrm{t}}\right]\right) / 2$ foi sempre não significante (e em uma das quatro estimações teve sinal errado).

Para o período de 1/1985 a 2/1999, nenhuma variável relacionada com nível de atividade (tanto esperada para o futuro quanto passada) foi significante em nenhuma estimação. Nessas regressões, a variável dependente foi explicada basicamente pelos choques do petróleo, pela constante e pelo termo $\operatorname{MA}(1)$.

Observamos que o quadro não melhorou quando utilizamos estimações com mínimos quadrados ordinários, o que seria compatível com a hipótese $(E t-1[y t+y t+1]+E t-2[y t-1+y t]) / 2$ fracamente exógeno ${ }^{33}$, a qual não pôde ser nem corroborada nem rejeitada pelos testes de Hausman. Nesse teste, supõe-

\footnotetext{
${ }^{33}$ Observamos que Roberts assumiu, em suas estimações, nível de atividade em $\mathrm{t}$ fracamente exógeno. Ele não mostrou, no entanto, resultados de testes de exogeneidade.
} 
se que os desvios padrão das estimações via TSLS tenham variância maior de que as estimações via OLS. Isto foi violado em todas as estimações mostradas na tabela 15. Em duas delas, a estatística do teste foi negativa.

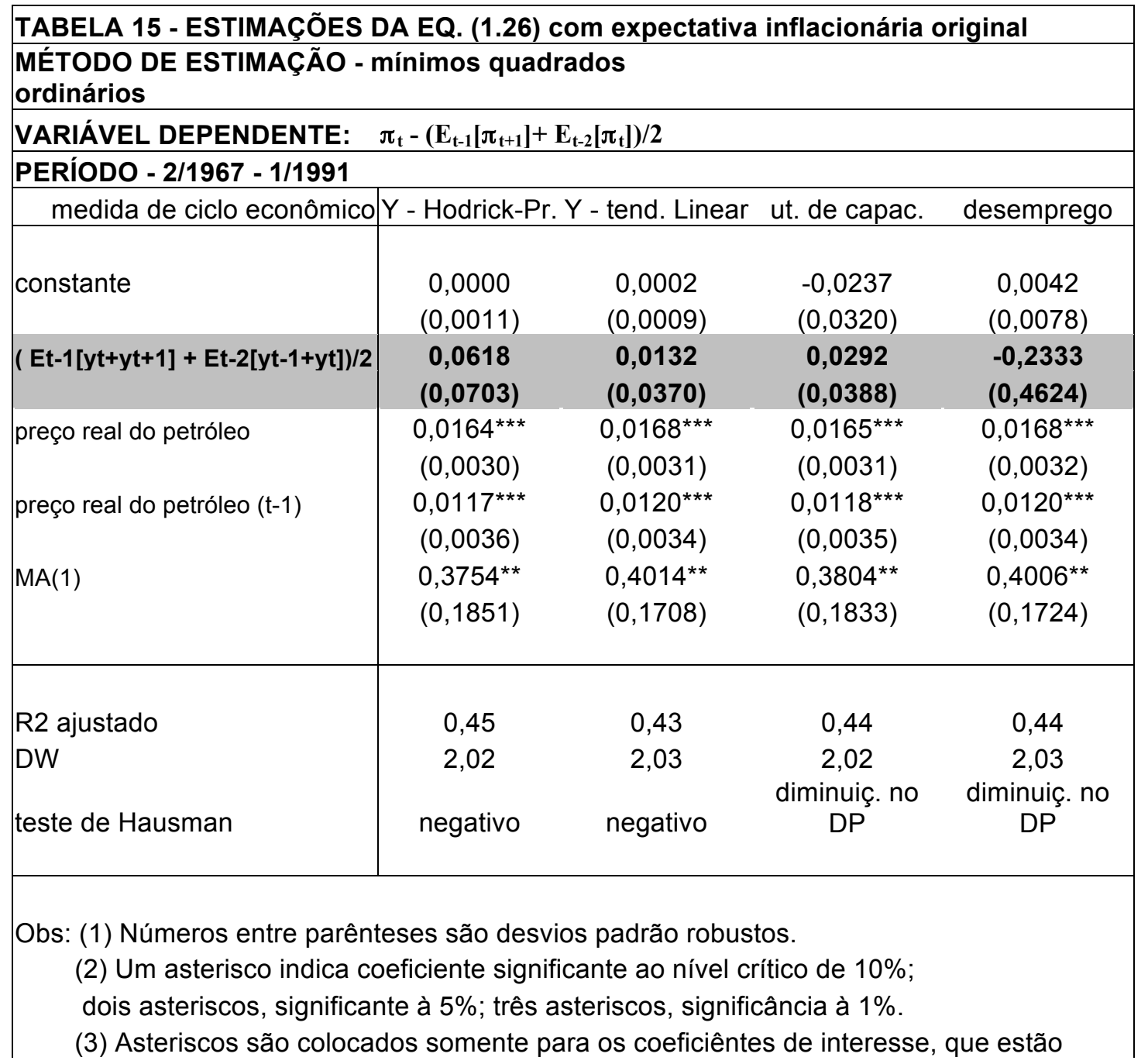


A comparação entre $\cdot\left[E_{t-1}\left[\pi_{t+1}\right]\right]$ (a linha contínua e menos volátil) e $\left[E_{t-1}\left[\pi_{t+1}\right]\right]$ Taylor é mostrada nas figuras 11 (período 2/1967 - 1/1991) e 12 (período 1/1985 - 2/1999) abaixo. Mostramos apenas os resultados das estimações sem histerese, pois nas estimações com ela, os coeficientes do primeiro período tiveram sempre o sinal errado. Elas nos mostram que $\left[\mathrm{E}_{\mathrm{t}-1}\left[\pi_{t+1}\right]\right]$ Taylor tem grandes oscilações que não têm nenhuma correspondência com as expectativas dos agentes, especialmente nas épocas de desinflação esperada (antecipada pelos agentes).

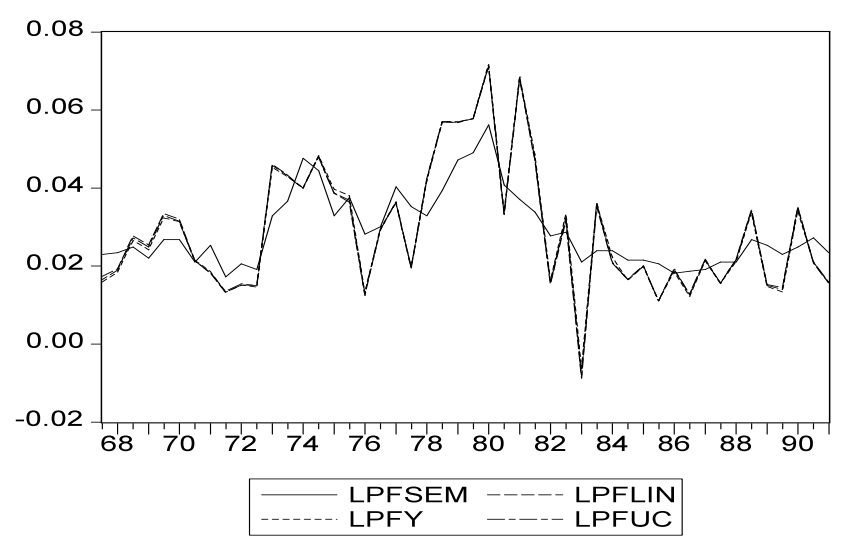


Fig. 11 - Gráfico de $E_{t-1}\left[\pi_{t+1}\right]$ (Ipfsem) contra suas estimativas obtidas através de estimações com o modelo de Taylor (mais voláteis). Período 2/1967 - 1/1991

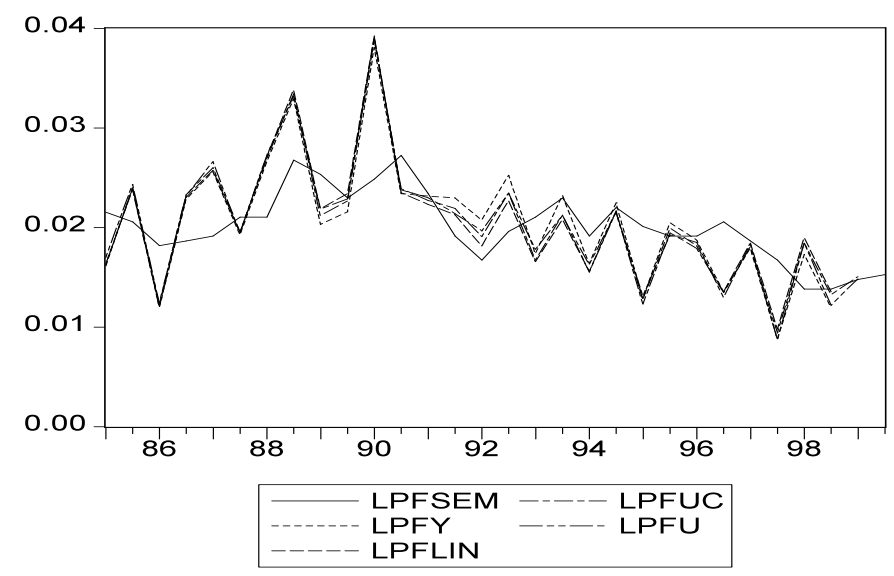

Fig. 12 - Gráfico de $E_{t-1}\left[\pi_{t+1}\right]$ (Ipfsem) contra suas estimativas obtidas através de estimações com o modelo de Taylor (mais voláteis). Período 1/1985 - 2/1999

\section{C) A ROBUSTÊS DOS RESULTADOS FRENTE À POSSIBILIDADE DE ERROS DE MEDIDA}

Conforme foi dito na seção 2.2 , várias análises, incluindo a nossa, rejeitaram a hipótese de que as expectativas inflacionárias reportadas na "survey" do UMSDC sejam não viesadas. Argumentamos, então, que no caso limite de a totalidade do viés ser devida a erros de medida, as verdadeiras expectativas dos agentes poderiam ser aproximadas por $E_{t-1}\left[\pi b_{t+1}+\pi b_{t+2}\right]_{\text {unbiased }}$ , dada por: 
$E_{t-1}\left[\pi b_{t+1}+\pi b_{t+2}\right]_{\text {unbiased }}=\left[\pi b_{t+1}+\pi b_{t+2}\right]_{\text {fitted }}$

$=-2.100+1.364\left[E_{t-1}\left[\pi b_{t+1}+\pi b_{t+2}\right]\right]^{\prime s u r v e y "}$

onde $E_{t-1}\left[\pi b_{t+1}+\pi b_{t+2}\right]_{u n b i a s e d}$ corresponde à série das expectativas inflacionárias expurgadas do viés. Conforme já dissemos, no entanto, estas expectativas expurgadas de viés não correspondem à nossa estimativa das verdadeiras expectativas dos agentes. Nós não sabemos se algum percentual do viés se deve a erros de medida nem, caso isto ocorra, qual é esse percentual.

$\mathrm{O}$ uso de $\mathrm{E}_{\mathrm{t}-1}\left[\pi \mathrm{b}_{\mathrm{t}+1}+\pi \mathrm{b}_{\mathrm{t}+2}\right]_{\text {unbiased }}$ no lugar das expectativas originais possibilitou alguma melhora no desempenho do modelo de Taylor, mas consideramos que os resultados ainda permaneceram bastante ruins.

A equação (1.5”) continuou com um grande número de coeficientes de interesse com o sinal errado, algumas vezes em nível significante. A hipótese de que o coeficiente de $\left(\pi_{t}-E_{t-2}\left[\pi_{t}\right]\right)$ é igual a um só não foi rejeitada a $5 \%$ de significância em uma das quinze estimações. O coeficiente do nível de atividade esperado não foi significante com o sinal correto nenhuma vez e apresentou o sinal errado onze vezes (em uma delas de modo significante a $5 \%)$.

Mostramos, nas tabelas 16 a 19 abaixo, os resultados das estimações de (1.5"). Os gráficos com $\left[E_{t-1}\left[\pi_{t+1}\right]\right]$ e $\left[E_{t-1}\left[\pi_{t+1}\right]\right]$ Taylor , apesar de não estarem aqui apresentados, apresentaram o mesmo padrão do caso sem correção de viés. 


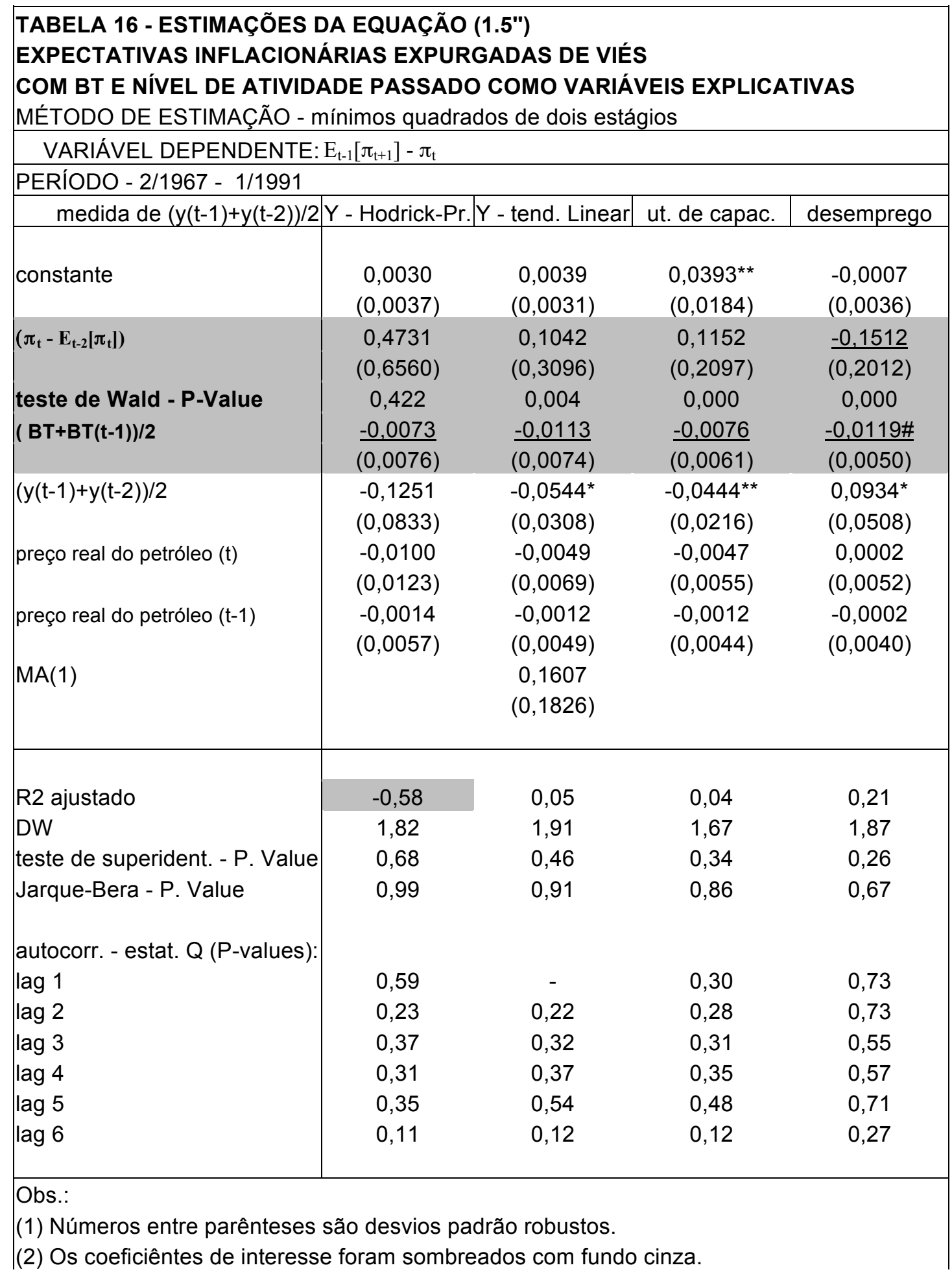


(3) Números sublinhados em vermelho indicam coeficientes com sinal errado.

(4) \# indica coeficiente com sinal errado e significante ao nível crítico de $5 \%$ ou menos.

(5) Um asterisco indica coeficiente (quando não tem sinal errado) significante ao nível crítico de $10 \%$; dois asteriscos, significante à $5 \%$; três asteriscos, significância à $1 \%$.

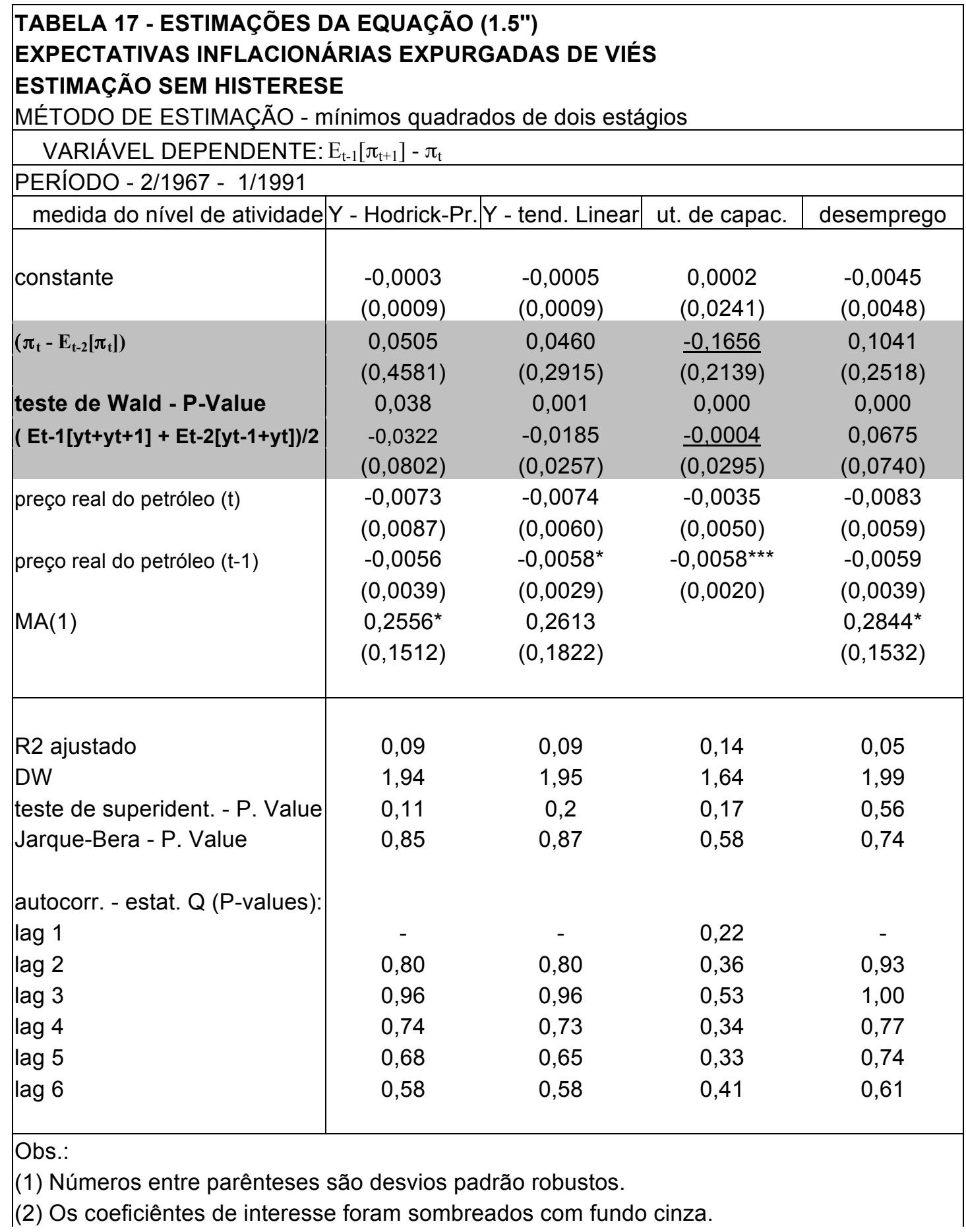


(3) Números sublinhados em vermelho indicam coeficientes com sinal errado.

(4) \# indica coeficiente com sinal errado e significante ao nível crítico de $5 \%$ ou menos.

(5) Um asterisco indica coeficiente (quando não tem sinal errado) significante ao nível crítico de $10 \%$; dois asteriscos, significante à $5 \%$; três aster., significância à $1 \%$.

\begin{tabular}{|c|c|c|c|}
\hline $\begin{array}{l}\text { TABELA } 18 \text { - ESTIMAÇÕES DA } \\
(1.5 ") \\
\text { EXPECTATIVAS INFLACIONÁRI } \\
\text { COM BT E NÍVEL DE ATIVIDADE } \\
\text { MÉTODO DE ESTIMAÇÃO - mínir }\end{array}$ & $\begin{array}{l}\text { EQUAÇÃO } \\
\text { AS EXPURGADA } \\
\text { PASSADO CON } \\
\text { nos quadrados d }\end{array}$ & $\begin{array}{l}\text { DE VIÉS } \\
\text { VARIÁVEIS E } \\
\text { dois estágios }\end{array}$ & LICATIVAS \\
\hline VARIÁVEL DEPENDENTE: & $\mathrm{E}_{\mathrm{t}-1}\left[\pi_{\mathrm{t}+1}\right]-\pi_{\mathrm{t}}$ & & \\
\hline PERÍODO - 1/1985 - 2/1999 & & & \\
\hline medida de $(\mathrm{y}(\mathrm{t}-1)+\mathrm{y}(\mathrm{t}-2)) / 2$ & $\mathrm{Y}$ - tend. Linear & ut. de capac. & ut. de capac. \\
\hline constante & $\begin{array}{l}-0,0001 \\
(0,0024)\end{array}$ & $\begin{array}{c}0,0035 \\
(0,0225)\end{array}$ & $\begin{array}{l}-0,0032 \\
(0,0029)\end{array}$ \\
\hline $\begin{array}{l}\left(\pi_{t}-E_{t-2}\left[\pi_{t}\right]\right) \\
\text { teste de Wald - P-Value } \\
(B T+B T(t-1)) / 2\end{array}$ & $\begin{array}{c}\frac{-0,2007}{(0,1565)} \\
0,000 \\
0,0017 \\
(0,0059)\end{array}$ & $\begin{array}{c}\frac{-0,3871}{(0,3204)} \\
0,000 \\
0,0042 \\
(0,0060)\end{array}$ & $\begin{array}{c}\frac{-0,3160}{(0,2829)} \\
0,000 \\
0,0022 \\
(0,0049)\end{array}$ \\
\hline$(\mathrm{y}(\mathrm{t}-1)+\mathrm{y}(\mathrm{t}-2)) / 2$ & $\begin{array}{l}-0,0025 \\
(0,0178)\end{array}$ & $\begin{array}{l}-0,0059 \\
(0,0270)\end{array}$ & $\begin{array}{c}0,0470 \\
(0,0571)\end{array}$ \\
\hline preço real do petróleo (t) & $\begin{array}{l}-0,0070^{* *} \\
(0,0031)\end{array}$ & $\begin{array}{l}-0,0041 \\
(0,0060)\end{array}$ & $\begin{array}{l}-0,0047 \\
(0,0049)\end{array}$ \\
\hline preço real do petróleo (t-1) & $\begin{array}{l}-0,0044^{*} \\
(0,0025)\end{array}$ & $\begin{array}{l}-0,0039 \\
(0,0035)\end{array}$ & $\begin{array}{l}-0,0037 \\
(0,0027)\end{array}$ \\
\hline R2 ajustado & 0,48 & 0,55 & 0,55 \\
\hline DW & 1,54 & 1,72 & 1,73 \\
\hline teste de superident. - P. Value & 0,26 & 0,49 & 0,65 \\
\hline Jarque-Bera - P. Value & 0,93 & 0,99 & 1,00 \\
\hline Estabilidade - Wald - P.Value & 0,02 & 0,02 & 0,10 \\
\hline $\begin{array}{l}\text { autocorr. - estat. Q (P-values): } \\
\text { lag } 1\end{array}$ & 0,19 & 0,43 & 0,46 \\
\hline $\operatorname{lag} 2$ & 0,11 & 0,20 & 0,25 \\
\hline $\operatorname{lag} 3$ & 0,18 & 0,18 & 0,24 \\
\hline $\operatorname{lag} 4$ & 0,15 & 0,18 & 0,14 \\
\hline $\operatorname{lag} 5$ & 0,22 & 0,20 & 0,20 \\
\hline $\operatorname{lag} 6$ & 0,31 & 0,28 & 0,300 \\
\hline
\end{tabular}


Obs.:

(1) Números entre parênteses são desvios padrão robustos.

(2) Os coeficiêntes de interesse foram sombreados com fundo cinza.

(3) Números sublinhados em vermelho indicam coeficientes com sinal errado.

(4) \# indica coeficiente com sinal errado e significante ao nível crítico de $5 \%$ ou menos.

(5) Um asterisco indica coeficiente (quando não tem sinal errado) significante ao nível crítico de $10 \%$; dois asteriscos, significante à $5 \%$; três asteriscos, significância à $1 \%$.

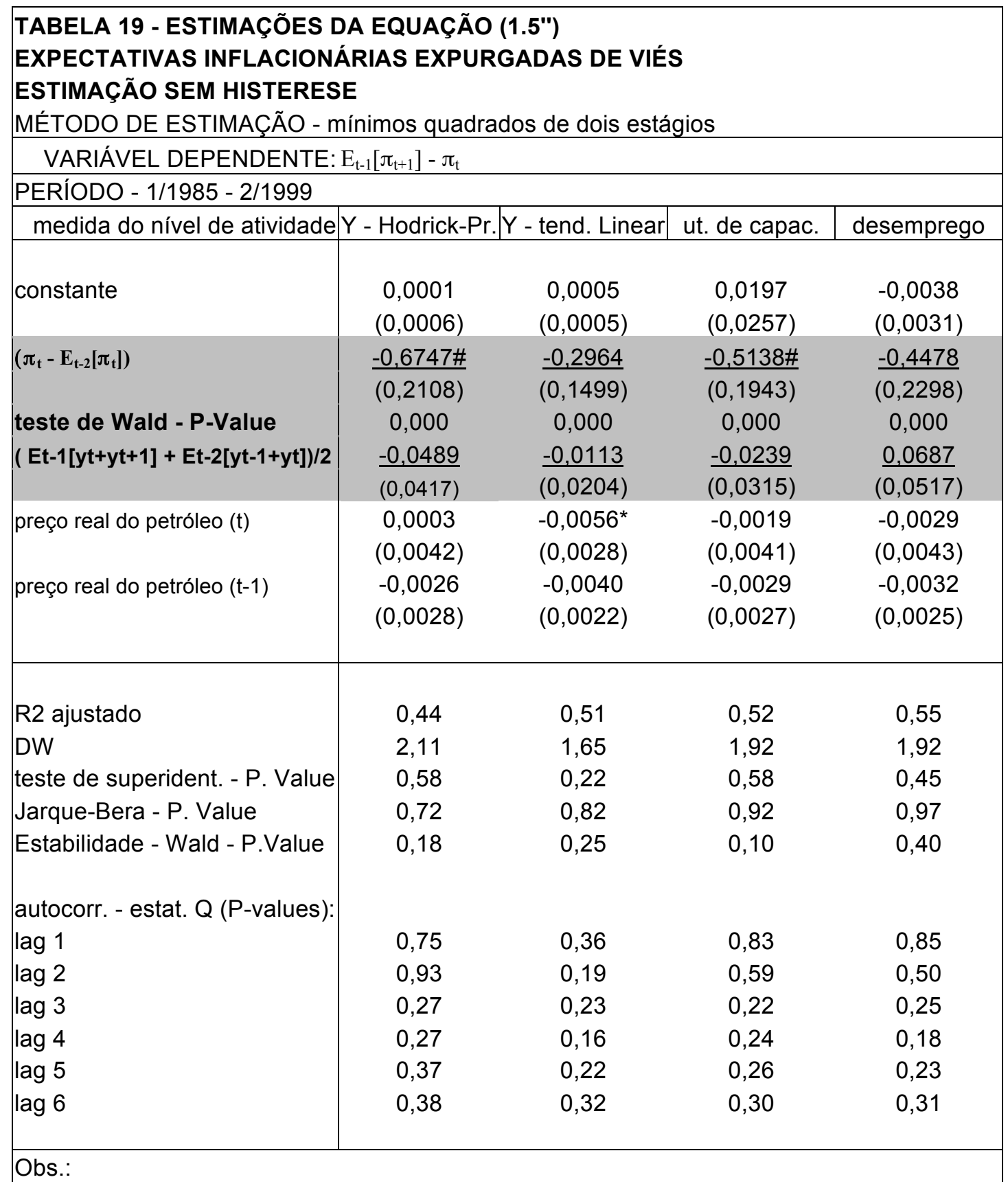


(1) Números entre parênteses são desvios padrão robustos.

(2) Os coeficiêntes de interesse foram sombreados com fundo cinza.

(3) Números sublinhados em vermelho indicam coeficientes com sinal errado.

(4) \# indica coeficiente com sinal errado e significante ao nível crítico de $5 \%$ ou menos.

(5) Um asterisco indica coeficiente (quando não tem sinal errado) significante ao nível crítico de $10 \%$; dois asteriscos, significante à $5 \%$; três aster., significância à $1 \%$.

\section{D) ESTIMAÇÕES SEM COMBINAR BT COM}

\section{O NÍVEL DE ATIVIDADE PASSADO}

Finalmente, fizemos também estimações nas quais $\left(\mathrm{y}_{\mathrm{t}-1}+\mathrm{y}_{\mathrm{t}-2}\right) / 2$ não aparece junto com BT entre as variáveis explicativas. Os resultados, mostrados abaixo, não modificam em nada nossa análise acima. Conforme observamos no início desta seção, não reportamos regressões nas quais não foi possível eliminar a autocorrelação dos resíduos, caso de (1.5") com expectativas inflacionárias sem expurgo de viés nas estimações dos dois períodos. 


\begin{tabular}{|c|c|c|}
\hline $\begin{array}{l}\text { TABELA } 20 \text { - ESTIMAÇÕES D } \\
\text { SOMENTE BT COMO MEDIDA } \\
\text { MÉTODO DE ESTIMAÇÃO - m }\end{array}$ & ágios & \\
\hline & $: \mathrm{E}_{\mathrm{t}-1}\left[\pi_{\mathrm{t}+1}\right]-\pi_{\mathrm{t}}$ & \\
\hline EXPECTATIVAS INFLACIONÁ & & \\
\hline PERÍODO & $2 / 1967-1 / 1991$ & $1 / 1985-2 / 1999$ \\
\hline constante & $\begin{array}{c}0,0041 \\
(0,0026)\end{array}$ & $\begin{array}{l}-0,0005 \\
(0,0017)\end{array}$ \\
\hline$\left(\pi_{t}-E_{t-2}\left[\pi_{t}\right]\right)$ & $\frac{-0,3353}{(0,1938)}$ & $\frac{-0,6806 \#}{(0,2828)}$ \\
\hline teste de Wald - P-Value & 0,000 & 0,000 \\
\hline$(\mathrm{BT}+\mathrm{BT}(\mathrm{t}-1)) / 2$ & $\frac{-0,0092}{(0,0057)}$ & $\begin{array}{c}0,0016 \\
(0,0045)\end{array}$ \\
\hline preço real do petróleo (t) & $\begin{array}{c}0,0018 \\
(0,0056)\end{array}$ & $\begin{array}{l}(0,0002 \\
(0,0050)\end{array}$ \\
\hline preço real do petróleo (t-1) & $\begin{array}{l}-0,0021 \\
(0,0034)\end{array}$ & $\begin{array}{l}-0,0027 \\
(0,0029)\end{array}$ \\
\hline R2 ajustado & 0,14 & 0,49 \\
\hline DW & 1,98 & 2,11 \\
\hline teste de superident. - P. Value & 0,18 & 0,43 \\
\hline Jarque-Bera - P. Value & 0,78 & 0,74 \\
\hline Estabilidade - Wald - P.Value & - & 0,01 \\
\hline autocorr. - estat. Q (P-values): & & \\
\hline $\operatorname{lag} 1$ & 0,98 & 0,75 \\
\hline $\operatorname{lag} 2$ & 0,83 & 0,93 \\
\hline $\operatorname{lag} 3$ & 0,89 & 0,24 \\
\hline $\operatorname{lag} 4$ & 0,73 & 0,26 \\
\hline $\operatorname{lag} 5$ & 0,84 & 0,36 \\
\hline $\operatorname{lag} 6$ & 0,82 & 0,35 \\
\hline
\end{tabular}


(3) Números sublinhados em vermelho indicam coeficientes com sinal errado.

(4) \# indica coeficiente com sinal errado e significante ao nível crítico de $5 \%$ ou menos.

(5) Um asterisco indica coeficiente (quando não tem sinal errado) significante ao nível crítico de $10 \%$; dois asteriscos, significante à $5 \%$; três asteriscos, significância à $1 \%$.

\begin{tabular}{|c|c|c|c|c|}
\hline $\begin{array}{l}\text { TABELA } 21 \text { - ESTIMAÇÕES DA } \\
\text { SOMENTE BT COMO MEDIDA D } \\
\text { MÉTODO DE ESTIMAÇÃO - míni }\end{array}$ & $\begin{array}{l}\text { EQUAÇÃO (1 } \\
\text { E NÍVEL DE } \\
\text { mos quadrad }\end{array}$ & $\begin{array}{l}\text { 26) } \\
\text { TIVIDADE } \\
\text { de dois estágic }\end{array}$ & & \\
\hline VARIÁVEL DEPENDENTE: & $\pi_{t}-\left(E_{t-1}\left[\pi_{t+1}\right]+1\right.$ & $\left.t-2\left[\pi_{t}\right]\right) / 2$ & & \\
\hline PERÍODO & $2 / 1967$ & $1 / 1991$ & $1 / 1985$ & $2 / 1999$ \\
\hline EXPECT. INFLACIONÁRIAS & sem expurgo & com expurgo & sem expurgo & com expurgo \\
\hline constante & $\begin{array}{l}-0,0054^{*} \\
(0,0030)\end{array}$ & $\begin{array}{c}0,0008 \\
(0,0022)\end{array}$ & $\begin{array}{c}-0,0064^{* *} \\
(0,0023)\end{array}$ & $\begin{array}{l}-0,0018 \\
(0,0026)\end{array}$ \\
\hline$(\mathrm{BT}+\mathrm{BT}(\mathrm{t}-1)) / 2$ & $\frac{0,0119}{(0,0074)}$ & $\begin{array}{l}-0,0014 \\
(0,0052)\end{array}$ & $\frac{0,0053}{(0,0059)}$ & $\frac{0,0016}{(0,0066)}$ \\
\hline $\begin{array}{l}\text { preço real do petróleo (t) } \\
\text { preço real do petróleo (t-1) } \\
M A(1)\end{array}$ & $\begin{array}{c}0,0150^{* * *} \\
(0,0040) \\
0,0089^{* *} \\
(0,0042) \\
0,3648^{* *} \\
(0,1545)\end{array}$ & $\begin{array}{c}0,0136^{* * *} \\
(0,0030) \\
0,0052 \\
(0,0031)\end{array}$ & $\begin{array}{c}0,0090^{* * *} \\
(0,0028) \\
0,0083^{\star * *} \\
(0,0028) \\
0,9657^{\star * *} \\
(0,0250)\end{array}$ & $\begin{array}{c}0,0079^{* *} \\
(0,0030) \\
0,0075^{* *} \\
(0,0029) \\
0,9899^{* * *} \\
(0,0002)\end{array}$ \\
\hline $\begin{array}{l}\text { R2 ajustado } \\
\text { DW } \\
\text { teste de superident. - P. Value } \\
\text { Jarque-Bera - P. Value } \\
\text { autocorr. - estat. Q (P-values): } \\
\operatorname{lag} 1 \\
\operatorname{lag} 2 \\
\operatorname{lag} 3 \\
\operatorname{lag} 4 \\
\operatorname{lag} 5 \\
\operatorname{lag} 6\end{array}$ & $\begin{array}{c}- \\
0,81 \\
0,83 \\
0,38 \\
0,46 \\
0,56\end{array}$ & $\begin{array}{l}0,25 \\
0,48 \\
0,66 \\
0,49 \\
0,62 \\
0,74\end{array}$ & $\begin{array}{c}- \\
0,44 \\
0,12 \\
0,24 \\
0,38 \\
0,44\end{array}$ & $\begin{array}{l}- \\
0,30 \\
0,29 \\
0,47 \\
0,64 \\
0,75\end{array}$ \\
\hline $\begin{array}{l}\text { Obs.: } \\
\text { (1) Números entre parênteses s } \\
\text { (2) Os coeficiêntes de interesse }\end{array}$ & os $p$ & bustos. & & \\
\hline
\end{tabular}


com sinal errado.

(4) \# indica coeficiente com sinal errado e significante ao nível crítico de $5 \%$ ou menos.

(5) Um asterisco indica coeficiente (quando não tem sinal errado) significante ao nível crítico de $10 \%$; dois asteriscos, significante à $5 \%$; três asteriscos, significância à $1 \%$.

\section{E) CONCLUSÕES}

Os resultados obtidos nesta seção nos mostraram que o modo como os agentes formaram suas expectativas, durante os períodos analisados, não tem no modelo de Taylor com informação defasada uma boa aproximação. Fica colocada, então, a questão de quais as considerações que os agentes tiveram

por trás destas expectativas. Em outras palavras, para entender a inércia inflacionária e o custo das estabilizações, temos que obter um modelo que explique estas expectativas reais. Este objetivo será perseguido no próximo capítulo. 
CAPÍTULO 3

MODELOS COM INÉRCIA

INFLACIONÁRIA ANTECIPADA

E O CUSTO DAS

ESTABILIZAÇÕES NOS EUA 
No capítulo anterior verificamos que as expectativas dos agentes não são compatíveis com o modelo de Taylor, nem mesmo se adicionarmos a ele a hipótese de informação defasada. Como elas desempenham um fator preponderante dentro do modelo, esta rejeição implica na necessidade de outras hipóteses (que nos levam a novos modelos) para explicar a inércia inflacionária e o custo das estabilizações.

Este capítulo procura apontar alternativas teóricas para resolver este problema e confronta-las com os dados. Como os gráficos e estimações da seção 2.3 indicaram que boa parte da perda de produto associada às estabilizações foi antecipada pela maior parte dos agentes, os modelos que discutiremos neste capítulo tentarão explicar este ponto.

A primeira hipótese aventada, que já havia sido postulada por Roberts (1998), é a de um modelo com agentes heterogêneos com uma parcela da população formando suas expectativas de modo não consistente. Ela é exposta na seção 3.1 .

$\mathrm{Na}$ seção 3.2, trabalhamos com a idéia de que o custo das estabilizações decorre da prudência dos agentes, postulada em Simonsen 
(1986) e que recebeu um novo tratamento em Dow, Simonsen e Werlang (1993).

Em 3.3, desenvolvemos uma abordagem pautada na economia comportamental, que utiliza conceitos da psicologia social cognitiva, como aversão à perda, "fairness" e viés de julgamento a favor de si próprio (VJFSP).

Em 3.4 analisamos como diferenciar empiricamente os modelos e, finalmente, em 3.5 mostramos os resultados da confrontação com os dados.

Voltamos a observar que não contemplamos, no nosso trabalho, a tradicional hipótese de expectativas adaptativas. Isto se deve ao fato de que ela modela apenas o modo como são formadas as expectativas inflacionárias, se omitindo quanto à questão das expectativas relativamente ao nível de atividade, quando nossa análise foca justamente a relação entre ambas. 


\section{1 - AGENTES HETEROGÊNEOS E INÉRCIA INFLACIONÁRIA}

Roberts deu seguimento ao artigo de 1997 com um trabalho (Roberts (1998)) no qual procura desenhar como seria um modelo com expectativas imperfeitamente racionais e verificar se ele é capaz de gerar custos em estabilizações e inércia inflacionária compatíveis com os verificados nos dados. Ele analisa duas possibilidades: em uma delas, parte da população é racional e outra parte é ingênua, enquanto na outra as expectativas de cada agente são parcialmente racionais e parcialmente um mero reflexo da inflação passada. Esta segunda alternativa nos leva a algo similar ao modelo com informação defasada e agente representativo, que foi rejeitada pela seção 2.4. A outra, por outro lado, possibilita que os agentes mais bem informados antecipem o fato de que haverá uma recessão quando houver uma estabilização, pois eles sabem que a outra parcela dos agentes fixará seus preços em um nível acima do compatível com o equilíbrio (equilíbrio de Nash dada a política monetária). 
Deste modo, podemos ter a média das expectativas com uma correlação positiva entre as expectativas de variação da inflação e nível de atividade.

Vale a pena observar que apesar de Mankiw e Reis (2002) terem utilizado a hipótese de agente representativo quando fazem o tratamento formal, a idéia de informação que se propaga lentamente entre diferentes agentes é destacada no texto do artigo deles.

No modelo, parte dos agentes têm expectativas ingênuas e os outros têm expectativas racionais. Para desenvolve-lo, analizaremos em primeiro lugar o que ocorre no caso em que todos os agentes são ingênuos. Em um modelo com expectativas ingênuas, ou seja, quando as expectativas relativas às taxas de inflação futuras são uma mera extrapolação da inflação passada, temos:

$$
E_{t-1}^{N}\left[\pi_{t}\right]=E_{t-1}^{N}\left[\pi_{t+1}\right]=\pi b_{t}
$$

onde $\pi b_{t}$ é a última taxa de inflação conhecida, cobrindo o período que vai do início de t-1 até o início de t.

Expectativas ingênuas com relação ao nível de produto futuro podem também ser assumidas como extrapolação do que ocorreu no passado (de modo que poderíamos denominá-las também expectativas estáticas):

$$
E_{t-1}^{N}\left[y_{t}\right]=E^{N-1}\left[y_{t+1}\right]=y_{t-1}
$$


Em um modelo com reajustes justapostos temos, conforme derivação no capítulo 1:

$$
\begin{array}{r}
\pi_{t}=\left(E_{t-1}\left[\pi_{t+1}\right]+E_{t-2}\left[\pi_{t}\right]\right) / 2+(\beta / 2) \cdot\left(E_{t-1}\left[\left(y_{t}+y_{t+1}\right) / 2\right]+E_{t-2}\left[\left(y_{t-1}+y_{t}\right) / 2\right]\right) \\
+(1 / 2) \cdot\left(v_{t}+v_{t-1}\right)
\end{array}
$$

Assim, em um modelo com expectativas ingênuas teremos sempre:

$\pi_{\mathrm{t}}=\left(\left[\pi \mathrm{b}_{\mathrm{t}}\right]+\left[\pi \mathrm{b}_{\mathrm{t}-1}\right]\right) / 2+(\beta / 2) \cdot\left(\mathrm{y}_{\mathrm{t}-1}+\mathrm{y}_{\mathrm{t}-2}\right)+(1 / 2) \cdot\left(v_{\mathrm{t}}+v_{\mathrm{t}-1}\right)$

Enquanto $y_{t}$ será dado pela equação quantitativa já explicitada na seção 1.2:

$$
y_{t} \equiv m_{t}-p_{t}
$$

onde $\mathrm{m}_{\mathrm{t}}$ é o produto nominal, controlado pelo gestor de política econômica.

Com isto, em uma estabilização nós sempre teremos:

1) Expectativas prevendo inflação estável.

2) Os agentes esperando recessão a partir do segundo período da estabilização.

3) Deste modo, a partir do segundo período da estabilização a taxa de inflação começará a cair apesar de os agentes preverem inflação estável. 
Este caso é de pouco interesse porque as "surveys" nos mostram que parte da queda da taxa de inflação é antecipada pela média das expectativas dos agentes. Mas podemos obter este efeito se parte dos agentes tiver expectativas racionais ${ }^{34}$ e 0 restante deles tiver expectativas ingênuas. Conforme mostraram Haltiwanger e Waldman (1986, 1989), havendo complementariedade estratégica entre agentes racionais e ingênuos, o comportamento destes últimos terá um efeito mais do que proporcional à sua participação na população. Isto ocorre porque os agentes racionais antecipam o comportamento dos agentes ingênuos e o próprio efeito da complementariedade sobre os agentes racionais, o que faz com que o comportamento destes últimos se aproxime do dos agentes ingênuos.

Haltiwanger e Waldman (1986) mostram que em uma estabilização préanuncida e crível com apenas parte dos agentes sendo racional, teremos taxa de inflação caindo e recessão. Os agentes racionais (que, por definição, conhecem o modelo) anteciparão (parcialmente, caso não haja uso eficiente das informações) estes fatos em suas expectativas. Se eles corresponderem a uma parcela importante da população (como, por exemplo, 75\%, o percentual estimado por Roberts), a expectativa média da população será de estabilização com recessão.

Voltaremos a este modelo na seção 3.4 , onde daremos a ele um tratamento formal mais acabado.

\footnotetext{
${ }^{34}$ Depois dos comentários da seção (1.4), convém explicitar o conceito de expectativas racionais deste modelo. Seus agentes racionais utilizam um conjunto de informações não restrito apenas à inflação e produto do período anterior (o conjunto de informações utilizadas pelos agentes ingênuos) e têm expectativas consistentes (o que não é o caso dos agentes ingênuos, conforme o item 3 acima).
} 


\section{2 - INCERTEZA KNIGHTIANA E O CUSTO DAS ESTABILIZAÇÕES}

No nosso terceiro modelo de referência ${ }^{35}$, a inércia inflacionária decorre da incerteza que os agentes sentem quando ocorre uma política de estabilização. Ele se baseia nas idéias contidas em Simonsen (1986) e reelaboradas sob um novo arcabouço em Dow, Simonsen e Werlang (1993) (a partir de agora DSW).

Frank Knight (1921) definiu incerteza como uma situação na qual os agentes não têm uma distribuição de probabilidade a respeito de uma variável aleatória pautada em critérios objetivos. Em contraposição, ele chamou de risco o caso no qual os agentes têm certeza a respeito da distribuição das probabilidades. O exemplo clássico de incerteza knightiana é o da aposta em uma corrida de cavalos e o de risco knightiano é o da aposta em um dado não viciado. Alguns trabalhos, como Schmeidler $(1982,1989)$ e Gilboa (1987),

\footnotetext{
${ }^{35} \mathrm{O}$ primeiro foi o modelo de Taylor permitindo a possibilidade de informação defasada e o segundo o modelo com agentes heterogêneos.
} 
modelaram o comportamento diante da incerteza knightiana como sendo mais prudente do que o diante de risco. Esta prudência foi modelada fazendo com que a escolha, pelo critério de maximização da utilidade esperada, se paute não apenas na probabilidade (subjetivamente avaliada) de cada estado da natureza e no valor de cada estratégia em cada um destes estados, mas também se dando um peso adicional a probabilidades de estados considerados ruins.

Feito este preâmbulo, faremos, no item A abaixo, a derivação do modelo de DSW (1993) ${ }^{36}$. No item B discutiremos, então, a plausibilidade das hipóteses inerentes ao modelo.

\section{A) O MODELO DE DSW}

Assume-se uma economia com um continuum de bens não armazenáveis, cada um produzido por um indivíduo que determina seu preço. Os preços são fixados simultaneamente, com cada agente ignorando a escolha do outro, e permanecem fixos durante um determinado período. Assume-se também um governo que controla o produto nominal, denominado $\mathrm{R}$, que é préanunciado com credibilidade total e irrepreensível.

Cada indivíduo é indicado por um número real $x \in[0,1]$, sendo o preço do bem produzido por este indivíduo denominado $P_{x}$. Assumimos, então o nível geral de preços dado por um agregador não atômico de preços dado por:

\footnotetext{
${ }^{36}$ Este item não tem pretensão de originalidade e reproduz algumas passagens literais do artigo citado.
} 


$$
P=g\left(\int_{[0,1]} z\left(x, P_{x}\right) d x\right)
$$

com (3.4) sendo uma função crescente para o preço de cada um dos bens e homogênea de grau um.

A função utilidade de cada indivíduo é

$$
U_{x}=U_{x}\left(P_{x}, P, R\right)
$$

que é homogênea de grau zero em $\left(P_{x}, P, R\right)$ e decrescente em $P$. Observamos que a hipótese de agentes não atômicos em (3.4) implica que o peso de $\mathrm{P}_{\mathrm{x}}$ no nível geral de preços é zero, de modo que cada um faz sua maximização de $U_{x}\left(P_{x}, P, R\right)$ mantendo tanto $P$ quanto $R$ constantes.

Supomos, então, que para cada par $(P, R)$, há um único $P_{x}$ que maximiza a utilidade de $\mathrm{x}$, dado por:

$$
P_{x}=f_{x}(P, R)
$$

Sendo (3.6) uma função contínua, real, homogênea de grau um e crescente nas duas variáveis., com $f_{x}(P, 0)=0$ e $f_{x}(P, \infty)=\infty$.

Em um contexto no qual não se leva a incerteza knightiana em conta, a solução do modelo é obtida do seguinte modo:

As hipóteses acima implicam que a função: 
$h(P, R)=g\left(\int_{[0,1]} z\left(x, f_{x}(P, R)\right) d x\right)$

É contínua, homogênea de grau um, crescente nas duas variáveis e que para qualquer $P>0$ temos $h(P, 0)=0$ e $h(P, \infty)=\infty$. Isto implica que, para qualquer $\mathrm{P}$ positivo existe um único $\mathrm{R}$ positivo tal que:

$P=h(P, R)$

Como $h(P, R)$ é homogêneo de grau um, esta equação é resolvida por $R$ $=\mathrm{P} / \beta$, onde $\beta$ é uma constante positiva. $\mathrm{O}$ equilíbrio de Nash deste jogo é único e é obtido com todos os agentes se comportando de acordo com a equação (3.6) e tomando P como a solução da equação (3.8). Esta solução existe e é única:

$$
P=\beta R
$$

O equilíbrio apresenta as propriedades usuais que se obtêm em modelos com expectativas racionais: o produto real $Y=R / P$ independe da oferta monetária (ou seja, a moeda é neutra) e $\mathrm{P}$ não depende de seus valores passados.

Analisaremos, agora, a solução do modelo levando-se em conta a incerteza knightiana. Para isto, devemos primeiro explicar como é feita a 
escolha dos agentes quando trabalhamos com probabilidades subjetivas não aditivas (Schmeidler (1982, 1989) e Gilboa (1987)) e explicitar a definição de equilíbrio de Nash sob incerteza, dada por Dow e Werlang (1994).

O procedimento tradicional para se lidar com incerteza em economia é o postulado por Savage (1954), que reduz todos os problemas relacionados com ela ao mesmo tratamento dado ao risco. Ou seja, utiliza-se o mesmo procedimento para lidar com probabilidades objetivas e subjetivas.

O modelo Schmeidler-Gilboa introduz uma importante modificação ao admitir a maximização da utilidade esperada com uma distribuição de probabilidades não aditivas dos estados da natureza. Probabilidades não aditivas, refletindo a aversão à incerteza, satisfazem a condição:

$$
\mathbf{P}(\mathrm{A})+\mathbf{P}(\mathrm{B}) \leq \mathbf{P}(\mathrm{A} \cup \mathrm{B})+\mathbf{P}(\mathrm{A} \cap \mathrm{B})
$$

Onde $\mathbf{P}(A)$ significa a probabilidade subjetiva de que ocorra o evento $A$. Em particular, $\mathbf{P}(A)+\mathbf{P}\left(A^{C}\right)$ pode ser menor do que 1. Ou seja a soma da probabilidade subjetiva de cada um dos eventos tidos como possíveis pode ser menor do que 1. A diferença pode ser interpretada como uma medida da aversão à incerteza do agente com relação ao evento A. Chamando esta medida de coeficiente de aversão à incerteza e a representado por c, temos:

$$
c(\mathbf{P}, A)=1-\left(\mathbf{P}(A)+\mathbf{P}\left(A^{C}\right)\right.
$$


É necessário, então, modelar como é feita a escolha sob incerteza knightiana. Assumindo-se aversão à incerteza constante (ou seja, c é o mesmo para todo A), um modo de se fazer isto é o de que o valor esperado sob incerteza de uma variável aleatória positiva $X$ seja dado por:

$$
\operatorname{Ep}(X)=c \cdot \min X+(1-c) \cdot \mathrm{E}_{\mathrm{Q}}(X)
$$

onde $\mathrm{E}_{Q}(X)$ corresponde à soma do valor esperado de $X$ em cada estado da natureza que o agente acredita que pode ocorrer, vezes a probabilidade aditiva deste respectivo estado da natureza ocorrer. O termo min $X$ é igual ao valor esperado de $X$ no pior estado da natureza cogitado pelo agente.

A definição de equilíbrio de Nash sob incerteza é, então, dada por:

DEFINIÇÃO: "Dizemos que um par $\left(\boldsymbol{P}_{1}, \boldsymbol{P}_{2}\right)$ de probabilidades subaditivas $\boldsymbol{P}_{1}$ sobre $A_{1}$ e $\boldsymbol{P}_{2}$ sobre $A_{2}$ é um equilíbrio de Nash sob incerteza se existe um suporte de $\boldsymbol{P}_{1}$ e um suporte de $\boldsymbol{P}_{2}$ tal que:

(i) para todo a $a_{1}$ no suporte de $\boldsymbol{P}_{1}$, a $a_{1}$ maximiza a utilidade esperada do jogador 1 dado que ele acredita que a estratégia do jogador 2 é $\boldsymbol{P}_{2}$, e concomitantemente;

(ii) para todo $a_{2}$ do suporte de $\boldsymbol{P}_{2}, a_{2}$ maximiza a utilidade esperada do jogador 2 dado que ele acredita que a estratégia do jogador 1 é $\boldsymbol{P}_{1}$.

Onde o suporte de uma probabilidade não aditiva $\mathbf{P}$ é um evento $A$ tal que $P\left(A^{C}\right)=0$ e $P\left(B^{C}\right)>0$ para todo evento $B \neq A$ com $A \supset B$. 
Ou seja, o conceito de equilíbrio de Nash sob incerteza descreve a escolha da estratégia ótima com base em expectativas que levam em conta que os agentes são avessos à incerteza.

Dadas estas definições, podemos considerar o que ocorre no jogo com incerteza. Assume-se que a economia parte de uma situação com inflação alta (ou moderadamente alta) e estável, igual à taxa de crescimento de $\mathrm{R}$ que tem sido mantida constante há muito tempo. Em um dado momento o governo anuncia, com plena credibilidade, que mudará a política monetária e que $R$ ficará constante. Assumimos, então, que os agentes não têm certeza a respeito de qual será a taxa de inflação, mas que acreditam que ela não subirá - ou seja, provavelmente ela cairá e, na pior das hipóteses ela ficará estável. Na nossa notação, este último caso será identificado como $\mathrm{P}=\mathrm{P}_{\max }$.

Lembramos, então, que a utilidade dos agentes é dada por $U_{x}=U_{x}\left(P_{x}, P, R\right)$, que é homogênea de grau zero em $P_{x}$ e R. Sendo assim, o pior estado da natureza possível é aquele no qual $P=P_{\max }$. Sendo assim, $O$ valor esperado sob incerteza (equivalente à utilidade esperada no caso aditivo) do agente representativo, a ser maximizado, será igual a:

$$
V_{x}\left(P_{x}, P, P_{\max }, R\right)=(1-c) \cdot U_{x}\left(P_{x}, P, R\right)+c \cdot U_{x}\left(P_{x}, P_{\max }, R\right)
$$

Onde $U_{x}$ é igual à utilidade esperada com probabilidades aditivas. Dadas as hipóteses a respeito das equações do modelo, $V_{x}()$ terá seu valor máximo obtido com um $P_{x}$ dentro do intervalo aberto $] f_{x}(P, R), f_{x}\left(P_{\max }, R\right)[$. Ou 
seja, ao levar em conta a incerteza knightiana, os agentes escolherão preços mais elevados do que ocorreria no caso sem incerteza, porém menores do que no caso com $\mathrm{P}_{\max }$ associado ao $\mathrm{R}$ da nova política monetária.

Para demonstrar isso, suponha que há uma seleção contínua de funções que associam para cada $\left(P x, P, P_{\max }, R\right)$ o valor de $P_{x}$ que maximiza $V_{x}(P x, P$, $\left.P_{\max }, R\right)$. Chame esta função $\phi_{x}\left(P x, P, P_{\max }, R\right)$. A solução é homogênea de grau um nas três variáveis e crescente em cada uma delas. Além disto, para $\mathrm{P}$ $<\mathrm{P}_{\max }$, e para todo $\mathrm{x}$ :

$$
f_{x}(P, R)<\phi_{x}\left(P x, P, P_{\max }, R\right)<f_{x}\left(P_{\max }, R\right)
$$

O equilíbrio de Nash sob incerteza deste modelo (jogo) deve, então, ser a solução da equação:

$$
P=\theta\left(P, P_{\max }, R\right)
$$

Onde

$$
\theta\left(P, P_{\max }, R\right)=g\left(\int_{[0,1]} z\left(x, \phi_{x}\left(P x, P, P_{\max }, R\right)\right) d x\right)
$$

A função $\theta\left(P, P_{\max }, R\right)$ é homogênea de grau um em todas as suas variáveis, contínua, e crescente em cada variável. Combinando (3.7), (3.11) e (3.13), obtemos que para $P<P_{\max }$, e para todo $x$ :

$$
h(P, R)<\theta\left(P, P_{\max }, R\right)<h\left(P_{\max }, R\right)
$$


O que, assumindo-se $\beta R<P_{\max }$, resulta:

$$
\mathrm{P}=\mathrm{T}\left(\mathrm{P}_{\max }, \mathrm{R}\right) \quad, \quad \text { com } \quad \beta R<\mathrm{T}\left(\mathrm{P}_{\max }, \mathrm{R}\right)<\mathrm{P}_{\max }
$$

\section{Conseqüência 1:}

Não neutralidade da moeda antecipada pelos agentes, pois

$$
Y=R / P=R / T\left(P_{\max }, R\right)=1 / T\left(P_{\max } / R, 1\right)
$$

A neutralidade prevalece no longo prazo porque $P_{\max }$ vai se ajustando na direção de $\beta R$.

\section{Conseqüência 2:}

A taxa de inflação corrente depende da inflação passada, pois $P$ depende de $\mathrm{P}_{\max }$, igual ao nível de preços do período anterior corrigido pela inflação passada.

\section{B) AVALIAÇÃO DAS HIPÓTESES SUBJACENTES}

\section{AO MODELO DSW}

O modelo DSW tem três hipóteses-chaves:

DSW-1) Diante de uma situação de incerteza knightiana os agentes têm uma atitude prudente ou pessimista, que os leva a dar, em suas expectativas, 
um peso para o pior evento possível maior do que o ditado simplesmente por suas expectativas subjetivas.

DSW-2) (Dados os preços relativos) Os estados da natureza são ordenados de acordo com a taxa de inflação. Se ela for alta, teremos um estado da natureza ruim e se ela for baixa teremos um estado bom.

DSW-3) Há mais incerteza (relativamente à evolução da taxa de inflação) na situação de estabilização do que na situação anterior a ela.

A primeira hipótese é a mais complexa e merecerá uma discussão mais aprofundada. Do ponto de vista formal, o uso de probabilidades sub-aditivas tem obtido o respaldo de alguns novos trabalhos ${ }^{37}$ e tem se estendido a outros aspectos da escolha com risco ${ }^{38}$. Mas $(\mathrm{DSW}-1)$ diz respeito a uma modalidade específica de sub-aditividade que corresponde a uma hipótese sobre o comportamento dos agentes. Por isto, adotaremos a perspectiva da economia comportamental para discuti-la. A economia comportamental é uma agenda que tem estudado vários padrões de desvio do comportamento real dos indivíduos frente aos postulados no corpo tradicional da teoria econômica (no "mainstream") ${ }^{39}$. A maior parte de seus trabalhos é empírica mas ela tem seus fundamentos teóricos pautados na psicologia social cognitiva, que é "mainstream" em psicologia social.

A hipótese de aversão à incerteza knightiana remonta a trabalhos de Knight (1921) e Keynes (1921) e a pedra fundamental sobre qual a literatura

\footnotetext{
${ }^{37}$ Ver, por exemplo, Marinacci (1999).

${ }^{38}$ Como no caso das "chance attitudes" que fazem parte da "prospect theory" da economia comportamental. Ver, por exemplo, Prelec (1998).

${ }^{39}$ Ver Rabin $(1996,1998)$. A versão de 1996 é mais detalhada.
} 
mais recente sobre ela se ergueu é dada pelo chamado "paradoxo de Elsberg" ${ }^{40}$.

Elsberg (1961) fez alguns experimentos, nos quais foi mostrado que as pessoas preferiam loterias com probabilidades conhecidas do que não conhecidas. No experimento mais simples ${ }^{41}$, há duas urnas com 100 bolas cada uma. Na urna 1, há 50 bolas pretas e 50 vermelhas, enquanto na urna 2 também há apenas bolas pretas e vermelhas, mas em proporções desconhecidas. O experimento revelou, então, que as pessoas são indiferentes entre apostar em preto versus vermelho em ambas as urnas, mas preferem fazer apostas sobre a urna 1 do que sobre a urna 2. Em função deste tipo de comportamento, Elsberg argumentou, seguindo a mesma linha de Knight (1921) e Keynes, que o modo de agir das pessoas diante de incerteza depende não apenas da probabilidade percebida sobre o evento em questão, mas também da sua ambigüidade. Esta, foi caracterizada por Elsberg como "uma qualidade que depende do montante, tipo e 'unanimidade' da informação" e que esta determina "o grau de confiança na verosimilhança relativa de uma estimativa".

A utilização do paradoxo de Elsberg como justificativa para modelos nos quais os agentes têm uma atitude pessimista ou excessivamente prudente conta, no momento, com evidências contraditórias. Por um lado Heath e Tversky (1990) e Fox e Tversky (1995) obtiveram resultados contrários à ela. Por outro, os experimetos de Chow e Sarin (2001) Ihe foram favoráveis.

\footnotetext{
${ }^{40}$ Nesta análise do "paradoxo de Elsberg" e do comportamento diante de incerteza, seguiremos, sem pretensão de originalidade, Fox e Tversky (1995). Algumas passagens são cópias literais.

${ }^{41}$ Este problema já havia sido discutido por Keynes (1921).
} 
Para transmitir uma idéia de como este debate está sendo travado, relataremos um dos experimentos conduzidos por Fox e Tversky (1995). Neste experimento os sujeitos que dele participaram foram divididos em dois grupos. Para o primeiro grupo, os sujeitos deveriam dizer qual o valor máximo que eles pagariam por duas loterias: a primeira seria dada pela adivinhação da cor de uma bola retirada da urna 1 do experimento de Elsberg e a outra por uma adivinhação similar na urna 2. Em qualquer um dos casos, eles receberiam US $\$ 100,00$ se acertassem. A média obtida para a primeira loteria foi US $\$ 24,34$ (desvio padrão =2,21 e $N=67$ ) e para a segunda foi US\$14,85 (desvio padrão = 1,80 e $N=67$ ). Para o segundo grupo, era oferecida, para ser valorada, apenas uma das loterias, sem que fosse sugerido qualquer tipo de comparação com outra loteria. Neste caso, os que opinaram sobre a urna 1 ofereceram, em média, US\$17,94 (desvio padrão = 2,50 e $\mathrm{N}=35$ ), enquanto a urna 2 obteve US $\$ 18,42$ (desvio padrão = 2,87 e N = 39). A diferença entre os valores médios atribuídos a cada urna foi significante no cenário comparativo $(t(66)=6,00, p<$ 0,001) mas foi claramente não significante no cenário não comparativo $(\mathrm{t}(72)=$ $-0,12)$.

Em função deste e outros experimentos, Fox e Tversky concluíram que o paradoxo de Elsberg parece ser em grande medida um fenômeno comparativo, com a resposta ao problema sendo induzida pelo modo como ele é formulado (em linguagem da economia comportamental, a resposta depende da moldura - "framing" - da pergunta).

Os experimento feitos por Chow e Sarin (2001) apontaram, no entanto, para uma direção intermediária, mas suficiente para defender a hipótese de aversão à ambigüidade. - a de que a comparatividade explica parte dos 
resultados de Elsberg mas que a aversão à ambigüidade permanece significante mesmo quando se controla para a comparatividade. É importante notar que este resultado foi obtido mesmo quando se replicou um dos experimentos de Fox e Tversky (1995). Deste modo, Chow e Sarin (2001) concluíram que os resultados de Fox e Tversky (1995) não foram robustos.

Variações nos três artigos incluíram o uso de incentivos monetários (porém de baixo valor) e adivinhações sobre problemas dos quais as pessoas têm pouco conhecimento versus problemas que lhe são familiares (como, pedestres que caminhavam em Berkeley opinarem sobre o clima em São Francisco versus o clima em Istambul). Um único resultado que parece totalmente robusto diz respeito à escolha quando as pessoas se julgam ótimas conhecedoras de um assunto. Neste caso, o contexto comparativo leva a uma preferência por loterias com ambigüidade relacionadas com este assunto em relação a loterias sem ambigüidade de assuntos que lhes são indiferentes (mesmo que em ambas as loterias tenhamos apenas dois estados da natureza possíveis com $50 \%$ de chance cada um).

Dado o debate como ainda não concluído, trabalhos recentes da teoria da escolha $^{42}$ tem deixado aberta a possibilidade de diferenças de comportamento frente à incerteza versus risco, não se descartando a possibilidade de o primeiro caso apresentar discrepâncias mais acentuadas frente à teoria da utilidade esperada tradicional do que o segundo.

Em função da discussão acima, concluímos que o debate empírico sobre a hipótese (DSW-1) encontra certo suporte, ainda que não se tenha chegado a um veredito.

\footnotetext{
${ }^{42}$ Ver, por exemplo, Tversky e Wakker (1995), Prelec (1998) e Wakker (2001).
} 
Passemos, então, à hipótese (DSW-2) - Dados os preços relativos, os estados da natureza são ordenados de acordo com a taxa de inflação.

Esta hipótese é diferente do que geralmente se assume em economia que há outras variáveis macroeconômicas, além da taxa de inflação, que determinam o bem estar dos indivíduos. O mais usual é se assumir que a função de bem-estar social depende de duas variáveis macroeconômicas: a taxa de inflação e o nível de atividade (ou de emprego) ${ }^{43}$. Blanchard e Fischer (1989) argumentam, inclusive, que "a caracterização padrão da função objetivo dos gestores de política econômica põe mais peso nos custos da inflação do que é sugerido pela compreensão dos efeitos da inflação".

Por outro lado, pode-se alegar que em uma estabilização, taxa de inflação alta e desemprego elevado andam juntos. Quanto a este uso de (DSW-2) como hipótese simplificadora, ressalvamos que:

1) Este argumento não apareceu no modelo.

2) Isto não é exato para uma estabilização gradualista (pois a meta inflacionária é cadente ao longo dos períodos da estabilização, o que faz com que uma determinada taxa de inflação X\% gere níveis diferentes de desemprego em cada período).

3) Há correlação entre a taxa de inflação e o desemprego ou entre a primeira diferença da taxa de inflação e o desemprego?

4) A incerteza está presente, em níveis variados, não só em situações de estabilização. Como fica, então, a correlação entre desemprego e inflação quando esta está subindo? A última ressalva (a de número 4) levantada

\footnotetext{
${ }^{43}$ Ver Blanchard e Fischer (1989).
} 
relativamente à (DSW-2) nos leva diretamente à terceira e última hipótese que analisaremos (DSW-3)

Deste modo, avaliamos que a ordenação dos estados da natureza exclusivamente em função da taxa de inflação é uma simplificação que tem como principal ressalva nosso próximo ponto a ser analisado.

Finalmente, temos (DSW-3) - há mais incerteza (relativamente à evolução da taxa de inflação) em uma situação de estabilização do que na situação anterior a ela.

Ainda que exista consenso, obtido através de vários estudos empíricos e modelos teóricos ${ }^{44}$, correlacionando positivamente incerteza (quanto a preços relativos) e inflação elevada, a comparação entre os estados pré e durante estabilização depende de uma série de fatores. No contexto de estabilizações elevadas sem políticas de renda ou âncora cambial, a validade desta proposição não deve gerar contestação. Quando Simonsen (1986) escreveu seu trabalho, o problema que ele tinha em mente era exatamente este - o trabalho procurava justificar $o$ uso de políticas de renda diante de estabilizações de inflação elevada. Para o contexto do presente trabalho, no entanto, a utilização da hipótese pode não ser tão livre de crítica. $\mathrm{O}$ assunto poderia ser objeto de um estudo empírico próprio, mas, para sermos breves, utilizaremos como argumento apenas o que nos é mostrado no gráfico da figura 1 (pág. 67). Nele podemos ver que não tivemos, nos EUA, uma taxa de inflação alta estável. O período de inflação alta dos EUA foi caracterizado por

\footnotetext{
${ }^{44}$ Ver, por exemplo, Logue e Willet (1976) entre os estudos empíricos e Benabou (1989) entre os teóricos.
} 
alta volatilidade inflacionária. Boa parte desta volatilidade foi antecipada pelos agentes. Além disto, a figura 14 nos mostra que as previsões dos agentes a respeito das quedas na taxa de inflação (ou seja, das estabilizações) apresentaram um índice de acerto muito mais elevado do que as previsões de quando a inflação estava subindo. Ou seja, o cenário de inflação em alta pode ser visto como com incerteza maior ou pelo menos igual ao de inflação em queda.

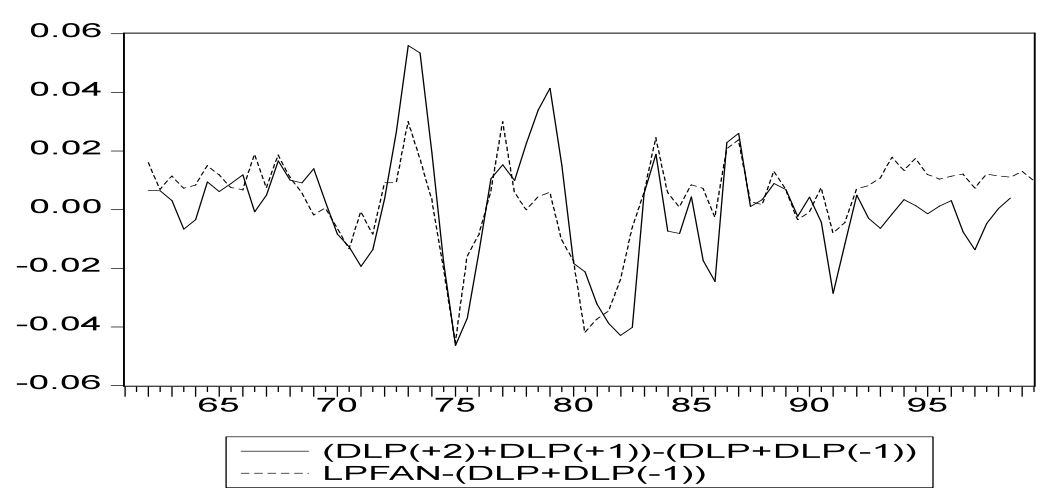

Fig. 13 - taxa de inflação dos próximos 12 meses menos a dos 12 meses passados (linha contínua) e previsão da taxa de inflação para os próximos 12 meses menos a taxa de inflação dos 12 meses passados (linha tracejada).

Deste modo, concluímos que a utilização da hipótese (DSW-3) dentro do contexto do presente trabalho necessita, no mínimo, de um estudo mais aprofundado que a corrobore. 


\section{3 - UMA ABORDAGEM COMPORTAMENTAL COM MERCADO DE TRABALHO}

Uma outra alternativa para explicar a antecipação do custo das estabilizações pelos agentes é obtida utilizando-se a abordagem da economia comportamental. Esta abordagem se pauta no corpo teórico da psicologia social cognitiva (PSC) que fornece certos padrões de comportamento estilizados que são fortemente corroborados por evidências empíricas.

Os padrões que utilizaremos redundam nas hipóteses de preferências que são pautadas em referências, o que gera aversão à perda, e levando em conta reciprocidade com julgamento viesado em favor de si próprio. Observamos que as evidências empíricas favoráveis a estas hipóteses são extremamente robustas e têm sido usadas diante dos mais variados contextos. Deste modo, não cabe a crítica de que seriam "ad hoc"

No nosso contexto específico, postulamos, então, que os reajustes salariais que implicariam uma estabilização sem custos são considerados injustos ("unfair") pelos empregados das empresas.

\footnotetext{
${ }^{45}$ Ver Rabin (2002). A assimilação crescente desta linha de abordagem foi coroada, recentemente, com o prêmio Nobel 2002 de economia dado a D.Kahneman e com a menção, no anúncio da premiação, do falecido A. Tversky.
} 
Nos itens A e B explicitaremos as hipóteses oriundas da PSC e relataremos algumas de suas evidências empíricas. Depois disto examinaremos, no item $\mathrm{C}$, a possível conexão entre estes conceitos e a antecipação do custo das estabilizações, através da hipótese mencionada no parágrafo anterior.

\section{A) REFERÊNCIAS E A AVERSÃo À PERDA}

A noção de que o comportamento dos agentes é indissociável de suas referências é central na PSC, e conta com sólidas evidências empíricas.

Um exemplo de evidência empírica favorável à importância das referências na determinação das preferências dos agentes é encontrado em Tversky e Kahneman (1991). Eles realizam um experimento no qual dividem um grupo de estudantes em duas partes. Para ambas, pede-se para imaginar que estão terminando um estágio profissional de meio período e que devem decidir agora qual é o próximo trabalho (também de meio período) que preferem. Para a primeira turma, pede-se para imaginar que se leva 10 minutos para chegar ao local de trabalho atual e que sua atividade implica um grau elevado de isolamento de contato social. Para a outra turma, pede-se para imaginar que o trabalho atual implica uma interação social muito satisfatória, mas que se leva 80 minutos para chegar ao local de trabalho. As pessoas de ambas as turmas deveriam escolher uma destas duas opções profissionais como próximo estágio: 
Trabalho $X$ : pequena interação social e 20 minutos para chegar ao local de trabalho.

Trabalho $\mathrm{Y}$ : sociabilidade moderada e 60 minutos para chegar ao local de trabalho.

O resultado foi que o trabalho $\mathrm{X}$ foi escolhido por $70 \%$ da primeira turma mas apenas por $33 \%$ da segunda turma (amostra=106 alunos , p-value $<0,01)$. Ou seja, a escolha do próximo trabalho foi influenciada pela referência dada pelo "status quo" (vivido na imaginação).

É interessante notar que a hipótese de preferências pautadas em referências não é incompatível com a hipótese de otimização por parte dos agentes e já foi utilizada por vários economistas ${ }^{46}$. Este ponto se aplica diretamente à macroeconomia, que admite a hipótese de que salários relativos importam. Temos aí claramente um caso no qual referências influem nas preferências dos indivíduos.

Um conceito que está diretamente ligado ao de preferências pautadas em referências é o de aversão à perda ("loss aversion"). A existência de aversão à perda implica que os agentes avaliam ganhos versus perdas, relativamente às suas referências, de modo assimétrico. A aversão à perda tem sido utilizada para explicar importantes paradoxos ("puzzles") econômicos, como o excessivo prêmio de risco do mercado de ações ${ }^{47}$ e a assimetria no comportamento do consumo frente a boas e más notícias ${ }^{48}$.

\footnotetext{
${ }^{46}$ Ver Rabin (1998).

${ }^{47}$ Ver Benartzi e Thaler (1995).

${ }^{48}$ Ver Shea (1995) e Bowman, Minehart e Rabin (1999).
} 
A regra de bolso (com base em diversos experimentos) é de que as perdas têm um peso equivalente à pelo menos duas vezes o dos ganhos. Este é um dos motivos ${ }^{49}$ pelos quais a maior parte das pessoas não se dispõe a pagar $\mathrm{R} \$ 50,00$ para uma loteria na qual há $50 \%$ de chance de se ganhar $\mathrm{R} \$ 150,00$ e $50 \%$ de chance não se ganhar nem perder nada. Agentes racionais deviam ser risco-neutros para loterias que não têm impacto significativo sobre sua riqueza, o que implica que o valor esperado da loteria é $\mathrm{R} \$ 75,00$. Usando a regra de bolso de que a perda tem pelo menos o dobro do valor do ganho, porém, a maior parte das pessoas só tenderia a pagar $\mathrm{R} \$ 50,00$ caso o prêmio da loteria com $50 \%$ de chance fosse acima de $R \$ 200,00^{50}$.

Os experimentos de laboratório têm mostrado que a aversão à perda não depende de haver ou não risco ou incerteza. Isto foi mostrado nos experimentos de Kaneman, Knetsch e Thaler (1990), onde pessoas que ganharam um objeto (caneca, caneta ou barra de chocolate) pedem (em média), para abrir mão deste, o dobro ou mais do que outras pessoas estariam dispostas a pagar por este objeto. Ou seja, perder o objeto parece valer duas vezes mais do que ganhá-lo (para pessoas escolhidas aleatoriamente). Estes resultados foram robustos a diversas variações que controlaram, para explicações alternativas à aversão à perda.

\footnotetext{
${ }^{49}$ Os outros motivos são:

- "chance attitudes", que fazem com que as pessoas subvalorizem uma probabilidade de ganho para a probabilidade $50 \%$ mas supervalorizem (ou seja paguem mais por cada ponto percentual de chance) uma probabilidade de ganho pequena (como $1 \%$ ou $5 \%$ ).

- Miopia, ou seja as pessoas analisam o problema de modo isolado, e não no contexto intertemporal.

Para uma descrição do modelo de escolha mais difundido da economia comportamental (Chamado de "prospect theory") ver Tversky e Kahneman (1992). Para comparar esta opção com outras, ver Camerer (1995).

${ }^{50}$ Conforme a nota anterior, no entanto, para uma loteria com probabilidade de ganho baixa, as pessoas costumam estar dispostas a pagar mais do que o compatível com uma função utilidade risco-neutra.
} 
Os experimentos mostraram também que há algo como "rendimentos decrescentes" na sensibilidade à perda e ao ganho ${ }^{51}$. Isto implica uma função de valoração de ganhos e perdas dada por algo como:

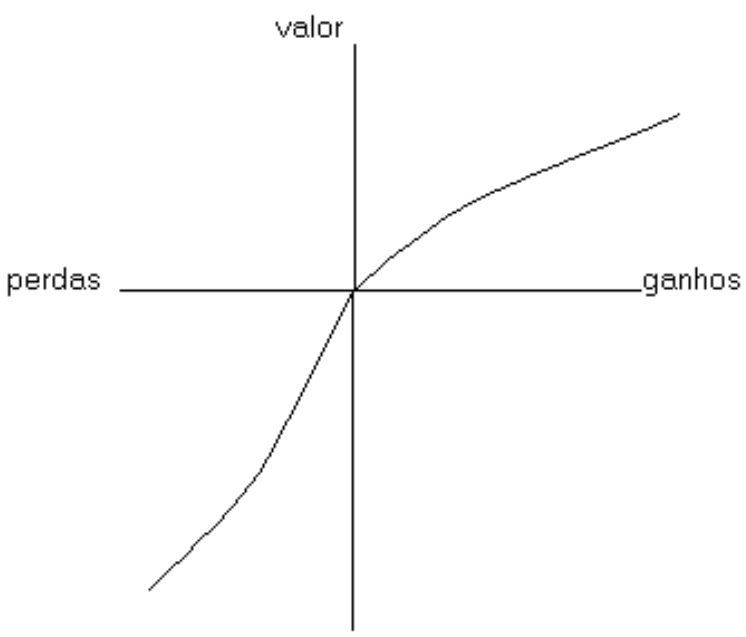

Fig. 14 - Função Valor

Este tipo de função valor implica que as pessoas tendem a ser avessas ao risco para ganhos e propensas ao risco ("risk-seeking") para perdas. Em função disso, as partes envolvidas em uma negociação tendem a adotar estratégias mais arriscadas quando (subjetivamente) avaliam que estão negociando perdas do que quando estão negociando ganhos ${ }^{52}$.

\footnotetext{
${ }^{51}$ Ver Kahneman e Tversky (1979) e Tversky e Kahneman (1991).

${ }^{52}$ Ver Neale e Bazerman (1985), por exemplo.
} 


\section{B) RECIPROCIDADE E O VIÉS DE JULGAMENTO EM FAVOR DE SI PRÓPRIO (VJFSP)}

Como disse Rabin (1996), "virtualmente todo pesquisador que examinou comportamento em experimentos tem concluído que as preferências se diferenciam do auto-interesse puro de modo não trivial". Uma das modalidades de desvio do auto-interesse puro que tem sido mais estudada é a atitude chamada de reciprocidade, associada à noção de "fairness".

A importância de "fairness" e reciprocidade está solidamente estabelecida na PSC e sua utilização dentro do contexto de relações econômicas é corroborada por um número enorme de trabalhos, feitos principalmente após o clássico Kaneman, Knetsch e Thaler (1986). Em função desse elevado volume de trabalhos, reservamos o apêndice B para um resumo da literatura. Observamos que, conforme se pode verificar nas referências deste apêndice, grande parte desses trabalhos foi publicada nos periódicos mais importantes de economia.

A idéia de reciprocidade tem uma forte analogia com a estratégia "tit for tat" de jogos dinâmicos, mas tem também diferenças com relação a esta. Ela postula que, se um agente for bem tratado ou tratado com generosidade, será esperada uma retibuição e ele tenderá a dá-la; mas se seu interagente lhe faz algo em seu prejuízo que fuja aos parâmetros do que ele considera razoável (justo ou "fair"), ele tencionará uma retaliação. Não se deixa de considerar, no entanto, que a retribuição, a falta desta e a retaliação têm todas um custo. $O$ 
que o agente faz, então, é pesar os dois lados da moeda, predisposição e custo, ao escolher o que fazer. Diferentemente de uma estratégia "tit for tat", no entanto, a retribuição ou retaliação pode ocorrer mesmo que não haja jogo dinâmico pela frente - uma pessoa viajando por um lugar que nunca mais voltará não deixa de dar gorjetas esperadas e merecidas a um garçom. Ao menos em parte, isto pode ser atribuído à reciprocidade também fazer parte das preferências dos agentes.

É verdade que existem mercados nos quais o preço resultante da interação entre oferta e demanda é considerado o próprio preço justo ("fair"). Isto ocorre, por exemplo, nos mercados de "commodites". Okun (1981) postulou, no entanto, a hipótese de que isto não ocorre nos mercados nos quais há relações de clientela e no mercado de trabalho. E Akerlof (1982) e Akerlof e Yellen (1990) desenvolveram modelos de salário-eficiente relacionados com "fairness".

Mas no que diz respeito à reciprocidade, o que interessa é a avaliação subjetiva dos agentes a respeito do que é "fair", e não uma análise ética sofisticada de um terceiro não envolvido.

Um grande número de estudos, como Kahneman, Knetsch e Thaler (1986), mostram que a avaliação dos indivíduos a respeito do que é "fair" geralmente se pauta em critérios heurísticos que não são racionais do ponto de vista dos economistas. A robustez deste resultado diante de graus elevados de motivação tem sido objeto de controvérsia, mas um artigo relativamente recente no mais importante periódico de $\mathrm{PSC}^{53}$ mostrou evidências corroborando uma hipótese que concilia as contradições que apareciam no

\footnotetext{
${ }^{53}$ Pelhan e Neter (1995).
} 
confronto de trabalhos anteriores. Segundo este trabalho, o efeito da motivação sobre a qualidade de um julgamento depende da dificuldade deste julgamento. Assim, para uma questão complexa, as pessoas tendem a recorrer a uma regra heurística ("não racional") para fazer uma avaliação, mesmo que haja fortes incentivos em jogo. Este trabalho mostra que uma maior motivação tende, na verdade, a gerar uma maior propensão a se adotar uma regra heurística tida como "intuitiva" ou "normal" (ou seja, a reduzir a probabilidade de que o sujeito aja de modo "racional" em favor de um procedimento tido como "normal").

Uma das modalidades de erro de avaliação mais recorrentes é dada pelo chamado viés de julgamento em favor de si próprio ("self-serving bias"), VJFSP, que conta com evidências contundentes, como Babcock, Loewenstein, Issacharoffe e Camerer (1995). Este viés implica que, em uma avaliação sobre o que é "fair", o mesmo conjunto de informações é processado de modos diferentes, de acordo com o interesse do sujeito. Informações que tendem a levar o ponto de referência do indivíduo para uma direção que serve ao seu interesse recebem uma atenção bem maior do que as que levam sua noção do que é "fair" para uma direção contrária ao seu interesse. Para a maior parte das pessoas este mecanismo ocorre inconscientemente e, muitas vezes, este viés gera perdas para quem nele incorre.

\section{C) "FAIRNESS" E O CUSTO DAS ESTABILIZAÇÕES}

Explicadas e justificadas as hipóteses de aversão à perda, reciprocidade e VJFSP, resta-nos, finalmente, ligar estas idéias com o fenômeno da 
antecipação do custo das estabilizações. Esta conexão pode ocorrer mediante as seguintes hipóteses do nosso "modelo com fairness":

(F1) A avaliação dos empregados sobre se um reajuste salarial é ou não "fair" depende de certas referências. Geralmente se assume que uma das referências mais importantes é o próprio nível salarial que leva a taxa de desemprego a seu nível de equilíbrio de mercado puro (ou seja, de equilíbrio sem considerações do tipo "fairness"). Assumiremos que uma outra referência importante é a taxa de inflação passada (ver discussão abaixo).

(F2) A possibilidade de reciprocidade faz com que as empresas levem em conta a avaliação a respeito do que é "fair" ao definirem os reajustes salariais efetivos (como em Akerlof (1982)).

(F3) Devido ao VJFSP, o peso da referência inflação passada é maior quando se espera uma queda na taxa de inflação (e taxa de desemprego elevada) do que quando se espera uma alta da taxa de inflação (e taxa de desemprego baixa).

(F4) Devido à aversão à perda, os empregados reagem (ver discussão abaixo) de modo muito mais sensível a uma política salarial tida como injusta do que a uma política salarial generosa.

Conforme já explicamos, as hipóteses de reciprocidade, VJFSP e aversão à perda já foram testadas várias vezes e contam com evidências suficientes para serem consideradas bastante plausíveis. Neste sentido, testar o modelo equivale essencialmente a testar (F1), que é uma hipótese voltada especificamente para o nosso contexto. Ou, ainda mais especificamente, equivale a testar a inflação passada como referência importante, uma vez que ninguém questionaria a importância do mercado na determinação dos salários. 
Mas avaliamos que a hipótese (F1) não é padrão em trabalhos sobre inflação e estabilização com abordagem comportamental simplesmente pelo ineditismo da aplicação desta abordagem a este assunto. Apesar disso, vemos esta hipótese aventada em Blanchard e Katz $(1997)^{54}$ e aparecendo também em Modigliani e Schioppa (1978). Além disso, a hipótese de que a taxa de inflação passada importa é uma velha conhecida dos economistas brasileiros e da CEPAL ${ }^{55}$, estando por trás da motivação do trabalho de DSW da seção 3.2.

Em Blanchard e Katz (1997), o eventual motivo pelo qual a inflação passada poderia ter um peso desproporcional na fixação dos salários seria o fato de ela refletir os reajustes salariais do passado recente. Poderíamos, no entanto, pensar em outras razões. Uma que nos parece bastante plausível é a de que os dois choques do petróleo e as estabilizações dos anos 70 e 80 geraram um cenário bastante complexo para os assalariados e que a regra de reposição da inflação passada tem o atrativo de ser uma referência bastante simples. Conforme já discutimos no item anterior, Pelhan e Neter (1995) mostraram que as pessoas tendem a utilizar regras heurísticas simples diante de problemas complexos, mesmo quando têm motivações fortes para resolver corretamente a questão.

Observamos que há um outro trabalho recente no qual as referências dos empregados influem na dinâmica da taxa de inflação e no nível de emprego. Este trabalho é Ball e Moffit (2001), que utiliza antigas idéias de

\footnotetext{
${ }^{54}$ Pág. 54. Neste exemplar do Journal of Economic Perspectives, há cinco artigos sobre a NAIRU (taxa de desemprego que não acelera a inflação) e Blanchard e Katz fazem o artigo que representa a opinião dos novos Keynesianos.

${ }^{55}$ Ver Simonsen (1970) e Sunkel (1958).
} 
"conflito distributivo" ${ }^{26}$ sem entrar em maiores considerações comportamentais. Neste artigo, os empregados têm expectativas inflacionárias ingênuas e aspiram a um reajuste salarial real que tem relação com o histórico do aumento de produtividade. Com isso, quando a taxa de crescimento da produtividade cai há um deslocamento para cima da NAIRU ("non accelerating of inflation rate of unemployment"). Ball e Moffit supõem que quando a taxa de crescimento da produtividade sobe, como na segunda metade dos anos 90, a NAIRU cai (ao contrário do presente trabalho, eles não postularam nenhum tipo de assimetria). Ou seja, em Ball e Moffit, expectativas ingênuas ajudam a resolver com uma certa facilidade as dissonâncias entre as aspirações dos empregados e a realidade. Fazer algo semelhante utilizando expectativas de "survey" torna a modelagem bem mais complicada. Avaliamos, no entanto, que, para a amostra que utilizaremos na estimação do nosso modelo (período de 1967/2 a 1991/2), o procedimento que adotamos através da hipótese (F1) engloba considerações relacionadas com os choques de oferta em conflito com as aspirações dos assalariados. Vejamos: dados os reajustes salariais, um choque favorável reduz a taxa de inflação e um adverso a eleva. Para o período que analisaremos, os choques de produtividade mais importantes foram os dois choques do petróleo, dois choques adversos bastante fortes. Conforme dissemos acima, a demanda por um reajuste que cubra a inflação passada (sem expurgo dos choques) pode, então, sinalizar simplesmente uma referência para uma demanda de manutenção do poder de compra diante

\footnotetext{
${ }^{56}$ Ver Grubb, Jackman e Layard (1982) e velhos conhecidos dos brasileiros, como Resende (1981) e Arida (1982), e da CEPAL, como Sunkel (1958).
} 
destes choques e de uma taxa de desemprego acima da "natural". Voltaremos ao assunto "choques do petróleo" na seção 3.5 .

Não dispomos de evidências, com "surveys" e experimentos de laboratório nem para corroborar nem para rejeitar diretamente $(F 1)$. No apêndice C mostramos que fazer este tipo de avaliação em uma "survey" é algo bastante complicado. Talvez este seja um motivo importante por trás de as "surveys" citadas no item (ii) do apêndice B terem foco quase exclusivo no fortíssimo repúdio a cortes nominais no salário. Mas a importância de "fairness" para a determinação dos salários não se restringe à fundamentação da hipótese de que dificilmente empresas fazem cortes nominais salariais. Citando Blinder e Choi (1990), "o resultado mais forte (obtido na "survey" deles) foi o de que os administradores acreditam que "fairness" desempenha um papel central na motivação dos trabalhadores e que uma política salarial justa ("fair") significa algo bem mais complicado do que simplesmente não cortar salários”. Ou, citando Kaufman (1984): "As firmas sentiam que reduções salariais, especialmente se não acompanhadas por informações críveis a respeito de uma crise financeira, seriam recebidas como uma afronta. isso diz respeito não só a cortes no salário nominal, mas também, em uma menor extensão, a aumentos salariais inferiores à taxa de inflação".

\section{As hipóteses (F3) e (F4), por sua vez, implicam uma espécie de} “curva de Phillips da primeira diferença ${ }^{57}$ esperada” assimétrica. Quando se esperar uma política monetária expansionista, a hipótese $(\mathrm{F} 3)$ implica que o

\footnotetext{
${ }^{57}$ Relação negativa entre a aceleração da inflação e a taxa de desemprego, enquanto a curva de Phillips original nos reporta uma relação negativa entre a taxa de inflação e a taxa de desemprego.
} 
salário tido como justo será muito próximo do determinado pelo modelo de Taylor. Por outro lado, quando os agentes previrem uma desinflação, reduções no nível de reajuste salarial tidas como justas serão movidas principalmente por elevações na taxa de desemprego esperado. A hipótese (F4), por sua vez, implica que quando a avaliação a respeito do reajuste salarial justo mais diverge do que é ditado pelo mercado (ou seja, quando se espera queda na taxa de inflação), é quando a reação dos trabalhadores (a resposta em termos de esforço, greves ou rotatividade da mão de obra frente à diferença entre salário justo e efetivo) é mais forte.

Assim, (F3) e (F4) implicam que quando se esperar queda na taxa de inflação se esperará uma taxa de desemprego significativamente elevada, enquanto quando se esperar alta na taxa de inflação se esperará um nível de desemprego pouco ou não significantemente diferente do ditado pela taxa de longo prazo.

Observamos que (F1) nos diz que o salário considerado justo é influenciado pelo mercado e também por outros fatores e (F2) em conjunto com (F4) implica que uma política salarial injusta tende a ter algum tipo de efeito negativo sobre a produtividade do trabalho (as "surveys" do anexo B nos indicaram principalmente queda no esforço, elevação na rotatividade da mão de obra e queda na qualidade dos candidatos a entrar na empresa). Isto não implica que o salário a ser pago pelas empresas será o salário justo nem o salário "de mercado puro", tendendo, na verdade a ser algo dentro deste intervalo (pois, como já dissemos, os agentes levam em conta não só suas preferências por reciprocidade, mas também o custo desta). As hipótese (F3) e (F4), por sua vez, implicam em que quando se espera que a taxa de inflação vá 
subir, o salário ficará mais próximo de seu nível "de mercado puro", enquanto quando se previr uma desinflação ele ficará mais longe deste nível de "mercado puro". Um modo de se visualizar a localização do salário efetivo dentro deste intervalo é através de um modelo de salário eficiente com "fairness" e monitoramento imperfeito, mostrado no apêndice 4.

\section{4 - TESTES PARA OS MODELOS}

Finalmente, passaremos os modelos discutidos neste capítulo para 0 contexto de reajustes justapostos, de modo a confronta-los com os dados. Faremos isto com os três modelos. Em todos os casos, assumiremos:

- Salários ficam fixos durante dois períodos.

- 50\% dos empregados tem seus salários reajustados em cada determinado período.

- Markups constantes e normalizados para zero.

\section{A) O MODELO COM AGENTES HETEROGÊNEOS}

Em primeiro lugar, visualizaremos separadamente o modo como os reajustes salariais são feitos nos dois casos extremos: somente agentes racionais e somente agentes ingênuos. O primeiro caso, de agentes racionais, foi derivado no apêndice $C$ e é dado por: 
$\left(w_{t}-w_{t-2}\right)=\left\{(1 / 2) \cdot E_{t-1}\left[\pi_{t}+\pi_{t+1}\right]+(1 / 2) \cdot\left(\pi_{t-1}+\pi_{t-2}\right)\right\}+\chi \cdot E_{t-1}\left[\left(y_{t}+y_{t+1}\right) / 2\right]$

Ou seja, os reajustes são dados por uma média entre a inflação passada e a futura esperada mais um componente associado ao nível de atividade esperado. As conseqüências desta regra foram analisadas no capítulo 1. Já no caso de agentes ingênuos, teremos:

$$
\begin{aligned}
& \left(w_{t}-w_{t-2}\right)=\left\{(1 / 2) \cdot E_{t-1}\left[\pi_{t}+\pi_{t+1}\right]+(1 / 2) \cdot\left(\pi_{t-1}+\pi_{t-2}\right)\right\}+\chi \cdot E_{t-1}\left[\left(y_{t}+y_{t+1}\right) / 2\right] \\
& \text { com } E_{t-1}\left[\pi_{t}+\pi_{t+1}\right]=\left(\pi b_{t-1}+\pi b_{t-2}\right), E_{t-1}\left[\left(y_{t}+y_{t+1}\right) / 2\right]=\left(y_{t-1}+y_{t-2}\right) / 2
\end{aligned}
$$

(Onde $\pi b_{t}=p b_{t}-p b_{t-1}$ e $p b_{t}$ é o log do nível de preços no início do período t. O início do período t é o instante de tempo no qual se passa do período $\mathrm{t}-1$ para o período t. No modelo sem expectativas racionais, $\pi_{\mathrm{t}}$ é ainda desconhecida no final de $t-1$, enquanto $\pi b_{t}$ é conhecida. $\left(\pi b_{t}+\pi b_{t-1}\right)$ é a taxa de inflação dos últimos 12 meses).

A equação (3.32) só difere de (3.31) pelas restrições a respeito das expectativas e por termos $\left(\pi b_{t-1}+\pi b_{t-2}\right)$ no lugar de $\left(\pi_{t-1}+\pi_{t-2}\right)$. Deste modo, (1.26) permanece válida no modelo com agentes ingênuos, desde que se acrescente a ela as restrições de (3.32). A equação (1.26) determina a taxa de inflação efetiva. No capítulo 1 vimos também como devem ser as expectativas em um modelo no qual todos os agentes são racionais. As restrições de (3.32), por sua vez, nos dizem como são as expectativas dos agentes ingênuos. Só nos resta, então, examinar como serão as expectativas dos agentes 
sofisticados (racionais) quando parte da população é constituída de agentes ingênuos.

A relação entre a evolução esperada, em termos agregados, da taxa de inflação e o nível esperado de atividade é dada por:

$$
\begin{aligned}
& \left.\mathrm{E}_{\mathrm{t}-1}\left[\pi \mathrm{b}_{\mathrm{t}+2}+\pi \mathrm{b}_{\mathrm{t}+1}\right]\right) / 2-\left(\pi \mathrm{b}_{\mathrm{t}}+\pi \mathrm{b}_{\mathrm{t}-1}\right) / 2=\alpha \cdot\left\{\left(\mathrm{E}_{\mathrm{t}-1}^{\mathrm{R}}\left[\pi \mathrm{b}_{\mathrm{t}+2}+\pi \mathrm{b}_{\mathrm{t}+1}\right]\right) / 2-\left(\pi \mathrm{b}_{\mathrm{t}}+\pi \mathrm{b}_{\mathrm{t}-1}\right) / 2\right\}= \\
& \gamma\left\{\alpha \mathrm{E}^{\mathrm{R}-1}\left[\left(\mathrm{y}_{\mathrm{t}}+\mathrm{y}_{\mathrm{t}+1}\right) / 2\right]+(1-\alpha) \mathrm{E}_{\mathrm{t}-1}^{\mathrm{N}}\left[\left(\mathrm{y}_{\mathrm{t}}+\mathrm{y}_{\mathrm{t}+1}\right) / 2\right]\right\}+\varepsilon_{\mathrm{t}}, 0<\alpha<1
\end{aligned}
$$

Onde $E_{t-1}[$ ] é o operador das expectativas agregadas da população como um todo, $E_{t-1}^{R}$ ] corresponde às expectativas dos agêntes racionais e $E_{t-}^{N}$ 1[ ] corresponde às expectativas dos agentes ingênuos. A parcela de agentes racionais na população é $\alpha$ e a de agentes ingênuos é (1- $\alpha)$.

A variável dependente de (3.33) será dada pela expectativa dos agentes sofisticados multiplicada pelo percentual destes agentes na população (pois para os agentes ingênuos temos, por definição, $\left.\left.\left(E^{N-1}{ }\left[\pi b_{t+2}+\pi b_{t+1}\right]\right) / 2=\left(\pi b_{t}+\pi b_{t-1}\right) / 2\right)\right)$.

Deste modo, $\left.\left(E_{t-1}\left[\pi b_{t+2}+\pi b_{t+1}\right]\right) / 2-\left(\pi b_{t}+\pi b_{t-1}\right) / 2\right)$ só pode ser explicada pela parcela de $E_{t-1}\left[\left(y_{t}+y_{t+1}\right) / 2\right.$ dada pelas expectativas dos agentes sofisticados. Os agentes ingênuos subestimarão a inflação quando esta subir e a superestimarão quando ela cair, o que os levará a fixarem preços (salários) muito altos quando a inflação está caindo e muito baixos quando ela está subindo. Como os agentes racionais sabem disto e sabem também que o nível de atividade é dado pelo produto nominal, que é fixado (anunciado) exógenamente pelo gestor da política econômica, dividido pelo nível de preços, 
eles anteciparão corretamente que quedas na inflação levam a recessão a elevações na inflação geram booms. Além disto, Hastiwanger e Waldman (1986 e 1989) mostraram que havendo complementaridade estratégica (ou seja, com salários relativos importando), os agentes sofisticados mimetizarão parcialmente o comportamento dos agentes ingênuos ao fixarem seu preços (salários). Deste modo, poderemos ter $\gamma>0$, desde que o efeito descrito neste parágrafo prevaleça sobre o descrito no capítulo 1. Neste caso, poderíamos admitir este modelo como explicação para a inércia inflacionária e o custo das estabilizações.

Por outro lado, a estimação de

$\left.\mathrm{E}_{\mathrm{t}-1}\left[\pi \mathrm{b}_{\mathrm{t}+2}+\pi \mathrm{b}_{\mathrm{t}+1}\right]\right) / 2-\left(\pi \mathrm{b}_{\mathrm{t}}+\pi \mathrm{b}_{\mathrm{t}-1}\right) / 2=\gamma \mathrm{E}_{\mathrm{t}-1}\left[\left(\mathrm{y}_{\mathrm{t}}+\mathrm{y}_{\mathrm{t}+1}\right) / 2\right]+\lambda\left[\left(\mathrm{y}_{\mathrm{t}-1}+\mathrm{y}_{\mathrm{t}-2}\right) / 2\right]+\varepsilon_{t}$

Deve gerar um $\lambda$ espuriamente significante e igual a $\{-(1-\alpha) \gamma\}$. Esta "histerese" espúria da estimação tenderia a ocorrer porque há uma parcela (1- $\alpha)$ de agentes ingênuos nas expectativas agregadas a respeito de $\left(\mathrm{y}_{t}+\mathrm{y}_{t+1}\right) / 2$, cujas expectativas são iguais a $\left(\mathrm{y}_{\mathrm{t}-1}+\mathrm{y}_{\mathrm{t}-2}\right) / 2$ e que não explicam nada de $\left.E_{t-1}\left[\pi b_{t+2}+\pi b_{t+1}\right]\right) / 2-\left(\pi b_{t}+\pi b_{t-1}\right) / 2$. O que explica esta variável dependente é a expectativa dos agentes racionais multiplicada pela parcela da população que eles representam, o que é igual a:

$\alpha E_{t-1}^{R}\left[\left(y_{t}+y_{t+1}\right) / 2\right]=E_{t-1}\left[\left(y_{t}+y_{t+1}\right) / 2\right]-(1-\alpha)\left[\left(y_{t-1}+y_{t-2}\right) / 2\right]$ 
Por outro lado, esta histerese espúria não deveria aparecer na estimação de:

$\pi_{t}-\left(\pi b_{t}+\pi b_{t-1}\right) / 2=\phi E_{t-1}\left[\left(y_{t}+y_{t+1}\right) / 2\right]+\varepsilon_{t} \quad, \quad \phi>0$

\section{B) O MODELO COM INCERTEZA}

O modelo simplesmente prevê que a incerteza faz os preços embutirem uma espécie de prêmio de risco que eleva a taxa de desemprego. Assim, elevada incerteza esperada implica um nível de desemprego esperado também elevado. Como foi postulado que as situações de incerteza mais elevada são dadas pelas estabilizações, o modelo prevê desemprego elevado esperado quando elas ocorrerem. Deste modo, teremos, ao invés de (3.33), a seguinte equação:

$$
\begin{gathered}
\left(E_{t-1}\left[\pi b_{t+2}+\pi b_{t+1}\right]\right) / 2-\left(\pi b_{t}+\pi b_{t-1}\right) / 2=D_{E \cdot \gamma} E_{t-1}\left[\left(y_{t}+y_{t+1}\right) / 2\right]+\varepsilon_{t} \\
, \quad \gamma>0
\end{gathered}
$$

Que é idêntica a (3.35) com exceção de $D_{E}$, que é uma variável dummy que é igual a um quando há uma estabilização e zero caso contrário.

Quando não há estabilização, temos o modelo de Taylor. Vimos na seção 1.2 que quando há uma alta antecipada na taxa de inflação, o modelo de 
Taylor implica um nível de atividade esperado mais baixo do que o de estado estacionário. Por outro lado, a especificação deste, dada por (1.5"), é bem diferente da que necessitamos, dada por:

$\left(E_{t-1}\left[\pi b_{t+2}+\pi b_{t+1}\right]\right) / 2-\left(\pi b_{t}+\pi b_{t-1}\right) / 2=D_{N E \cdot \gamma} E_{t-1}\left[\left(y_{t}+y_{t+1}\right) / 2\right]+\varepsilon_{t}$

Levando ambos os fatores em conta, podemos dizer que tanto a obtenção de $D_{\mathrm{NE} \cdot \gamma}<0$ quanto a de $D_{\mathrm{NE} \cdot \gamma}=0$ podem ser compatíveis com o modelo de Taylor. Já um $D_{\mathrm{NE} \cdot \gamma}>0$ só seria gerado por condições bastante específicas, pouco prováveis em uma série de praticamente quatro décadas, como a nossa $a^{58}$.

Juntando (3.36) e (3.37), para verificarmos o que ocorre tanto quando quanto a inflação cai quanto quando ela sobe, e substituindo $\left(E_{t-1}\left[\pi_{t+1}\right]-\pi_{t}\right)$ de (3.34) por $\left.\left\{E_{t-1}\left[\pi b_{t+2}+\pi b_{t+1}\right]\right) / 2-\left(\pi b_{t}+\pi b_{t-1}\right) / 2\right\}$ por aproximação, temos:

$$
\begin{aligned}
& \left(E_{t-1}\left[\pi b_{t+2}+\pi b_{t+1}\right]\right) / 2-\left(\pi b_{t}+\pi b_{t-1}\right) / 2=D_{E \cdot \gamma} \cdot E_{t-1}\left[\left(y_{t}+y_{t+1}\right) / 2\right]
\end{aligned}
$$

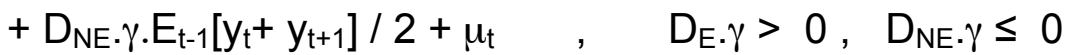

Onde $D_{E}$ é a dummy valendo 1 quando está ocorrendo uma estabilização e zero caso contrário e $D_{\mathrm{NE}}$ é a dummy valendo 1 quando não há estabilização e zero quando há. Neste modelo, quando não se espera inflação

\footnotetext{
${ }^{58}$ Conforme diremos na seção 3.5 , não houve quebra estrutural nas estimações deste capítulo.
} 
estável, se espera recessão. Como uma dummy é o reverso da outra, elas são perfeitamente correlacionadas. Porém, como elas estão multiplicando uma outra variável, a equação (3.38) não tem problema de identificação ${ }^{59}$.

Porém, na discussão teórica a respeito do modelo DSW, questionamos a hipótese de que, diante de economias com inflação moderada, haja muita diferença na incerteza frente a quedas versus elevações na taxa de inflação. Se supusermos que há incerteza similar em ambos os casos, teremos taxa esperada de desemprego elevada sempre que a inflação estiver "volátil". Em função disto, nosso prognóstico final do modelo com incerteza e expectativas consistentes é dado por:

$$
\begin{aligned}
& \left(E_{t-1}\left[\pi b_{t+2}+\pi b_{t+1}\right]\right) / 2-\left(\pi b_{t}+\pi b_{t-1}\right) / 2=D_{E \cdot \gamma} \cdot E_{t-1}\left[\left(y_{t}+y_{t+1}\right) / 2\right]
\end{aligned}
$$

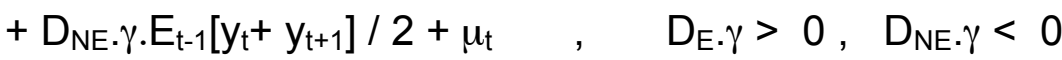

Mas uma outra alternativa interessante é juntar esta hipótese de aversão à incertesa com a do modelo anterior, de agentes heterogêneos. Se fizermos isto quando a inflação estiver subindo, a incerteza gerará recessão mas os agentes ingênuos gerarão expansão, e quando a inflação cair ambos geram recessão. Isto nos leva à:

\footnotetext{
${ }^{59} \mathrm{O}$ uso de Dummies iteragindo com outras variáveis como fazemos aqui é uma prática bastante usual. Ver Suits (1984) e Greene (1997, cap. 8), por exemplo.
} 


$$
\begin{aligned}
& \left(E_{t-1}\left[\pi b_{t+2}+\pi b_{t+1}\right]\right) / 2-\left(\pi b_{t}+\pi b_{t-1}\right) / 2=D_{E} \cdot \gamma \cdot E_{t-1}\left[\left(y_{t}+y_{t+1}\right) / 2\right]
\end{aligned}
$$

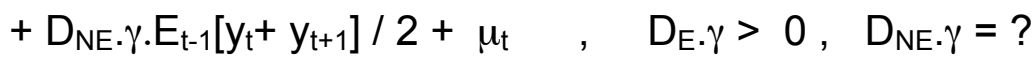

Além disto, como no item A, este modelo com agentes heterogêneos e incerteza knightiana deverá também apresentar "histerese espúria”.

\section{C) O MODELO COM FAIRNESS}

As propriedades do modelo com "fairness" (ou comportamental) desenvolvido na seção anterior implicam um modelo com forte assimetria, tendendo a se comportar como um modelo de mercado puro quando se espera alta na taxa de inflação e com forte inércia diante de desinflações. Para facilitar nossa tarefa de derivar um modelo para estimação, enfocaremos primeiro o caso com inércia (para desinflações) e depois o caso sem inércia (para elevações na taxa de inflação).

Para o caso das desinflações, os reajustas salariais podem ser aproximados por algo como:

$$
\mathrm{w}_{\mathrm{t}}-\mathrm{w}_{\mathrm{t}-2}=\left(\pi \mathrm{b}_{\mathrm{t}}+\pi \mathrm{b}_{\mathrm{t}-1}\right)+2 \phi \mathrm{E}_{\mathrm{t}-1}\left[\left(\mathrm{y}_{\mathrm{t}}+\mathrm{y}_{\mathrm{t}+1}\right) / 2\right]+2 \varepsilon_{\mathrm{t}} \quad, \quad \phi>0
$$

$\phi>0$, mas não o suficiente para manter o mercado de trabalho em seu nível de estado estacionário. 
Alternativamente à equação (3.40) podemos pensar em w determinado por:

$\mathrm{w}_{\mathrm{t}}-\mathrm{W}_{\mathrm{t}-2}=\left(\pi \mathrm{b}_{\mathrm{t}}+\pi \mathrm{b}_{\mathrm{t}-1}\right)+2 \phi \mathrm{E}_{\mathrm{t}-1}\left[\mathrm{y}^{\mathrm{r}} \mathrm{t}+\mathrm{y}^{\mathrm{r}} \mathrm{t}+1\right] / 2+2 \varepsilon_{\mathrm{t}}$

Onde $E_{t-1}\left[y^{n} t+y^{x} t+1\right] / 2$ é o nível do produto esperado caso

$E_{t-1}\left[w_{t}\right]-w_{t-2}=\left(\pi b_{t}+\pi b_{t-1}\right)$ e $E_{t-1}\left[w_{t+1}\right]-w_{t-1}=E_{t-1}\left[\pi b_{t+1}\right]+\pi b_{t}$ (ou seja, caso os salários para t e t+1 fossem fixados simplesmente através de uma regra pura de indexação defasada). Esta equação assume um grau mais elevado de racionalidade do que (3.40), com os trabalhadores capazes de raciocinar em termos de equilíbrio geral. Isto nos abriria a possibilidade de atingir uma estabilização sem custos, caso se utilize a política adequada ${ }^{60}$.

$E_{t-1}\left[y^{\pi} t^{n} y^{x}{ }_{t+1}\right] / 2$ não é observável, mas podemos usar (3.40) para efeito de inferência mesmo que a equação correta de w seja (3.41). A principal conseqüência estatística da utilização de (3.40), caso (3.41) seja a equação correta, deve ser uma elevação na autocorrelação, pois é bastante provável que $\left\{E_{t-1}\left[\begin{array}{lll}y^{z} & t^{+} y^{t} & t+1\end{array}\right] / 2-E_{t-1}\left[\begin{array}{lll}y_{t}+y_{t+1}\end{array}\right] / 2\right\}$ seja autocorrelacionada. Porém, a eventual autocorrelação em uma estimação com o uso de (3.40) pode se dever a outros fatores, como w depender de outros fatores não observáveis e autocorrelacionados. Portanto, podemos verificar se os dados rejeitam ou não o modelo com "fairness", mas não podemos rejeitar (3.40) contra (3.41) nem vice e versa.

\footnotetext{
${ }^{60}$ Ver Lunardelli (1997).
} 
Utilizamos, então, novamente as mesmas definições de $p_{t}$ (o preço médio do período t) e $\pi_{t}$ (a taxa de inflação entre $p_{t}$ e $p_{t-1}$ ) utilizadas no modelo de Taylor:

$$
\begin{aligned}
& p_{t}=\left(w_{t}+w_{t-1}\right) / 2 \rightarrow w_{t}=2 p_{t}-w_{t-1} \\
& \pi_{t}=p_{t}-p_{t-1}
\end{aligned}
$$

Usando o fato de que $\left(w_{t-1}-w_{t-1}\right)=0$ em (3.40) e rearranjando, obtemos:

$\left[\left(w_{t}+w_{t-1}\right)-\left(w_{t-1}+w_{t-2}\right)\right]-\left(\pi b_{t}+\pi b_{t-1}\right)=2 \phi E_{t-1}\left[\left(y_{t}+y_{t+1}\right) / 2\right]+2 \varepsilon_{t}$

que, utilizando (1.2) e (1.3), nos dá:

$\pi_{t}=\psi\left(\pi b_{t}+\pi b_{t-1}\right) / 2+\phi E_{t-1}\left[\left(y_{t}+y_{t+1}\right) / 2\right]+\varepsilon_{t} \quad, \psi=1, \phi>0$

e

$\pi_{t}-\left(\pi b_{t}+\pi b_{t-1}\right) / 2=\phi E_{t-1}\left[\left(y_{t}+y_{t+1}\right) / 2\right]+\varepsilon_{t} \quad, \quad \phi>0$

Adiantamos que não foi possível rejeitar a restrição $\psi=1 \mathrm{em}$ todas as nossas estimações, de modo que prosseguiremos trabalhando com (3.43) ao 
invés de (3.42). A equação (3.43) nos reporta o modo como se pautam os reajustes de salários (preços) quando se espera queda na taxa de inflação ( $A$ equação (1.26) desempenhava este mesmo papel diante do modelo de Taylor).

Se, além disto, as expectativas dos agentes forem consistentes com o modo como eles fixam seus preços, elas serão dadas por:

$$
\mathrm{E}_{\mathrm{t}-1}\left[\pi_{\mathrm{t}}\right]-\left(\pi \mathrm{b}_{\mathrm{t}}+\pi \mathrm{b}_{\mathrm{t}-1}\right) / 2=\theta \mathrm{E}_{\mathrm{t}-1}\left[\left(\mathrm{y}_{\mathrm{t}}+\mathrm{y}_{\mathrm{t}+1}\right) / 2\right]+\varepsilon_{\mathrm{t}} \quad, \quad \theta=(3 / 2) \cdot \phi
$$

e

$$
\left(E_{t-1}\left[\pi b_{t+2}+\pi b_{t+1}\right]\right) / 2-\left(\pi b_{t}+\pi b_{t-1}\right) / 2=\gamma E_{t-1}\left[\left(y_{t}+y_{t+1}\right) / 2\right]+\varepsilon_{t}, \quad \gamma=2 . \phi
$$

Observamos que temos dados a respeito de $\mathrm{E}_{\mathrm{t}-1}\left[\pi \mathrm{b}_{\mathrm{t}+2}+\pi \mathrm{b}_{\mathrm{t}+1}\right]$ mas não a respeito de $E_{t-1}\left[\pi_{t}\right]$, o que nos permite estimar (3.45) mas não (3.44). As restrições que impusemos a respeito da relação entre os coeficientes das regressões (3.44) e (3.44) com os de (3.43) merecem uma explicação. Elas decorrem de assumirmos que o que está por trás das nossas equações é uma relação linear entre o nível de atividade e a variação "instantânea" da taxa de inflação. Com isto, o valor dos coeficientes das equações acima deve ser linearmente relacionado à distância entre os centros das duas taxas de inflação da subtração que constitui cada uma das nossas variáveis dependentes.

Na equação (3.43) a variável dependente é uma diferença entre $\pi_{t}$ e $\left(\pi b_{t}+\pi b_{t-1}\right) / 2$, duas taxas de inflação semestrais. $\pi_{t}$ é a taxa de inflação do 
período que começa no meio do semestre $\mathrm{t}-1$ e vai até o meio do semestre t. $\mathrm{O}$ centro deste período é o início do período t. Do mesmo modo, o centro do período coberto pela taxa inflacionária $\pi b_{t}+\pi b_{t-1}$ é o início do período $t-1$. A diferença entre estes dois centros é de seis meses.

Em (3.44) temos novamente, como variável dependente, a diferença de duas taxas de inflação medidas em termos semestrais: a dos próximos 6 meses e $\left(\pi b_{t}+\pi b_{t-1}\right) / 2$. O centro da primeira é o meio do semestre t e o da segunda é o início do semestre anterior, o que nos dá um intervalo de 9 meses entre os dois centros. Em (3.45) a diferença entre os centros dos períodos das duas taxas de inflação da variável dependente corresponde a 12 meses $^{61}$.

A rejeição das restrições de (3.45) implica que as expectativas não são consistentes, mas se $\gamma>0$, não rejeitamos a hipótese de que as expectativas dos agentes se pautam em algo semelhante ao modelo com inércia decorrente de "fairness". Neste caso, poderemos ter, por exemplo, um modelo com "fairness" e agentes heterogêneos.

As especificações que discutimos até agora foram para situações de queda na taxa de inflação, ou seja, para estabilizações. Conforme dissemos acima, quando se espera alta da taxa de inflação, o mercado de trabalho funciona praticamente sem as restrições associadas ao modelo com "fairness". Assim como para o modelo com incerteza knightiana, temos dois modelos possíveis: o modelo de Taylor e o modelo com agentes heterogêneos. Como

\footnotetext{
${ }^{61}$ Dividimos $\left(\mathrm{E}_{\mathrm{t}-1}\left[\pi \mathrm{b}_{\mathrm{t}+2}+\pi \mathrm{b}_{\mathrm{t}+1}\right]\right)$ por 2 na equação (3.45) para converter todas as taxas de inflação dos modelos em taxas semestrais.
} 
conseqüência, teremos, novamente, dois modelos com dummies para períodos com ou sem estabilização (ou com inflação subindo versus caindo).

Para o modelo completo teremos, então, as seguintes expecificações:

i) Para o caso com agente representativo e expectativas consistentes:

$$
\begin{aligned}
& \left(E_{t-1}\left[\pi b_{t+2}+\pi b_{t+1}\right]\right) / 2-\left(\pi b_{t}+\pi b_{t-1}\right) / 2=D_{D \cdot \gamma} E_{t-1}\left[\left(y_{t}+y_{t+1}\right) / 2\right] \\
& +D_{u \cdot \gamma} E_{t-1}\left[y_{t}+y_{t+1}\right] / 2+\varepsilon_{t} \quad, \quad D_{D} \cdot \gamma>0, \quad D_{u} \cdot \gamma \leq 0 \\
& \pi_{t}-\left(\pi b_{t}+\pi b_{t-1}\right) / 2=D_{D} \cdot \phi E_{t-1}\left[\left(y_{t}+y_{t+1}\right) / 2\right]+D_{u \cdot \phi} E_{t-1}\left[y_{t}+y_{t+1}\right] / 2+\varepsilon_{t} \\
& , \quad D_{D} \cdot \phi=(1 / 2) \cdot D_{D} \cdot \gamma>0,
\end{aligned}
$$

Onde $D_{D}$ é uma dummy que assume valor 1 quando se espera queda na taxa de inflação e zero caso contrário e $D_{\cup}$ assume valor 1 quando se espera alta na taxa de inflação e zero caso contrário.

ii) Para o caso com agentes heterogêneos:

$$
\begin{aligned}
& \left(E_{t-1}\left[\pi b_{t+2}+\pi b_{t+1}\right]\right) / 2-\left(\pi b_{t}+\pi b_{t-1}\right) / 2=D_{D \cdot \gamma} E_{t-1}\left[\left(y_{t}+y_{t+1}\right) / 2\right] \\
& +D_{U \cdot \gamma} E_{t-1}\left[y_{t}+y_{t+1}\right] / 2+\varepsilon_{t} \quad, \quad D_{D} \cdot \gamma>0, \quad D_{U} \cdot \gamma \geq 0 \\
& \pi_{t}-\left(\pi b_{t}+\pi b_{t-1}\right) / 2=D_{E} \cdot \phi_{1} E_{t-1}\left[\left(y_{t}+y_{t+1}\right) / 2\right]+D_{U} \cdot \phi_{1} E_{t-1}\left[y_{t}+y_{t+1}\right] / 2+\varepsilon_{t} \\
& , \quad D_{D \cdot \phi}=(1 / 2) . D_{D} \cdot \gamma
\end{aligned}
$$


Além disto, (3.48) deverá apresentar a "histerese espúria" derivada no item A, mas (3.49) não. Observamos que temos $D_{\cup} \cdot \gamma \geq 0$ em (3.48) apesar de termos $\gamma>0$ em (3.33) porque o efeito dos agentes heterogêneos pode gerar inconsistência mas não ser significante para explicar isoladamente a inércia inflacionária e o custo das estabilizações.

\section{D) CONFRONTANDO OS MODELOS}

Conforme a análise acima, os modelos deste capítulo podem ser confrontados fazendo-se testes "nested" com as estimações (3.48) e (3.49). O fato de o modelo com incerteza knightiana utilizar dummies para situações de estabilização versus não estabilização e de o modelo comportamental utilizar dummies de alta versus baixa esperada na taxa de inflação não resultou diferenças relevantes entre estimações e que não altera nossa análise. Utlizaremos as dummies de inflação em alta/baixa (lembramos que as evidências da economia experimental favorecem o modelo comportamental frente ao modelo com incerteza knightiana).

Sendo assim, as equações dos modelos só diferem entre si no sinal dos coeficientes e nas restrições. Mostramos o que se espera das estimações de cada modelo na tabela 22. O que ocorre é, em resumo:

i) caso as dummies revelem que há assimetria, necessitamos do modelo com "fairness" ou do com incerteza knightiana. 
ii) Caso não tenhamos $D_{U} \cdot \gamma<0$ e se rejeite que os coeficientes de (3.48) sejam iguais a metade dos de (3.47), teremos agentes heterogêneos.

iii) não temos como diferenciar empiricamente 0 modelo comportamental com agentes heterogêneos do modelo com incerteza e agentes heterogêneos.

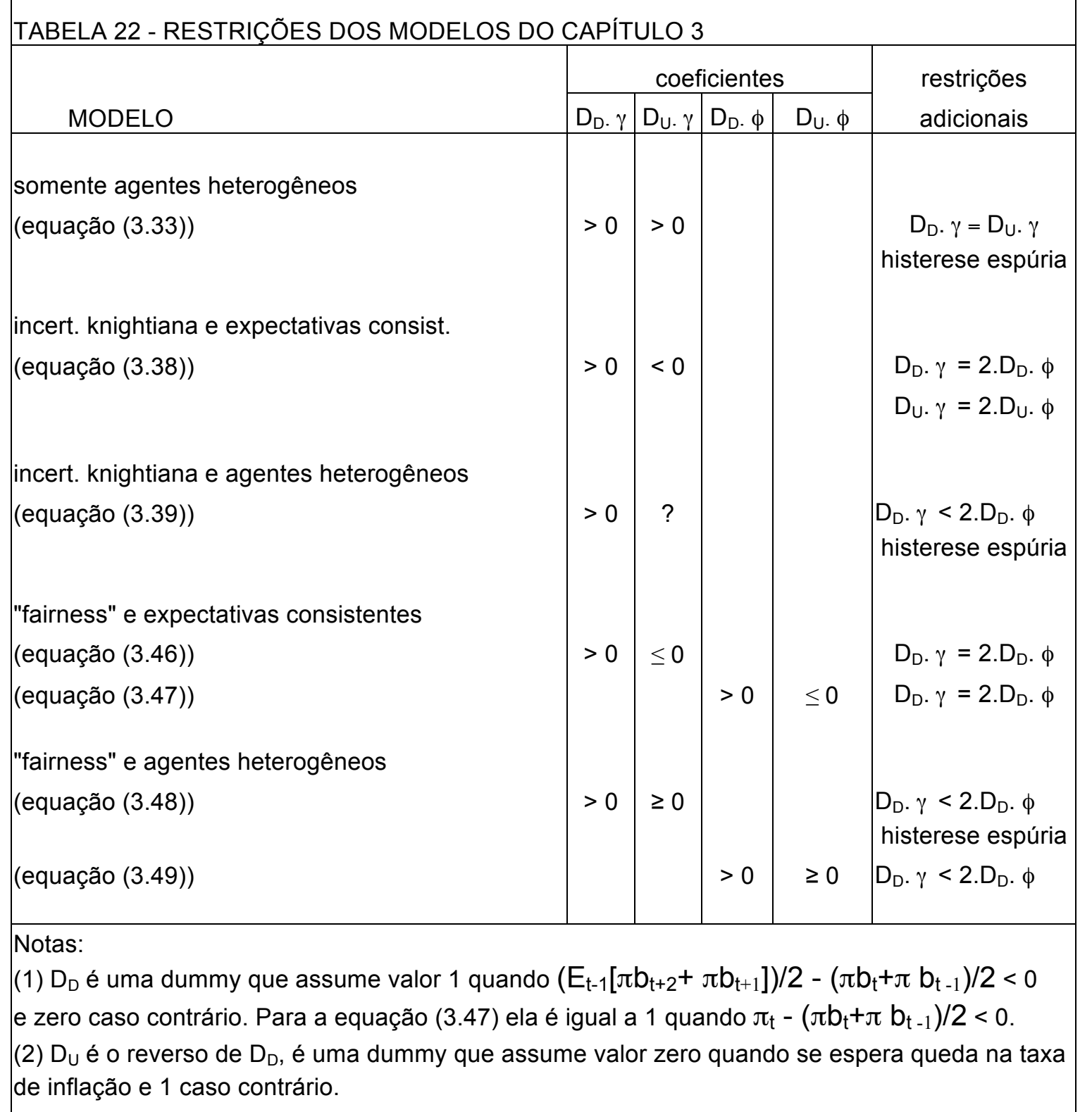




\section{E) NOTA SOBRE ASSIMETRIAS CORRELATAS}

Para finalizar, observamos que a hipótese de uma curva de Phillips (da primeira diferença da taxa de inflação) assimétrica não é usual, mas existem trabalhos que mostram assimetrias relacionadas com ela.

Cover (1988), mostrou que choques não esperados contracionistas na política monetária tem um impacto sobre o produto significantemente maior do que choques (também não esperados) expancionistas. Este resultado foi confirmado por Long e Summers (1988).

Dibooglu e Enders (2001) verificaram assimetria nos ajustes do salário real frente a choques de produtividade e de desemprego para o Canadá, mas não para os EUA. No nosso caso, a assimetria que postulamos não é relativamente à ajustes no salário real, mas à dinâmica dos reajustes dos salários nominais.

Enders e Hurn (2002), por sua vez, mostraram evidências de assimetria em uma especificação de curva de Phillips para a Austrália. Porém, os propósitos, a especificação e os resultados deles foram bem diferentes dos nossos.

Dentre os trabalhos encontrados na literatura, Romer e Romer (1989, 1990) são os que têm motivação mais próxima da nossa. Eles argumentam que as evidências que obtiveram mostram que a política monetária gera efeitos significantemente mais fortes sobre o produto em épocas de estabilização do que em períodos sem estabilização. Esta assimetria é bastante próxima da que postulamos, pois, na série que analisamos, quase todos os períodos nos quais 
os agentes esperam queda na taxa de inflação podem ser considerados épocas de estabilização.

Estes trabalhos dos Romer foram bastante criticados $^{62}$, mas nossa metodologia não compartilhou de seus pontos polêmicos. Os ataques que podem ser considerados mais graves foram os contra foi a hipótese de que “dummies" relacionadas com estabilizações são exógenas. No nosso caso, obviamente não assumimos a exogeneidade de $D_{D}$ e $D_{U}$, pois elas são diretamente função das nossas variáveis dependentes.

Além disto, a interpretação que eles deram para a assimetria encontrada está diretamente ligada com esta hipótese atacada: disseram que a medida correta do efeito da política monetária é apurada durante os períodos de estabilização, pois é o momento no qual ela é exógena. No nosso caso, os motivos pelos quais a política monetária pode gerar efeitos mais fortes quando há estabilizações são completamente diversos deste, tendo sido discutidos ao longo deste capítulo.

\footnotetext{
${ }^{62}$ Ver Hoover e Perez (1994a, 1994b) e Leeper (1997), para ataques à metodologia dos Romer e Romer e Romer $(1994,1997)$ para as respostas.
} 


\section{5 - A METODOLOGIA E OS RESULTADOS DAS ESTIMAÇÕES}

\section{A) A METODOLOGIA}

Como dissemos no último item da seção anterior, as "dummies" das nossas regressões são endógenas. Além disto, não assumimos exogeneidade de $E_{t-1}\left[\left(y_{t}+y_{t+1}\right) / 2\right]$, do mesmo modo que procedemos no capítulo 2. Como nossas variáveis são justapostas, novamente admitimos um termo MA(1) e utilizamos a metodologia de Fair $(1970,1984)$ em estimações com mínimos quadrados de dois estágios.

Desta vez não houve quebra estrutural significante (a 10\%) de modo que mostraremos as estimações que fizemos para a amostra inteira que analisamos, de 1/1961 a 2/1999. Estimações para o período 1967/2-1991/1 apresentaram resultados similares aos da amostra inteira e os para 1/19852/1999 apresentaram desvios-padrão mais elevados e coeficientes menos significantes.

Devido ao fato de estarmos testando uma assimetria, não utilizamos mais BT como medida da dinâmica esperada do nível de atividade, mas BC ("business conditions"), que é igual ao percentual de "good times" menos o percentual de "bad times" mais 100.

O fato de as dummies serem endógenas fez com que tivéssemos que escolher "a dedo" os instrumentos para obtermos projeções razoavelmente 
boas das variáveis $D_{\cup} \cdot B C C$ e $D_{D} \cdot B C C$, onde $B C C$ significa a variável $B C$ menos sua média (ou seja, "centralizada"). Procuramos utilizar os seguintes instrumentos em todas as estimações ${ }^{63}: \mathrm{BCC}_{\mathrm{t}-3}, \mathrm{BCC}_{\mathrm{t}-4}, \mathrm{BCC}_{\mathrm{t}-5}, \mathrm{UCC}_{\mathrm{t}-3}, \mathrm{LUCC}_{\mathrm{t}-}$ 3, YLIN $\mathrm{t}_{\mathrm{t}-3}, \mathrm{YLIN}_{\mathrm{t}-5}, \mathrm{i}_{\mathrm{t}-2}-\left(\mathrm{i}_{\mathrm{t}-5}+\mathrm{i}_{\mathrm{t}-6}\right) / 2,\left(\mathrm{i}_{\mathrm{t}-2}-\mathrm{E}_{\mathrm{t}-3}\left[\pi_{\mathrm{t}-2}\right]\right)-\left(\mathrm{i}_{\mathrm{t}-42}-\mathrm{E}_{\mathrm{t}-5}\left[\pi_{\mathrm{t}-4}\right]\right)$, oil $\mathrm{l}_{\mathrm{t}}$, oil $\mathrm{t}_{\mathrm{t}-1}$, oil $\mathrm{l}_{-2}$, oilt-3, oilt 4 .

Sendo:

$$
\begin{aligned}
& \text { BCC = "business conditions" menos sua média } \\
& \text { UCC = Utilização de capacidade menos sua média } \\
& \text { LUCC = log de UCC } \\
& \text { YLIN = desvio do produto real com relação à tendência linear } \\
& \mathrm{i}_{\mathrm{t}}=\text { taxa de juros dos "FED funds" do trimestre anterior a t } \\
& \text { oil }{ }_{\mathrm{t}}=\text { log da variação do preço real do petróleo (início do período t menos }
\end{aligned}
$$
início do período t-1)

Com estes instrumentos, obtivemos um $R^{2}$ de $70,0 \%$ para a projeção de $D_{D} . B C C$ e de $52,0 \%$ para a projeção de Du.BCC. O uso de variáveis "centralizadas" pela média foi fundamental na obtenção destes resultados. Não foi possível a obtenção de uma projeção melhor do que esta para a variável Du.BCC que não gerasse superidentificação. Estes valores projetados e realizados são mostrados nos gráficos abaixo.

\footnotetext{
${ }^{63}$ De todas as regressões mostradas nas tabelas desta seção, em apenas duas não fizemos isto. Nelas, retiramos oil(t) e oil(t-1) para evitarmos superidentificação.
} 

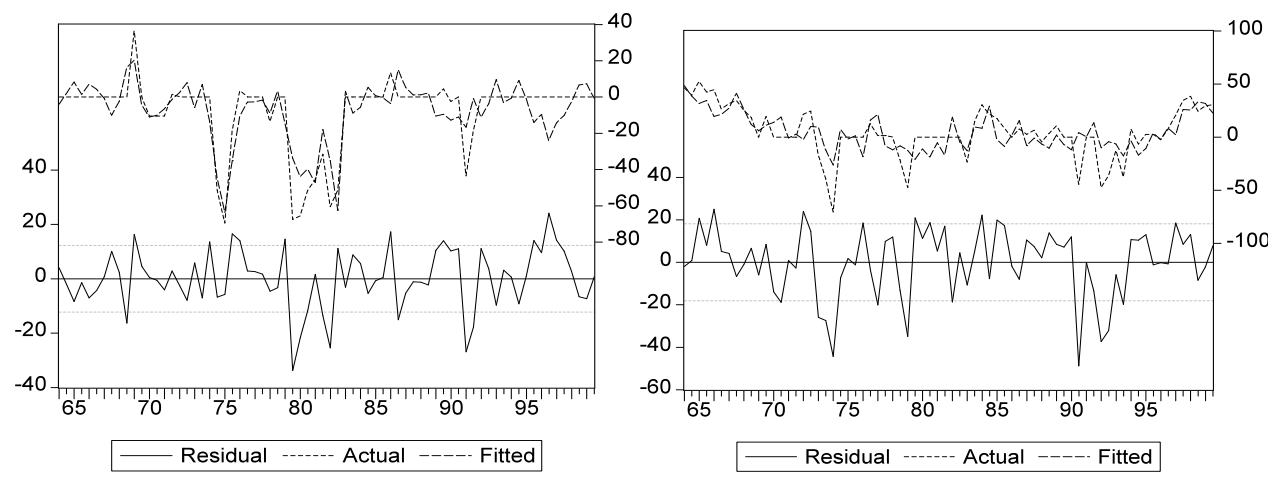

Fig. 15 - Valores realizados e projetados de $D_{D} . B C C$ (esquerda)

e Du.BCC (direita)

Adicionalmente, utilizamos como instrumentos apenas os "lags" 3, 4 e 5 da medida de nível de atividade utilizada na regressão. Assim como fizemos para testar o modelo de Taylor, rodamos estimações com quatro diferentes medidas de nível de atividade (pautadas, respectivamente, no desvio do produto real com relação à tendência do filtro HP e tendência linear, na utilização de capacidade da indústria e na taxa de desemprego). Observamos que as estimações com o log destas medidas do nível de atividade obtiveram resultados inferiores aos aqui reportados (o mesmo havia ocorrido nas estimações do modelo de Taylor).

Além disto, procuramos avaliar a robustez dos resultados frente à possibilidade de erros de medida (vide tabela 28) e diante da incorporação de 5 "lags" da variável "log da variação do preço do petróleo real" aos nossos modelos (vide a maior parte das estimações das tabelas 24 a 28).

Nas estimações com histerese utilizamos BCC e o primeiro "lag" do nível de atividade como variáveis explicativas. Nas sem histerese, $E_{t-1}\left[\left(y_{t}+y_{t+1}\right) / 2\right]$ 
foi obtido com uma estimação análoga a da equação (2.7), apenas substituindo BT pelo log de BCC.

\section{B) OS RESULTADOS}

Boa parte das estimações que estimamos apresentou autocorrelação e não é mostrada (pois representam estimativas viesadas, na medida em que temos estimações com TSLS e variáveis defasadas como instrumentos). Mostramos, nas seis tabelas abaixo, as estimações que não apresentaram este problema. 


\begin{tabular}{|c|c|c|c|c|}
\hline $\begin{array}{l}\text { TABELA } 23 \text { - RESULTADO } \\
\text { VARIÁVEL DEPENDENTE: } \\
\text { EXPECTATIVA INFLACION }\end{array}$ & $\begin{array}{l}\text { S DAS ESTIMA } \\
\mathrm{E}_{\mathrm{t}-1}\left[\pi \mathrm{b}_{\mathrm{t}+2}+\pi \mathrm{b}_{\mathrm{t}+1}\right] \\
\text { ÁRIA ORIGINAL }\end{array}$ & $\begin{array}{l}\text { ÇÕES DA EC } \\
]) / 2-\left(\pi b_{t}+\pi b_{t}\right. \\
-/ \text { PERÍODC }\end{array}$ & $\begin{array}{l}\text { QUAÇÃO (3.4 } \\
t-1) / 2 \\
\text { O: } 1 / 1961-2 / 1\end{array}$ & $\begin{array}{l}\text { 8) } \\
999\end{array}$ \\
\hline medida de $\mathrm{y}(\mathrm{t}-1)$ & $y$ - Hodrick-Pr. & $y-t$. Linear & ut. de capac. & desemprego \\
\hline Intercepto & $\begin{array}{l}0,0033^{* * *} \\
(0,0010)\end{array}$ & $\begin{array}{c}0,0029^{* * *} \\
(0,0010)\end{array}$ & $\begin{array}{c}0,0031 \\
(0,0010)\end{array}$ & $\begin{array}{c}0,0030^{* * *} \\
(0,0010)\end{array}$ \\
\hline$D_{D} \cdot B C C(t)$ & $\begin{array}{l}0,0268^{* * *} \\
(0,0056)\end{array}$ & $\begin{array}{l}0,0175^{*} \\
(0,0097)\end{array}$ & $\begin{array}{l}0,0243^{* * *} \\
(0,0052)\end{array}$ & $\begin{array}{c}0,0233^{* * *} \\
(0,0067)\end{array}$ \\
\hline$D_{U} \cdot B C C(t)$ & $\begin{array}{l}0,0086^{* *} \\
(0,0042)\end{array}$ & $\begin{array}{l}0,0139^{* *} \\
(0,0061)\end{array}$ & $\begin{array}{l}0,0110^{* *} \\
(0,0045)\end{array}$ & $\begin{array}{l}0,0110^{* *} \\
(0,0047)\end{array}$ \\
\hline$D_{D} \cdot y(t-1)$ & $\begin{array}{l}-0,0379 \\
(0,1058)\end{array}$ & $\begin{array}{c}0,0689 \\
(0,0803)\end{array}$ & $\begin{array}{c}0,0001 \\
(0,0004)\end{array}$ & $\begin{array}{l}-0,0003 \\
(0,0018)\end{array}$ \\
\hline$D_{u} \cdot y(t-1)$ & $\begin{array}{l}-0,0038 \\
(0,0455)\end{array}$ & $\begin{array}{l}-0,0349 \\
(0,0300)\end{array}$ & $\begin{array}{l}-0,0003 \\
(0,0003)\end{array}$ & $\begin{array}{c}0,0008 \\
(0,0008)\end{array}$ \\
\hline $\mathrm{MA}(1)$ & $\begin{array}{c}0,3803 \\
(0,1015)\end{array}$ & $\begin{array}{c}0,3415^{\star * *} \\
(0,1114)\end{array}$ & $\begin{array}{c}0,3788^{* * *} \\
(0,1032)\end{array}$ & $\begin{array}{c}0,3654^{\star * \star} \\
(0,1066)\end{array}$ \\
\hline R2 ajustado & 0,51 & 0,46 & 0,49 & 0,49 \\
\hline DW & 1,91 & 1,89 & 1,91 & 1,92 \\
\hline teste de superid. - P-value & 0,18 & 0,20 & 0,18 & 0,23 \\
\hline Jarque-Bera - P-value & 0,84 & 0,78 & 0,70 & 0,76 \\
\hline $\begin{array}{l}\text { Teste Wald (P-value): } \\
\text { DD. } \gamma=\text { DU. } \gamma\end{array}$ & 0,016 & 0,560 & 0,060 & 0,173 \\
\hline $\begin{array}{l}\text { correlograma (P-values): } \\
\text { lag } 1\end{array}$ & - & - & - & - \\
\hline $\operatorname{lag} 2$ & 0,55 & 0,20 & 0,37 & 0,35 \\
\hline $\operatorname{lag} 3$ & 0,47 & 0,27 & 0,36 & 0,40 \\
\hline $\operatorname{lag} 4$ & 0,28 & 0,26 & 0,26 & 0,27 \\
\hline $\operatorname{lag} 5$ & 0,31 & 0,19 & 0,19 & 0,21 \\
\hline $\operatorname{lag} 6$ & 0,44 & 0,29 & 0,30 & 0,32 \\
\hline $\begin{array}{l}\text { Notas: } \\
\text { (1) Números entre parêntese } \\
\text { (2) Um asterisco indica coefi } \\
\text { dois asteriscos, significante }\end{array}$ & $\begin{array}{l}\text { s são desvios } p \\
\text { ciente significan } \\
5 \% \text {, três asteri }\end{array}$ & $\begin{array}{l}\text { adrão robust } \\
\text { te ao nível cr } \\
\text { scos, significe }\end{array}$ & $\begin{array}{l}\text { os. } \\
\text { ático de } 10 \% \text {, } \\
\text { ância à } 1 \% \text {. }\end{array}$ & \\
\hline
\end{tabular}




\begin{tabular}{|c|c|c|}
\hline $\begin{array}{l}\text { TABELA } 24 \text { - RESULTADOS DA } \\
\text { VARIÁVEL DEPENDENTE: (E } \mathrm{E}_{\mathrm{t}-1}[\pi \\
\text { EXPECTATIVA INFLACIONÂRIA } \\
\text { CONTROLADA PARA CHOQUES }\end{array}$ & $\begin{array}{l}\text { ESTIMAÇÕES D } \\
\left.\left.D_{t+2}+\pi b_{t+1}\right]\right) / 2-\left(\pi b_{t}\right. \\
\text { DRIGINAL / PER } \\
\text { DO PETRÓLEO F }\end{array}$ & $\begin{array}{l}\text { A EQUAÇÃO (3.48) } \\
+\pi b_{t-1} / 2 \\
\text { ODO: } 1 / 1961-2 / 199 s \\
\text { ASSADOS }\end{array}$ \\
\hline medida de $y(t-1)$ & y-Hodr.-Presc. & Util. Capacidade \\
\hline intercepto & $\begin{array}{c}0,0025^{* * *} \\
(0,0008)\end{array}$ & $\begin{array}{l}0,0022^{* *} \\
(0,0009)\end{array}$ \\
\hline $\begin{array}{l}D_{D} \cdot B C C(t) \\
D_{U} \cdot B C C(t)\end{array}$ & $\begin{array}{l}0,0182^{* * *} \\
(0,0060) \\
0,0075^{* *} \\
(0,0036)\end{array}$ & $\begin{array}{l}0,0152^{* * *} \\
(0,0051) \\
0,0079^{*} \\
(0,0045)\end{array}$ \\
\hline $\begin{array}{l}D_{D} \cdot y(t-1) \\
D_{U} \cdot y(t-1)\end{array}$ & $\begin{array}{c}-0,1182 \\
(0,1568) \\
0,0218\end{array}$ & $\begin{array}{c}-0,0443 \\
(0,0758) \\
0,0099\end{array}$ \\
\hline & $(0,0475)$ & $(0,0262)$ \\
\hline var. Preço real petr. (bt) & $\begin{array}{l}-0,0012 \\
(0,0039)\end{array}$ & $\begin{array}{l}-0,0020 \\
(0,0045)\end{array}$ \\
\hline var. Preço real petr. (bt-1) & $\begin{array}{l}-0,0093 \\
(0,0041)\end{array}$ & $\begin{array}{l}-0,0109^{* *} \\
(0,0045)\end{array}$ \\
\hline var. Preço real petr. (bt-2) & $\begin{array}{c}-0,0119^{* * *} \\
(0,0041)\end{array}$ & $\begin{array}{l}-0,0122 \\
(0,0046)\end{array}$ \\
\hline var. Preço real petr. (bt-3) & $\begin{array}{l}-0,0106^{* *} \\
(0,0040)\end{array}$ & $\begin{array}{l}-0,0109^{* *} \\
(0,0042)\end{array}$ \\
\hline var. Preço real petr. (bt-4) & $\begin{array}{l}-0,0082^{* *} \\
(0,0038)\end{array}$ & $\begin{array}{l}-0,0084^{* *} \\
(0,0038)\end{array}$ \\
\hline MA (1) & $\begin{array}{c}0,3086^{* * *} \\
(0,1022)\end{array}$ & $\begin{array}{l}0,3269^{* * *} \\
(0,1118)\end{array}$ \\
\hline R2 ajustado & 0,58 & 0,58 \\
\hline DW & 1,84 & 1,87 \\
\hline teste de superid. - P-value & 0,57 & 0,36 \\
\hline Jarque-Bera - P-value & 0,19 & 0,10 \\
\hline $\begin{array}{l}\text { Teste Wald (P-value): } \\
D_{D} \cdot \gamma=D_{U} \cdot \gamma\end{array}$ & 0,141 & 0,191 \\
\hline $\begin{array}{l}\text { correlograma (P-values): } \\
\operatorname{lag} 1 \\
\operatorname{lag} 2 \\
\operatorname{lag} 3 \\
\operatorname{lag} 4 \\
\operatorname{lag} 5 \\
\operatorname{lag} 6\end{array}$ & $\begin{array}{c}- \\
0,20 \\
0,40 \\
0,57 \\
0,67 \\
0,76\end{array}$ & $\begin{array}{c}- \\
0,11 \\
0,24 \\
0,41 \\
0,46 \\
0,58\end{array}$ \\
\hline $\begin{array}{l}\text { Notas: } \\
\text { (1) Números entre parênteses s } \\
\text { (2) Um asterisco indica coeficier } \\
\text { dois asteriscos, significante à } 5 \% \\
\end{array}$ & $\begin{array}{l}\text { svios padrão } \\
\text { nificante ao n } \\
\text { asteriscos, } \mathrm{s} \\
\end{array}$ & $\begin{array}{l}\text { ustos. } \\
\text { I crítico de } 10 \% \text {, } \\
\text { ificância à } 1 \% \text {. }\end{array}$ \\
\hline
\end{tabular}




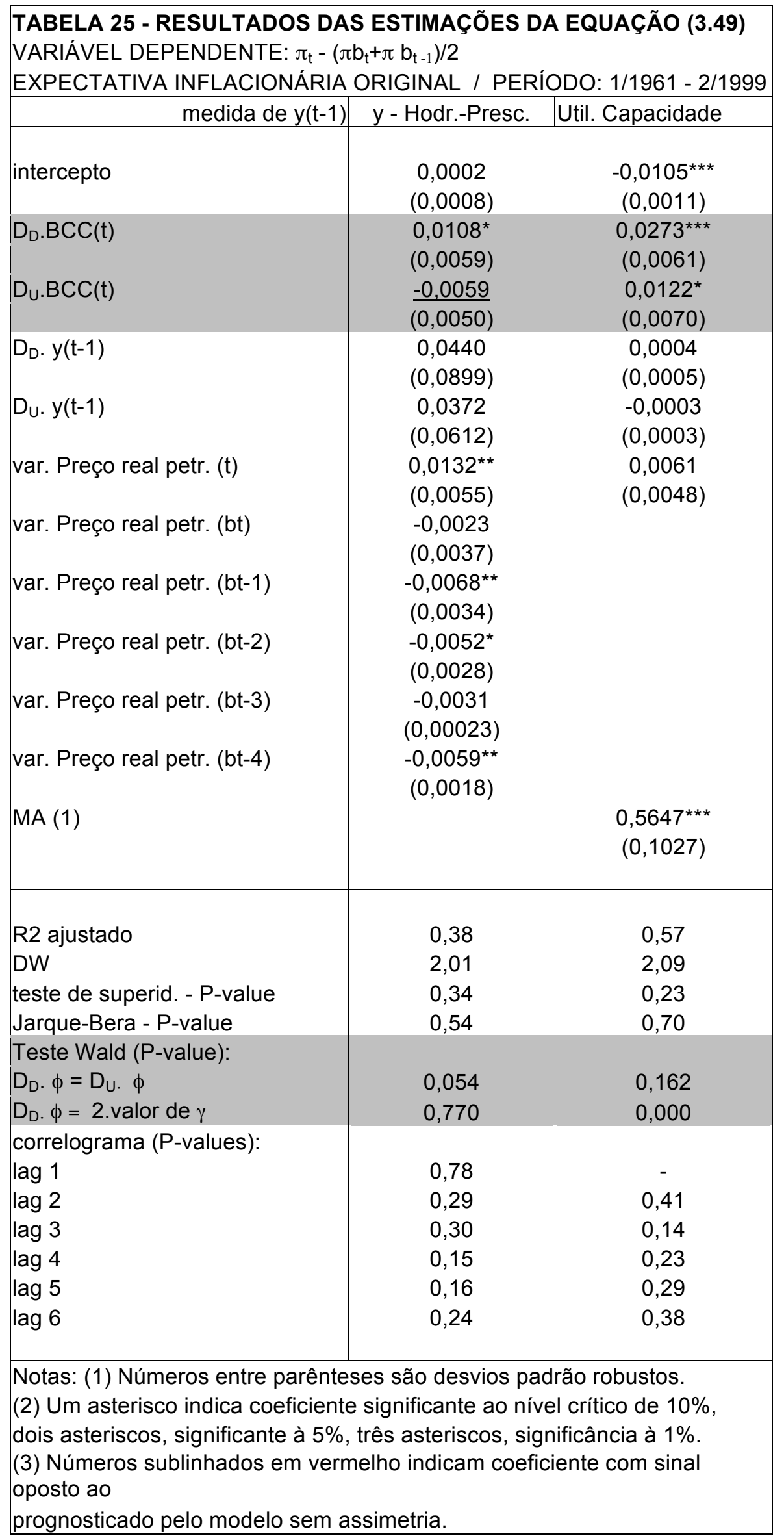




\begin{tabular}{|c|c|c|}
\hline $\begin{array}{l}\text { TABELA } 26 \text { - ESTIMAÇÕES S } \\
\text { EXPECT. INFLAC. ORIGINAIS }\end{array}$ & $\begin{array}{l}\text { OMENTE COM BCC } \\
\text { / PERÍODO: } 1 / 1961-2 / 1999\end{array}$ & \\
\hline EQUAÇÃO & $(3.48)$ & (3.49) \\
\hline VAR. DEPENDENTE & $\left(\mathrm{E}_{\mathrm{t}-1}\left[\pi \mathrm{b}_{\mathrm{t}+2}+\pi \mathrm{b}_{\mathrm{t}+1}\right]\right) / 2-\left(\pi \mathrm{b}_{\mathrm{t}}+\pi \mathrm{b}_{\mathrm{t}-1}\right) / 2$ & $\pi_{t}-\left(\pi b_{t}+\pi b_{t-1}\right) / 2$ \\
\hline Intercepto & $\begin{array}{r}0,0031^{* * *} \\
(0,0010)\end{array}$ & $\begin{array}{c}0,0003 \\
(0,0007)\end{array}$ \\
\hline$D_{D} \cdot B C C(t)$ & $\begin{array}{l}0,0244^{* * *} \\
(0,0049)\end{array}$ & $\begin{array}{l}0,0152^{* * *} \\
(0,0050)\end{array}$ \\
\hline$D_{U} \cdot B C C(t)$ & $\begin{array}{l}0,0089^{* *} \\
(0,0041)\end{array}$ & $\frac{-0,0056}{(0,0052)}$ \\
\hline var. Preço real petr. (t) & & $\begin{array}{l}0,0140 * * * \\
(0,0049)\end{array}$ \\
\hline var. Preço real petr. (bt) & & $\begin{array}{l}-0,0011 \\
(0,0035)\end{array}$ \\
\hline var. Preço real petr. (bt-1) & & $\begin{array}{l}-0,0060^{*} \\
(0,0033)\end{array}$ \\
\hline var. Preço real petr. (bt-2) & & $\begin{array}{l}-0,0034 \\
(0,0026)\end{array}$ \\
\hline var. Preço real petr. (bt-3) & & $\begin{array}{l}-0,0029 \\
(0,0027)\end{array}$ \\
\hline var. Preço real petr. (bt-4) & & $\begin{array}{c}-0,0057^{\star *} \\
(0,0023)\end{array}$ \\
\hline $\mathrm{MA}(1)$ & $\begin{array}{c}0,3893^{* * *} \\
(0,1024)\end{array}$ & \\
\hline R2 ajustado & 0,53 & 0,31 \\
\hline DW & 1,92 & 1,95 \\
\hline teste de superid. - P-value & 0,16 & 0,47 \\
\hline Jarque-Bera - P-value & 0,70 & 0,87 \\
\hline $\begin{array}{l}\text { Testes Wald (P-values): } \\
\text { DD. } \gamma=\text { DU. } \gamma \text { ou DD. } \phi=\text { DU. } \phi\end{array}$ & 0,017 & 0,011 \\
\hline $\begin{array}{l}\text { correlograma (P-values): } \\
\operatorname{lag} 1 \\
\operatorname{lag} 2 \\
\operatorname{lag} 3 \\
\operatorname{lag} 4 \\
\operatorname{lag} 5 \\
\operatorname{lag} 6\end{array}$ & $\begin{array}{l}- \\
0,42 \\
0,45 \\
0,29 \\
0,27 \\
0,39\end{array}$ & $\begin{array}{c}0,92 \\
0,3 \\
0,25 \\
0,18 \\
0,17 \\
0,25\end{array}$ \\
\hline \begin{tabular}{|l} 
Notas: \\
(1) Números entre parênteses \\
(2) Um asterisco indica coeficie \\
dois asteriscos, significante à 5 \\
(3) Números sublinhados em v \\
prognosticado pelo modelo sen
\end{tabular} & $\begin{array}{l}\text { são desvios padrão robustos. } \\
\text { nte significante ao nível crítico de } \\
\% \text {, três asteriscos, significância à } \\
\text { ermelho indicam coeficiente com si } \\
\text { l assimetria. }\end{array}$ & $\begin{array}{l}10 \% \\
1 \% \text {. } \\
\text { inal oposto ao }\end{array}$ \\
\hline
\end{tabular}




\begin{tabular}{|c|c|c|}
\hline $\begin{array}{l}\text { TABELA } 27 \text { - ESTIMAÇÕES SEM HISTERE } \\
\text { VARIÁVEL DEPENDENTE: : } \pi_{\mathrm{t}}-\left(\pi \mathrm{b}_{\mathrm{t}}+\pi \mathrm{b}_{\mathrm{t}-1}\right) / 2 \\
\text { PERÍODO: } 1 / 1961-2 / 1999\end{array}$ & A EQUAÇÃO & \\
\hline medida de $D_{D} \cdot \gamma E_{t-1}\left[\left(y_{t}+y_{t+1}\right) / 2\right]$ & y- Hodr.-Presc. & desemprego \\
\hline Intercepto & $\begin{array}{c}0,0005 \\
(0,0006)\end{array}$ & $\begin{array}{c}0,0007 \\
(0,0006)\end{array}$ \\
\hline$D_{D \cdot \gamma} E_{t-1}\left[\left(y_{t}+y_{t+1}\right) / 2\right]$ & $\begin{array}{l}0,1507^{* * *} \\
(0,0566)\end{array}$ & $\begin{array}{r}-0,2517^{* *} \\
(0,1005)\end{array}$ \\
\hline DU. $\gamma \mathrm{E}_{\mathrm{t}-1}\left[\left(\mathrm{yt}_{\mathrm{t}}+\mathrm{y}_{\mathrm{t}+1}\right) / 2\right]$ & $\begin{array}{c}0,0255 \\
(0,0622)\end{array}$ & $\frac{0,0728}{(0,1018)}$ \\
\hline var. Preço real petr. (t) & $\begin{array}{l}0,0188^{* * *} \\
(0,0029)\end{array}$ & $\begin{array}{l}0,0180^{* * *} \\
(0,0026)\end{array}$ \\
\hline var. Preço real petr. (bt) & $\begin{array}{l}-0,0023 \\
(0,0030)\end{array}$ & $\begin{array}{l}-0,0034 \\
(0,0026)\end{array}$ \\
\hline var. Preço real petr. (bt-1) & $\begin{array}{l}-0,0055 \\
(0,0034)\end{array}$ & $\begin{array}{l}-0,0056 \\
(0,0031)\end{array}$ \\
\hline var. Preço real petr. (bt-2) & $\begin{array}{c}-0,0062^{* * *} \\
(0,0021)\end{array}$ & $\begin{array}{l}-0,0070^{* *} \\
(0,0023)\end{array}$ \\
\hline var. Preço real petr. (bt-3) & $\begin{array}{l}-0,0032 \\
(0,0020)\end{array}$ & $\begin{array}{l}-0,0029 \\
(0,0022)\end{array}$ \\
\hline var. Preço real petr. (bt-4) & $\begin{array}{c}-0,0070^{* * *} \\
(0,0016)\end{array}$ & $\begin{array}{c}-0,0058^{\star \star \star} \\
(0,0022)\end{array}$ \\
\hline R2 ajustado & 0,44 & 0,37 \\
\hline DW & 2,01 & 1,89 \\
\hline teste de superid. - P-value & 0,30 & 0,31 \\
\hline Jarque-Bera - P-value & 0,02 & 0,27 \\
\hline $\begin{array}{l}\text { Testes Wald (P-values): } \\
\text { DD. } \phi=\text { DU. } \phi\end{array}$ & - & 0,072 \\
\hline $\begin{array}{l}\text { correlograma (P-values): } \\
\operatorname{lag} 1 \\
\operatorname{lag} 2 \\
\operatorname{lag} 3 \\
\operatorname{lag} 4 \\
\operatorname{lag} 5 \\
\operatorname{lag} 6\end{array}$ & $\begin{array}{l}0,87 \\
0,98 \\
0,86 \\
0,38 \\
0,43 \\
0,52\end{array}$ & $\begin{array}{l}0,73 \\
0,93 \\
0,82 \\
0,17 \\
0,11 \\
0,18\end{array}$ \\
\hline $\begin{array}{l}\text { Notas: (1) Números entre parênteses são des } \\
\text { (2) Um asterisco indica coeficiente significant } \\
\text { dois asteriscos, significante à } 5 \% \text {, três asteris } \\
\text { (3) Números sublinhados em vermelho indica } \\
\text { prognosticado pelo modelo sem assimetria. }\end{array}$ & $\begin{array}{l}\text { padrão robustos. } \\
\text { nível crítico de } 10 \\
\text { significância à } 1 \% \\
\text { eficiente com sin }\end{array}$ & \\
\hline
\end{tabular}




\begin{tabular}{|c|c|c|c|}
\hline $\begin{array}{r}\text { TABELA } 28 \text { - RESULTADOS DA } \\
\text { ROBUSTÊS FRENT } \\
\text { INFLACIONÁRIA EX }\end{array}$ & $\begin{array}{l}\text { IS ESTIMAÇÕES } \\
\text { E À ERROS DE } \\
\text { KPURGADA DE I }\end{array}$ & $\begin{array}{l}\text { DA EQUAÇÃO } \\
\text { MEDIDA (EXPEC } \\
\text { /IÉS) }\end{array}$ & $\begin{array}{l}(3.48) \\
\text { TATIVA }\end{array}$ \\
\hline medida de $\mathrm{y}(\mathrm{t}-1)$ & $\mathrm{y}$ - tend. Linear & $\mathrm{y}$ - tend. Linear & y - ut. de capac. \\
\hline intercepto & $\begin{array}{c}0,002 \\
(0,0015)\end{array}$ & $\begin{array}{c}0,001 \\
(0,0010)\end{array}$ & $\begin{array}{c}0,0006 \\
(0,0011)\end{array}$ \\
\hline $\begin{array}{l}D_{D} \cdot B C C(t) \\
D_{U} \cdot B C C(t)\end{array}$ & $\begin{array}{c}0,009 \\
(0,0092) \\
0,000 \\
(0,0069)\end{array}$ & $\begin{array}{c}0,008 \\
(0,0184) \\
0,001 \\
(0,0120)\end{array}$ & $\begin{array}{c}0,0096 \\
(0,0097) \\
0,0027 \\
(0,0112)\end{array}$ \\
\hline$D_{D} \cdot y(t-1)$ & $\begin{array}{c}0,104 \\
(0,0706)\end{array}$ & $\begin{array}{l}-0,0384 \\
(0,1952)\end{array}$ & $\begin{array}{l}-0,0010 \\
(0,0017)\end{array}$ \\
\hline$D_{u} \cdot y(t-1)$ & $\begin{array}{l}-0,0282 \\
(0,0422)\end{array}$ & $\begin{array}{c}0,002 \\
(0,0486)\end{array}$ & $\begin{array}{c}0,0004 \\
(0,0005)\end{array}$ \\
\hline var. Preço real petroleo (bt) & & $\begin{array}{c}0,000 \\
(0,0072)\end{array}$ & $\begin{array}{c}0,0014 \\
(0,0087)\end{array}$ \\
\hline var. Preço real petroleo (bt-1) & & $\begin{array}{l}-0,0078 \\
(0,0051)\end{array}$ & $\begin{array}{l}-0,0060 \\
(0,0073)\end{array}$ \\
\hline var. Preço real petroleo (bt-2) & & $\begin{array}{l}-0,0122 \\
(0,0061)\end{array}$ & $\begin{array}{l}-0,0099 \\
(0,0082)\end{array}$ \\
\hline var. Preço real petroleo (bt-3) & & $\begin{array}{l}-0,0072 \\
(0,0043)\end{array}$ & $\begin{array}{l}-0,0108 \\
(0,0071)\end{array}$ \\
\hline var. Preço real petroleo (bt-4) & & $\begin{array}{l}-0,0066 \\
(0,0052)\end{array}$ & $\begin{array}{l}-0,0100 \\
(0,0067)\end{array}$ \\
\hline MA (1) & $\begin{array}{l}0,2425^{* *} \\
(0,1191)\end{array}$ & $\begin{array}{c}0,3356^{* * *} \\
(0,1247)\end{array}$ & $\begin{array}{l}0,3293^{* *} \\
(0,1353)\end{array}$ \\
\hline R2 ajustado & 0,28 & 0,27 & 0,14 \\
\hline DW & 1,94 & 1,88 & 1,84 \\
\hline teste de superid. - P-value & 0,30 & 0,11 & 0,20 \\
\hline Jarque-Bera - P-value & 0,95 & 0,01 & 0,11 \\
\hline $\begin{array}{l}\text { Testes Wald (P-values): } \\
D_{\mathrm{D}} \cdot \gamma=\mathrm{D}_{\mathrm{U}} \cdot \gamma\end{array}$ & 0,432 & - & 0,366 \\
\hline $\begin{array}{l}\text { correlograma (P-values): } \\
\operatorname{lag} 1 \\
\text { lag } 2 \\
\operatorname{lag} 3 \\
\operatorname{lag} 4 \\
\operatorname{lag} 5 \\
\operatorname{lag} 6\end{array}$ & $\begin{array}{c}- \\
0,39 \\
0,67 \\
0,18 \\
0,29 \\
0,35\end{array}$ & $\begin{array}{c}- \\
0,10 \\
0,25 \\
0,34 \\
0,31 \\
0,40\end{array}$ & $\begin{array}{c}- \\
0,31 \\
0,59 \\
0,78 \\
0,69 \\
0,72\end{array}$ \\
\hline $\begin{array}{l}\text { Notas: (1) Números entre parên } \\
\text { (2) Um asterisco indica coeficie } \\
\text { dois asteriscos, significante à } 5\end{array}$ & $\begin{array}{l}\text { es sao desvio } \\
\text { significante a } \\
\text { três asterisco }\end{array}$ & $\begin{array}{l}\text { nível crítico de } \\
\text { significância à }\end{array}$ & \\
\hline
\end{tabular}


O quadro geral pode, então, ser assim descrito:

1) Começando pelo pior resultado, a tabela 26 nos mostra que as estimações com as expectativas inflacionárias expurgadas de viés foram muito ruins, não resultando nenhum coeficiente significante com exceção dos termos MA(1), os quais foram necessários para eliminar a autocorrelação dos resíduos. Em outra regressão, da tabela 25, os resíduos não foram normais. Focaremos, então, a maior parte da nossa análise apenas as outras onze regressões.

2) Em todas estas onze regressões, a iteração entre $D_{D}$ e a variável que mede a expectativa a respeito do nível de atividade futuro ${ }^{64}$ teve o sinal correto e foi significante. Por outro lado, em três destas estimações a iteração desta variável com $D_{u}$ teve o sinal oposto ao prognosticado pelo modelo sem assimetria (ainda que não em níveis sigificantes).

3) Em todas as onze estimações o coeficiente da iteração com $D_{D}$ citada acima foi maior ${ }^{65}$ do que o da iteração com $D_{\cup}$. Em seis delas esta diferença foi estatisticamente significante (estatística $\chi^{2}$ do teste de Wald com $p$-value menor do que $10 \%)$.

4) Por outro lado, o fato de uma restrição de $\left\{D_{D} . \phi=2\right.$.(valor de $\left.\left.\gamma\right)\right\}$, da tabela 23 ter sido rejeitada a 0,1\% de significância constitui uma evidência a favor da hipótese de que uma parcela dos agentes tem expectativas inconsistentes. Esta conjectura é reforçada por termos obtido oito coeficientes

\footnotetext{
${ }^{64} \mathrm{Na}$ maior parte das estimações esta variável foi $\mathrm{BCC}_{\mathrm{t}}$. Apenas nas estimações da tabela 25 ela foi representada por $\mathrm{E}_{\mathrm{t}-1}\left[\left(\mathrm{y}_{\mathrm{t}}+\mathrm{y}_{\mathrm{t}+1}\right) / 2\right]$.

${ }^{65} \mathrm{Na}$ regressão com desemprego futuro esperado, da tabela 25 , o raciocínio é o mesmo, mas com o sinal contrário.
} 
de $D_{u} . B C C$ significantemente positivos e nenhum significantemente negativo. Com relação à hipótese de histerese espúria ${ }^{66}$ em (3.48), avaliamos que nossos resultados não geraram evidências muito fortes. Temos apenas o fato de (3.49) ter gerado duas estimações (as da tabela 25) de modelos sem histerese com resíduos não autocorrelacionados enquanto (3.48) não nos legou nenhuma.

5) concluímos, então, que a representação que melhor se coaduna com os dados parece ser a de uma combinação de pelo menos um dos modelos que implica assimetria com a hipótese de uma parcela dos agentes ter expectativas inconsistentes.

6) Nossos resultados foram robustos ao controle frente a choques do petróleo, como mostram várias estimações das tabelas 24 a 28 .

7) Dados os resultados ruins da tabela 26, caso o viés das expectativas inflacionárias captadas pelo UMSDC se devam a erros de medida, nossos resultados ficam comprometidos.

\footnotetext{
${ }^{66}$ Ver seção 3.4 item A.
} 
CONCLUSÕES 
Este trabalho teve como objetivo a verificação de quais são os modelos capazes de explicar a inércia inflacionária e o custo das estabilizações nos EUA. Recorremos a dados da pesquisa junto ao consumidor da Universidade de Michigan para obtermos informações a respeito das expectativas reais dos agentes a respeito tanto da taxa de inflação quanto do nível de atividade. Trabalhos anteriores, dentro do nosso assunto (como Roberts $(1997,1998)$ ), utilizaram apenas as expectativas inflacionárias desta pesquisa. Nosso procedimento permitiu o teste de uma variação do modelo de Taylor com informação defasada (uma hipótese bastante em voga desde os trabalhos de Roberts $(1997,1998))$ e revelou uma assimetria na inércia inflacionária. Uma outra contribuição importante do trabalho foi discutir esta assimetria dentro do contexto da economia comportamental.

As principais conclusões deste trabalho são:

1) Parcela importante do custo das estabilizações inflacionárias dos EUA dos anos 67 a 99 não pode ser explicada através do modelo de Taylor com contratos salariais de um ano em conjunto com hipóteses de falta de credibilidade e difusão lenta, para agentes homogêneos, das informações a respeito da política monetária e suas conseqüências.

2) A metodologia que desenvolvemos na seção 3.4 para testar os três fatores que aventamos ter potencial para explicar estes custos - a hipótese de que parte da população tem expectativas ingênuas e inconsistentes, um modelo com incerteza knightiana e um modelo com "fairness" - nos sugere que o modelo que teve melhor aderência aos dados combina uma ou ambas as 
representações que implicam assimetria (o modelo comportamental ou o modelo com incerteza knightiana) com a hipótese de agentes heterogêneos com uma parcela deles tendo expectativas ingênuas e inconsistentes.

Observamos que:

1) Não analisamos o que ocorre com modelos de Taylor com contratos salariais de mais de um ano. Eles podem ser um fator importante por traz dos elevados custos de estabilização nos EUA vis-à-vis o que ocorre em outros países. Se tomarmos como base os dados levantados por Ball (1994b), a taxa de sacrifício média das estabilizações (exclusive as que tiveram políticas de renda) de alguns dos países da OCDE, em termos de perda de produto em potencial, período de 1960 a 1991, séries trimestrais, equivaleu a:

\begin{tabular}{|c|c|}
\hline ia & \\
\hline Janadá & \\
\hline rança .... & $0,75 \%$ \\
\hline anha & $2,92 \%$ \\
\hline & 1,7 \\
\hline 0 & $0,93 \%$ \\
\hline & 1,57 \\
\hline ido & \\
\hline & \\
\hline
\end{tabular}

Média exclusive EUA ... 1,54\%

Como os EUA possuem a particularidade de que grande parte dos contratos salariais negociados por sindicatos tem duração de três anos, este pode ser o motivo por traz de seus custos de estabilização terem sido maiores do que a média obtida nos outros países analisados. Além disto, nestes 
contratos de três anos, os salários pactuados são diferentes em cada um destes anos - o que, conforme análises já citadas de Ball (1994a) e Bonomo e Garcia (1994) dificulta a obtenção de estabilizações neutras em termos de produto.

Convém notar, porém, que os contratos de três anos não são capazes de gerar a assimetria que discutimos.

2) Nosso estudo compreendeu modelos com reajustes que seguiam apenas regras dependentes do tempo, de modo que não analisamos o que ocorreria se dependessem também do estado. Quanto a isto, observamos que Almeida e Bonomo (1997) mostraram que, na ausência de falta de credibilidade, o modelo com regras dependentes do estado e expectativas racionais gera estabilizações instantâneas sem custo. Ou seja, nele não há necessidade de gradualismo ou pré-anúncio, que eram necessários para se obter uma estabilização sem custos em um modelo com regra dependente do tempo. Deste modo, estabilizações com custos antecipados pelos agentes pedem, também no contexto de modelos com regras dependentes do estado, algo como os modelos explicitados no capítulo três.

3) Uma outra hipótese bastante em foco na literatura mais recente é a de que a inércia inflacionária decorre de uma indexação pela inflação passada feita automaticamente entre os momentos, mais esparsos, em que as firmas tomam decisões de preço com base em um conjunto mais completo de informações. Exemplos deste tipo de abordagem são encontrados em Bonomo e Garcia (1994) e Christiano, Eichenbaum e Evans (2001). Uma evolução 
natural deste tipo de modelo é encontrada em Cespedes, Kumhof e Parrado (2002), onde a regra de reajustes automáticos não se restringe unicamente a possibilidade de indexação pela inflação passada. Nossa avaliação da aplicação desta abordagem para resolver o problema aqui colocado é a de que:

i) Ela se aplica muito mais a casos de inflação elevada (Bonomo e Garcia (1994) estão isentos desta crítica) do que aos EUA, onde a duração média do período em que os preços ficam fixos se manteve alta mesmo durante os anos 70 e 80 (ver vários trabalhos citados por Taylor (1999)).

ii) Ela não gera a assimetria que nós verificamos e nem a inconsistência expectacional, que também contou com algumas evidências.

4) Nossa análise se aplica principalmente aos casos de inflação moderada. Para uma abordagem comportamental estudando que ocorre quando a taxa de inflação está próxima de zero, ver Akerlof, Dickens e Perry (1996, 2001).

Finalizamos dizendo que já estão em curso novas estimações, que mostram que os resultados aqui reportados são bastante robustos. Entre elas, temos as estimações do modelo de Taylor com BC (índice de "business conditions" com base nas respostas de todos os agentes pesquisados) no lugar de BT, estimações de todas as regreções com log de BCC e pequenas mudanças no período da taxa de inflação passada das variáveis dependentes das regressões do capítulo 3.

Duas extensões do trabalho que pretendemos realizar em breve incluem uma aplicação para o caso brasileiro e uma rediscussão da questão da 
credibilidade em estabilizações. Diante do que foi dito aqui, avaliamos que esta credibilidade demanda um montante adicional de capacidade fiscal e vontade política, para suportar uma elevação medianamente prolongada na taxa de juros real e sua inerente recessão. Parte destas pode ser, no entanto virtual ${ }^{67}$ (desde que haja esta credibilidade). Além disto, deve-se estar aberto para o uso da psicologia cognitiva para entender os ciclos políticos.

${ }^{67}$ Ver Lunardelli (1997). 


\section{APÊNDICE A \\ SIMULAÇÕES DE ESTABILIZAÇÕES EM UMA ECONOMIA SEM RIGIDEZ REAL}

Mostramos aqui as simulações das políticas mostradas na seção (1.1c) para o caso de $\beta=1$, equivalente à ausência de rigidez real.

a) estabilização pré anunciada:

Até o período $\mathrm{t}=2, \mathrm{~m}_{\mathrm{t}}=\mathrm{t}$ e é anunciado em $\mathrm{t}=1$ que, a partir do período seguinte, $\mathrm{m}$ ficará constante (para sempre), igual a 2.

\begin{tabular}{|l|lllll|}
\hline Período & $\mathrm{t}=0$ & $\mathrm{t}=1$ & $\mathrm{t}=2$ & $\mathrm{t}=3$ & $\mathrm{t}=4$ \\
\hline $\mathrm{M}$ & 0 & 1 & 2 & 2 & 2 \\
$\mathrm{~W}$ & 0.5 & 1,5 & 2 & 2 & 2 \\
$\mathrm{P}$ & 0 & 1 & 1,75 & 2 & 2 \\
$\mathrm{Y}$ & 0 & 0 & 0,25 & 0 & 0 \\
\hline
\end{tabular}

Ou seja, ocorre um boom em $\mathrm{t}=2$, durando apenas este período.

b) estabilização sem gradualismo e sem anúncio prévio:

Evolução de $\mathrm{m}$ idêntica à do caso anterior, mas com a mudança anunciada em $\mathrm{t}=2$ ao invés de em $\mathrm{t}=1$,

\begin{tabular}{|l|lllll|}
\hline Período & $\mathrm{t}=0$ & $\mathrm{t}=1$ & $\mathrm{t}=2$ & $\mathrm{~T}=3$ & $\mathrm{t}=4$ \\
\hline $\mathrm{M}$ & 0 & 1 & 2 & 2 & 2 \\
$\mathrm{~W}$ & 0.5 & 1,5 & 2,5 & 2 & 2 \\
$\mathrm{P}$ & 0 & 1 & 2 & 2,25 & 2 \\
$\mathrm{Y}$ & 0 & 0 & 0 & $-0,25$ & 0 \\
\hline
\end{tabular}

Ou seja, ocorre uma recessão em $\mathrm{t}=3$, durando apenas este período.

c) estabilização gradualista anunciada no final do período anterior à mudança:

Assim como na simulação (b), a mudança de política só é anunciada em $t=2$, mas desta vez há uma regra de transição:

Até $\mathrm{t}=2, \mathrm{~m}=\mathrm{t}$

$\mathrm{Em} \mathrm{t}=3, \mathrm{~m}$ aumenta 0,5, atingindo 2,5.

Depois disto, $m$ permanece constante em 2,5 


\begin{tabular}{|llllll|}
\hline Período & $\mathrm{t}=0$ & $\mathrm{t}=1$ & $\mathrm{t}=2$ & $\mathrm{t}=3$ & $\mathrm{t}=4$ \\
\hline $\mathrm{M}$ & 0 & 1 & 2 & 2,5 & 2,5 \\
$\mathrm{~W}$ & 0.5 & 1,5 & 2,5 & 2,5 & 2,5 \\
$\mathrm{P}$ & 0 & 1 & 2 & 2,5 & 2 \\
$\mathrm{Y}$ & 0 & 0 & 0 & 0 & 0 \\
\hline
\end{tabular}

Não ocorrendo nem boom nem recessão. 


\section{APÊNDICE B \\ RESUMO DA LITERATURA A RESPEITO DA \\ IMPORTÂNCIA DE "FAIRNESS" E \\ RECIPROCIDADE PARA ECONOMIA}

As evidências podem ser divididas em três modalidades: experimentos de laboratório, "surveys" e "trabalhos de campo".

\section{i) EXPERIMENTOS DE LABORATÓRIO}

Um dos experimentos mais estudados é o do chamado "jogo de ultimato". Nele, uma quantia em dinheiro deve ser dividida entre duas pessoas. Primeiramente uma delas determina qual a parte de cada uma e, em seguida, a outra pessoa diz se aceita ou não. Caso esta segunda pessoa aceite a divisão, cada uma recebe o proposto, caso contrário, ninguém recebe nada. O jogo não é repetido (ao menos não com o mesmo parceiro-adversário), de modo que o prognóstico da teoria dos jogos é o de que a segunda pessoa terá predisposição a aceitar até mesmo uma parcela bastante pequena do bolo e que a primeira (sabendo disso), proporá uma divisão bastante desigual a seu favor. Os resultados são, no entanto, extremamente robustos ${ }^{68}$ no sentido de um desvio significativo do equilíbrio que não leva em conta "fairness" e a possibilidade de retaliação. A maioria esmagadora dos proponentes escolhe divisões mais próximas de $50 \%$ para cada um do que de uma divisão muito desigual. A maior parte dos que não fazem isso tem sua proposta rejeitada (não recebendo, portanto, nada). Este resultado se repetiu mesmo quando realizado em países nos quais a renda dos que jogam é pequena relativamente ao valor jogado ${ }^{69}$ e estas pessoas jogam um número de vezes (dez vezes) suficiente para se considerar que apreenderam a natureza do $\mathrm{jogo}^{70}$. A principal conseqüência do aprendizado (no contexto de apostas de valor elevado) foi diminuir a rejeição de propostas medianamente desiguais. Ainda assim, propostas bastante desiguais continuavam sendo, via de regra, rejeitadas ${ }^{71}$.

As evidências encontradas nos experimentos com jogos de ultimato têm sido favoráveis à postulação de que "fairness" deve ser incorporada à análise

\footnotetext{
${ }^{68}$ Ver Roth (1995) e Slonim e Roth (1998).

${ }^{69}$ Ver Cameron (1995).

${ }^{70}$ Em Slonim e Roth (1998) há simultaneamente apostas altas relativamente à renda dos jogadores $\mathrm{e}$ repetição (com jogadores diferentes) em dez vezes.

${ }^{71}$ Ver Slonim e Roth (1998). No experimento com apostas mais altas, cada rodada valia o equivalente a 62,5 horas de trabalho dos jogadores. Havia 15 duplas. Na primeira rodada, 11 proponentes ofereceram mais de $40 \%$ ao outro jogador, com uma rejeição. Dos outros quatro, três tiveram suas propostas rejeitadas. Na décima e última rodada, 14 proponentes ofereceram mais do que $30 \%$ (a moda foi entre $40 \%$ e $45 \%$ ) para o parceiro-adversário, sem nenhuma rejeição e o único que ofereceu menos (abaixo de $24,5 \%$ ) teve sua proposta rejeitada. Assim, a média das propostas aceitas foi equivalente à $42,7 \%$ do bolo (para o segundo jogador) na primeira rodada e $39,0 \%$ na última. A média de todas as ofertas (aceitas e rejeitadas) foi de $37,5 \%$ do bolo (para o segundo jogador) na primeira rodada e $37,2 \%$ na última rodada.
} 
econômica. Mas, como o poder de retaliação do segundo jogador destes jogos é muito grande, há quem argumente que a transposição imediata deste resultado para outras situações econômicas deve ser feita com cautela ${ }^{72}$. Com relação a este ponto, foram feitos vários outros experimentos procurando simular certas situações econômicas concretas.

Alguns experimentos simularam o mercado de trabalho. Em Feher, Kirchsteiger e Riedl (1993), as firmas definiam um nível salarial e, em seguida, os contratados decidiam o nível de esforço. As firmas não sabiam quem fora contratado, apenas o nível de esforço obtido em, após a fixação do salário. Os contratados sabiam que um esforço maior aumentava o lucro das "firmas". O resultado do experimento foi que o nível dos salários mostrou-se altamente significante na determinação do grau de esforço.

No experimento conduzido por Charness (1998), o salário era determinado em algumas rodadas pela firma e, em outras, exogenamente. $O$ resultado obtido foi de que, quando os salários foram escolhidos livremente pelas firmas, o nível de esforço teve uma resposta mais intensa às variações dos salários.

Foram feitos, também, experimentos simulando mercados de bens com relações de clientela. Kalchelmeier, Limberg e Schadewald (1991a e 1991b) e Franciscosi, Kujal, Michelitsch, Simth e Deng (1995) conduziram experimentos simulando o mercado de vendas por correspondência ("postedoffer markets"). Este último trabalho é particularmente interessante porque estendeu o experimento por vários períodos, permitindo uma análise da dinâmica dos preços. No experimento, havia seis vendedores e seis compradores. Os vendedores fixavam os preços sem saberem das ofertas a vigorar dos concorrentes e os compradores decidiam quanto e de quem comprar. Em um determinado período houve uma mudança na tributação que implicou uma elevação tanto no custo marginal quanto no lucro de equilíbrio. $O$ preço de equilíbrio é dado pelo custo marginal. Foram feitas, então, três séries de simulação. Em uma delas, foi revelado o lucro dos vendedores, em outra foi revelado apenas o custo marginal e, na terceira série foram revelados apenas os preços. Cada rodada foi feita com atores diferentes. Os resultados foram que quando se revelou o custo marginal, o preço atingiu imediatamente (na mesma rodada em que houve a alteração tributária) o equilíbrio. Na rodada em que o lucro foi revelado, os preços foram ajustados lentamente, demorando dez períodos para atingir o equilíbrio. Na terceira rodada, o ajuste ocorreu de forma intermediária entre os dois casos anteriores, mais próximo porém, do ajuste instantâneo. A conclusão do artigo foi de que "fairness" pode atrapalhar o ajuste dos mercados no curto prazo, mas o equilíbrio é atingido no médio/longo prazo. Contribui para isto a noção de que a avaliação do que é "fair" depende dos níveis de referência dos agentes, que se ajustam ao longo do tempo (na medida em que o preço caminha para o equilíbrio de longo prazo, o preço "fair" vai se ajustando na mesma direção).

\footnotetext{
${ }^{72}$ Ver Rabin (1997).
} 


\section{ii) "SURVEYS"}

Além dos experimentos de laboratório, outro tipo de evidência a favor da importância de "fairness" em economia tem sido trazido por enquetes que fazem perguntas aos agentes econômicos - as "surveys".

Um dos primeiros estudos nesta direção foi o artigo de Kaneman, Knetsch e Thaler (1986). Nele, pediu-se para as pessoas opinarem sobre o que seria apropriado diante de certas situações. Certificou-se de que "fairness" é vista como relevante no mercado de trabalho e nas relações de clientela, que as pessoas esperam que se dê praticamente o mesmo nível de gorjeta quer se pretenda voltar ao restaurante ou não e que a avaliação do que é aceitável ou não depende de referenciais que são ilógicos do ponto de vista matemático, mas que fazem sentido do ponto de vista cognitivo (por exemplo: considera-se mais aceitável cortar o desconto relativamente a uma lista "oficial", mas reconhecidamente não praticada, de preços do que elevar este preço sem lista de referência alguma). Com relação ao mercado de trabalho, este artigo apurou que cortes nominais de salário em uma economia sem inflação são encarados como uma injustiça muito maior do que cortes no salário real acompanhados de elevações no salário nominal.

Foram realizadas várias "surveys" sobre política salarial e mercado de trabalho. Podemos citar Kaufman (1984), Blinder e Choi (1990), Bewley (1994, 1995), Agell e Lundborg (1995) e Campbell e Kamlani (1997). Em todos os casos as perguntas foram feitas para os empregadores ou os executivos responsáveis pela política salarial e, em alguns casos incluíam também respostas de consultores e advogados trabalhistas. As "surveys" contemplaram empresas de tamanho pequeno, médio e grande, com algum viés de representatividade em favor das médias e, principalmente, grandes. Elas perguntaram qual a opinião dos entrevistados sobre diversas teorias econômicas a respeito do mercado de trabalho e sobre o modo como eles vêem sua política salarial.

Um resultado unânime que emergiu destas "surveys" foi o de que o corte de salários durante uma recessão seria visto, por parte dos trabalhadores, como um procedimento muito injusto e que isto faria com que eles reduzissem o esforço. Foi apontado também que, além de gerar queda no esforço, a medida elevaria o "turn over", que os funcionários mais produtivos seriam os primeiros a buscar outro emprego, e que cairia a qualidade de novos candidatos à contratação.

A "survey" de Agell e Lundborg, no que talvez seja o resultado mais radical destas "surveys", revelou que $81 \%$ dos empregadores industriais suecos acreditavam que a ameaça de corte de menos de $50 \%$ dos empregos não tornaria um corte nominal dos salários aceitável por parte de seus empregados.

A "survey" de Campbell e Kamlani foi feita com base em uma amostra razoavelmente representativa de empresas dos EUA (grandes Indústrias e empresas financeiras estavam, porém, super-representadas). A maior parte dos respondentes era composta de executivos que definiam a política salarial da empresa. Foram obtidos resultados como estes: 
- Os empregadores esperavam que um corte de $10 \%$ nos salários nominais levaria a uma queda de esforço de (na média) $15,4 \%$ entre os empregados de colarinho branco, $19,4 \%$ entre os de colarinho azul e de $22,7 \%$ entre os menos qualificados. Os de colarinho branco, apesar de terem uma redução no esforço esperado menor do que os outros, teriam uma maior predisposição a procurar um novo emprego.

- Indagados sobre se a razão por trás desta redução do esforço estaria mais relacionada com gratidão e lealdade ou com uma simples queda no custo de oportunidade da perda do emprego, 69,2\% apontaram a primeira alternativa, $4,4 \%$ a segunda e $26,4 \%$ ambas.

- Indagados sobre se a queda no esforço associada ao corte de $10 \%$ no salário nominal diminuiria caso a empresa tivesse feito isso por estar tendo prejuízo (vis-à -vis a uma situação na qual a empresa estivesse tendo alto lucro), $88 \%$ dos empregadores disseram que isso mudaria muito ou moderadamente o comportamento no caso dos empregados de colarinho branco, $85,6 \%$ no caso dos de colarinho azul e $74,1 \%$ no dos menos qualificados.

- Em contraste com o resultado obtido por Agell e Lundborg, os empregadores americanos achavam que $42,8 \%$ dos de colarinho branco, $40,7 \%$ dos de colarinho azul e $40,4 \%$ dos menos qualificados prefeririam um corte de $10 \%$ nos salários a um aumento de $10 \%$ na probabilidade de perda do emprego. Ainda $16,9 \%, 21,2 \%$ e $19,9 \%$, respectivamente, não conseguiram opinar sobre as preferências de cada uma das categorias.

Blinder e Choi (1990) entrevistaram 19 executivos responsáveis pela política salarial de empresas com número de empregados variando de 60 à 80.000. Eles indagaram a respeito da pertinência das diversas teorias econômicas em explicar o modo como os salários são fixados e as razões da manutenção dos salários em níveis acima dos que os desempregados estariam dispostos a receber. Na percepção destes executivos, "fairness" desempenha um papel preponderante na motivação dos trabalhadores e, portanto, na determinação dos salários. Questionados a respeito dos efeitos de uma política salarial injusta, $84 \%$ disseram que elevaria a rotatividade, $95 \%$ que o nível de esforço cairia e todos $(100 \%)$ disseram que a qualidade dos futuros candidatos a trabalhar na empresa cairia.

Bewley (1995) fez um estudo bastante amplo, entrevistando 372 pessoas, entre donos e presidentes de empresas (pequenas, médias e grandes), recrutadores profissionais, conselheiros de desempregados, líderes sindicais, consultores e 4 advogados trabalhistas. A expressão utilizada no trabalho (que parece ter emergido das entrevistas) para definir o ponto mais importante na política salarial das empresas foi a "manutenção do "moral elevado" ("good morale"), que implicaria na "disposição de fazer sacrifícios pessoais para o bem da organização". Indagados sobre "por que não tiravam vantagem de uma recessão para reduzir custos trabalhistas", a resposta foi de que isto geraria um "dano ao moral". Eles disseram que aproveitavam estas ocasiões, no entanto, para demitir trabalhadores menos produtivos ${ }^{73}$. Segundo

\footnotetext{
${ }^{73}$ Esta "survey" revelou, também, que os indivíduos que se encontram desempregados durante uma recessão se dispõem a aceitar trabalhos para os quais estão superqualificados. Isto explica como se
} 
Bewley, "a maior parte dos empregadores não disse que um moral baixo geraria um impacto imediato muito grande sobre a produtividade em seu sentido mecânico. Eles pareciam ter em mente os efeitos a longo prazo sobre a coesão da organização".

"Surveys" também foram utilizadas por Binder (1994) para perguntar diretamente às empresas como elas avaliavam as teorias dos economistas a respeito de rigidez de preços. Foram solicitadas entrevistas a uma amostra representativa dos setores privados não regulados, exclusive agricultura, pecuária e instituições que não visam lucro. $61 \%$ das empresas contatadas concordaram em atender ao pedido. As entrevistas ocorreram entre abril de 1990 e março de 1992, tendo sido feitas por estudantes de pós-graduação de Princeton, diretamente treinados pelo autor. Listamos, abaixo, as seis primeiras colocadas entre as doze teorias incluídas na pesquisa, de acordo com a avaliação dos entrevistados sobre a pergunta "quão importante é esta idéia na redução da velocidade do ajustamento de preços na sua empresa?". Os entrevistados davam uma nota de 1 (totalmente sem importância) a 4 (muito importante) para cada teoria. Reproduzimos, também, a média da nota atribuída e o percentual das empresas sobre as quais o autor avaliou que a teoria se aplicaria, que a qualificaram como relevante.

O ranking (pelo critério notas) das teorias foi:

1- não querer elevar os preços antes de a concorrência o fazer (nota 2,77 e $60,6 \%$ de aceitação entre as empresas pertinentes).

2- só ajustar os preços depois de os custo subirem, e não devido a elevações na demanda (nota 2,66 e 55,5\% de aceitação entre as empresas pertinentes).

3- Durante o tempo em que o preço fica fixo, adota-se alguma flexibilidade quanto à qualidade dos serviços que vêm junto com o produto (preferência por reduzir a qualidade a elevar o preço) - (nota 2,58 e $71,2 \%$ de aceitação entre as empresas pertinentes).

4- Compromissos implícitos com a clientela (de manter o preço fixo por um determinado intervalo de tempo) - (nota 2,40 e 73,9\% de aceitação entre as empresas pertinentes).

5- Preços são fixos por contrato (nota 2,11 e 57,7\% de aceitação entre as empresas pertinentes).

6- "Menu cost" (nota 1,89 e 46,7\% de aceitação entre as empresas pertinentes).

Observamos que três das quatro teorias melhor colocadas podem ser estreitamente relacionadas com a idéia de "fairness". A que ficou em quarto lugar (e com o maior percentual de aceitação entre as empresas pertinentes) é a própria teoria de Okun (1981) a respeito de "fairness" e clientela. Quanto a que ficou em segundo lugar, Kaneman, Knetsch e Thaler (1986) mostraram que $82 \%$ dos indivíduos entrevistados consideravam injusta uma elevação de 
preços devida apenas a uma pressão temporária de demanda (já reajustes devidos a pressões de custo foram considerados justos). Em relação à que ficou em terceiro lugar, a "maquiagem" pode ser considerada mais aceitável pelos clientes do que a elevação de preços (esta idéia também encontra algum respaldo em Kaneman, Knetsch e Thaler (1986)). Observamos ainda que até mesmo parte dos motivos por trás da teoria que ficou em primeiro lugar pode ser atribuída à prudência para não gerar antipatia junto aos clientes.

\section{iii) TRABALHOS DE CAMPO}

Para além dos experimentos de laboratório e das "surveys", as evidências sobre "fairness" em economia com base em metodologias econométricas mais usuais são um terreno ainda pouco explorado. Um trabalho digno de menção é encontrado em Akerlof, Dickens e Perry (1996). Este trabalho defende o ponto de vista de que fairness seria o motivo por trás do repúdio à cortes nominais nos salários. A hipótese de que existe rigidez frente ao corte nominal de salários foi recentemente atacada por trabalhos teóricos e empíricos justamente por não ser passível de derivação a partir dos microfundamentos. Akerlof, Dickens e Perry (1996) mostram que as evidências empíricas contrárias podem ser inteiramente atribuídas a erros de medida, e que as evidências livres deste problema apontam para o fato estilizado de que cortes no salário nominal só ocorrem quando a situação financeira das empresas é bastante precária.

Observamos ainda que estes mesmos três autores têm um artigo de 2001 que desenvolve um modelo no qual a dinâmica dos reajustes de preços e salários tem, além da questão "fairness", outros desvios com relação aos microfundamentos, também pautados na PSC. Eles mostram que as perdas por se incorrer nestes desvios, quando a maior parte dos agentes assim procede, são de segunda ordem e que os dados da economia norte-americana são consistentes com o modelo.

Para finalizar, observamos há outros trabalhos empíricos que também postulam a hipótese de "fairness" por trás de fatos econômicos mas que podem ser atribuídos a outros fatores. Campbell e Katz (2001), argumentam que o fato de firmas mais lucrativas pagarem salários mais elevados do que firmas menos lucrativas não precisa ser, necessariamente, atribuído a considerações do tipo "fairness". Ele pode simplesmente refletir diferenças de poder de barganha, pois firmas mais lucrativas tendem a ter um custo de oportunidade mais alto quando demitem um empregado. A maior parte das evidências que nós reportamos procurou, no entanto, isolar o fator "fairness" de outras possibilidades. Os experimentos de laboratório têm exatamente este propósito e as "surveys" procuravam justamente fazer com que os entrevistados escolhessem a mais adequada dentre diferentes teorias. 


\section{APÊNDICE C \\ A DIFICULDADE DA OBTENÇÃO \\ DE EVIDÊNCIAS DE "SURVEY" A RESPEITO \\ DA HIPÓTESE (F1)}

Em primeiro lugar, vejamos qual o reajuste salarial concedido de acordo com o modelo de Taylor. A equação (1.6) nos dá:

$w_{t}=(1 / 2) \cdot E_{t-1}\left[p_{t}+p_{t+1}\right]+\chi \cdot E_{t-1}\left[\left(y_{t}+y_{t+1}\right) / 2\right]+\xi_{t}$

Suponha, agora, que partimos de uma situação hipotética, na qual a economia está em estado estacionário, com inflação moderada estável e pleno emprego. Neste caso, o (log do) reajuste salarial de $w_{t}$ é dado por:

$$
\begin{aligned}
\left(w_{t}-w_{t-2}\right)= & (1 / 2) \cdot E_{t-1}\left[p_{t}+p_{t+1}\right]+\chi \cdot E_{t-1}\left[\left(y_{t}+y_{t+1}\right) / 2\right] \\
& +\xi_{t}-\left\{(1 / 2) \cdot\left(p_{t-1}+p_{t 2}\right)+\xi_{t-1}\right\}
\end{aligned}
$$

o que, desconsiderando-se os termos $\xi_{\mathrm{t}}$ e $\xi_{\mathrm{t}-1}$, e levando-se em conta que a taxa de inflação estava estável até o final de $\mathrm{t}-1$, nos dá:

$$
\left(w_{t}-w_{t-2}\right)=\left\{(1 / 2) \cdot E_{t-1}\left[\pi_{t}+\pi_{t+1}\right]+(1 / 2) \cdot\left(\pi_{t-1}+\pi_{t-2}\right)\right\}+\chi \cdot E_{t-1}\left[\left(y_{t}+y_{t+1}\right) / 2\right]
$$

Ou seja, o reajuste salarial é dado por uma média entre a taxa de inflação futura esperada e a passada, mais um componente associado ao desvio de produto esperado. Portanto, perguntar simplesmente se as empresas levam em conta a inflação passada para determinar o nível de reajuste salarial não nos permitiria corroborar ou rejeitar (F1).

Para complicar ainda mais a inferência através de pergunta direta, um modelo com rigidez inflacionária não necessita que o peso da inflação passada sobre o reajuste salarial efetivo seja maior do que o explicitado em (B.1). Se as expectativas dos agentes forem consistentes com o modelo com "fairness", se os agentes esperarem uma recessão, eles esperarão um reajuste inflacionário menor do que o ditado simplesmente pela referência dada pela inflação passada. Ou seja, teremos, para os reajustes efetivos, algo que seria difícil de distinguir da equação (B.1).

Pelo mesmo motivo apontado no parágrafo anterior, uma eventual rejeição do modelo $\mathbf{F M}$ e não rejeição do modelo de Taylor em um teste casado similar ao feito por Roberts (com as correções de especificação que apontamos no capítulo 1) também pode não significar muita coisa. 


\section{APÊNDICE D \\ UM MODELO DE SALÁRIO EFICIENTE COM "FAIRNESS" E MONITORAMENTO IMPERFEITO}

Dentre os vários modelos de salários eficientes, os modelos com monitoramento imperfeito, como o de Shapiro e Stiglitz (1984), são os mais populares. Os modelos com "fairness" (como os de Akerlof (1982) e Akerlof e Yellen (1990)) ocupam, provavelmente, a segunda colocação. Nada impede, no entanto, que os dois efeitos ocorram simultaneamente - que, simultaneamente, haja reciprocidade por parte do trabalhador relativamente ao tratamento dispensado pela firma e que ele leve em conta o custo de ser surpreendido trabalhando pouco.

É interessante notar, inclusive, que a idéia de que normas sociais (estreitamente relacionada com o conceito de "fairness") desempenham um papel importante pode ser usada para rebater a principal crítica ao modelo de Shapiro e Stiglitz - de que se fosse estipulada uma multa para o trabalhador apanhado gazeteando, o salário eficiente cairia ao nível do salário de reserva. Podemos argumentar que este tipo de procedimento não é adotado simplesmente porque não é socialmente aceitável.

Além disto, a junção dos dois modelos nos permite obter um modelo no qual o salário de equilíbrio é resultado conjunto tanto de fatores econômicos quanto de reciprocidade.

Nosso modelo é quase idêntico ao de Kimball (1994), o modelo de Shapiro e Stiglitz dinâmico. Nossa única alteração é a de assumir que o grau de desprazer do trabalhador em se esforçar é função do tratamento dispensado a ele pela firma. Se ele é extremamente bem tratado e remunerado, há um prazer derivado da retribuição. Se ele é tratado e remunerado de modo injusto isto gera ressentimento. Deste modo, a função de utilidade instantânea do trabalhador i é dada por:

$$
\begin{gathered}
\mathrm{u}_{\text {it }}=\left(\mathrm{W}_{\text {it }} / \mathrm{P}_{\mathrm{t}}\right)^{\circ}-\mathrm{e} \cdot \max \left[\left(\mathrm{Wf}_{\mathrm{t}} / \mathrm{W}_{\mathrm{it}}\right), 1\right] \\
0<\theta \leq 1, \quad \mathrm{e}=0 \text { ou } 1
\end{gathered}
$$

Onde $W$ é o salário nominal, $P$ é o nível geral de preços, e é seu nível de esforço e Wf é o salário que o trabalhador considera justo . A equação (D.1) nos diz que o tamanho do desprazer gerado por empreender um nível de esforço igual a 1 depende de a remuneração ser ou não injusta. Como é usual nestes modelos ${ }^{74}$ assumimos um limite superior para a reciprocidade. Este limite superior foi normalizado para 1 , de modo que pode haver retaliação mas não gratidão. Há possibilidade de alguma gratidão entrar no modelo através de um limite superior acima de 1 , que não modificaria qualitativamente nossos resultados.

A utilidade intertemporal do trabalhador i é dada por:

$$
\mathrm{U}_{\mathrm{it}}=\int \mathrm{u}_{\mathrm{s}} \cdot \exp (-\mathrm{r} .(\mathrm{s}-\mathrm{t})) \mathrm{ds}
$$

\footnotetext{
${ }^{74}$ Ver Akerlof (1982) e Akerlof e Yellen (1990).
} 
Onde $\int \mathrm{d}$ s é a integral de u para o intervalo de tempo que vai de $\mathrm{t}$ até infinito. As equações dinâmicas que nos dão o valor de gazetear ou se esforçar em t são dadas por:

$$
\begin{aligned}
& r . V_{E t}^{S}=\left(W_{i t} / P_{t}\right)^{-}+(b+q) \cdot\left(V_{u t}-V_{E t}^{s}\right)+\dot{V}_{E t}^{S} \\
& r . V_{E t}^{N}=\left(W_{i t} / P_{t}\right)^{\circ}-e \cdot m a x\left[\left(W_{t} / W_{i t}\right), 1\right]+b \cdot\left(V_{u t}-V_{E t}^{N}\right)+\dot{V}_{E t}^{N}
\end{aligned}
$$

Onde r é a taxa de desconto intertemporal, b é uma taxa exógena de "turnover", q é a probabilidade (também exógena) de um gazeteador ser descoberto. $V^{S}$ é o valor de se estar empregado e gazetear, $V^{N}{ }_{E}$ é o valor de se estar empregado e se esforçar e $V_{u}$ é o valor de estar desempregado.

A equação (D.3) nos dá a "rentabilidade" do "ativo" estar empregado e não se esforçar. Ela é igual à utilidade do salário (igual a $\left.\left(\mathrm{W}_{\text {it }} / \mathrm{P}_{\mathrm{t}}\right)^{\mathrm{p}}\right)$ mais a probabilidade de perda do emprego (que no caso de um trabalhador gazeteador é igual a $(b+q)$ ) vezes a diferença entre o valor dos "ativos" "estar desempregado" e "estar empregado" (esta diferença tem valor negativo, pois neste modelo há desemprego involuntário, de modo que $\mathrm{V}_{\mathrm{ut}}<\mathrm{V}_{\mathrm{Et}}$ ).

A equação (D.4) é similar à (D.3), diferindo apenas por incluir a desutilidade do esforço e pelo fato de que um trabalhador que não gazeteia tem uma probabilidade menor de ser demitido.

A empresa deve pagar um salário alto o suficiente para que o trabalhador decida empreender o grau de esforço igual a 1. A condição necessária para isto (chamada "non shirking condition") é:

$\mathrm{V}^{\mathrm{N}}{ }_{\mathrm{Et}}=\mathrm{V}_{\mathrm{Et}}^{\mathrm{S}}$

Diferenciando ambos os lados de (D.5) com relação ao tempo, obtemos:

$\dot{\mathrm{V}}^{\mathrm{N}}{ }_{\mathrm{Et}}=\dot{\mathrm{V}}_{\mathrm{Et}}^{\mathrm{S}}$

Subtraindo (D.3) de (D.2) e usando (D.5) e (D.6), obtemos:

$\mathrm{V}^{N}{ }_{E t}=V_{U t}+\left\{e \cdot \max \left[\left(\mathrm{Wf}_{t} / \mathrm{W}_{\mathrm{it}}\right), 1\right]\right\} / \mathrm{q}$

Diferenciando ambos os lados de (D.5) com relação ao tempo, obtemos:

$\dot{\mathrm{V}}_{\mathrm{Et}}=\dot{\mathrm{V}}_{\mathrm{Ut}}$

Temos que $V_{U t}$ é dado por:

$r V_{U t}=a_{t} \cdot\left(V_{E t}^{N}-V_{U t}\right)+\dot{V}_{U t}$

onde $a_{t}$ é a taxa de ascensão da condição de desempregado para a de empregado.

Utilizando(D.6) em (D.8), obtemos: 
e, utilizando (D.7) e (D.8) em (D.9'), para eliminar $V_{U t}$ e $V_{U t}$, obtemos: $r \cdot\left[V_{E t}^{N}-\left\{e \cdot \max \left[\left(W_{t} / W_{i t}\right), 1\right]\right\} / q\right]=$

$a_{t} \cdot\left[\left\{e \cdot \max \left[\left(\left(W f_{t} / W_{i t}\right)-\kappa 1\right), \kappa 2\right]\right\} / q\right]+\dot{V}_{E t}^{N}$

Usando (D.3) e (D.7) em (D.10), chegamos a:

$\left(W_{i t} / P_{t}\right)^{0}=e \cdot \max \left[\left(W_{t} / W_{i t}\right), 1\right] \cdot\left[1+\left(a_{t}+b+r\right) / q\right]$

Assim, quando $W_{t}>W f_{t}$, teremos o resultado idêntico ao de Shapiro e Stiglitz (ou seja, neste caso, prevalece o salário de "mercado puro"):

$\left(W_{i t} / P_{t}\right)^{\circ}=e \cdot\left[1+\left(a_{t}+b+r\right) / q\right]$

$E$ quando $W_{t} \leq W f_{t}$, teremos:

$W_{\text {it }}=F\left(W f_{t}, P_{t}, a_{t}\right)$

Onde $a_{t}$ é a taxa de ascensão da condição de desempregado para a de empregado, dada pela identidade que determina o fluxo de trabalhadores empregados:

$\dot{L}_{t} \equiv a_{t} \cdot\left[N_{t}-L_{t}\right]-b \cdot L_{t}$

Onde $\mathrm{N}$ é o número total de trabalhadores da economia (suposto, por simplificação, constante), $\dot{L}$ é o número de trabalhadores empregados e $L$ sua diferenciação com relação ao tempo.

Rearranjando (3.29) chegamos a:

$a_{t}=\left(L_{t}+b N\right) /\left(N-L_{t}\right)$

Finalmente, usando (3.29') em (3.28), obtemos:

$W_{\text {it }}=F\left(W f_{t}, P_{t}, L_{t}, \dot{L}_{t}\right)$

Com todas as derivadas parciais positivas. Ou seja, o salário nominal depende positivamente do salário avaliado como "fair" ("justo"), do nível de preços (esperado), do nível de emprego (esperado) e da primeira diferença (esperada) deste. A importância da primeira diferença do desemprego esperado é inerente ao modelo de monitoramento imperfeito e não à reciprocidade. 
Observamos, ainda, que na medida em que Wf leve em conta o W efetivo e as condições de mercado (hipóteses que são usuais em modelos com "fairness" e que estão plenamente de acordo com experimentos de laboratório e com o corpo teórico da psicologia social cognitiva), ele tende, ao longo do tempo, a convergir para seu nível de equilíbrio de longo prazo. 


\section{BIBLIOGRAFIA}

AGELL, J.; LUNDBORG, P. Theories of Pay and Unemployment: Survey Evidence from Swedish Manufacturing Firms. The Scandinavian Journal of Economics, v. 97, n.2, p.295-307, 1995

AKERLOF, G. A. Labor Contracts as Partial Gift Exchange. Quarterly Journal of Economics, v. 97, Nov, p.543-569, 1982

AKERLOF, G. A ; YELLEN, J. A Near Rational Model of the Business Cycle, with Wage and Price Inertia. Quarterly Journal of Economics, v.100, supplement, p.823-38, 1985

The Fair Wage Effort Hypothesis and Unemployment. Quarterly Journal of Economics, 105, 255-283, 1990

AKERLOF, G. A; DICKENS, W. T.; PERRY, G. L. The Macroeconomics of Low Inflation. Brooking Papers on Economic Activity, n.1, 1996.

Near Rational Wage and Price Setting and the Optimal Rates of Inflation and Unemployment. Brooking Papers on Economic Activity, n.1, 2001.

ALLAIS, MARCEL. Le component the I'Homme Rationel Devant le Risque, Critique des Postulates et Axiomes de l'Ecole Americaine.

Econometrica, 21, 503-546, 1953

ALMEIDA, H; BONOMO M. A. Optimal State-Dependent Rules, Credibility, and Inflationary Inertia. Texto para Discussão - PUC-RJ, Rio de Janeiro. 1997

ANGRIST. Grouped Data Estimation and testing in Simple Labor Supply Models". Journal of Econometrics, v.47, p.243-66, 1991

ARIDA, PERSIO. Reajuste salarial e Inflação. Pesquisa e Planejamento Econômico, v.12, n. 2, p.311-342, 1982

AZARIADIS, Costas. Implicit contract and Underemployment Equilibria. Journal of political Economy, v.83, p.1183-1202, 1975

BABCOCK, L.; LOEWNSTEIN, G.; ISSACHAROFF, S.; CAMERER, C. Biased Judjments of Fairness in Bargaining. American Economic review, v.85, n.5, p.1337-43, 1995

BAGESTANI, H. Survey Evidence on the Muthian rationality of the Inflation Forcasters of US Consumers. Oxford Bulletin of Economics and Statistics, v.54, p.173-186, 1992

BAKHSHI, H.; YATES, A.. Are UK Inflation Expectation Rational?. Bank of England, 1998 
BALL, LAURENCE. Credible Disinflation with Staggered Price setting. National Bureau of Economic Research (Cambrige, MA), Working Paper $n$. 3555, December, 1990

Credible Disinflation with Staggered Price Setting. American Economic Review, v.84, p.282-89, 1994a

What Determines the Sacrifice Ratio?. In: MANKIW, G. Monetary

Policy, The Univ. of Chicago Press, 1994b

Disinflation with Imperfect Credibility. Journal of Monetary Economics, v.35, p.5-24, 1995

Near-Rationality and Inflation in Two Monetary Regimes, NBER Working Paper, n.7988, outubro, 2000

BALL, L.; CECCHETTI, S. Imperfect Information and Staggered Pricing". American Economic Review, v.78, p.999-1018, 1988

BALL, L.; MANKIW, N. G.. The NAIRU in Theory and Practice. Journal of Economic Perspectives, no prelo, 2002

BALL, L.; MOFFITT, R.. Productivity Growth and the Phillips Curve. John Hopkins University Working Paper, n.450, junho, 2001

BALL, L.; ROMER, D. Real Rigidities and the Non-Neutrality of Money". Review of Economic Studies, v.57, p.183-203, 1990

BANERJEE, A.; DOLADO, J. HENDRY, D.; SMITH, G. W. Exploring Equilibrium Relationships in Econometrics through Static Models: Some Monte Carlo Evidence. Oxford Bulletin of Economics and Statistics, v.52, p.95-104, 1986

BARRO, ROBERT. Reputation in a Model of Monetary Policy with Incomplete Information. Journal of Monetary Economics, v.17, n.1 (Jan.), p.320, 1986

BENABOU, ROLAND. Optimal Price Dynamics and Speculation with a Storable Good. Econometrica. V.57, p.41-80, 1989

BENARTZI, S.; THALER, R. H.. Myopic Loss Aversion and the Equity Premium Puzzle. Quarterly Journal of Economics, v.110, n.1, p.73-92, 1995

BERNANKE, B. S.; PARKINSON, M. L. Procyclical Labor Productivity and Competing Theories of the Business Cycle: Some Evidence from Interwar U.S. Manufacturing Industries. Journal of Political Economy, v.99, n.31, p.439-459, 1991

BEWLEY, T. F. Depressed Labor Market as Explained by Participants. American Economic Review, v.85, n.2, p.250-54, 1995 
BLANCHARD, O. J; FISCHER, S. Lectures on macroeconomics. MIT Press. 1989

BALNCHARD, O.; KATZ, L. F.. What We Know and Do Not Know About the Natural Rate of Unemployment. Journal of Economic perspectives, v.11, n.1, p.51-72, 1997

BLANCHARD, O. J.; KYIOTAKI, N. Monopolistic Competition and the Effects of Aggregate Demand. American Economic Review, v.77, p.647-66, 1987

BLANCHFLOWER, D.; OSWALD, A. The Wage Curve. MIT Press, Cambridge, MA. 1994

BLINDER, A. S. On Sticky Prices: Academic Theories Meet the Real World. In: MANKIW, G., Monetary Policy, The Univ. of Chicago Press, 1994

Is There a Core of Practical Macroeconomics That We Should All Believe? American Economic Review, v.87, n.2, 240-243, 1997

BLINDER, A. S.; CHOI, D. H. A Shred of Evidence on Theories of Wage Stickiness. Quarterly Journal of Economics, v.105, n.4, p.1003-15, 1990

BONOMO, M.; GARCIA, R.. Indexation Staggering and Disinflation. Journal of Development Economics, v.43, p.39-58, 1994

BOWMAN, D.; MINEHART, D.; RABIN, M.. Loss Aversion in a Consumption-Saving Model. Journal of Economic Behavior \& Organization, v.38, p.155-178, 1999

CALVO, GUILHERMO. Staggered Prices in a Utility Maximizing Framework. Journal of Monetary Economics, v.12, n.3, p.398, 1983

Credibility and the Dynamics of Stabilization Policy: a Basic Framework. IMF Working Paper, n.90/110, 1990

CAMERER, COLIN. Individual Decision Making. In Kagel, J. e Roth, A. E. eds. The Handbook of Experimental Economics. Princeton Univ. Press. 1995

CAMERON, LISA. Rising the Stakes in the Ultimatum Game: Experimental Evidence From Indonesia. Princeton Univ., Industrial Relation Section, Working Paper, n.345, 1995

CAMPBELL, C. M.; KAMLANI, K. S.. The Reasons for Wage Rididity: Evidence from a Survey of Firms. Quarterly Journal of Economics, Aug., 1997

CAPLIN, A. S.; SPULBER, D. F.. Menu Costs and the Neutrality of Money". Quarterly Journal of Economics, v.102, n.4, p.703-725, 1987 
CARD, D.; HYSLOP, D. Does Inflation Grease the Wheels of the Labor Market/". In: ROMER, C.; ROMER D. eds. Reducing Inflation, Univ. of Chicago Press, 1997

CESPEDES, L. F.; KUMHOF, M.; PARRADO, E. Macroeconomic Dynamics under Inflation Inertia - an Optimizing Model. Latin American Meeting of the Econometric Society. 2002

CHARNESS, G. Attribution and Reciprocity in a Simulated Labor Market: An Experimental Investigation. Economics. Working Paper - Universtiy of California, Berkeley, n.43, 1998

CHARY, V. V.; KEHOE, P. J.; MCGRATTAN, E. R. Sticky Price Models of the Business Cycle: Can the Contract Multiplier Solve the Persistence Problem?. Econometrica, v.68, n.5,p.1151-1179, 2000

CHRISTIANO, L. J.; EICHENBAUM, M.; EVANS, C. Nominal Ridgities and the Dynamic Effects of a Shock to Monethary Policy". Mimeo, Northwestern University, 2001

CHOW, C. C.; SARIN, R. K. Comparative Ignorance and the Elsberg Paradox. Journal of Risk and Uncertainty, 22,02, 129-139, 2001

COVER, J. P.. Asymmetric Effects of Positive and Negative MoneySupply Shocks. University of Alabama, 1988

DAVIDSON, R.; MACKINNON, J.. Estimation and Inference in Econometrics. New York, Oxford Univ. Press, 1993

DIBOOGLU, S.; ENDERS, W. Do Real Wages Respond Asymetrically to Unemplyment Shocks? Evidence from the U.S. and Canada. Journal of Macroeconomics, Fall, 4, 495-515, 2001

DOW, J.; WERLANG S. R. C. Uncertainty Aversion, Risk Aversion and the Optimal Choice of Porfolio. Econometrica, v.60, p.197-204, 1992

Nash Equilibrium under Knightian Uncertainty: Breaking Down Backward Induction. Journal of Economic Theory, v.64, p.305-324, 1994

DOW, J.; SIMONSEN, M. H.; WERLANG, S.R.C.. Knightian Rational Expectations, Inflationary Inertia and Money Neutrality. Texto para discussão EPGE - Fundação Getúlio Vargas. Rio de Janeiro. Junho, 1993

ELLSBERG, D.. Risk, Ambiguity and the Savage Axioms. Quarterly Journal of Economics, v.75, p.643-669, 1961

ENDERS, W.; HURN, S.. Asymmetric Price Adjustment and the Phillips Curve. Jornal of Macroeconomics, a publicar, 2002 
FAIR, R. C. The Estimation of Simultaneous Equation Models with Lagged Endogenous Variables and First Order Serially Correlated Errors. Econometrica, v.38, n.3, p.507-516, 1970

Specification, Estimation, and Analysis of Macroecnometric Models, Harvard University Press. 1984

FEHR, E.; KIRCHSTEINER, G.; RIEDL, A. Does fairness Prevent Market Clearing? An Experimental Investigation. Quarterly Journal of Economics, May, p.437-59, 1993

Involuntary Unemployment and Non-Compensating Wage Differentials in an Experimental Labor Market. Economic Journal, v.106, p.106-21, 1996

FETHKE, G.; POLICANO, A. Wage Contingencies, the Paterns of Negotiation and Aggregate Implications of Alternative Contracts Structures. Journal of Monetary Economics, v.14, p>151-170, 1984

FISCHER, STANLEY. Long Term Contracts, Rational Expectations, and the Optimal Money Supply Rule. Journal of Political economy, v.85, n.1, p.191-205, 1977

FOX, C. R.; TVERSKY, A. Ambiguity Aversion and Comparative Ignorance. Quarterly Journal of Economics, agosto, p.585-603, 1995

FRANCISCOSI, R.; PRAVEEN, K.; MICJELITSCH, R.; SMITH, V.; DENG, G. Fairness: Effect on Temporary and equilibrium price in Posted-Offer Markets. Economic Journal, v.105, p.938-50, 1995

FRIEDMAN, MILTON. The Methodology of Positive Economics". In: FRIEDMAN, M.: Essays in Positive Economics. Univ. of Chicago Press. 1953

Nobel Lecture: Inflation and Unemployment. Journal of Political Economy, v.85, n.3, p.451-72, 1977

FUHRER, JEFF. The (Un)Importance of Forward-Looking Behavior in Price Specification. Journal of Money, Credit and Banking, v.29, n.3, p.338350, 1997

FUHRER, J.; MOORE, G. Inflation Persistence. Quarterly Journal of Economics, Feb., p.127-59, 1995

HALTIWANGER, J.; WALDMAN, M. Limited Rationality and Synergism: The Implications for Macroeconomics. John Hopkins University Working Paper no. 183, revised. 1986

Limited Rationality and strategic Complements: the implications for Macroeconomics. Quartely Journal of Economics, v.104, agosto, 1989

HEATH, C.; TVERSKY, A.. Preferences and Belief: Ambiguity and Competence in Choice under Uncertainty. Journal of Risk and Uncertainty. V.6, 5-28, 1991 
HOOVER, K. D.; PEREZ, S. J.. Post Ergo Propter Once More - an Evaluation of 'Does Monetary Policy Matter?' in the Spirit of James Tobin. Journal of Monetary Economics, v.34, p.47-73, 1994

Money May Matter, but How Could We Know?. Journal of Monetary Economics, v. 34. p.89-99, 1994

GALÍ, J.; GERTLER, M. Inflation Dynamics: A Strutural Econometric Analysis. Journal of Monetary Economics, v.44, p.195-222, 1999

GILBOA, ITZHAK. Expected Utility with Purely Subjective Non-Aditive Probabilities. Journal of Mathematical Economics, 16, 65-88, 1987

GORDON, R. J. Time-Varying NAIRU and its Implications for Economic Policy. Journal of Economic Perspectives, v.11, n.1, p.11-32, 1997

GRUBB, D.; JACKMAN, R. E LAYARD, R.. Causes of the Current Stagflation. Review of Economic Studies, v.49, p.707-730, 1982 1997

GREENE, W. H.. Econometric Analysis. Prentice Hall, New jersey.

JOHANSEN, SOREN. Statistical Analysis of Cointegration Vectors. Journal of Economic Dynamics and Control, v.12, p. 231-254, 1988

JEANNE, OLIVER. Generating Real Persistent Effects of Monetary Shocks: How Much Nominal Rigidity do we Really Need?. National Bureau for Economic Recearch Working Paper n. 6.258, 1997

KAHNEMAN, D.; KNETSCH, J. L.; THALER, R.; Fairness as a Constraint on Profit Seeking: Entitlements in the Market. American Economic Review, v.76, n.4, p.728-741, 1986

Experimental Tests of the Endowment Effect and the Coase Theorem. Journal of Political Economy, v.98, p.1325-48, 1990

KAHNEMAN, D.; TVERSKY, A.. Prospect Theory: an Analysis of Decision under Risk. Econometrica, v.47, p.263-291, 1979

KALCHEMEIER, S.; LIMBERG, S.; SCHADEWALD, M. A Laboratory Market Examination of the Consumer Price Response to Information about Producers' Cost and Profits. The Accounting Review, v.66, n.4, p.694-717, 1991a

Fairness in Markets: A Laboratory Investigation. Journal of Economic Psychology, v.12, p.447-64, 1991b

KAUFMAN, R. T. On Wage Stickness in Britain's Competitive Sector. British Journal of Industrial Relations. V. 22, n.1, 101-11, 1984

KEYNES, J. M. A Treatise on Probability. Londres, Macmillan. 1921 
KIMBAL, M. S. Labor-Market Dynamics When Unemployment Is a Worker Discipline Device. American Economic Review, v.84, n.4, p.1045-59, 1994

The Quantitative Analysis of the Basic Neomonetarist Model. Journal of Money Credit and Banking, v.27, p.1241-77, 1995

KILEY, M. T.. Staggered Price Setting, Partial Adjustment, Real Rigidities and Sunspots. Federal Reserve Board of Governors. 1997

KNIGHT, FRANK H.. Risk Uncertainty and Profit. Boston, Houghton Mifllin. 1921

KRUEGER, A. B.. Measuring Labor's Share. NBER Working Paper, n.7006, 1999

KWIATLOWSKI, D.; PHILLIPS, P.; SCHMIDT, P.; SHIN, Y. Testing the Hypothesis of Stationarity Against the Alternative of a Unit Root. Journal of Econometrics, v.54, p.159-178, 1992

LEEPER, E. M.. Narative and VAR Approaches to Monetary Policy: Common Identification Problems. Journal of Monetary Economics, v.40, p.641-657, 1997

LEVINE, D. I. Fairness, Markets, and Ability to Pay: Evidence from Compensation Executives. American Economic Review, v.83, n.5, p.1241-59, 1993

LONG, B.; SUMMERS, L. H.. How Does Macroeconomic Policy Affect Output? Brooking Papers on Economic Activity, n.2, p.433-485, 1988

LUCAS, ROBERT. Expectations and the Neutrality of Money. Journal of Economic Theory, v.4, p.103-124, 1972

Econometric Policy Evaluation: A Critique. Carnegie Rochester Conference Series on Public Policy 1, 19-46, 1976

LUNARDELLI, ANDRÉ. A Terapia da Recessão Virtual. Economia Aplicada, v.1, n.4, p.641-661, 1997

MANKIW, N. G.. Near Rationality and Inflation in Two Monetary Regimes. NBER Working Paper, n.7988, 2000

The inexorable and Mysterious Tradeoff between Inflation and Unemployment. Economic Journal, v.111, n. 471, p.45, 2001

MANKIW, N. G.; REIS, R.. Sticky Information Versus Stiky Prices: A proposal to Replace the New Keynesian Phillips curve. Quarterly Journal of Economics, v.117, n.4(nov. - a publicar), 2002 
MARINACCI, MASSIMO. Limit Laws for Non-Addtive Probabilities and Their Frequentist Interpretation. Journal of Economic Theory, v.84, n.2, p.145-195, 1999

MCCALLUM, BENNETT. Comment. NBER Macroeconomics Annual, p.355-359, 1997

MODIGLIANI, F.; SCHIOPPPA, T. P.. The Economy with 100\% Plus Wage Indexation". Mimeo., Department of Economics, MIT, 1978

NEALE, M.; BAZERMAN, M. H.. The Effects of Framing and Overconfidence on Bargaining Behaviors and Outcomes. Academy of Management Journal, v.28, n.1, p.34-49, 1985

NELSON, C. R.; PLOSSER, C. I. Trends versus Random Walks in Macroeconomic Time Series: Some Evidence and Implications. Journal of Monetary Economics, v.10, p.139-162, 1982

OCHS, JACK. Coordination Problems. In: KAGEL; ROTH. The Handbook of Experimental Economics. Princeton Univ. Pres. 1995

OKUN, A. M. Prices and Quantities: A Macroeconomic Analysis. Washington DC, The Brooking Institution. 1981

PELHAN, B. W.; NETER, E. The Effect of Motivation of Judgment Depends on the Difficulty of the Judgment. Journal of personality and Social Psychology, v.68, n.4, p.581-94, 1995

PHELPS, EDMUND. Disinflation without Recession: Adaptative Guideposts and Monetary Policy. Weltwirtsshaftliches Archiv, n.114, p.783809,1978

PHILLIPS, A. W. The Relation between Unemployment and the Rate of Change of Money Wage Rates in United Kingdom, 1861-1957. Economica, v.25, Aug., p.283-300, 1958

PHILLIPS, P. C. B.; HANSEN, B. E.. Statistical Inference in Instrumental Variable Regression with I(1) Processes. Review of Economic Studies, v.57, p.99-125, 1990

PRELEC, DRAZEN. The Probability Weighting Function. Econometrica. V.66, n.3, 497-527, 1998

RABIN, MATTHEW. Incorporating Fairness into Game Theory. American Economic Review, v.83, n.5, p.1280-1302, 1993

Psychology and Economics. Mimeo. 1996

Bargaining Structure, Fairness and Efficiency. Working Paper, University of California at Bekeley, 1997 
Psychology and Economics, Journal of Economic Literature, v.XXXVI, p.11-46, 1998

A perspective on Psychology and Economics. European Economic Review, no prelo, 2002

RESENDE, A. L.. Incompatibilidade Distributiva e Inflação Estrutural. Estudos Econômicos, v.11, n.3, 1981

ROBERTS, J. M. Is Inflation Sticky?. Journal of Monetary Economics, v.39, p.173-96, 1997

Inflation Expectation and the Transmition of Monetary Policy. Board of Governors of the Federal Reserve, Finance and Economics Discussion Series Paper, n. 43, 1998

ROMER, C. D.; ROMER, D.. Does Monetary Policy Matter? A New test in the Spirit of Friedman and Schwartz. NBER Macroeconomics Annual v.4, p.121-170, 1989

New Evidenses on the Monetary Transmission Mecanism. Brooking Papers on Economic Activity, n.1, p.149-198, 1990 88, 1994

Monetary Policy Matters. Journal of Monetary Economics, v.34, p.75-

Identification and the Narrative Approach: A Reply to Leeper. Journal of Monetary Economics, v.40, p.659-665, 1997

ROMER, DAVID. Advanced Macroeconomics. McGraw-Hill, 1996 Segunda edição, 2001

ROTEMBERG, J. J.; WOODFORD, M.. The Cyclical Behavior of Prices and Costs. In: Taylor e Woodford, eds. Handbook of Macroeconomics. 1999

ROTH, ALVIN. Bargain Experiments. In: KAGEL; ROTH. The Handbook of Experimental Economics. Princeton Univ. Pres. 1995

SARGENT, T. J. Bounded Rationality in Macroeconomics. Oxford, Claredon Press. 1993

SARGENT, T. J.; WALLACE, N. Some Unpleasant Monetarist Arithmetic. The Federal Reserve Bank of Minneapolis Quarterly Review, Fall, 1981

SAVAGE, L. J.. The Foundations of Statistics. John Wiley, New York (Segunda edição -1972 Dover, New York), 1954

SHAPIRO, C.; STIGLITZ, J. E. Equilibrium Unemployment as a Worker Dicipline Device. American Economic Review, v.74, n.3, p.433-444, 1984

SHEA, J.. Union Contracts and the Life-Cycle / Permanent-Income Hypothesis. American Economic Review, v.85, p.186-200, 1995 
SHERWIN, MURRAY. Inflation Targeting - The New Zealand Experience. Conference on Price Stability, Inflation Targets and Monetary Policy, Bank of Canada. 1997

SHMEIDLER, DAVID. Subjective Probability Without Aditivity. Working Paper of The Foeder Institute for economic Research, Tel Aviv University. 1982

Subjective Probability and Expected Utility Without Additivity.

Econonetrica, v.57, p.571-587. 1989

SIMON, H. A. Rationality as Process and as Product of Thought.

American Economic Review , v.68, n.2, p.1-16, 1978

SIMONSEN, M. H.. Inflação: Gradualismo x Tratamento de Choque. Rio de Janeiro, APEC, 1970

Rational Expectations, Income Policies and Game Theory, Revista de Econometria, v.6, p. 7-46, 1986

Rational Expectation, Income Policy and Inflationary Inertia. IN ANDERSON,P. W.; ARROW, K. J.; PINES, D.: The Economy as an Evolving Complex System. Addison-Wesley Publishing Co., 205-241. 1988

SIMONSEN, M. H.; CYSNE, R. P. Macroeconomia, Ed. Atlas, São Paulo. (Segunda Edição -1995). 1989

SLONIM, R.; ROTH, A. E. Learnig in High Stakes in the Slovak Republic. Econometrica, v.66, p.569-96, 1998

SUITS, D.. Dummy Variables: Mecanics vs. Interpretation. Review of Economics and Statistics, v.66, p.177-180, 1984

SUNKEL, OSWALDO. La Inflación Chilena: Um Enfoque Heterodoxo. EI Trimestre Economico, v.25, n.4, out.-dez., 1958

TAM, T. C.; WERLANG, S. R. C. The Bayesian Foundations of Solution Concepts of Games. Journal of Economic Theory, v.45, p.370-91, 1988

TAYLOR, J. B. Staggered Wage Setting in a Macro Model. American Economic Review, v.69, n.2, p.108-113, 1979

Aggregate Dynamics and Staggered Contracts. Journal of Political Economy, v.88, n.11, p.1-23, 1980

Union Wage Settlements During Disinflation. American Economic Review, v.73, p.981-93, 1983

Macroeconomic Policy in a World Economy. Nova York e Londres, W. W. Norton \& Company, 1993

Staggered Price Setting in Macroeconomics. In: Taylor e Woodford, eds. Handbook of Macroeconomics. 1999

TOWNSEND, ROBERT. Market Anticipations, Rational Expectations and Bayesian Analysis. International Economic Review, v.19, p.481-94, 1978 
TVERSKY, A.; KAHNEMAN, D. Loss Aversion in Riskless Choice: A Reference-Dependent Model. Quarterly Journal of Economics, Nov., p.103961, 1991.

Advances in Prospect Theory - Cumulative Representation of Uncertainty. In Kaneman e Tversky: Choices values and Frames, Cambrige Univ. Press, Cambrige UK (2000), p.44-65. Originalmente publicado em: Journal of Risk and Uncertainty, v.5, 297-323, 1992

TVERSKY, A.; WAKKER, P.. Risk Attitudes and decision Weights. Econometrica. V.63, n.6, 1255-1280, 1995

WAKKER, PETER. Testing and Characterizing Properties of Nonadditive Measures Through Violations of the Sure Thing principle. Econometrica. V.69, n.4, 1039-1059, 2001

WERLANG, S. R. C. Simonsen, Inflação, Expectativas Racionais e o Pós-Keynesianos. Revista Brasileira de Economia, v.52 - encarte especial, p.161-66, 1998

WILLIAMS, A. W. The Formation of Prices Forecasts in Experimental Markets. Journal of Money Credit and Banking. V.19, p.1-18, 1987 2001

WOODFORD, M. Optimizing Models with Nominal Ridgidities. Mimeo. 